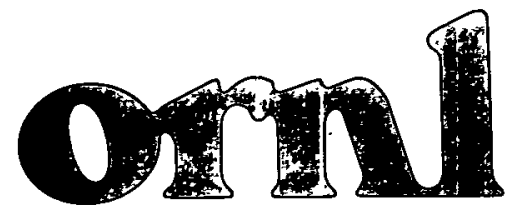

OA服 RGE

NATONAL

LABORATORY

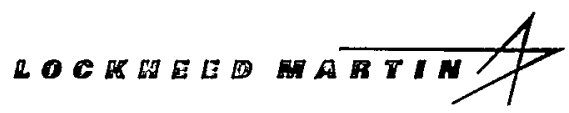

SUBCRITICAL NOISE ANALYSIS

MEASUREMENTS WITH FRESH

AND SPENT RESEARCH

REACTOR FUEL ELEMENTS (U)

\author{
Timothy E. Valentine \\ John T. Mihalczo \\ Robert C. Kryter \\ Virgil C. Miller
}

Measurement Science Section

Instrumentation and Controls Division

February 1999

Prepared by the

Oak Ridge National Laboratory

Oak Ridge, Tennessee 37831 managed by

Lockheed Martin Energy Research Corp.

for the

U.S. DEPARTMENT OF ENERGY

under contract DE-AC05-96OR22464

MANAGED AND OPERATED BY

LOCKHEED MARTIN ENERGY RESEARCH CORPORATION

FOR THE UNTED STATES

DEPARTALENT OF ENERGY

ORNL-27 (3-95) 


\section{DISCLAIMER}

This report was prepared as an account of work sponsored by an agency of the United States Government. Neither the United States Government nor any agency thereof, nor any of their employees, make any warranty, express or implied, or assumes any legal liability or responsibility for the accuracy, completeness, or usefulness of any information, apparatus, product, or process disclosed, or represents that its use would not infringe privately owned rights. Reference herein to any specific commercial product, process, or service by trade name, trademark, manufacturer, or otherwise does not necessarily constitute or imply its endorsement, recommendation, or favoring by the United States Government or any agency thereof. The views and opinions of authors expressed herein do not necessarily state or reflect those of the United States Government or any agency thereof. 


\section{DISCLAIMER}

Portions of this document may be illegible in electronic image products. Images are produced from the best available original document. 


\title{
SUBCRITICAL SOURCE-DRIVEN NOISE ANALYSIS MEASUREMENTS WITH FRESH AND SPENT RESEARCH REACTOR FUEL ELEMENTS
}

\author{
Timothy E. Valentine \\ John T. Mihalczo \\ Robert C. Kryter \\ Virgil C. Miller
}

Instrumentation and Controls Division

Oak Ridge National Laboratory

\author{
Prepared by \\ OAK RIDGE NATIONAL LABORATORY \\ Oak Ridge, Tennessee 37831-6004 \\ managed by \\ LOCKHEED MARTIN ENERGY RESEARCH CORP. \\ for the \\ U.S. DEPARTMENT OF ENERGY \\ under contract DE-AC05-96OR22464
}


This page intentionally left blank. 


\section{CONTENTS}

LISTT OF FIGURES . $\mathrm{v}$

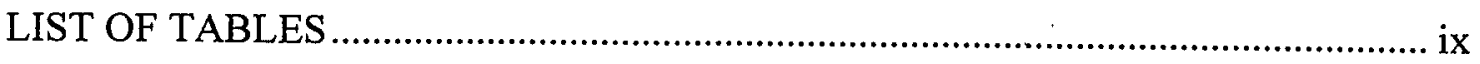

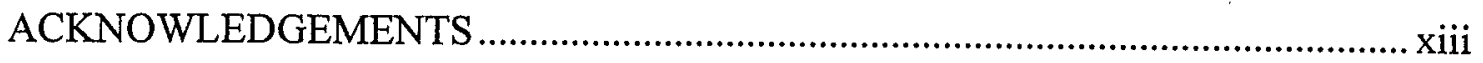

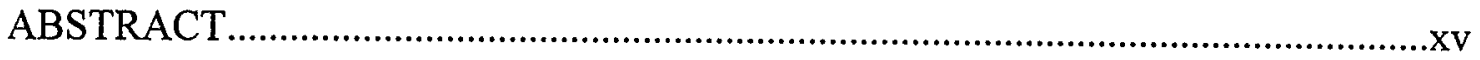

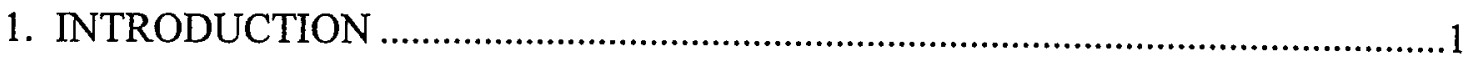

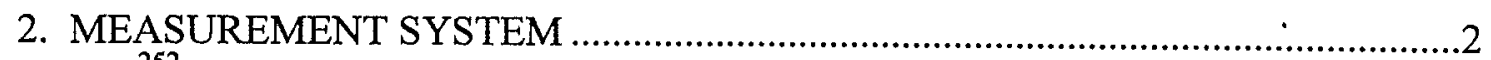

$2.1{ }^{252}$ CF SOURCE

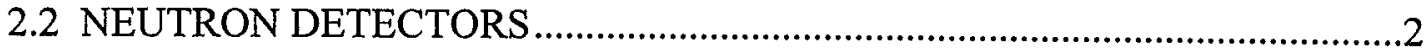

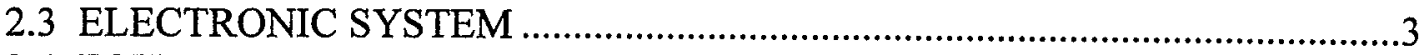

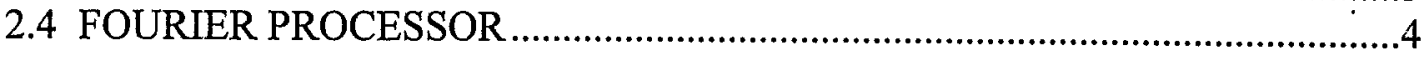

3. MEASUREMENT ASSEMBLY CONFIGURATION …............................................

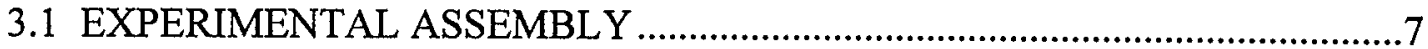

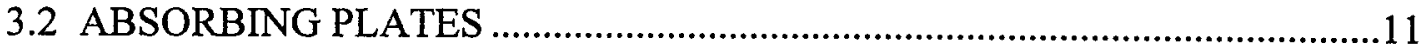

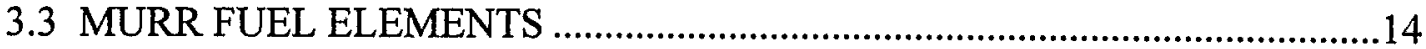

3.4 EXPERIMENTAL ASSEMBLY DIMENSIONAL CALIBRATION …….........17

4. FRESH FUEL MEASUREMENTS …….............................................................19

4.1 INVERSE MULTIPLICATION MEASUREMENTS ....................................19

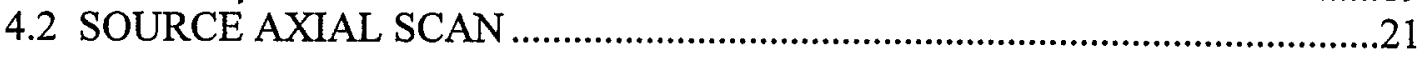

4.3 FUEL-TO-DETECTOR SEPARATION …………........................................26

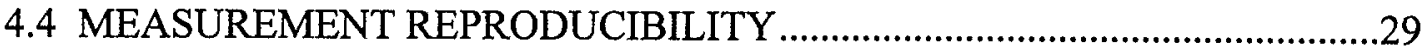

4.5 FUEL ELEMENT SEPARATION MEASUREMENTS ……..............................45

4.5.1. Movement of All Fuel Elements ..............................................................45

4.5.2 Movement of North Fuel Element.............................................................53

4.5.3 Movement of East Fuel Element ………………..................................55

4.6 FUEL ORIENTATION MEASUREMENTS ……….....................................57

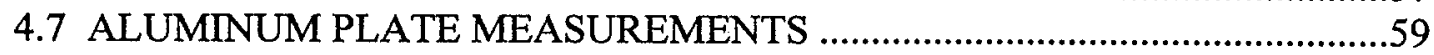

4.8 LEAD PLATE MEASUREMENTS ………..................................................67

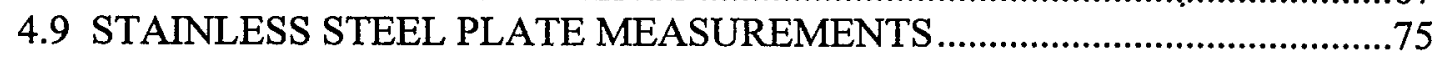

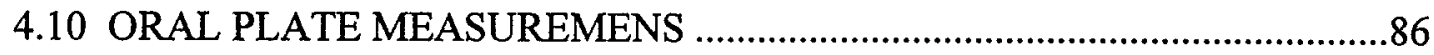

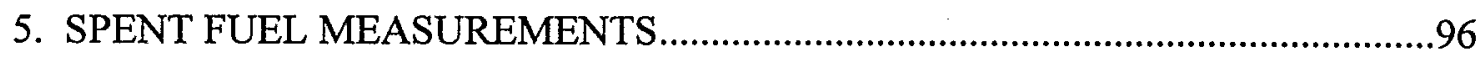

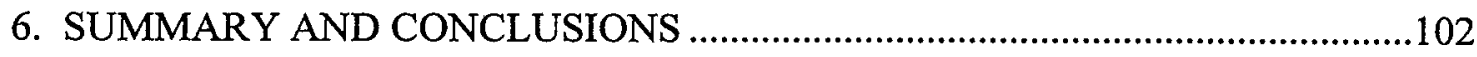

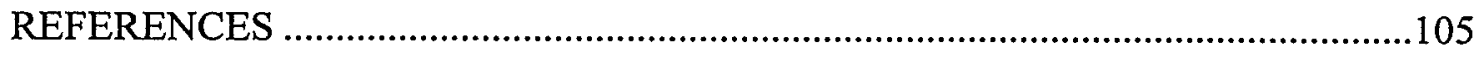

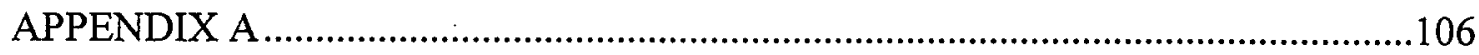




\section{CONTENTS (continued)}

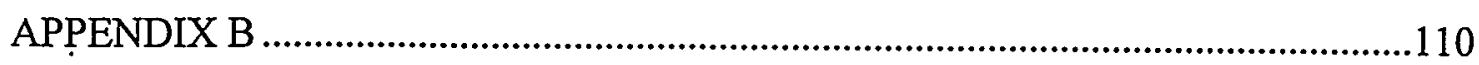

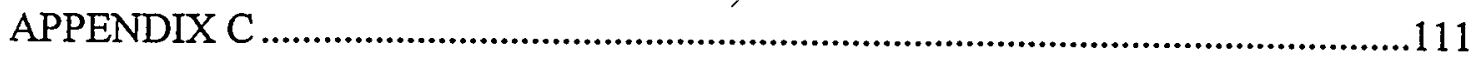

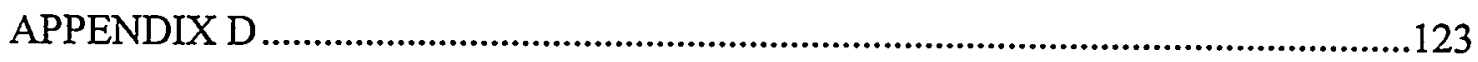

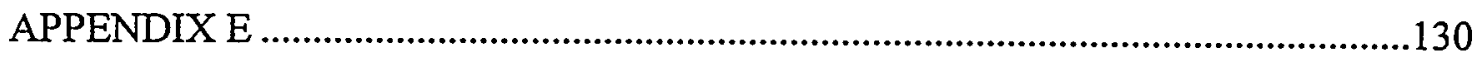

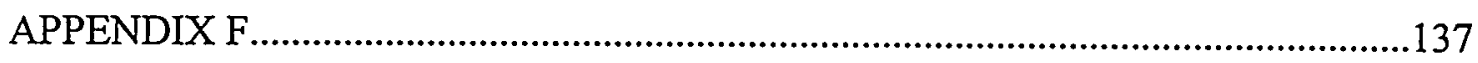

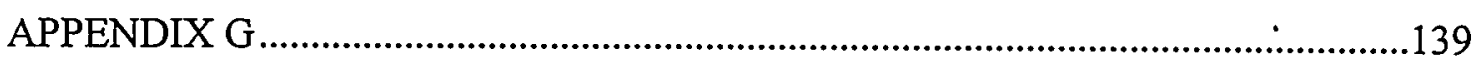

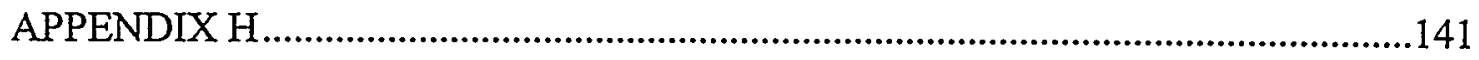




\section{LIST OF FIGURES}

Fig. 2.1 ${ }^{252} \mathrm{Cf}$ pulse-height curve as a function of the discriminator threshold..........................................................................................................

Fig. 2.2 Sketch of equipment configuration................................................................5

Fig. 3.1 Photograph from top of experimental assembly in fresh water tank ...........8

Fig. 3.2 Photograph of the assembly slide plates ......................................................8

Fig. 3.3 Photograph of the H-shaped cruciform .........................................................

Fig. 3.4 Photograph of fuel element support post ..................................................10

Fig. 3.5 Photograph of fuel elements in standard orientation ..................................10

Fig. $3.6 \quad$ Photograph of plate measurements .............................................................11

Fig. 3.7 Sketch of MURR fuel assembly construction.............................................14

Fig. 3.8 MURR fuel element end fitting .................................................................16

Fig. $3.9 \quad$ Calibration measurement tools ....................................................................18

Fig. $3.10 \quad$ Aluminum slide plate ................................................................................18

Fig. 4.1 Inverse multiplication curve for four atmosphere ${ }^{3} \mathrm{He}$ detectors as a function of fuel element position ...................................................................20

Fig. 4.2 Detector count rates as a function of source axial position ........................22

Fig. 4.3 Spectral ratio values 24 and 45 as a function of source axial position ......25

Fig. 4.4 Detector count rate as a function of detector-fuel element separation.......27

Fig. 4.5 Spectral ratio 23 value for reference measurements at plate spacing .........32

Fig. 4.6 Spectral ratio 24 value for reference measurements at plate spacing .........33

Fig. 4.7 Spectral ratio 25 value for reference measurements at plate spacing .........34

Fig. 4.8 Spectral ratio 34 value for reference measurements at plate spacing .........35

Fig. 4.9 Spectral ratio 35 value for reference measurements at plate spacing .........36 


\section{LIST OF FIGURES (continued)}

Fig. 4.10 Spectral ratio 45 value for reference measurements at plate spacing .........37

Fig. 4.11 Spectral ratio 23 value for close-spaced reference measurements..............39

Fig. 4.12 Spectral ratio 24 value for close-spaced reference measurements..............40

Fig. 4.13 Spectral ratio 25 value for close-spaced reference measurements..............41

Fig. 4.14 Spectral ratio 34 value for close-spaced reference measurements..............42

Fig. 4.15 Spectral ratio 35 value for close-spaced reference measurements..............43

Fig. 4.16 Spectral ratio 45 value for close-spaced reference measurements..............44

Fig. 4.17 Spectral ratio values for fuel element traverse measurements from closed-space reference position .48

Fig. 4.18 Spectral ratio values for fuel element traverse measurements from in-contact position...........................................................................................

Fig. 4.19 Spectral ratio 23 values as a function of aluminum plate mass .................61

Fig. 4.20 Spectral ratio 24 values as a function of aluminum plate mass ..................62

Fig. 4.21 Spectral ratio 25 values as a function of aluminum plate mass .................63

Fig. 4.22 Spectral ratio 34 values as a function of aluminum plate mass ..................64

Fig. 4.23 Spectral ratio 35 values as a function of aluminum plate mass ...................65

Fig. 4.24 Spectral ratio 45 values as a function of aluminum plate mass ..................66

Fig. 4.25 Spectral ratio 23 values as a function of lead plate mass............................69

Fig. 4.26 Spectral ratio 24 values as a function of lead plate mass.............................70

Fig. 4.27 - Spectral ratio 25 values as a function of lead plate mass..............................71

Fig. 4.28 Spectral ratio 34 values as a function of lead plate mass............................72

Fig. 4.29 Spectral ratio 35 values as a function of lead plate mass.............................73

Fig. 4.30 Spectral ratio 45 values as a function of lead plate mass.............................74 


\section{LIST OF FIGURES (continued)}

Fig. 4.31 Spectral ratio 23 values as a function of stainless steel plate mass ............79

Fig. 4.32 Spectral ratio 24 values as a function of stainless steel plate mass ...........80

Fig. 4.33 Spectral ratio 25 values as a function of stainless steel plate mass ............81

Fig. 4.34 Spectral ratio 34 values as a function of stainless steel plate mass ...........82

Fig. 4.35 Spectral ratio 35 values as a function of stainless steel plate mass ...........83

Fig. 4.36 Spectral ratio 45 values as a function of stainless steel plate mass ............84

Fig. 4.37 Spectral ratio 23 values as a function of BORAL plate mass.....................90

Fig. 4.38 Spectral ratio 24 values as a function of BORAL plate mass.....................91

Fig. 4.39 Spectral ratio 25 values as a function of BORAL plate mass.....................92

Fig. 4.40 Spectral ratio 34 values as a function of BORAL plate mass.....................93

Fig. 4.41 Spectral ratio 35 values as a function of BORAL plate mass......................94

Fig. 4.42 Spectral ratio 45 values as a function of BORAL plate mass.....................95

Fig. 5.1 Spent fuel measurement configuration ......................................................97

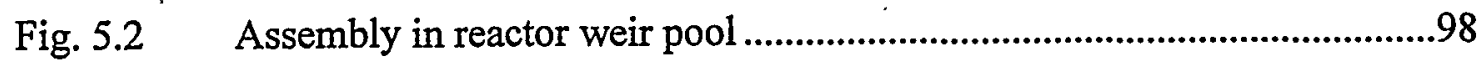

Fig. H.1 Frequency-dependent average spectral ratio 23 for reference measurements at plate spacing................................................................143

Fig. H.2 Frequency-dependent average spectral ratio 24 for reference measurements at plate spacing. 144

Fig. H.3 Frequency-dependent average spectral ratio 25 for reference measurements at plate spacing.

Fig. H.4 Frequency-dependent average spectral ratio 34 for reference measurements at plate spacing. .146

Fig.H.5 Frequency-dependent average spectral ratio 35 for reference measurements at plate spacing. 


\section{LIST OF FIGURES (continued)}

Fig. H.6 Frequency-dependent average spectral ratio 45 for reference measurements at plate spacing....................................................................148

Fig. H.7 Frequency-dependent average source auto spectrum for reference measurements at plate spacing

Fig. H.8 Frequency-dependent average detector auto spectrum for reference measurements at plate spacing

Fig. H.9 Frequency-dependent real source-detector cross spectrum for reference measurements at plate spacing...

Fig. H.10 Frequency-dependent imaginary source-detector cross spectrum for reference measurements at plate spacing.

Fig. H.11 Frequency-dependent real detector-detector cross spectrum for reference measurements at plate spacing...

Fig. H.12 Frequency-dependent imaginary detector-detector cross spectrum for reference measurements at plate spacing. 


\section{LIST OF TABLES}

Table 2.1 ${ }^{3} \mathrm{He}$-detector electronics settings for fresh fuel measurements....................4

Table $3.1 \quad$ Absorbing plate dimensions...........................................................12

Table 3.2 Aluminum plate composition.....................................................................12

Table 3.3 Stainless steel 304 plate composition ...........................................................13

Table $3.4 \quad$ Lead plate and shield composition.................................................................13

Table 3.5 BORAL plate composition ...................................................................13

Table $3.6 \quad$ Fuel assembly compositions ..................................................................15

Table 4.1 Reference count rates as a function of fuel element position .....................19

Table 4.2 Count rates as a function of fuel element position with four fuel elements

Table 4.3 Assembly configuration for source axial scan ...........................................21

Table 4.4 Detector count rate for varying source location..........................................21

Table 4.5 Spectral ratio values for varying source axial position...............................24

Table 4.6 Assembly configuration for detector spacing optimization........................26

Table 4.7 Detector count rates as a function of detector position................................26

Table 4.8 Spectral ratio values for varying detector position .....................................28

Table 4.9 Assembly configuration for plate-spacing reference measurements .........29

Table 4.10 Reference spectral ratio values with the fuel elements separated to position corresponding to the plate separation.............................................30

Table 4.11 Assembly configuration for close-spaced reference measurements ...........31

Table 4.12 Spectral ratio values for close-spaced reference measurements .................38

Table 4.13 Fuel separation measurements beginning at close-spaced reference position. 


\section{LIST OF TABLES (continued)}

Table 4.14 Spectral ratio values for fuel element traverse from close-spaced reference position.

Table 4.15 Fuel traverse measurements beginning at in-contact position

Table 4.16 Spectral ratio values for fuel element traverse from in-contact position...51

Table 4.17 Traverse of north fuel element beginning at close-spaced reference position.

Table 4.18 Spectral ratio values for north fuel element traverse from close-spaced reference position.

Table 4.19 Traverse of east fuel element beginning at close-spaced reference position.

Table 4.20 Traverse of east fuel element beginning at close-spaced reference position. .56

Table 4.21 Assembly configuration for different fuel orientation measurements .......57

Table 4.22 Spectral ratio values for different fuel element orientations......................58

Table 4.23 Measured spectral ratio values with varying number of 1/16-inch thick aluminum plates between the fuel elements 60

Table 4.24 Measured spectral ratio values with varying number of lead plates between the fuel elements

Table 4.25 Measured spectral ratio values with varying number of stainless steel plates between the fuel elements. .76

Table 4.26 Measured spectral ratio values with varying number of BORAL plates between the fuiel elements.

Table 5.1 Assembly configuration for spent fuel measurements...............................96

Table 5.2 Fuel element identifiers for spent fuel measurements .................................96

Table 5.3 Measured spectral ratio values for spent fuel measurements....................100

Table 5.4 Detector count rate values for spent fuel measurements ...........................101

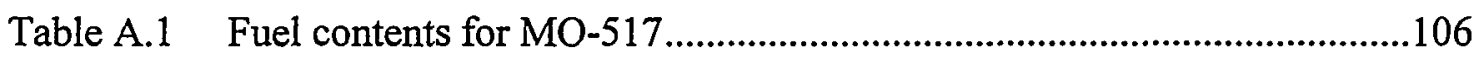




\section{LIST OF TABLES (continued)}

Table A.2 Fuel contents for MO-518 ......................................................................107

Table A.3 Fuel contents for MO-519 …............................................................108

Table A.4 Fuel contents for MO-520 .....................................................................109

Table B.1 Slide calibration data...........................................................................110

Table C.1 Source, detector, and fuel element configuration ....................................112

Table D.1 Electronic systems configuration............................................................123

Table E.1 Source and detector count rates ...............................................................130

Table F.1 Spectral ratio values for different forced air flow rates .............................138

Table G.1 Spectral ratio values for tilting of fuel elements......................................140 
This page intentionally left blank. 


\section{ACKNOWLEDGEMENTS}

The authors acknowledge the support of this program by the Savannah River Technology Center, Westinghouse Safety Management Solutions, Inc., and the Department of Energy. The work of John Zino and Tom Williamson of Westinghouse Safety Management Solutions, Inc. was essential in funding and planning the experiment. The authors acknowledge the support of the staff at the University of Missouri Research Reactor. The support of Chester Edwards, Das Kutikkad, Wale Oladiran, and the reactor operators at the University of Missouri was vital to the successful completion of these measurements. 
This page intentionally left blank. 


\begin{abstract}
The verification of the subcriticality is of utmost importance for the safe transportation and storage of nuclear reactor fuels. Transportation containers and storage facilities are designed such that nuclear fuels remain in a subcritical state. Such designs often involve excess conservatism because of the lack of relevant experimental data to verify the accuracy of Monte Carlo codes used in nuclear criticality safety analyses.

A joint experimental research program between Oak Ridge National Laboratory, Westinghouse Safety Management Solutions, Inc., and the University of Missouri was initiated to obtain measured quantities that could be directly related to the subcriticality of simple arrays of Missouri University Research Reactor (MURR) fuel elements. A series of measurements were performed to assess the reactivity of materials such as BORAL, stainless steel, aluminum, and lead that are typically used in the construction of shipping casks. These materials were positioned between the fuel elements. In addition, a limited number of measurements were performed with configurations of fresh and spent (irradiated) fuel elements to ascertain the reactivity of the spent fuel elements. In these experiments, fresh fuel elements were replaced by spent fuel elements such that the subcritical reactivity change could be measured.

The results of these measurements were used by Westinghouse Safety Management Solutions to determine the subcriticality of MURR fuel elements isolated by absorbing materials. The measurements were interpreted using the MCNP-DSP Monte Carlo code to obtain the subcritical neutron multiplication factor, $k_{\text {eff, }}$ and the bias in $k_{\text {eff }}$ that are used in criticality safety analyses.
\end{abstract}


This page intentionally left blank.

xvi 


\section{INTRODUCTION}

Subcritical source-driven noise-analysis measurements ${ }^{1,2}$ were performed with a variety of configurations of research reactor fuel elements at the Missouri University Research Reactor (MURR) in July 1998. These mêasurements were performed to assess the subcriticality of research reactor fuel elements separated by neutron absorbing materials and to determine the reactivity of spent (irradiated) fuel elements. This collaborative program between Oak Ridge National Laboratory, Westinghouse Safety Management Solutions, Inc., and the University of Missouri was undertaken to obtain benchmark subcritical measurements that address the excess conservatism associated with the transportation and storage of research reactor fuel elements at the Savannah River Technology Center.

The subcritical noise-analysis method involved measurement of the time-dependent responses of a ${ }^{252} \mathrm{Cf}$ source in an ionization chamber and of neutron detectors that were placed in or near the fissile system. The time-dependent detector responses were Fouriertransformed. The Fourier-transformed data were then complex multiplied to obtain a variety of auto and cross spectra. The complex multiplication of a signal with itself was termed an auto spectrum while the complex multiplication of two different signals was termed a cross spectrum. The detector auto spectra, the source-detector cross spectra, and the detector-detector cross spectra were obtained simultaneously in this measurement. The source-detector cross spectra were the frequency domain equivalent of the randomly pulsed neutron measurement ${ }^{3}$ while the detector auto spectra were the equivalent of the single detector Rossi- $\alpha$ measurement and the detector-detector cross spectra were the equivalent of the two-detector Rossi- $\alpha$ measurement. ${ }^{4}$ A certain ratio of these spectra has been shown to be independent of detection efficiency for many applications. This ratio has also been shown to be independent of the source strength in the absence of an inherent spontaneous fission source in the fissile material. This spectral ratio was directly related to the subcritical reactivity of the fissile system.

This report provides a description of the measurement system in Chapter 2. A description of the test assembly and fuel elements is provided in Chapter 3. The results of the fresh and spent fuel measurements are presented in Chapters 4 and 5 respectively. The conclusions and recommendations for future work are presented in Chapter 6. The Appendices provide additional data from the experiments. 


\section{MEASUREMENT SYSTEM}

The measurement system has three main components: $\mathrm{a}^{252} \mathrm{Cf}$-source ionization chamber, neutron detectors, and electronics with a Fourier analyzer. A brief description of these components is provided in this section of the report.

\section{$2.1{ }^{252} \mathrm{Cf}$ SOURCE}

The ${ }^{252} \mathrm{Cf}$ source was contained in an ionization chamber. The ionization chamber gas was a $90 \% \mathrm{Ar}, 10 \% \mathrm{~N}$ mixture at 1 atmosphere pressure. The ${ }^{252} \mathrm{Cf}$ source had an outer diameter of $2.54 \mathrm{~cm}$ and was approximately $2.54-\mathrm{cm}$ long. The ${ }^{252} \mathrm{Cf}$ mass of the source was approximately $0.11 \mu \mathrm{g}$ and approximately $99 \%$ of the spontaneous fission events were counted. The fraction of spontaneous fission events was determined from a pulse height curve of the ${ }^{252} \mathrm{Cf}$-source count rate as a function of the discriminator threshold setting. The discriminator only produced an output pulse if the input pulse exceeded the specified voltage amplitude. A plot of the count rate as a function of the discriminator threshold voltage is shown in Fig. $2.1 .{ }^{252} \mathrm{Cf}$ decayed by alpha particle emission and by spontaneous fission. The alpha decay rate was approximately 32 times the spontaneous fission rate. The ionization chamber pulses produced by the alpha particles were much lower in amplitude than those produced by the fission fragments. The heavier fission fragments lost more energy in the chamber gas. The alpha decay of the ${ }^{252} \mathrm{Cf}$ source was observed for low threshold settings as noted in the $35-\mathrm{mV}$ region of the curve. As the threshold was increased, the alpha particle events in the chamber were discriminated against and only pulses from the fission fragments were observed over the relatively flat portion of the pulse height curve. Further increase of the threshold eliminated some of the fission fragment pulses and caused the count rate to decrease. The discriminator threshold was set near the center of this curve so that approximately $99 \%$ of the spontaneous fission events were counted. At various times during the measurements, the ${ }^{252} \mathrm{Cf}$ pulse-height curve was measured. Approximately $99 \%$ of the spontaneous fission events were measured except for the spent fuel measurements in which only $98.5 \%$ of the spontaneous fission events were measured. A small correction was applied to the measured spectral ratio values to account for the fact that not all fission events were counted. Neutron counting measurements using a source traceable to the National Institute of Standards were performed to determine the fraction of ${ }^{252} \mathrm{Cf}$ fission events that were counted. The results of these measurements were as presented in Appendix E.

\subsection{NEUTRON DETECTORS}

Two pairs of Reuter Stokes ${ }^{3} \mathrm{He}$ neutron detectors were used in these measurements. Both detector sets had the same physical dimensions and only the gas type and pressure differed between the two types of detectors. The detectors had a nominal 2.54-cm OD and were approximately $51.7-\mathrm{cm}$ long. The nominal active length was approximately $40.6 \mathrm{~cm}$. The detector chamber was comprised of aluminum 1100 with a $0.0813-\mathrm{cm}$ wall 
thickness. The detectors used in the fresh fuel measurements had a ${ }^{3} \mathrm{He}$ and $\mathrm{CO}_{2}$ gas mixture with 4 atmospheres of ${ }^{3} \mathrm{He}$. The detectors used in the spent fuel measurements were comprised of ${ }^{3} \mathrm{He}$ and $\mathrm{CF}_{4}$ with 1 atmosphere of ${ }^{3} \mathrm{He}$.

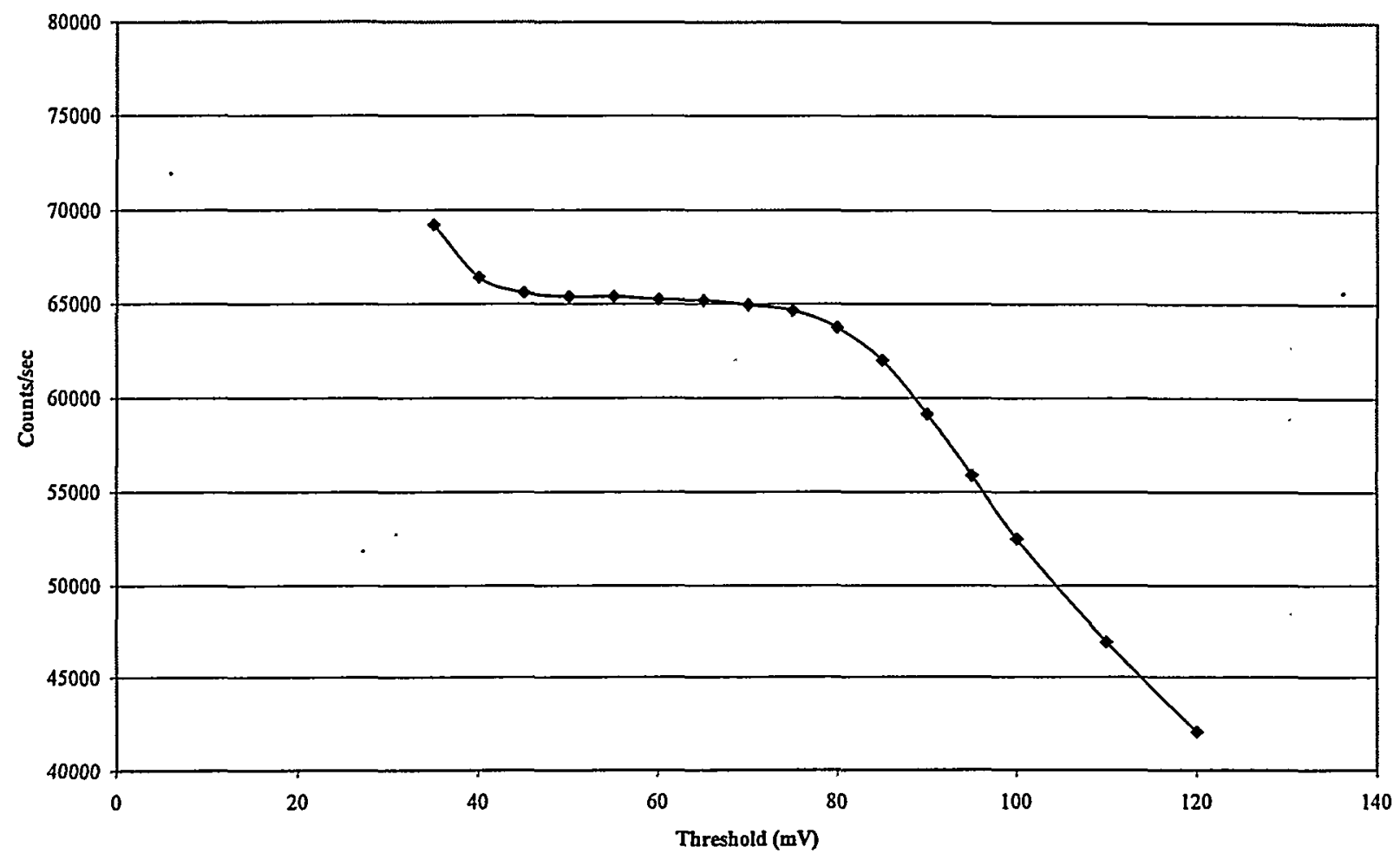

Fig. 2.1. ${ }^{252} \mathrm{Cf}$ pulse-height curve as a function of the discriminator threshold.

\subsection{ELECTRONIC SYSTEM}

The electronic system consisted of components that were used to convert the detector signals to an analog signal that could be digitized by the Fourier analyzer. The ${ }^{252} \mathrm{Cf}$ source was connected to a high-gain fast amplifier (AMP) with a high voltage (HV) input for the ionization chamber and a low voltage (DC) input to power the amplifier. The output was input to an ORTEC 935 constant fraction discriminator (CFD). The CFD was used to discriminate fission fragment pulses from alpha particle pulses. The output of the CFD was input to a RC filter to shape the NIM pulse from the CFD. The signal was then input to the Fourier analyzer where the signal was digitized. The signals from the ${ }^{3} \mathrm{He}$ detectors were sent to an ORNL developed preamplifier and then to an ORTEC 671 linear amplifier (AMP). A high voltage power supply was used to power the chamber. The ORTEC 671 linear amplifier time. constant was set at $0.25 \mu \mathrm{s}$. A modified preamplifier and fast timing linear amplifier were used in the spent fuel measurements. The modified preamplifier allowed the chambers to operate at higher count rates that 
were expected for the spent fuel measurements. The linear amplifier output was sent to an ORTEC 550A single-channel analyzer (SCA). The SCA was used to reject unwanted pulses or pulses due to gamma ray pileup. The SCA output was directed to a TTL-toNIM converter and then to the RC filter prior to being sent to the Fourier analyzer. A sketch of the electronic configuration is provided in Fig. 2.2. For the fresh fuel measurements, the SCA settings were such that all neutron capture events were counted. The SCA settings were varied in the spent fuel measurements to discriminate out the gamma ray pileup events.

The settings for the amplifiers and single channel analyzers were maintained for most of the measurements. The detector-system dead time was $500 \mathrm{~ns}$ for both the fresh and spent fuel measurements. The ${ }^{252} \mathrm{Cf}$-source electronics dead time was approximately $30 \mathrm{~ns}$ for the fresh fuel measurements and approximately $70 \mathrm{~ns}$ for the spent fuel measurements. The dead time was determined by performing measurements of the signal auto correlation function for each detection channel using the nuclear material identification system processor. The threshold setting for the ${ }^{252} \mathrm{Cf}$ source varied depending on the amplifier that was used in the measurements but was always set such that approximately $99 \%$ of the fission fragments were counted. The voltage, gain, and threshold settings for the detectors used in the fresh fuel measurements are provided in Table 2.1.

\begin{tabular}{|c|c|c|c|c|c|}
\hline \multicolumn{6}{|c|}{ Table 2.1. ${ }^{3}$ He-detector electronics settings for fresh fuel measurements } \\
\hline \multirow{2}{*}{$\begin{array}{c}\text { Detector } \\
\text { number }\end{array}$} & $\begin{array}{c}\text { Voltage } \\
(\mathrm{V})\end{array}$ & \multicolumn{2}{|c|}{ Linear amplifier } & \multicolumn{2}{c|}{ Single channel analyzer } \\
\cline { 3 - 6 } & Coarse gain & Fine gain & $\begin{array}{c}\text { Lower level } \\
(\mathrm{V})\end{array}$ & $\begin{array}{c}\text { Upper level } \\
(\mathrm{V})\end{array}$ \\
\hline 98D01023 (N) & 1300 & 20 & 8.50 & 1 & 10 \\
\hline 98D01024(S) & 1300 & 20 & 7.50 & 1 & 10 \\
\hline 98D01026(E) & 1300 & 20 & 7.84 & 1 & 10 \\
\hline 98D01028 (W) & 1300 & 50 & 7.50 & 1 & 10 \\
\hline
\end{tabular}

${ }^{2}$ Direction in parenthesis designate the physical location of the detector in the assembly.

\subsection{FOURIER PROCESSOR}

ZONIC Corporation developed the Fourier processor. The processor had eight input channels that were sampled synchronously and a throughput disk that was used to store the time series of the detector response. A digital signal processor was used to digitize the input signals. The digitized signals were then Fourier transformed prior to being complex multiplied to compute the auto and cross spectra. A $300 \mathrm{MHz}$ Macintosh computer was used to acquire and process the data from the processor using software developed by ZONIC Corporation. The software was programmable and was set such that all auto and cross spectra between the five channels could be calculated. The bandwidth, the number of data points, and the number of data blocks were all specified in the software. The spectral ratio values were computed from the auto and cross spectra. 

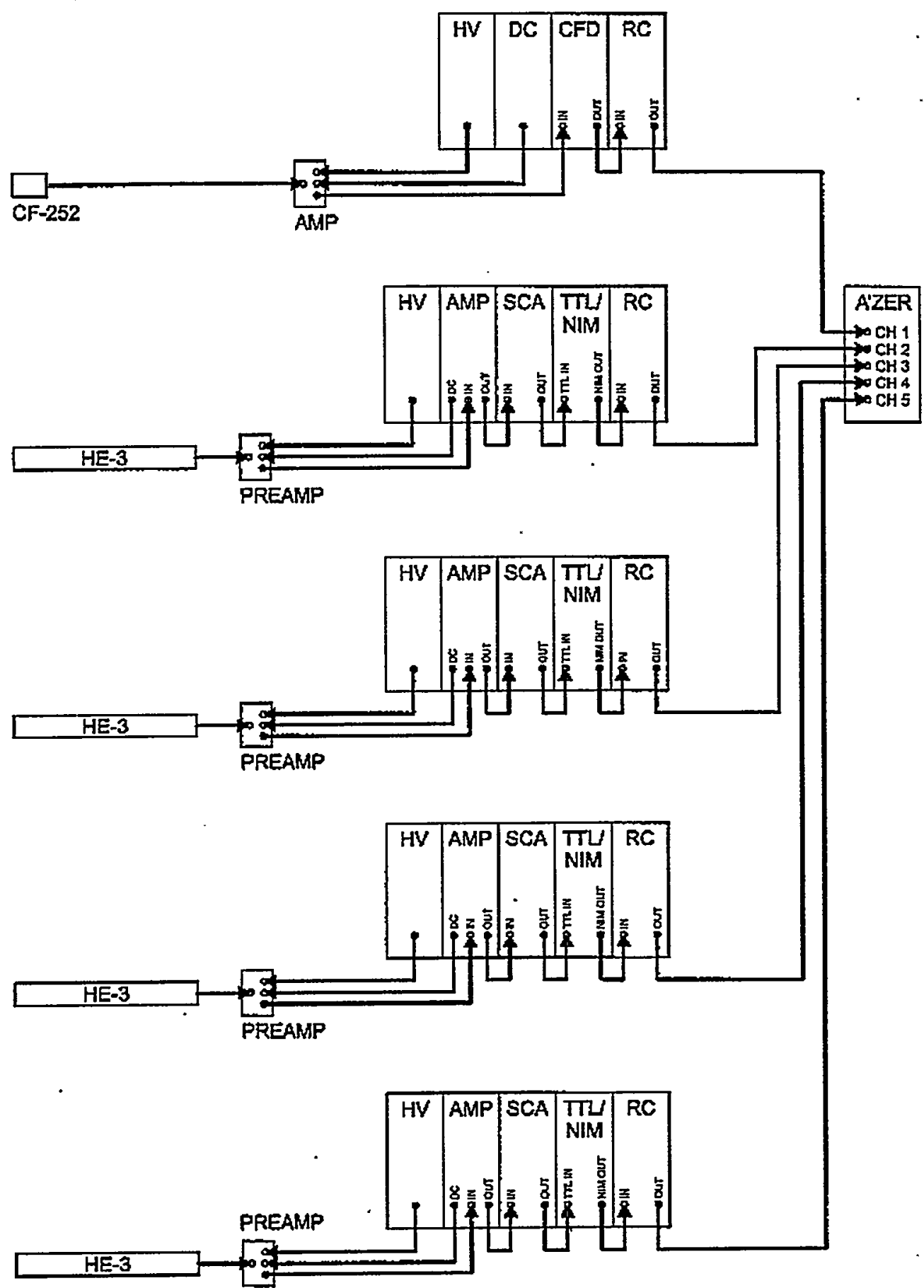

Fig. 2.2. Sketch of equipment configuration. 
The source and detector channels were such that the source was input into the first channel on the analyzer. The north detector was input into channel two of the analyzer and the south detector was input into channel three of the analyzer. The east and west detectors were input into analyzer channels four and five, respectively. These arrangements were used for all of the fresh fuel measurement configurations. The analyzer inputs were changed for the spent fuel measurements because not all detectors were used. The analyzer measured the auto spectra for each channel, $G_{i i}$, and the cross spectra between channels, $G_{i j}$. Six different spectral ratio values were obtained from the auto and cross spectra. The spectral ratio was defined as

$$
R_{i j}(\omega)=\frac{G_{1 i}^{*}(\omega) G_{1 j}(\omega)}{G_{11}(\omega) G_{i j}(\omega)},
$$

where $G_{I i}(\omega)$ was the source-detector cross spectrum between the source and channel $i$, $G_{l j}(\omega)$ was the source-detector cross spectrum between the source and channel $j, G_{I l}(\omega)$ was the source auto spectrum, $G_{i j}(\omega)$ was the cross spectrum between channels $i$ and $j$, and the ${ }^{*}$ denoted the complex conjugation. The six spectral ratios were designated as $R_{23}(\omega), R_{24}(\omega), R_{25}(\omega), R_{34}(\omega), R_{35}(\omega)$, and $R_{45}(\omega)$. The spectral ratios were averaged over the low frequency region where the ratio was essentially constant.

The spectral ratio has been shown to be proportional to the system reactivity without dependence on the effective delayed neutron fraction:

$$
R \sim C \frac{\Delta k}{k} .
$$

This expression only held if point kinetics was applicable and the system was not very subcritical. By measuring the change in the spectral ratio, an estimate of the change in the system reactivity was obtained using the relation give in Eq. 2.2. 


\section{MEASUREMENT ASSEMBLY CONFIGURATION}

Both fresh and spent fuel measurements were performed with the same experimental assembly. A variety of fresh fuel measurements were performed with various absorbing plates placed between the fuel elements.

\subsection{EXPERIMENTAL ASSEMBLY}

The experimental assembly was designed such that four MURR fuel assemblies in vertical positions could be spaced at varying distances from each other. The device sat on top of a freestanding $0.635-\mathrm{cm}$-thick, aluminum table that was either on the bottom of the fresh water tank or the reactor weir pool. The tank was a 7 -ft. high, 6-ft.-inside diameter high-density polyethylene structure with a wall thickness of $1.11 \mathrm{~cm}$. The assembly was positioned in the center of the tank such that the fuel elements were completely reflected by approximately $2 \mathrm{ft}$. of water. The experimental assembly is shown in Fig. 3.1.

The fuel assemblies were placed within a thin-walled aluminum sleeves that are evident in the photograph to protect the fuel elements. The sleeves were mounted on slide plates that allowed the fuel elements to be moved from the symmetric center in 1-mm increments. A nominal 2.54-cm-OD schedule-10 aluminum (type 1100) pipe was also positioned on the slide such that the detectors could be placed adjacent to the fuel elements. A 2.54-cm-thick lead collar was placed around the detector dry well for the spent nuclear fuel measurements. Each detector dry well could be positioned at five different locations on the aluminum slide plate such that the fuel-to-detector centerline distances could be varied from $7.5 \mathrm{~cm}$ to $13.5 \mathrm{~cm}$ in $1.5-\mathrm{cm}$ increments. An additional schedule-10 aluminum pipe was placed on the end of the slide to stabilize the detector dry well. The slide plate construction is shown in the photograph in Fig. 3.2.

Each fuel element could be moved independently of each other until the elements came into contact with a dry well located in the center of the assembly. The central dry well was used for the ${ }^{252} \mathrm{Cf}$ source. The dry wells are also evident in Fig. 3.1. The slide mechanisms consisted of an aluminum plate that had an aluminum receiver for one fuel assembly and one detector dry well. The slide plate was controlled by a threaded screw drive that could be operated remotely above the tank using the manual controls that are evident in Fig. 3.1. The drive was calibrated such that one complete turn on the handle corresponded to a $1-\mathrm{mm}$ slide movement. Mechanical counters were used to measure the fuel assembly position in steps of $0.1 \mathrm{~mm}$. The spacing between fuel elements could be changed independently to evaluate the interaction between elements. 


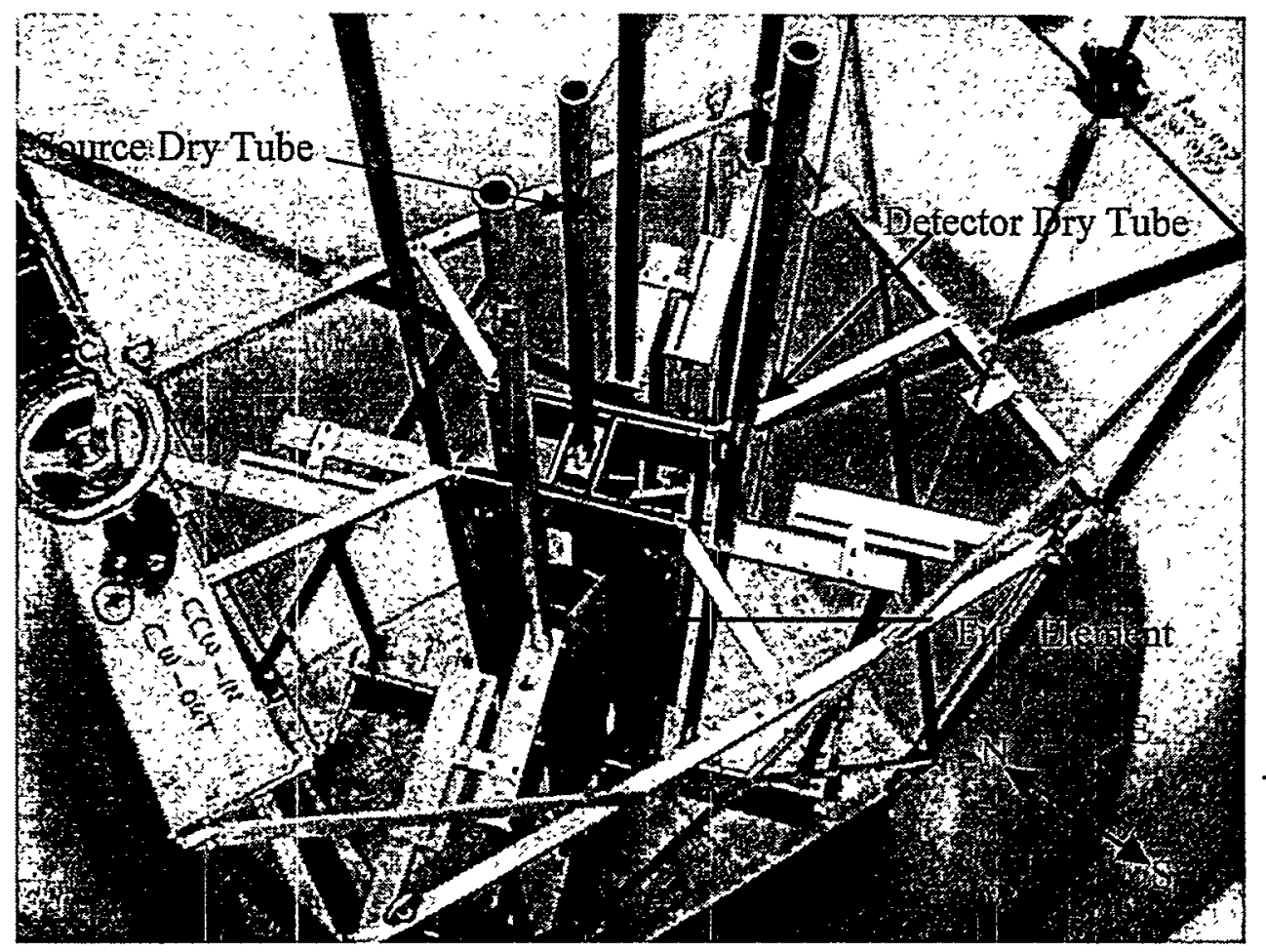

Fig. 3.1. Photograph from top of experimental assembly in fresh water tank.

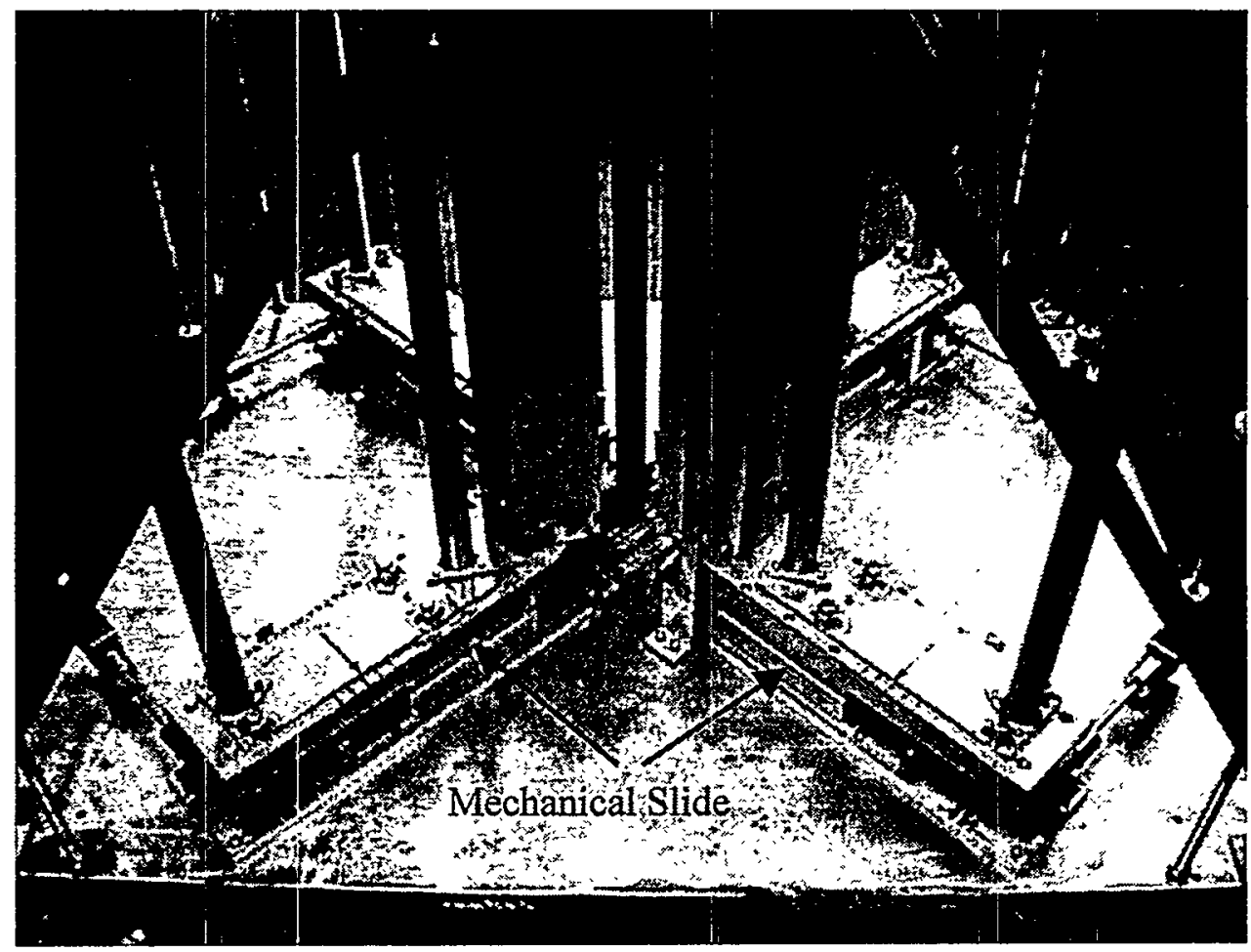

Fig. 3.2. Photograph of the assembly slide plates. 
The $\mathrm{H}$-shaped cruciform that was evident in Fig. 3.1 was used to locate the plates in the assembly. The cruciform had springs such that the absorbing plates were always closest to the fuel elements. The cruciform was designed such that a maximum $0.635-\mathrm{cm}$-thick plate could be positioned between the fuel elements. A close view of the $\mathrm{H}$-shaped cruciform is provided in Fig. 3.3. The outer edges of the plates in the East and West position were $7.770 \mathrm{~cm}$ from the center of the assembly. The outer edges of the plates in the North and South position were $2.959 \mathrm{~cm}$ from the center of the assembly. These plates simulated the use of such materials in spent fuel shipping casks.

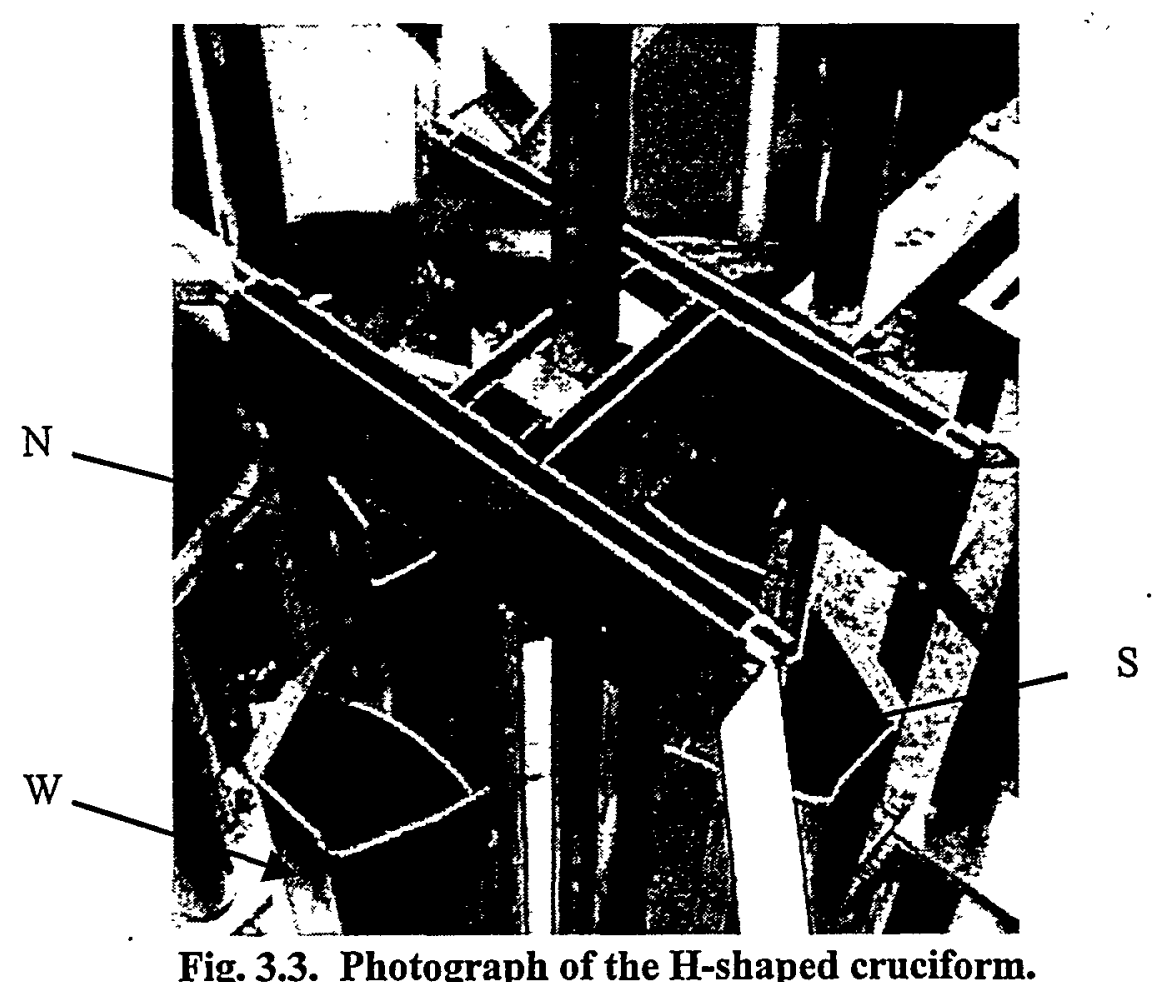

Fig. 3.3. Photograph of the H-shaped cruciform.

The fuel assemblies could be rotated on the aluminum post that was used to maintain the fuel elements in the vertical position. The fuel element support post is shown in the photograph in Fig. 3.4. In these measurements the fuel elements could be rotated on the aluminum support post. Typically, the elements in the North and South positions were located such that the small side of the fuel element was nearest the source dry well. This orientation of the fuel element was designated as orientation A. If the large side of the fuel element was located nearest the source dry well, the fuel element was in orientation B. A majority of the measurements were performed with the North and South elements in orientation A and with the East and West elements in orientation B because this configuration had the highest $k_{\text {eff. }}$ Measurements were also performed with all elements in orientation $\mathrm{A}$ and with all elements in orientation $\mathrm{B}$. The fuel elements located in the standard configuration are shown in the photograph in Fig. 3.5. The numbers 2 and 3 evident on the detector supports corresponded to the South and East positions respectively. 


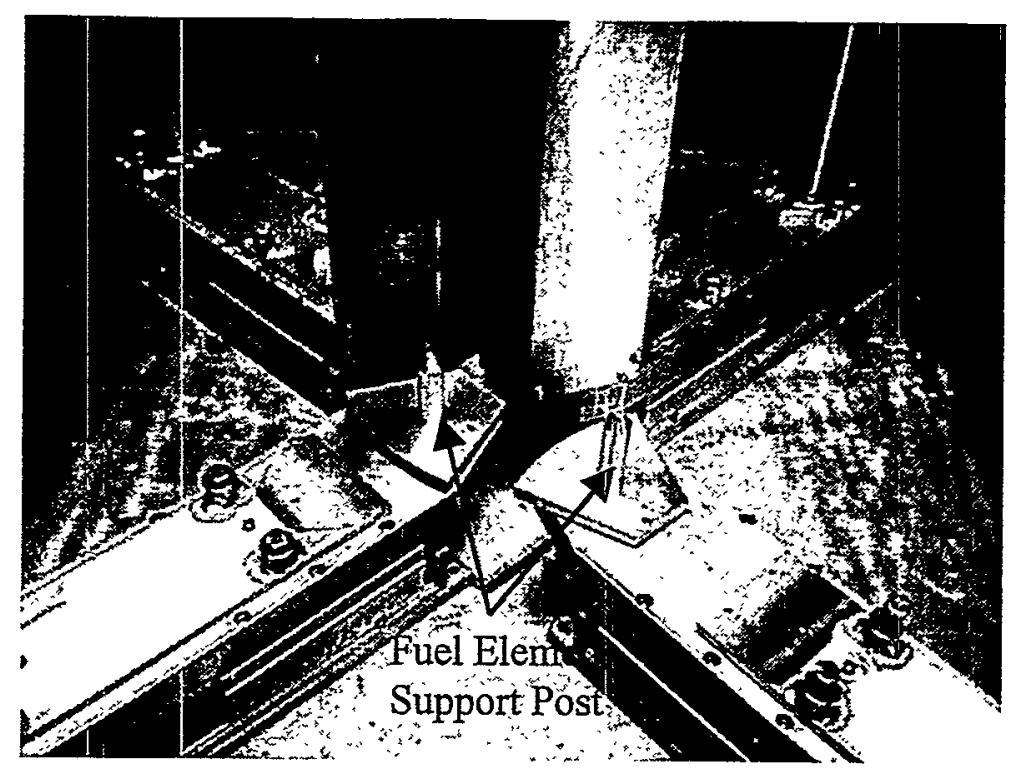

Fig. 3.4. Photograph of fuel element support post.

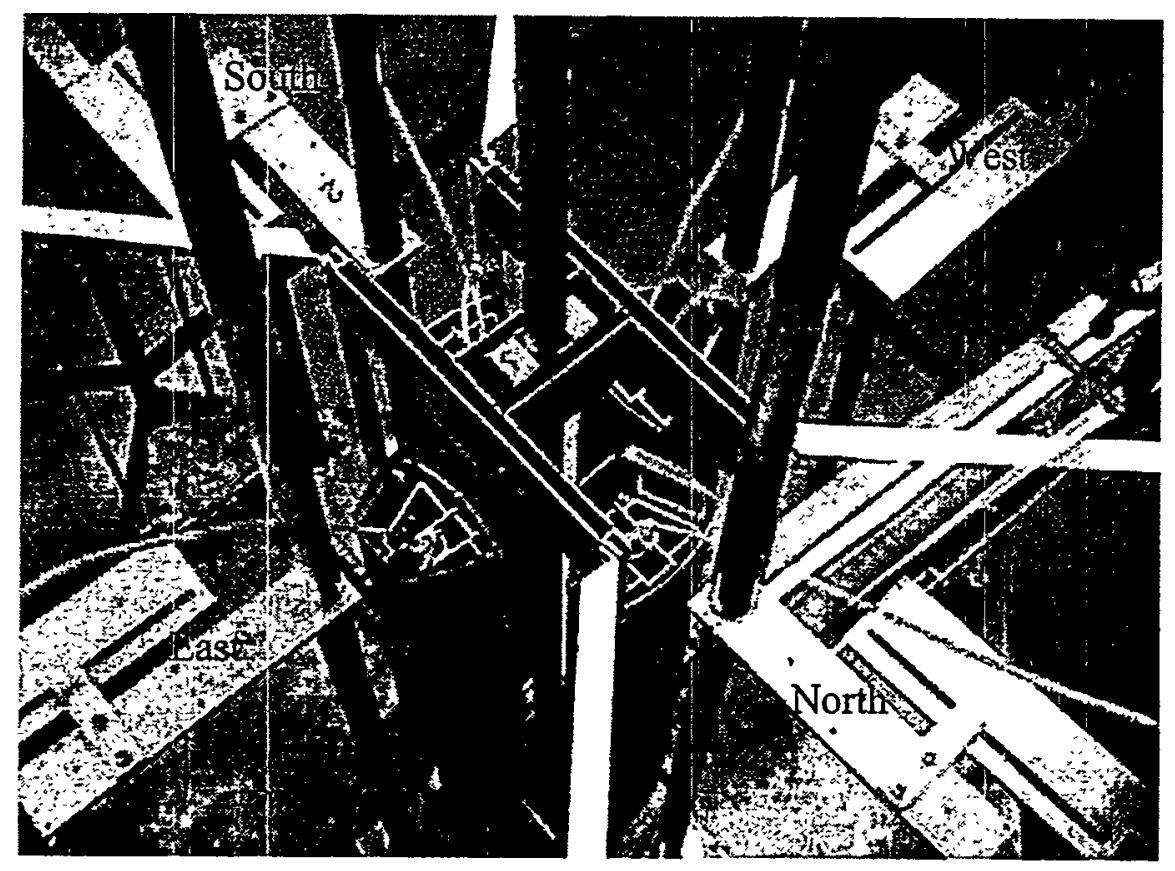

Fig. 3.5. Photograph of fuel elements in standard orientation. 
The vertical position of the ${ }^{252} \mathrm{Cf}$ source was variable using a clamping rod that was located on the top of the central dry well. The source ionization chamber was on the end of a 5-ft. long cable that was connected to the high gain fast amplifier that was mounted on the clamping rod. The source position was measurable to $0.318 \mathrm{~cm}$. The detectors used in the measurements were centered about the active region of the fuel elements. Small aluminum (type 1100) pipes were placed in the bottom of the detector dry wells to maintain the detectors at the centerline of the fuel elements while lead plugs were used in place of the aluminum plugs for the spent fuel measurements. A complete description of the experimental assembly was given in the design document developed by MURR ${ }^{5}$

\subsection{ABSORBING PLATES}

Absorbing plates were positioned between the fuel elements using the $\mathrm{H}$-shaped cruciform shown in Figs. 3.1 and 3.3. As previously stated, tension springs were used in the cruciform to push the plates toward the fuel elements. The plates were positioned vertically in the assembly and extended beyond the full length of the fuel elements as shown in the photograph in Fig. 3.6. As shown in Fig. 3.6, the fuel element shrouds were positioned to be in contact with the plates.

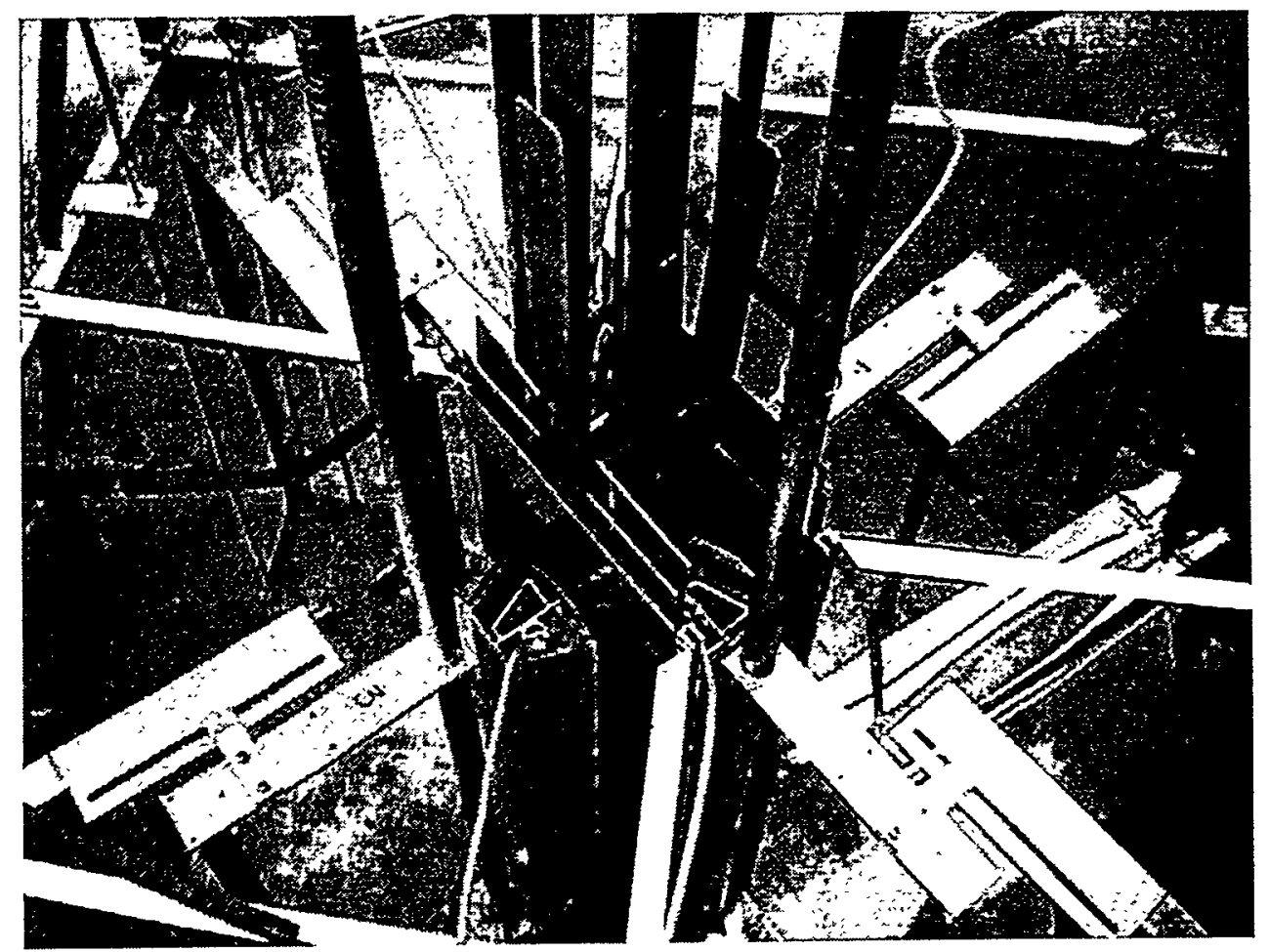

Fig. 3.6. Photograph of plate measurements. 
Aluminum 1100, stainless steel 304, lead, and borated-aluminum (BORAL) plates were used in these measurements. The dimensions of the plates are provided in Table 3.1 and were specified in English units as provided by the manufacturers. The plates had varying thickness and varying width. The narrow plates were used in the north and south positions while the wider plates were used in the east and west positions. Various combinations of plates were used to create a total plate thickness of approximately $0.635-\mathrm{cm}$. The dimensions and compositions of the plates were obtained from ref. 6 .

\begin{tabular}{|c|c|c|c|c|}
\hline \multicolumn{5}{|c|}{ Table 3.1. Absorbing plate dimensions } \\
\hline Plate type & Quantity & Thickness (in) & Width (in) & Length (in) \\
\hline 304 Stainless Steel & 3 & 0.120 & 11.875 & 48.0 \\
\hline & 3 & 0.060 & 4.875 & 48.0 \\
\hline Aluminum 1100 & 3 & 0.125 & 11.875 & 48.0 \\
\hline & 3 & 0.063 & 4.875 & 48.0 \\
\hline Lead & 2 & 0.257 & 4.875 & 48.0 \\
\hline & 2 & 0.378 & 11.875 & 48.0 \\
\hline BORAL & 2 & 0.075 & 4.875 & 48.0 \\
\hline & 2 & 0.075 & 11.875 & 48.0 \\
\hline
\end{tabular}

The Aluminum Company of America (ALCOA) provided aluminum plates that were used in these experiments. The 0.0630 -in. thick plates had slightly different isotopic compositions than the 0.1250 -in.-thick plates due to different manufacturing processes. The isotopic compositions for the aluminum plates are provided in Table 3.2. North American Stainless ${ }^{\circledR}$ (NAS) corporation manufactured the 4.875-in.-wide, 0.06-in.-thick 304SS plates, whereas Lukens@ Corporation (LC) manufactured the 0.120-in.-thick, 11.875-in.-wide plates. The material isotopic composition data for each plate is presented in Table 3.3. Nuclear Lead Corporation manufactured the lead plates and the lead shields that were used in the measurements. The chemical composition of the lead material is provided in Table 3.4. AAR Advanced Structures manufactured the BORAL $\otimes$ plates that had a nominal 0.075 -in. thickness with a 0.055 -in-thick aluminum. 1100 clad. The reported manufacturing tolerances were \pm 0.005 -in. thickness, \pm 0.062 -in. width, and +0.100 -in. length. The core material consisted of $\mathrm{B}_{4} \mathrm{C}$ and aluminum with a nominal chemical composition defined in Table 3.5. The nominal ${ }^{10} \mathrm{~B}$ loading of each plate was assumed to be $0.02 \mathrm{~g}^{10} \mathrm{~B} / \mathrm{cm}^{2}$ with an assumed alloy density of $2.489 \mathrm{~g} / \mathrm{cm}^{3}$.

\begin{tabular}{|c|c|c|}
\hline \multicolumn{3}{|c|}{ Table 3.2. Aluminum plate composition } \\
\hline Element & $\begin{array}{c}\text { 0.063-in. plates } \\
\text { (wt. \%) }\end{array}$ & $\begin{array}{c}0.125 \text {-in. plates } \\
\text { (wt. \%) }\end{array}$ \\
\hline Aluminum & 99.15 & 99.24 \\
\hline Copper & 0.15 & 0.14 \\
\hline Iron & 0.64 & 0.54 \\
\hline Silicon & 0.06 & 0.08 \\
\hline
\end{tabular}




\begin{tabular}{|c|c|c|}
\hline \multicolumn{3}{|c|}{ Table 3.3. Stainless steel 304 plate composition } \\
\hline Element & $\begin{array}{c}\text { NAS steel } \\
\text { (wt. \%) }\end{array}$ & $\begin{array}{c}\text { LC steel } \\
\text { (wt. \%) }\end{array}$ \\
\hline Iron & 70.841 & 70.724 \\
\hline Carbon & 0.041 & 0.07 \\
\hline Cobalt & 0.168 & 0.17 \\
\hline Chromium & 18.233 & 18.11 \\
\hline Copper & 0.298 & 0.40 \\
\hline Manganese & 1.495 & 1.51 \\
\hline Molybdenum & 0.301 & 0.39 \\
\hline Nickel & 8.140 & 8.03 \\
\hline Nitrogen & 0.055 & 0.07 \\
\hline Phosphorous & 0.027 & 0.029 \\
\hline Sulfur & 0.002 & 0.007 \\
\hline Silicon & 0.382 & 0.49 \\
\hline Tin & 0.017 & 0.0 \\
\hline
\end{tabular}

\begin{tabular}{|c|c|c|}
\hline \multicolumn{3}{|c|}{ Table 3.4. Lead plate and shield composition } \\
\hline Element & $\begin{array}{c}\text { Minimum impurities } \\
\text { (wt. \%) }\end{array}$ & $\begin{array}{c}\text { Maximum impurities } \\
\text { (wt. \%) }\end{array}$ \\
\hline Lead & 99.958 & 99.89 \\
\hline Silver & 0.002 & 0.020 \\
\hline Copper & 0.040 & 0.080 \\
\hline Zinc & 0.000 & 0.001 \\
\hline Iron & 0.000 & 0.002 \\
\hline Bismuth & 0.000 & 0.005 \\
\hline Arsenic, Antimony and Tin & 0.000 & 0.002 \\
\hline
\end{tabular}

\begin{tabular}{|c|c|}
\hline \multicolumn{2}{|c|}{ Table 3.5. BORAL plate composition } \\
\hline Element & Wt \% \\
\hline Aluminum & 69.0 \\
\hline Boron & 24.0 \\
\hline Carbon & 6.0 \\
\hline Iron & 0.5 \\
\hline Silicon & 0.1 \\
\hline Titanium & 0.1 \\
\hline Copper & 0.1 \\
\hline Zinc & 0.1 \\
\hline
\end{tabular}




\subsection{MURR FUEL ELEMENTS}

The MURR fuel elements that were used in these experiments were comprised of highly enriched uranium (93.15 wt\%). Each fuel element contained twenty-four curved uranium aluminum plates that were clad in aluminum. The uranium-aluminum $\left(\mathrm{UAl}_{3}\right)$ core region had a nominal 0.02 -in. thickness. The core region was clad in 0.015 -in. thick aluminum making a total nominal thickness of 0.05 in. The fuel plates were stacked together inside two side plates that maintained a fixed spacing ( $0.08 \mathrm{in})$ between the fuel plates that serve as cooling channels during reactor operation. The side plates were 0.15 -in. thick aluminum. A sketch of the fuel plate arrangement is provided in Fig. 3.7 .

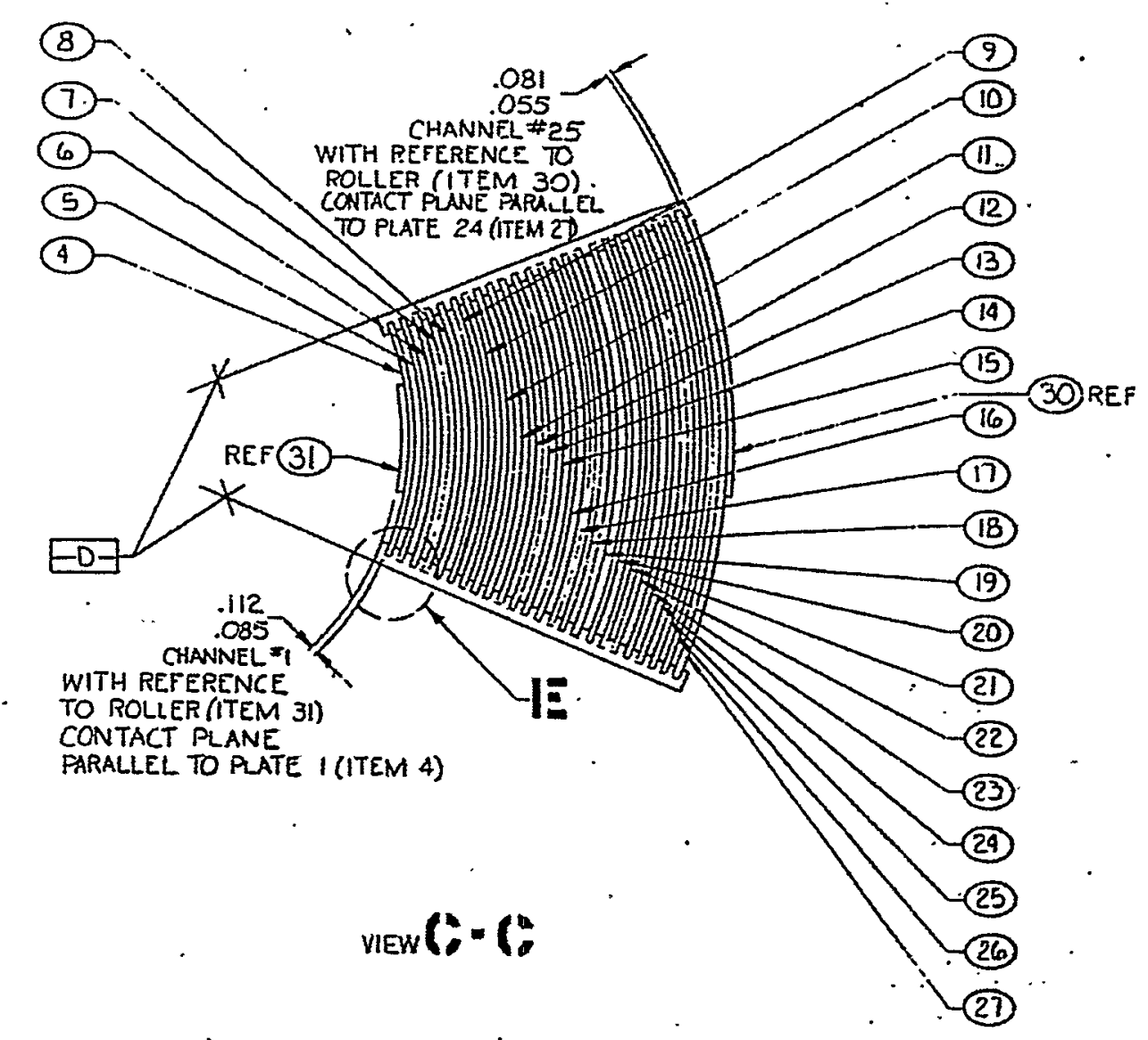

Fig. 3.7. Sketch of MURR fuel assembly construction. 
The 24 fuel plates and the aluminum side plates were connected together with an upper and lower end fitting. A sketch of an end fitting is shown in Fig. 3.8. The end fittings were made with a 0.72 -in-diameter locating-pin hole that was at the geometric center of the assembly. For these measurements, a locating pin with the same dimensions as those used in the reactor was used on the fuel assembly slide plate.

The material data for the fuel elements was provided by Babcock \& Wilcox and is given in Table 3.6. The total uranium mass, $\mathrm{UAl}_{3}$ mass, and the aluminum mass for each assembly is provided in Table 3.6. The tolerance for the water gap thickness was \pm 0.008 in. The tolerance for the uranium enrichment was $\pm 0.0005 \mathrm{wt} \%$ and the tolerance for the uranium mass was $\pm 0.1 \mathrm{~g}$. The composition of each plate is provided in Tables in Appendix A.

\begin{tabular}{|c|c|c|c|c|c|}
\hline \multicolumn{7}{|c|}{ Table 3.6. Fuel assembly compositions } \\
\hline Assembly & $\begin{array}{c}\text { Uranium } \\
(\mathrm{g})\end{array}$ & $\begin{array}{c}{ }^{25} \mathrm{U} \\
(\mathrm{g})\end{array}$ & $\begin{array}{c}\mathrm{UAl}_{3} \\
(\mathrm{~g})\end{array}$ & $\begin{array}{c}\mathrm{Al} \\
(\mathrm{g})\end{array}$ & $\begin{array}{c}\text { Enrichment } \\
(\mathrm{wt} \%)\end{array}$ \\
\hline MO-517 (N) & 830.48 & 773.60 & 1180.59 & 851.59 & 93.15 \\
\hline MO-518(S) & 830.36 & 773.48 & 1180.59 & 851.72 & 93.15 \\
\hline MO-519(E) & 830.39 & 773.52 & 1180.56 & 852.12 & 93.15 \\
\hline MO-520(W) & 830.62 & 773.73 & 1177.14 & 859.98 & 93.15 \\
\hline
\end{tabular}




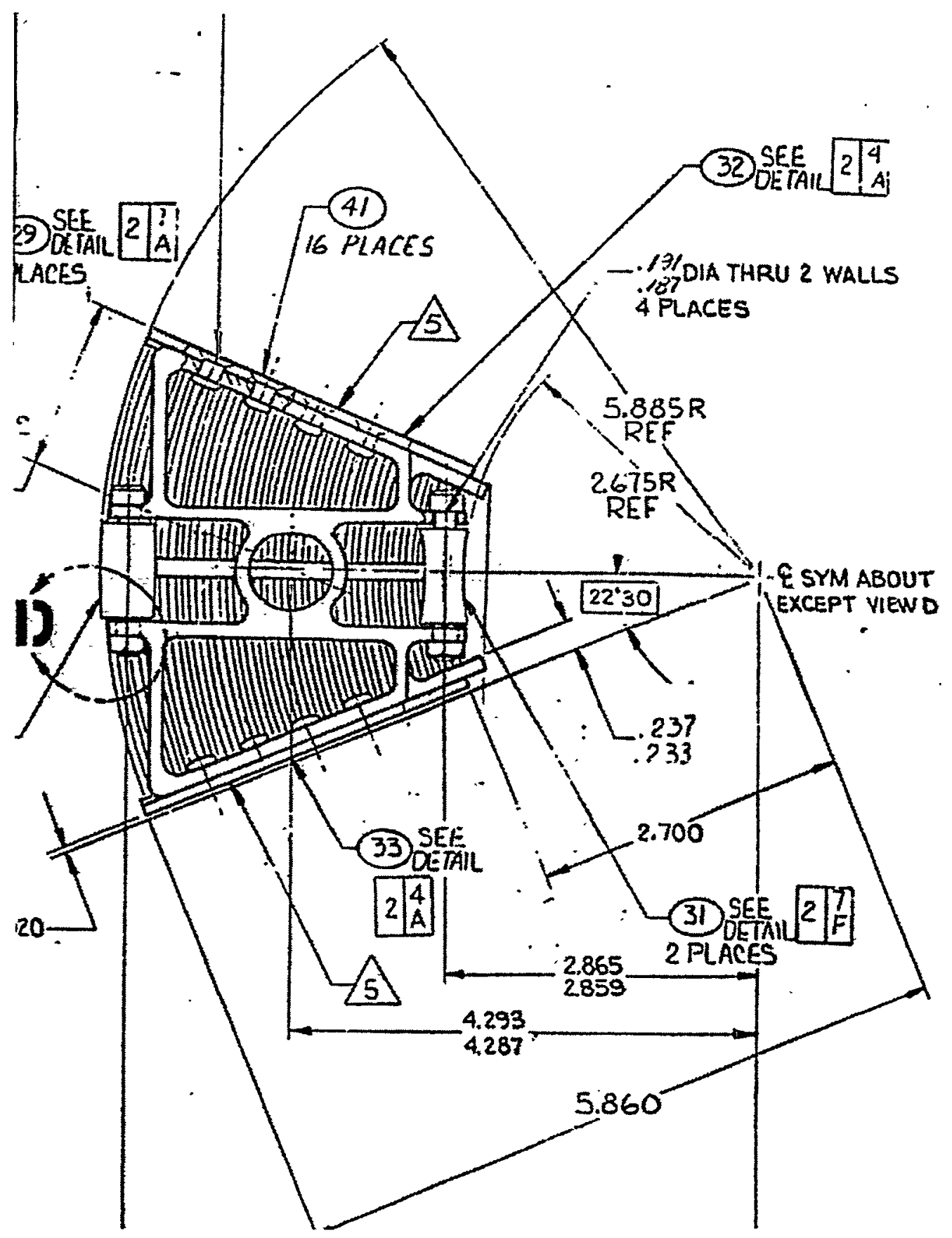

Fig. 3.8. MURR fuel element end fitting. 


\subsection{EXPERIMENTAL ASSEMBLY DIMENSIONAL CALIBRATION}

Before and after the fresh fuel measurements were completed a series of dimensional measurements were performed on the experimental assembly. Calibration measurements were necessary to establish the spacing between the fuel elements and the center of the source dry well and to set the mechanical counters. The center-to-fuel spacing was defined as the distance between the center of the source dry well and the center of the locating pin. This summary of the assembly calibration was obtained from ref. 6 .

Setting the mechanical counters on a specific value and using a caliper to measure the distance between the center of a dummy fuel assembly and the source dry well calibration measurements were performed. Using machined aluminum spacers to measure the distance between the fuel element locating pin and the source dry well provided additional calibration measurements. These aluminum spacers had widths of $2.00,4.00$, $6.00,8.00,10.00$, and $12.00 \mathrm{~cm}$. The mechanical counter positions were recorded for each of these spacers. The calipers and aluminum spacers used for calibrations are shown in Fig. 3.9.

The fuel-to-detector spacing was fixed and was determined by the aluminum slide plate on which the fuel assemblies and detector dry wells were mounted. The distances between the fuel element and the detector centerline in centimeters were 7.5, 9.0, 10.5, 12.0, and 13.5. The aluminum slide plate is shown in the photograph in Fig. 3.10. Four bolts were used to mount the detector dry well to the aluminum slide plate. Data for the calibration measurements are supplied in Appendix B.

The uncertainties in the measurement configuration were considered to use these measurements for subcritical benchmarks. The general manufacturing tolerances of the assemblies were \pm 0.005 in. whereas the tolerance for the slide mechanism was $\pm 0.1 \mathrm{~mm}$. The uncertainty in the detector position was small and was estimated to be \pm 0.005 in. 


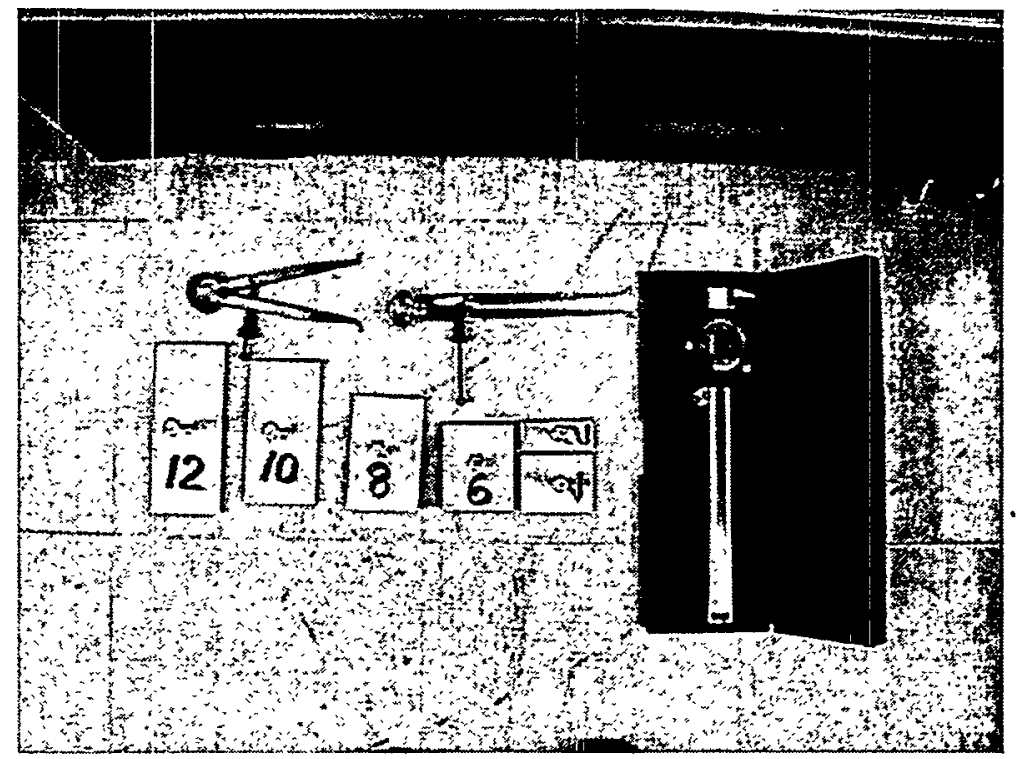

Fig. 3.9. Calibration measurement tools.

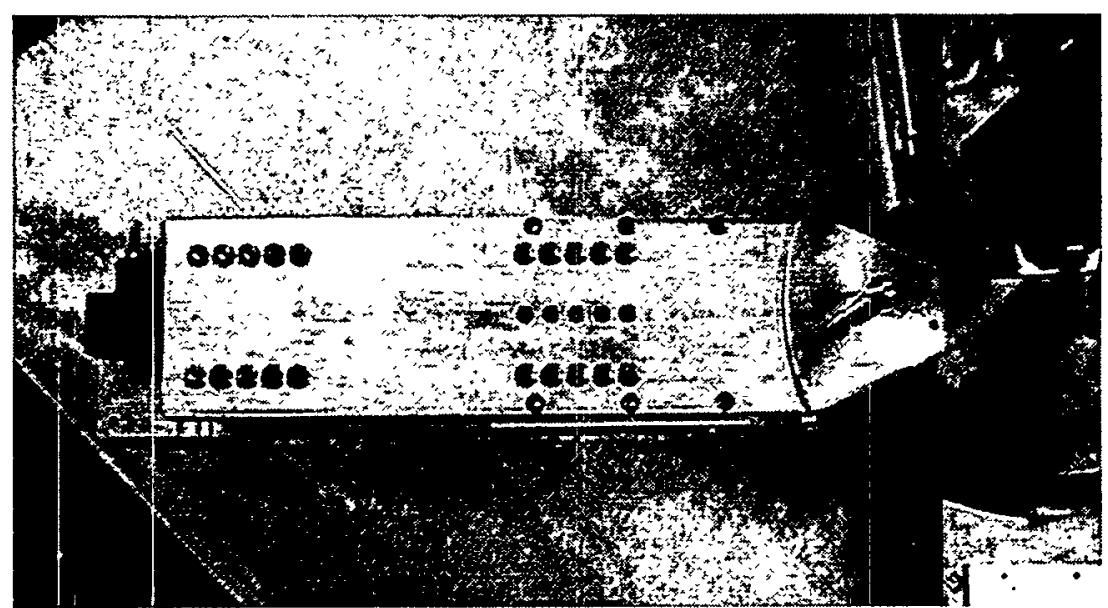

Fig. 3.10. Aluminum slide plate. 


\section{FRESH FUEL MEASUREMENTS}

A variety of measurements were performed with the fresh fuel elements in the fresh water tank. These measurements included inverse multiplication measurements, source scans, detector variation measurements, repeatability measurements, fuel element separation measurements, fuel orientation measurements, and plate measurements. Additional measurements were performed as reported in the Appendices.

\subsection{INVERSE MULTIPLICATION MEASUREMENTS}

Inverse multiplication measurements were performed to determine the closest position that the fuel elements could be placed and to satisfy NRC requirements. The source was placed in the center dry well and the four 4-atmosphere ${ }^{3} \mathrm{He}$ detectors were placed in their dry wells. A set of reference measurements with all aluminum fuel elements in the North and South positions were used for the inverse multiplication measurements because the detectors moved with the fuel elements as the fuel elements were brought closer together and because of the water that was displaced by the fuel elements. Detector counts at various center-to-fuel separations were acquired to obtain the needed references. The detector count rates were obtained as the fuel elements were brought closer together and were divided by the reference count rates at each position to obtain the properly normalized multiplication. The average multiplication was defined as the average multiplication of the four values obtained at each fuel element position. The fuel element position was defined as the sum of the four different position readings. The reference count rates for all four detectors as a function of the sum of the position indicators are contained in Table 4.1. The count rates for all for detectors as a function of the sum of the positions for measurements with four fuel elements are presented in Table 4.2. The inverse multiplication curve obtained from this data is presented in Fig. 4.1. The four fuel elements can be brought completely in contact with each other because the inverse multiplication curve did not extrapolate to $0.1\left(\mathrm{k}_{\mathrm{eff}}<0.90\right)$.

\begin{tabular}{|c|c|c|c|c|}
\hline \multicolumn{5}{|c|}{ Table 4.1. Reference count rates as a function of fuel element position } \\
\hline $\begin{array}{c}\text { Sum of fuel } \\
\text { element } \\
\text { position }\end{array}$ & $\begin{array}{c}\text { North detector } \\
\text { count rate } \\
\text { (counts/sec) }\end{array}$ & $\begin{array}{c}\text { South detector } \\
\text { count rate } \\
\text { (counts/sec) }\end{array}$ & $\begin{array}{c}\text { East detector } \\
\text { count rate } \\
\text { (counts/sec) }\end{array}$ & $\begin{array}{c}\text { West detector } \\
\text { count rate } \\
\text { (counts/sec) }\end{array}$ \\
\hline 2239 & 840 & 836 & 807 & 752 \\
\hline 1839 & 1040 & 1048 & 1010 & 939 \\
\hline 1439 & 1304 & 1311 & 1285 & 1169 \\
\hline 1239 & 1487 & 1479 & 1436 & 1341 \\
\hline 1039 & 1644 & 1657 & 1577 & 1474 \\
\hline 939 & 1852 & 1840 & 1586 & 1472 \\
\hline 739 & 2073 & 2071 & 1781 & 1661 \\
\hline 599 & 2207 & 2142 & 1977 & 1854 \\
\hline 559 & 2206 & 2147 & 2063 & 1926 \\
\hline 519 & 2212 & 2164 & 2143 & 2030 \\
\hline
\end{tabular}




\begin{tabular}{|c|c|c|c|c|}
\hline \multicolumn{5}{|c|}{ Table 4.2. Count rates as a function of fuel element position with four fuel elements } \\
\hline $\begin{array}{c}\text { Sum of fuel } \\
\text { element } \\
\text { position }\end{array}$ & $\begin{array}{c}\text { North detector } \\
\text { count rate } \\
\text { (counts/sec) }\end{array}$ & $\begin{array}{c}\text { South detector } \\
\text { count rate } \\
\text { (counts/sec) }\end{array}$ & $\begin{array}{c}\text { East detector } \\
\text { count rate } \\
\text { (counts/sec) }\end{array}$ & $\begin{array}{c}\text { West detector } \\
\text { count rate } \\
\text { (counts/sec) }\end{array}$ \\
\hline 2239 & 4003 & 4018 & 3212 & 3071 \\
\hline 1839 & 5596 & 5601 & 4551 & 4365 \\
\hline 1439 & 8148 & 8098 & 6688 & 6482 \\
\hline 1239 & 10021 & 9960 & 8243 & 8011 \\
\hline 1039 & 12291 & 12209 & 10144 & 9901 \\
\hline 939 & 14010 & 13863 & 11062 & 10816 \\
\hline 739 & 16759 & 16558 & 13258 & 13017 \\
\hline 599 & 18067 & 17759 & 14698 & 14458 \\
\hline 559 & 18220 & 17908 & 15086 & 14843 \\
\hline 519 & 18320 & 17981 & 15428 & 15235 \\
\hline
\end{tabular}

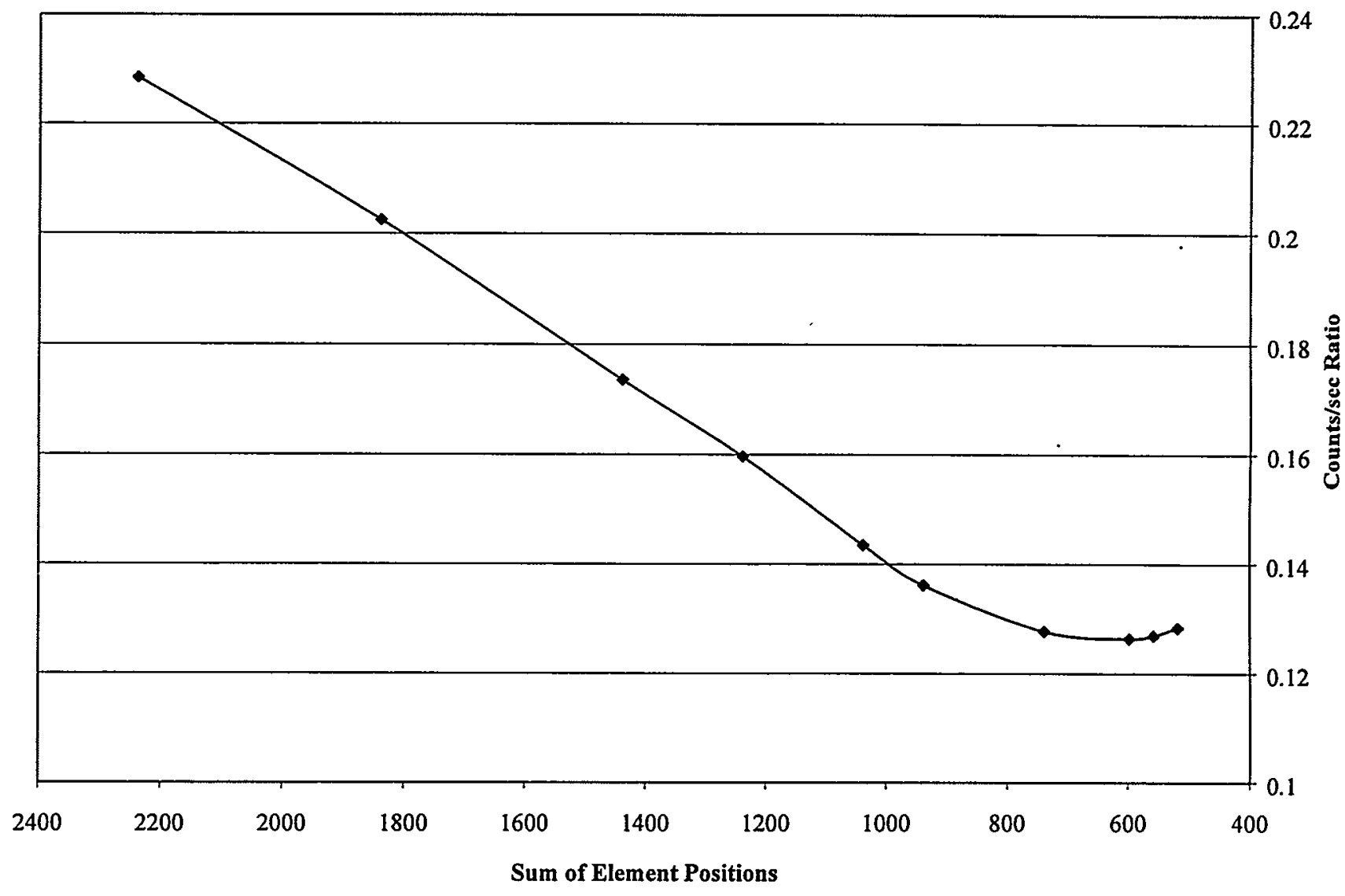

Fig. 4.1. Inverse multiplication curve for four atmosphere ${ }^{3} \mathrm{He}$ detectors as a function of fuel element position. 


\subsection{SOURCE AXIAL SCAN}

A series of measurements were performed to determine the sensitivity of the measurement to the axial source position and to determine the near optimum location for the source. The measurements were performed with the assembly configuration as described in Table 4.3.

\begin{tabular}{|c|c|c|c|c|}
\hline \multicolumn{5}{|c|}{ Table 4.3. Assembly configuration for source axial scan } \\
\hline Parameter & North & East & South & West \\
\hline Fuel Orientation & A & B & A & B \\
\hline $\begin{array}{c}\text { Center-to-Fue } \\
\text { Spacing (cm) }\end{array}$ & 6.745 & 8.109 & 6.712 & 8.299 \\
\hline $\begin{array}{c}\text { Detector-to-Fuel } \\
\text { Spacing (cm) }\end{array}$ & 10.5 & 10.5 & 10.5 & 10.5 \\
\hline
\end{tabular}

a Orientation A corresponds to the small side of the fuel element closest to the center and orientation B corresponds to the large side of the fiel element closest to the center.

b Spacing between fuel centerline and source dry well centerline.

c. Spacing between detector centerline and fuel element centerline.

Both count rate and noise analysis measurements were obtained as the source position was varied from $30 \mathrm{~cm}$ below the fuel centerline to $30 \mathrm{~cm}$ above the fuel centerline that covered the active region of the fuel element. After the measurements were completed, it was discovered that detector 3 (south position) was raised slightly due to tension in the detector cables. The count rates and spectral ratio values detectors that exclude detector 3 were used to determine the optimum source location. The optimum location of the source was very near the center of the fuel element. The detector count rates as a function of source position are provided in Table 4.4. The count rate for detector 3 was asymmetric because this detector was raised slightly from the fuel element centerline.

\begin{tabular}{|c|c|c|c|c|c|}
\hline \multicolumn{6}{|c|}{ Table 4.4. Detector count rate for varying source location } \\
\hline $\begin{array}{c}\text { Source } \\
\text { position }(\mathrm{cm})\end{array}$ & Number $^{\mathrm{a}}$ & $\begin{array}{c}\text { North } \\
\text { counts/sec }\end{array}$ & $\begin{array}{c}\text { East } \\
\text { counts/sec }\end{array}$ & $\begin{array}{c}\text { South } \\
\text { counts/sec }\end{array}$ & $\begin{array}{c}\text { West } \\
\text { counts/sec }\end{array}$ \\
\hline 30 & 20 & 7090 & -6007 & 9147 & 5860 \\
\hline 15 & 19 & 12494 & 10530 & 13886 & 10310 \\
\hline 10 & 18 & 14376 & 12117 & 14937 & 11867 \\
\hline 4 & 16 and 17 & 15361 & 13163 & 15104 & 12939 \\
\hline 0 & 14 and 15 & 15913 & 13385 & 14513 & 13132 \\
\hline-10 & 21 & 14476 & 12170 & 11538 & 12036 \\
\hline-15 & 22 & 12747 & 10710 & 9482 & 10637 \\
\hline-30 & 23 & 5106 & 4307 & 3316 & 4332 \\
\hline
\end{tabular}

a Measurement file number. 
The data in Table 4.4 was best illustrated by plotting the count rate as a function of source position as shown in Fig. 4.2. The detector count rates were symmetric about the fuel centerline except for detector 3 . The count rates indicated that the optimum location of the source was at the center of the fuel element because the neutron count rate was the highest with the source at the center of the active region of the fuel elements. After the source scan was complete, detector 3 was centered axially.

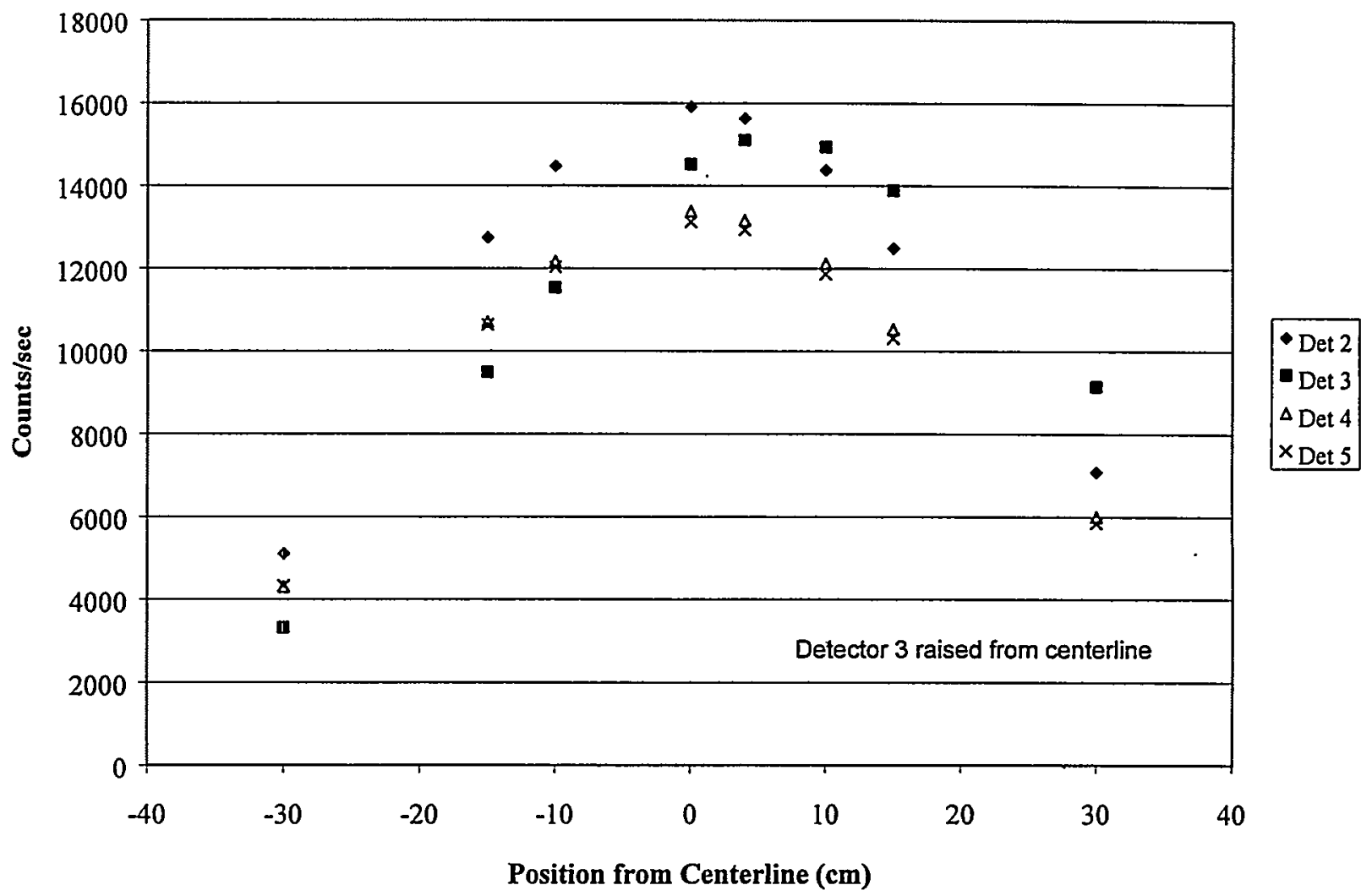

Fig. 4.2. Detector count rates as a function of source axial position. 
The spectral ratio values obtained from these measurements are presented in Table 4.5 and represented the low frequency average. The uncertainties in the spectral ratio values were computed as the standard deviation of the means. The spectral ratio values that were obtained using detector 3 (south position) were asymmetric because detector 3 was raised slightly above the centerline. Therefore, the optimum source location was determined by using spectral ratio values that did not involve detector 3 , namely spectral ratio values 24 , 25 , and 45 . These ratio values indicated that the optimum location of the source was near the fuel centerline. This was to be expected because the measurement configuration was essentially symmetric and indicated that the aluminum table did not have a significant affect on neutron reflection. The low frequency averages of the spectral ratio values 24 and 45 were as plotted as a function of source axial position in Fig. 4.3. These spectral ratio values peaked at the fuel centerline. 


\begin{tabular}{|c|c|c|c|c|c|c|c|c|c|c|c|c|c|}
\hline \multicolumn{14}{|c|}{ Table 4.5. Spectral ratio values for varying source axial position } \\
\hline \multirow{2}{*}{$\begin{array}{c}\text { Source } \\
\text { position }^{a} \\
(\mathrm{~cm})\end{array}$} & \multirow[b]{2}{*}{ No. } & \multicolumn{2}{|c|}{ Ratio 23} & \multicolumn{2}{|c|}{ Ratio 24} & \multicolumn{2}{|c|}{ Ratio 25} & \multicolumn{2}{|c|}{ Ratio 34} & \multicolumn{2}{|c|}{ Ratio 35} & \multicolumn{2}{|c|}{ Ratio 45} \\
\hline & & $\mathrm{R}^{\mathrm{b}}$ & $\sigma^{c}$ & $\mathrm{R}$ & $\sigma$ & $\mathrm{R}$ & $\sigma$ & $\overline{\mathrm{R}}$ & $\sigma$ & $\mathrm{R}$ & $\sigma$ & $\mathrm{R}$ & $\sigma$ \\
\hline 30 & 20 & 0.195 & 0.002 & 0.147 & 0.001 & 0.145 & 0.002 & 0.182 & 0.002 & 0.181 & 0.002 & 0.153 & 0.002 \\
\hline 15 & 19 & 0.287 & 0.002 & 0.241 & 0.003 & 0.242 & 0.003 & 0.271 & 0.003 & 0.269 & 0.003 & 0.249 & 0.003 \\
\hline 10 & 18 & 0.302 & 0.002 & 0.276 & 0.003 & 0.270 & 0.002 & 0.297 & 0.003 & 0.291 & 0.003 & 0.286 & 0.002 \\
\hline \multirow[t]{2}{*}{4} & 16 & 0.312 & 0.002 & 0.290 & 0.002 & 0.291 & 0.002 & 0.302 & 0.002 & 0.295 & 0.004 & 0.299 & 0.003 \\
\hline & 17 & 0.314 & 0.002 & 0.292 & 0.002 & 0.290 & 0.002 & 0.297 & 0.002 & 0.297 & 0.002 & 0.305 & 0.003 \\
\hline \multirow[t]{2}{*}{0} & $\overline{14}$ & 0.312 & 0.002 & 0.300 & 0.002 & 0.300 & 0.003 & 0.299 & 0.003 & 0.297 & 0.003 & 0.309 & 0.002 \\
\hline & 15 & 0.308 & 0.003 & 0.302 & 0.002 & 0.295 & 0.003 & 0.303 & 0.003 & 0.294 & 0.002 & 0.314 & 0.004 \\
\hline-10 & 21 & 0.268 & 0.002 & 0.279 & 0.002 & 0.276 & 0.002 & 0.257 & 0.003 & 0.253 & 0.002 & 0.292 & 0.003 \\
\hline-15 & 22 & 0.237 & 0.002 & 0.255 & 0.003 & 0.251 & 0.002 & 0.225 & 0.003 & 0.223 & 0.002 & 0.265 & 0.002 \\
\hline-30 & 23 & 0.092 & 0.001 & 0.112 & 0.002 & 0.113 & 0.001 & 0.086 & 0.001 & 0.087 & 0.001 & 0.115 & 0.002 \\
\hline
\end{tabular}

${ }^{a}$ Source position above and below centerline.

${ }^{b}$ Low frequency average of spectral ratio.

${ }^{\mathrm{c}}$ Standard deviation of the mean of the low frequency spectral ratio average. 


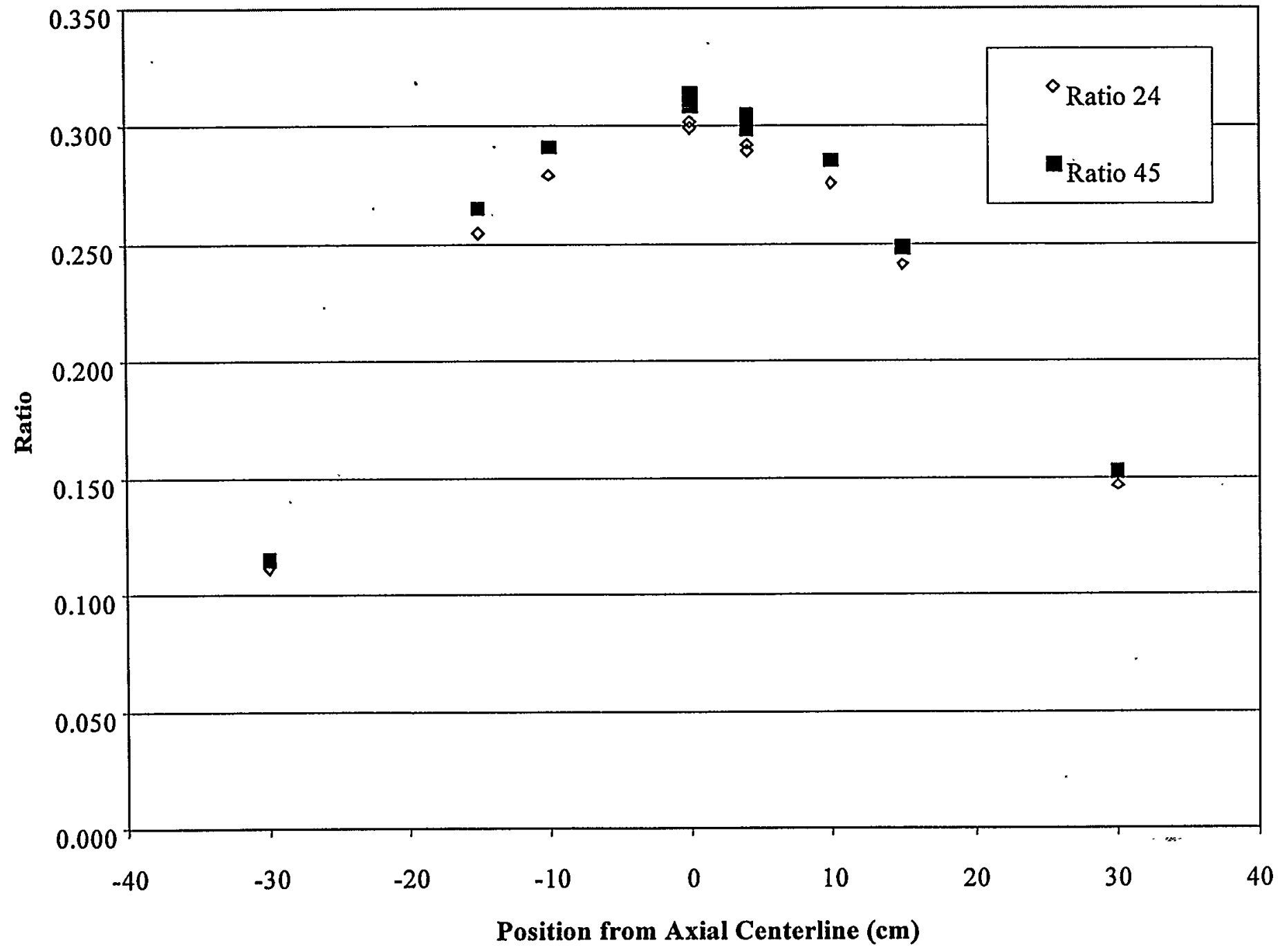

Fig. 4.3. Spectral ratio values 24 and 45 as a function of source axial position. 


\subsection{FUEL-TO-DETECTOR SEPARATION}

A series of measurements were performed to determine the best location of the detectors with respect to the fuel element centerline. The best location was determined such that the detectors had a relatively small affect on the system reactivity while maintaining high detector count rates. The fuel-element configuration for these measurements is provided in Table 4.6. The fuel spacing was selected to correspond to the spacing that would be used for the plate measurements. The fuel was in orientation $A B A B$.

\begin{tabular}{|c|c|c|c|c|}
\hline \multicolumn{5}{|c|}{ Table 4.6. Assembly configuration for detector spacing optimization } \\
\hline Parameter & North & East & South & West \\
\hline Fuel Orientation ${ }^{2}$ & $\mathrm{~A}$ & $\bar{B}$ & $\bar{A}$ & $\bar{B}$ \\
\hline $\begin{array}{l}\text { Center-to-Fuel } \\
\text { Spacing }(\mathrm{cm})^{\mathrm{b}}\end{array}$ & 8.114 & 12.665 & 8.127 & 12.941 \\
\hline
\end{tabular}

${ }^{a}$ Orientation $A$ corresponds to the small side of the fuel element closest to the center and orientation B corresponds to the large side of the fuel element closest to the center.

${ }^{\mathrm{b}}$ Spacing between fuel centerline and source dry well centerline.

Both count rate data and noise analysis data were used to determine the best location for the detectors. The detector count rates were the highest with the detectors closest to the fuel elements because of the reduced distance between the fissile material and the neutron detector. The count rate data as a function of the detector position is given in Table 4.7. The count rates decreased slightly as the detector was moved from $7.5 \mathrm{~cm}$ spacing to the $9 \mathrm{~cm}$ spacing and then reduced more significantly as the detector was moved further away from the fuel. The data presented in Table 4.8 are plotted in Fig. 4.4.

\begin{tabular}{|c|c|c|c|c|}
\hline \multicolumn{5}{|c|}{ Table 4.7. Detector count rates as a function of detector position } \\
\hline $\begin{array}{c}\text { Detector } \\
\text { position }(\mathrm{cm})\end{array}$ & $\begin{array}{c}\text { North } \\
\text { counts/sec }\end{array}$ & $\begin{array}{c}\text { East } \\
\text { counts/sec }\end{array}$ & $\begin{array}{c}\text { South } \\
\text { counts/sec }\end{array}$ & $\begin{array}{c}\text { West } \\
\text { counts/sec }\end{array}$ \\
\hline 7.5 & 8419 & 4967 & 8519 & 4954 \\
\hline 9.0 & 7868 & 4603 & 7864 & 4587 \\
\hline 10.5 & 6653 & 3886 & 6636 & 3859 \\
\hline 12.0 & 5341 & 3058 & 5212 & 3047 \\
\hline 13.5 & 4056 & 2320 & 3965 & 2325 \\
\hline
\end{tabular}

The spectral ratio values as a function of detector spacing were measured and are presented in Table 4.8. The spectral ratio values decreased as the detector was moved away from the fuel element indicating that the reactivity was increasing. The 4atmosphere ${ }^{3} \mathrm{He}$ detector behaved as a control rod close to the fuel element. The $9.0-\mathrm{cm}$ spacing was chosen as the best location because the detector had less impact on the reactivity than the $7.5-\mathrm{cm}$ spacing, and the detector count rate for the $9.0-\mathrm{cm}$ spacing was significantly higher than that for the $10.5,12.0$, or 13.5 -cm spacing. 


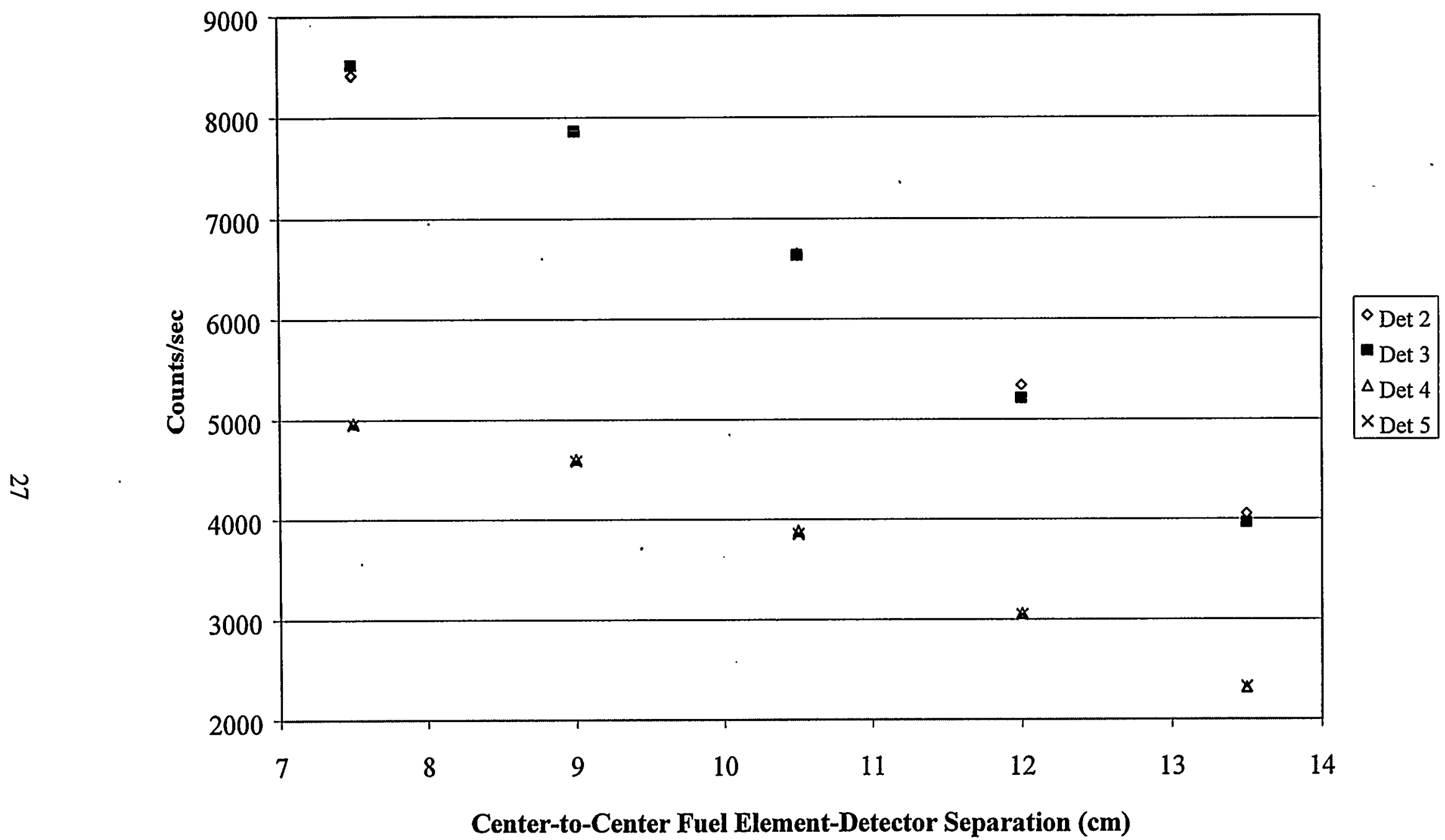

Fig. 4.4. Detector count rate as a function of detector-fuel element separation. 


\begin{tabular}{|c|c|c|c|c|c|c|c|c|c|c|c|c|c|}
\hline \multicolumn{14}{|c|}{ Table 4.8. Spectral ratio values for varying detector position } \\
\hline \multirow{2}{*}{$\begin{array}{l}\text { Detector } \\
\text { position } \\
\text { (cm) }\end{array}$} & \multirow[b]{2}{*}{ No. } & \multicolumn{2}{|c|}{ Ratio 23} & \multicolumn{2}{|c|}{ Ratio $24^{\mathrm{c}}$} & \multicolumn{2}{|c|}{ Ratio $25^{\mathrm{C}}$} & \multicolumn{2}{|c|}{ Ratio $34^{\mathrm{c}}$} & \multicolumn{2}{|c|}{ Ratio $35^{\mathrm{c}}$} & \multicolumn{2}{|c|}{ Ratio 45} \\
\hline & & $\mathrm{R}^{\mathrm{a}}$ & $\sigma^{b}$ & $\mathrm{R}$ & $\bar{\sigma}$ & $\mathrm{R}$ & $\sigma$ & $\mathrm{R}$ & $\sigma$ & $\overline{\mathrm{R}}$ & $\sigma$ & $\overline{\mathrm{R}}$ & $\bar{\sigma}$ \\
\hline 7.5 & 36 & 0.550 & 0.006 & 0.460 & 0.005 & 0.452 & 0.005 & 0.457 & 0.005 & 0.449 & 0.006 & 0.539 & 0.012 \\
\hline \multirow[t]{2}{*}{9.0} & 34 & 0.556 & 0.009 & 0.460 & 0.004 & 0.449 & 0.008 & 0.462 & 0.005 & 0.452 & 0.008 & 0.514 & 0.020 \\
\hline & 35 & 0.548 & 0.008 & 0.440 & 0.007 & 0.437 & 0.010 & 0.444 & 0.004 & 0.457 & 0.010 & 0.505 & 0.006 \\
\hline \multirow[t]{2}{*}{10.5} & 32 & 0.518 & 0.011 & 0.442 & 0.006 & 0.440 & 0.010 & 0.446 & 0.006 & 0.438 & 0.005 & 0.517 & 0.010 \\
\hline & 33 & 0.530 & 0.006 & 0.436 & 0.008 & 0.448 & 0.007 & 0.445 & 0.007 & 0.440 & 0.006 & 0.492 & 0.012 \\
\hline \multirow[t]{2}{*}{12.0} & 37 & 0.536 & 0.009 & 0.437 & 0.007 & 0.436 & 0.011 & 0.425 & 0.007 & 0.443 & 0.009 & 0.501 & 0.015 \\
\hline & 38 & 0.523 & 0.007 & 0.442 & 0.010 & 0.428 & 0.007 & 0.453 & 0.008 & 0.425 & 0.008 & 0.499 & 0.010 \\
\hline 13.5 & 39 & 0.521 & 0.004 & 0.433 & 0.002 & 0.425 & 0.003 & 0.443 & 0.004 & 0.426 & 0.002 & 0.507 & 0.007 \\
\hline
\end{tabular}




\subsection{MEASUREMENT REPRODUCIBILITY}

The reproducibility of the measurements was evaluated by repeating two particular measurement configurations at various times during the two weeks of measurements. The precision to which a measurement could be reproduced was important to use the results for benchmarking Monte Carlo calculations. The precision could have been best evaluated by repeating the same measurement numerous times. However, because of the short duration of this measurement program, only a small set of repeat measurements was performed.

Reference measurements were performed with the fuel elements separated to the position for the plate measurements without any plates being present. The orientation and configuration of the fuel assemblies for these measurements is given in Table 4.9 These measurements established the base values for the spectral ratio to which a measurement with plates were compared and were repeated at various times during the measurements over a one week period. The results of these measurements were indicative of the ability to reposition the fuel elements and repeat the measurements. The spectral ratio values obtained from these measurements are summarized in Table 4.10 . The individual measurement values were obtained by averaging the frequency dependent spectral ratio values over the low frequency range in which the spectral ratio was essentially flat. The standard deviations of the individual measurement values were the standard deviations of the means of the low frequency averages. The spectral ratio values for these measurements were averaged together using the inverse of the sample variance as a weight function. The resulting average is also presented in Table 4.10 along with the sample set standard deviation. The standard deviation of the sample set did not differ significantly from the standard deviation of the mean of the individual spectral ratio values thereby indicating that the variation between measurements was not significant. The standard deviation of the sample set was on the order of one to two percent of the low frequency average of the spectral ratio values. The standard deviation of the sample set was to be used when comparing measured and calculated spectral ratio values. The average frequency-dependent spectral signatures for these reference measurements are provided in Appendix $\mathrm{H}$.

\begin{tabular}{|c|c|c|c|c|}
\hline \multicolumn{5}{|c|}{ Table 4.9. Assembly configuration for plate-spacing reference measurements } \\
\hline Parameter & North & East & South & West \\
\hline Fuel Orientation ${ }^{\mathrm{a}}$ & $\mathrm{A}$ & $\bar{B}$ & A & B \\
\hline $\begin{array}{l}\text { Center-to-Fuel } \\
\text { Spacing }(\mathrm{cm})^{\mathrm{b}}\end{array}$ & 8.114 & 12.665 & 8.127 & 12.941 \\
\hline
\end{tabular}

${ }^{a}$ Orientation A corresponds to the small end of the fuel element closest to the center and orientation B corresponds to the large end of the fuel element closest to the center.

${ }^{b}$ Spacing between fuel centerline and source dry well centerline. 


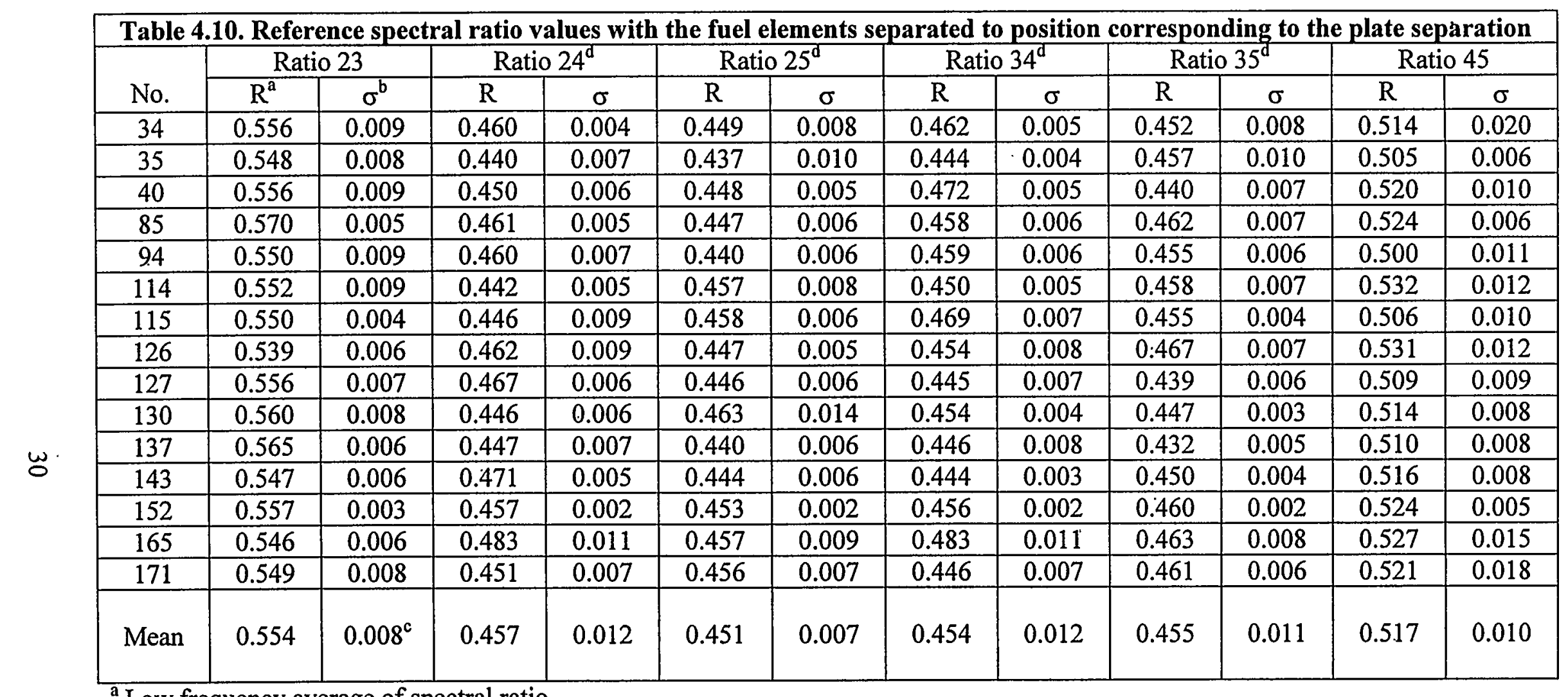

${ }^{a}$ Low frequency average of spectral ratio.

${ }^{b}$ Standard deviation of the mean of the low frequency spectral ratio average.

c Standard deviation of the sample set.

d Ratio values $24,25,34$, and 35 should be approximately the same. 
The data in Table 4.10 were best illustrated by plotting the spectral ratio value as a function of measurement number. These results are presented in Figs. 4.5 through 4.10. For most measurements, the individual measurement values were within one standard deviation of the average value of the sample set. The individual measured values with their uncertainties were all within two standard deviations of the average value and sample set standard deviation. The variation of the individual measurement values about the sample mean did not exhibit any particular trend as a function of time. However, additional measurements would have been necessary to determine the distribution of the individual measurement values about the sample mean because the sample set consisted of only 15 values.

A second set of nine reference measurements were performed with the fuel elements closer together. The fuel elements were in the same orientation as the previous measurements but were spaced much closer together. The assembly configuration for the close-spaced reference measurements is given in Table 4.11. Again these measurements indicated the ability to reproduce the measurements. The spectral ratio values obtained from these measurements are summarized in Table 4.12. The individual measurement values were obtained by averaging the frequency dependent spectral ratio values over the low frequency range in which the spectral ratio was essentially flat. The standard deviations of the individual measurement values were the standard deviations of the means of the low frequency averages. The spectral ratio values for these measurements were averaged together using the inverse of the sample variance as a weight function. The resulting average is also presented in Table 4.12 along with the sample set standard deviation. The standard deviation of the sample set was between one to two percent of the low-frequency spectral ratio value.

\begin{tabular}{|c|c|c|c|c|}
\hline Parameter & North & East & South & West \\
\hline Fuel Orientation $^{\mathrm{a}}$ & $\bar{A}$ & $\overline{\mathrm{B}}$ & $\overline{\mathrm{A}}$ & $\overline{\mathrm{B}}$ \\
\hline $\begin{array}{l}\text { Center-to-Fuel } \\
\text { Spacing }(\mathrm{cm})^{\mathrm{b}}\end{array}$ & 7.931 & 9.519 & 7.918 & . 9.615 \\
\hline
\end{tabular}

${ }^{a}$ Orientation $\mathrm{A}$ corresponds to the small end of the fuel element closest to the center and orientation B corresponds to the large end of the fuel element closest to the center.

${ }^{\mathrm{b}}$ Spacing between fuel centerline and source dry well centerline.

These results of the close-spaced reference measurements are presented in Figs. 4.11 through 4.16. For most measurements, the individual measurement values were within one standard deviation of the average value of the sample set. The individual measured values with their uncertainties were all within two standard deviations of the average value and sample set standard deviation. The variation of the individual measurement values about the sample mean did not exhibit any particular trend as a function of time. However, additional measurements would have been necessary to determine the distribution of the individual measurement values about the sample mean because the sample set consisted of only 9 values. 


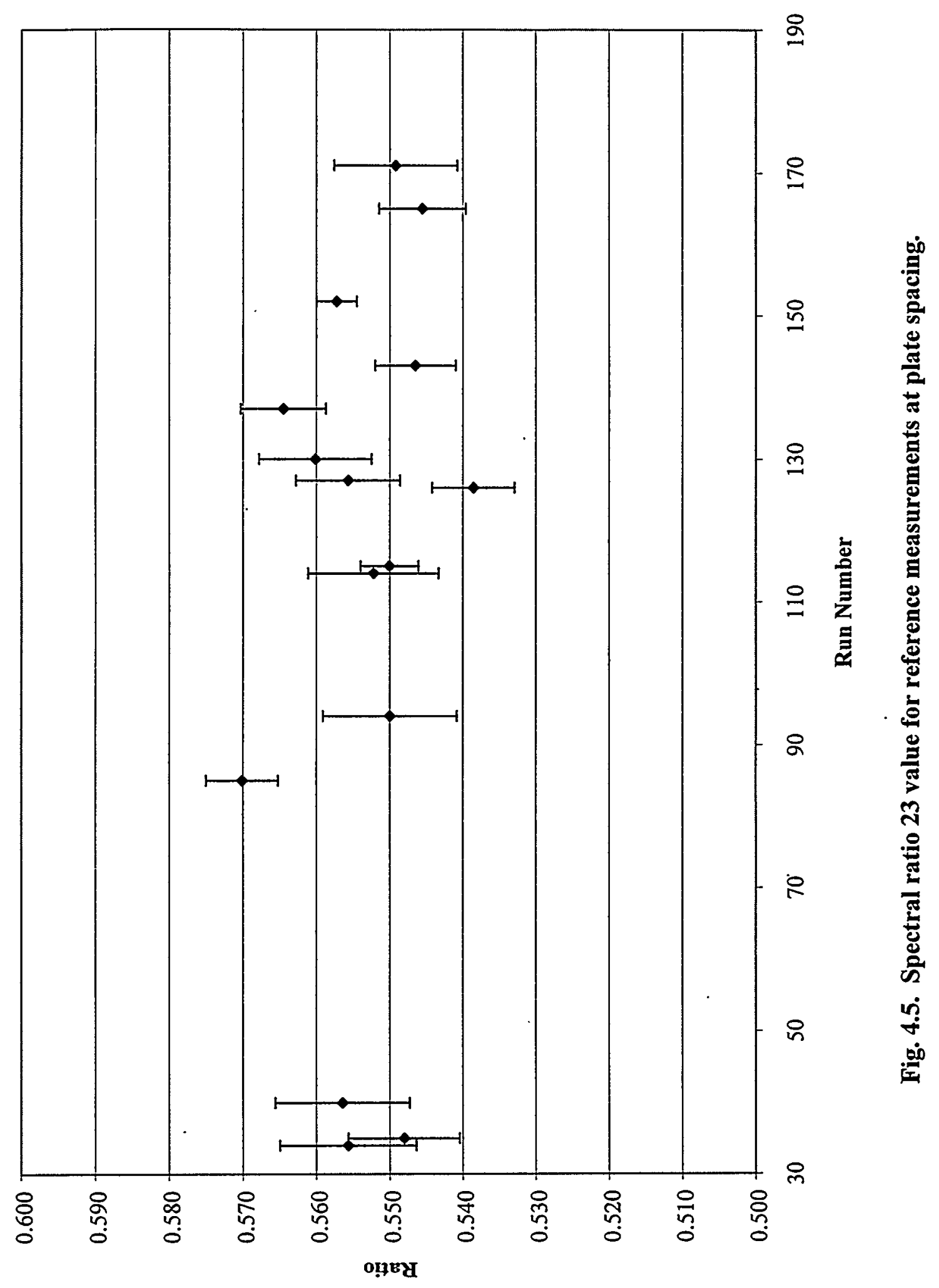




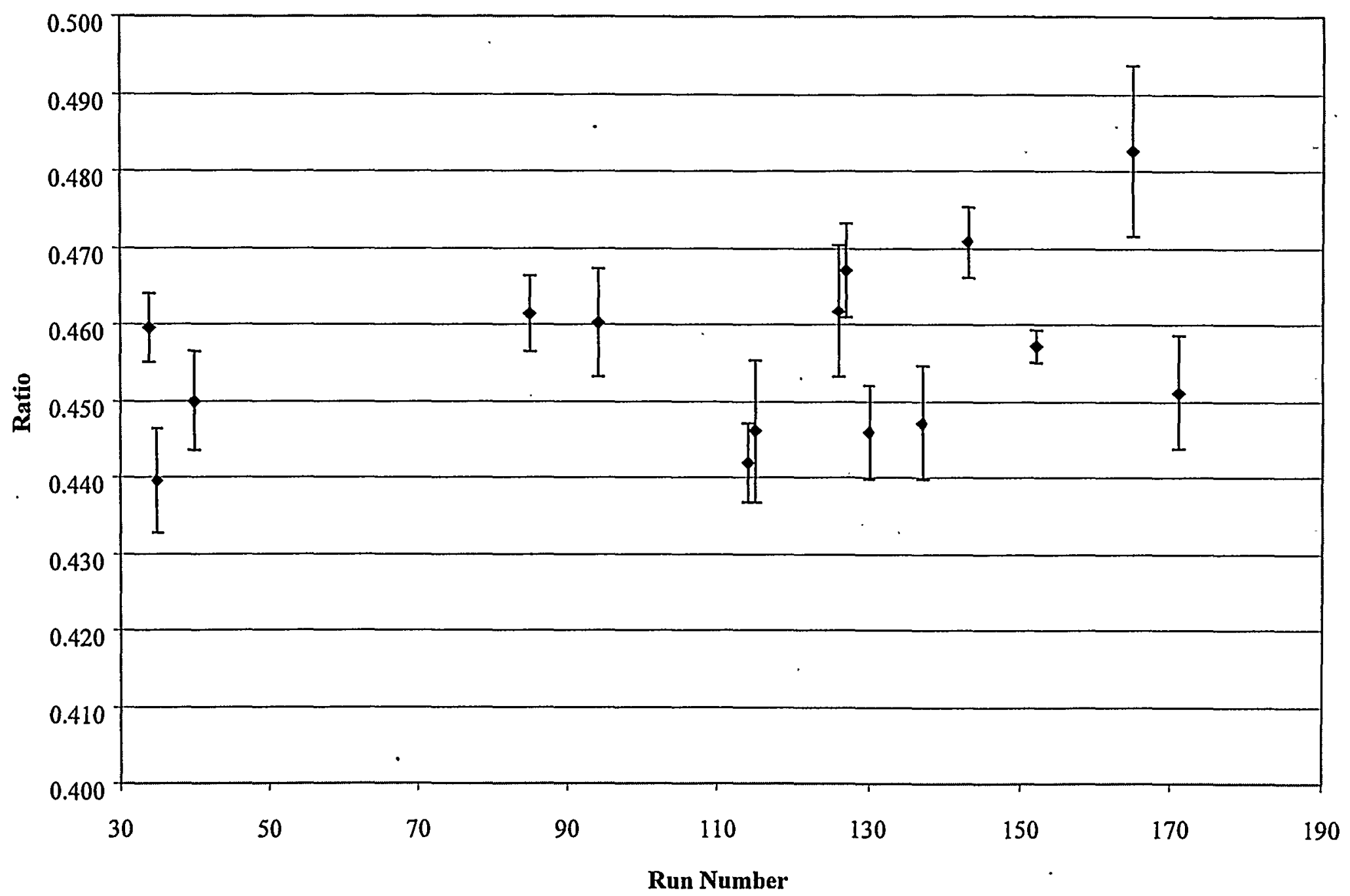

Fig. 4.6. Spectral ratio 24 value for reference measurements at plate spacing. 


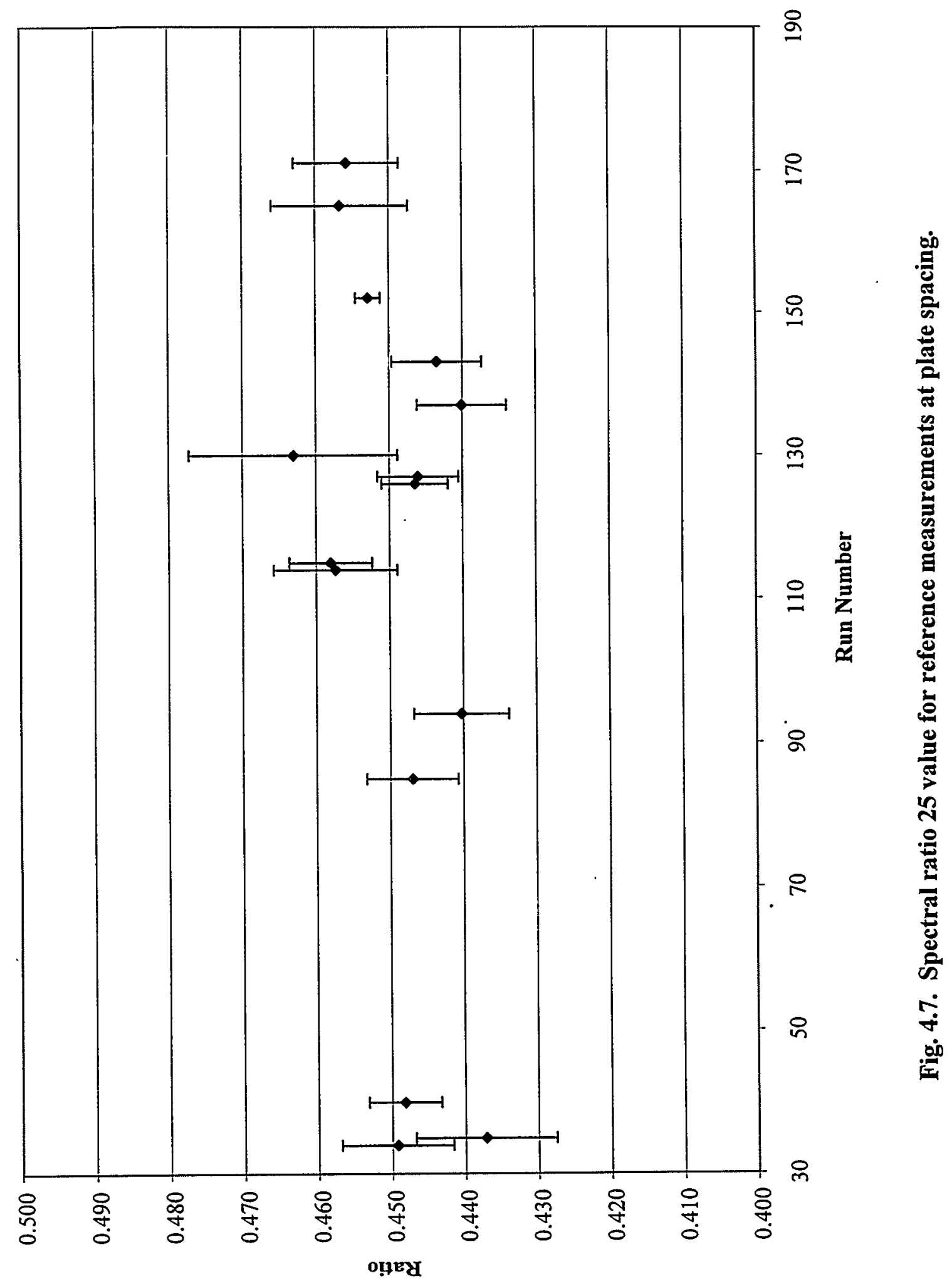




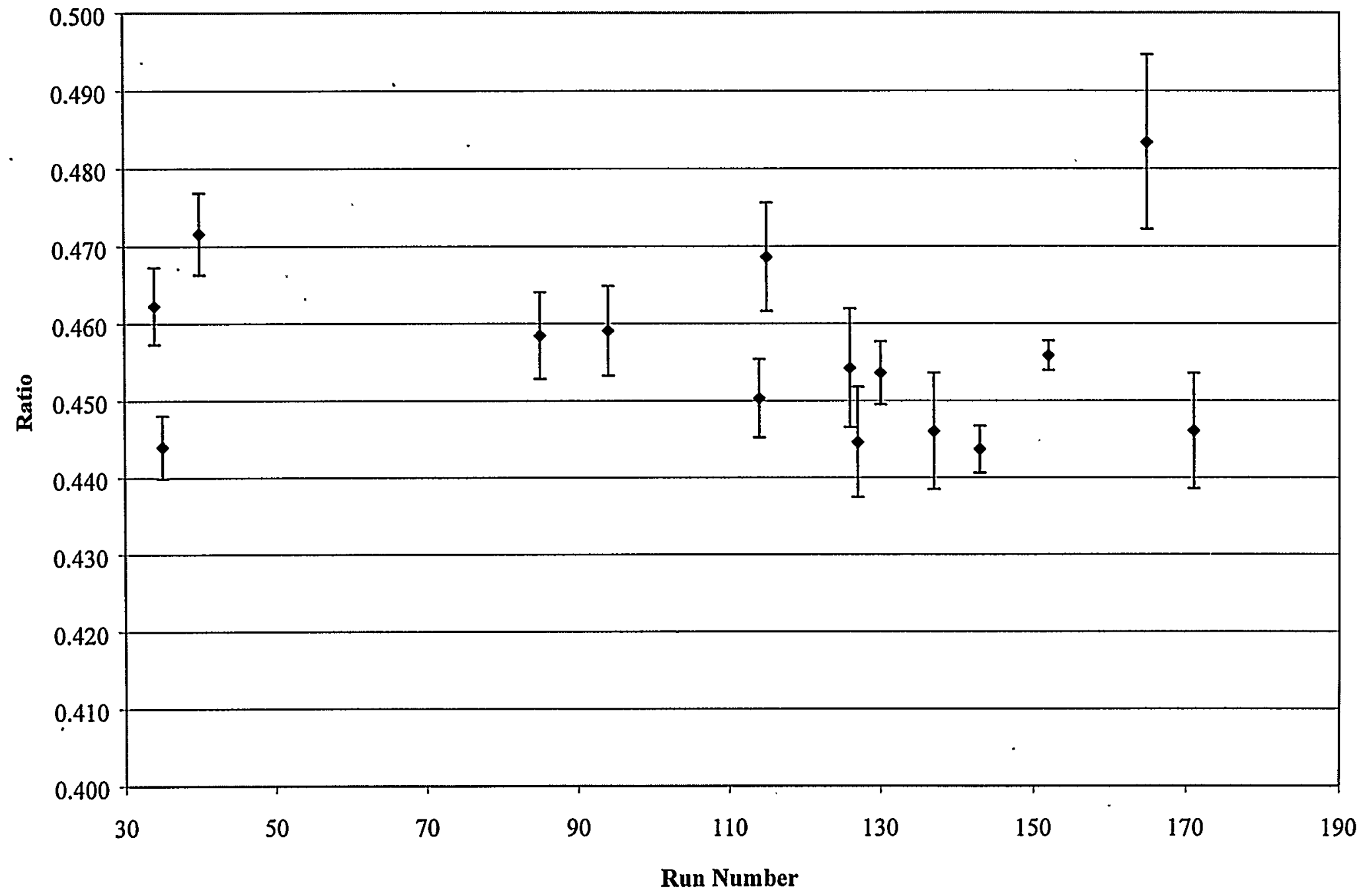

Fig. 4.8. Spectral ratio 34 value for reference measurements at plate spacing. 


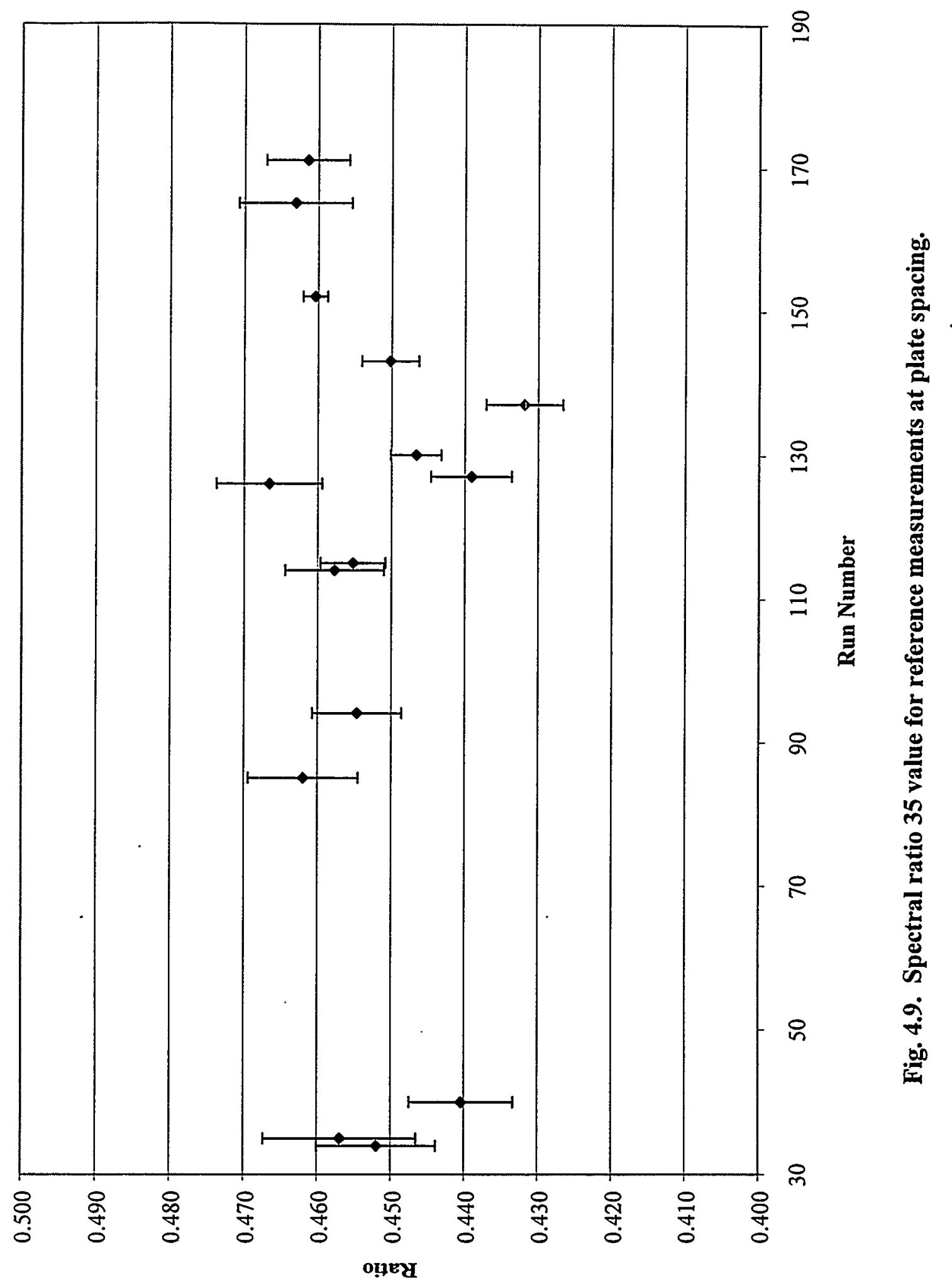




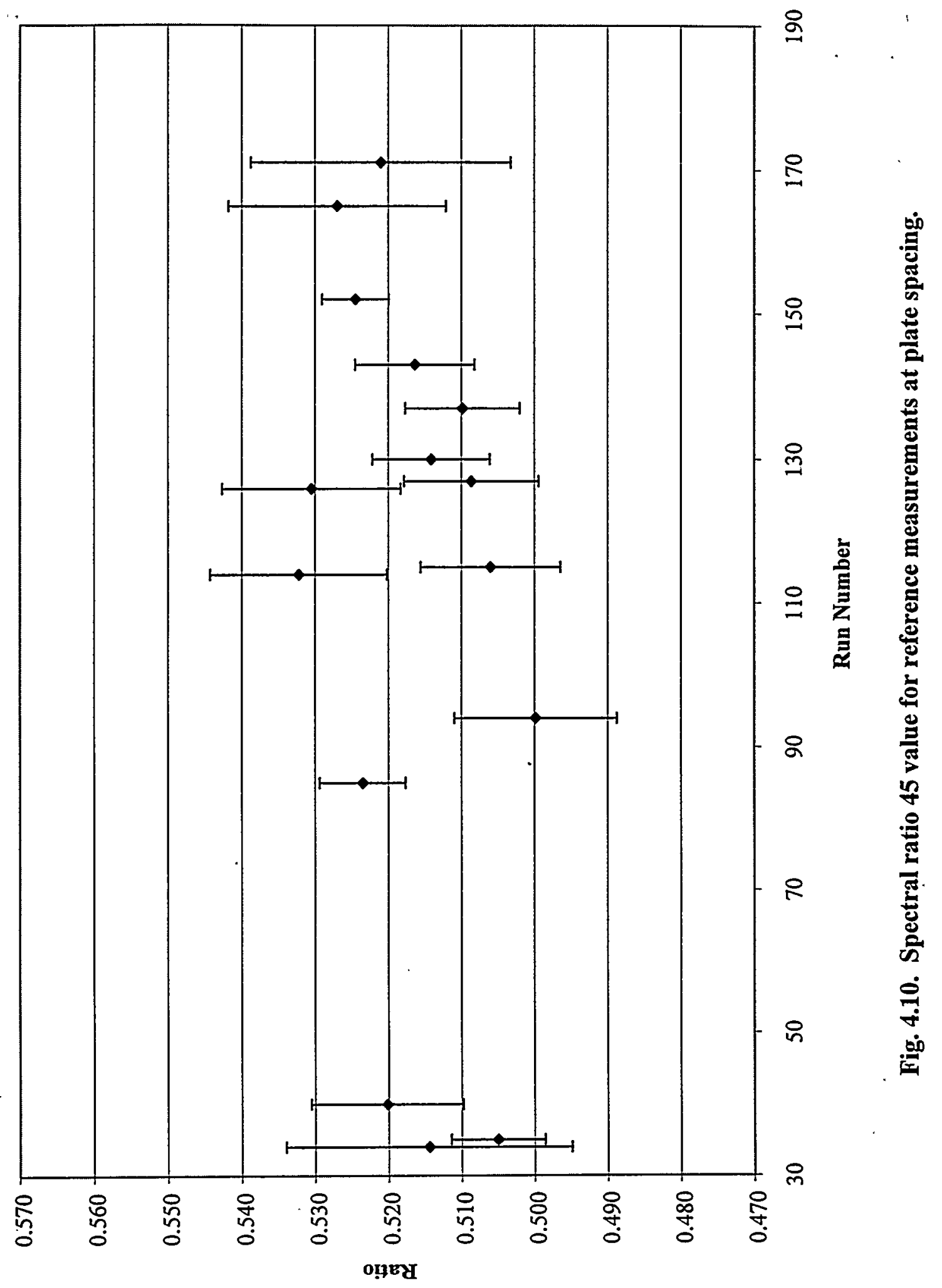




\begin{tabular}{|c|c|c|c|c|c|c|c|c|c|c|c|c|}
\hline \multirow[b]{2}{*}{ No. } & \multicolumn{2}{|c|}{ Ratio 23} & \multicolumn{2}{|c|}{ Ratio $24^{\mathrm{d}}$} & \multicolumn{2}{|c|}{ Ratio $25^{\mathrm{d}}$} & \multicolumn{2}{|c|}{ Ratio $34^{\mathrm{d}}$} & \multicolumn{2}{|c|}{ Ratio $35^{\mathrm{d}}$} & \multicolumn{2}{|c|}{ Ratio 45} \\
\hline & $\mathrm{R}^{\mathrm{a}}$ & $\sigma^{b}$ & $\mathrm{R}$ & $\sigma$ & $\overline{\mathrm{R}}$ & $\sigma$ & $\mathrm{R}$ & $\sigma$ & $\mathrm{R}$ & $\sigma$ & $\mathrm{R}$ & $\sigma$ \\
\hline 41 & 0.387 & 0.003 & 0.352 & 0.003 & 0.352 & 0.003 & 0.342 & 0.002 & 0.349 & 0.006 & 0.373 & 0.003 \\
\hline 46 & 0.385 & 0.003 & 0.347 & 0.003 & 0.345 & 0.005 & 0.360 & 0.003 & 0.342 & 0.003 & 0.376 & 0.004 \\
\hline 47 & 0.389 & 0.002 & 0.351 & 0.002 & 0.346 & 0.002 & 0.355 & 0.002 & 0.349 & 0.002 & 0.377 & 0.003 \\
\hline 54 & 0.380 & 0.003 & 0.346 & 0.003 & 0.349 & 0.004 & 0.350 & 0.003 & 0.337 & 0.003 & 0.385 & 0.007 \\
\hline 59 & 0.382 & 0.004 & 0.353 & 0.003 & 0.350 & 0.005 & 0.356 & 0.004 & 0.348 & 0.003 & 0.385 & 0.004 \\
\hline 65 & 0.379 & 0.003 & 0.357 & 0.003 & 0.353 & 0.002 & 0.364 & 0.004 & 0.352 & 0.003 & 0.380 & 0.002 \\
\hline 66 & 0.388 & 0.004 & 0.354 & 0.003 & 0.353 & 0.004 & 0.362 & 0.003 & 0.353 & 0.003 & 0.377 & 0.003 \\
\hline 141 & 0.388 & 0.003 & 0.359 & 0.004 & 0.354 & 0.003 & 0.360 & 0.002 & 0.351 & 0.002 & 0.389 & 0.005 \\
\hline 142 & 0.393 & 0.003 & 0.354 & 0.004 & 0.357 & 0.003 & 0.352 & 0.002 & 0.357 & 0.002 & 0.380 & 0.004 \\
\hline Mean & 0.387 & $0.005^{c}$ & 0.352 & 0.004 & 0.351 & 0.004 & 0.355 & 0.007 & 0.349 & 0.006 & 0.379 & 0.005 \\
\hline
\end{tabular}

${ }^{a}$ Low frequency average of spectral ratio.

${ }^{b}$ Standard deviation of the mean of the low frequency spectral ratio average.

${ }^{c}$ Standard deviation of the sample set.

${ }^{d}$ Ratio values $24,25,34$, and 35 should be approximately the same. 


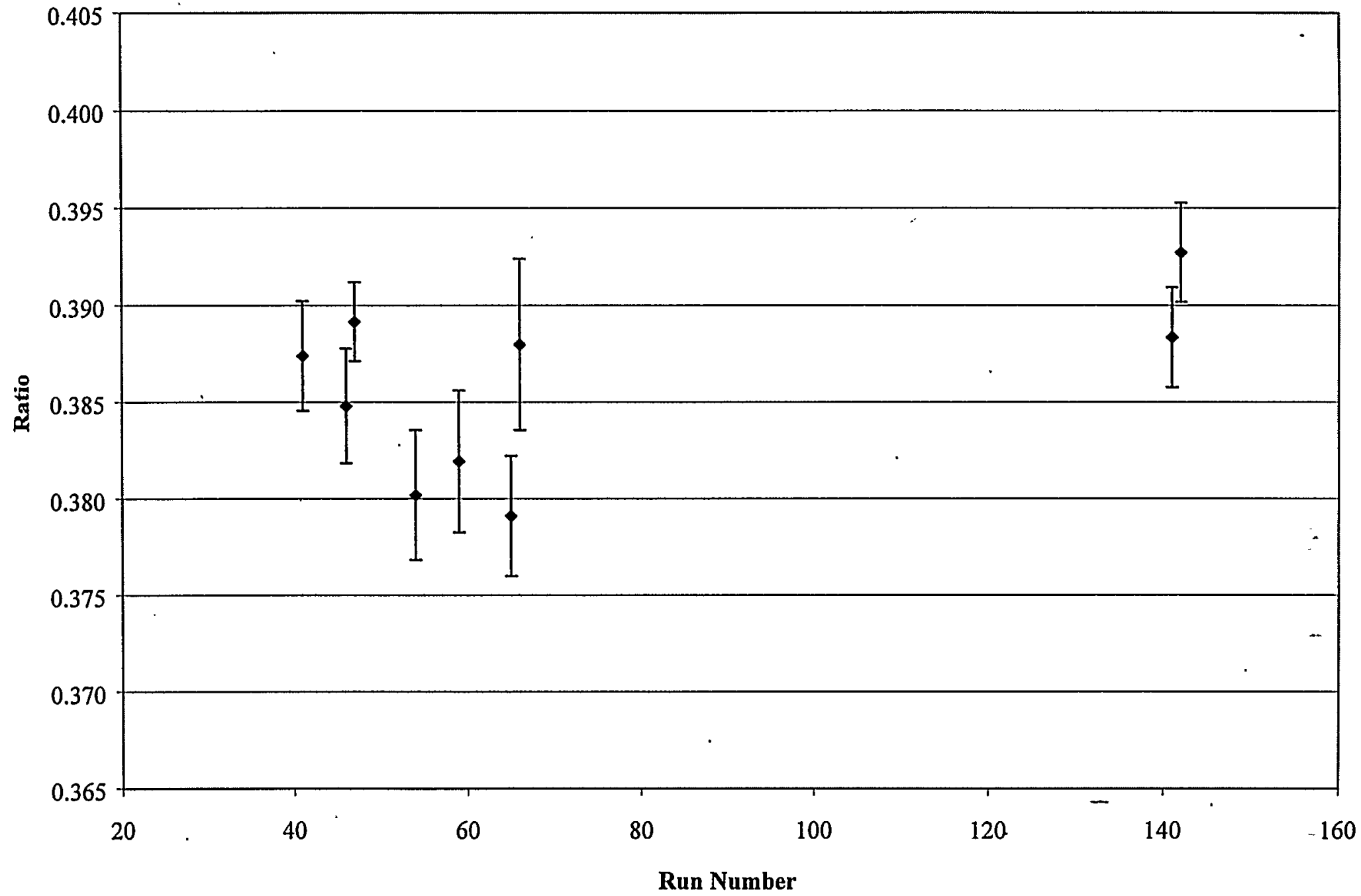

Fig. 4.11. Spectral ratio 23 value for close-spaced reference measurements. 


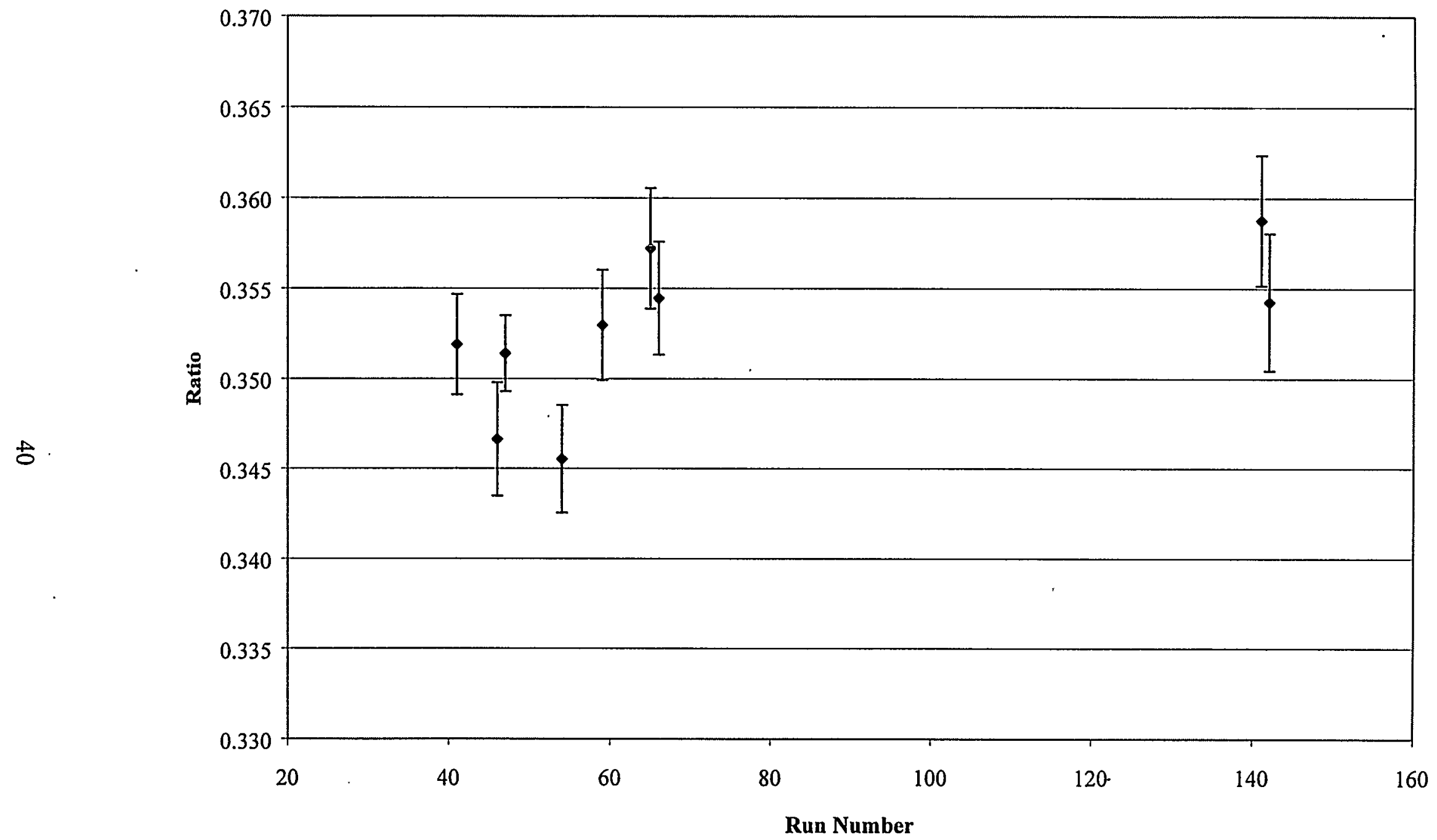

Fig. 4.12. Spectral ratio 24 value for close-spaced reference measurements. 


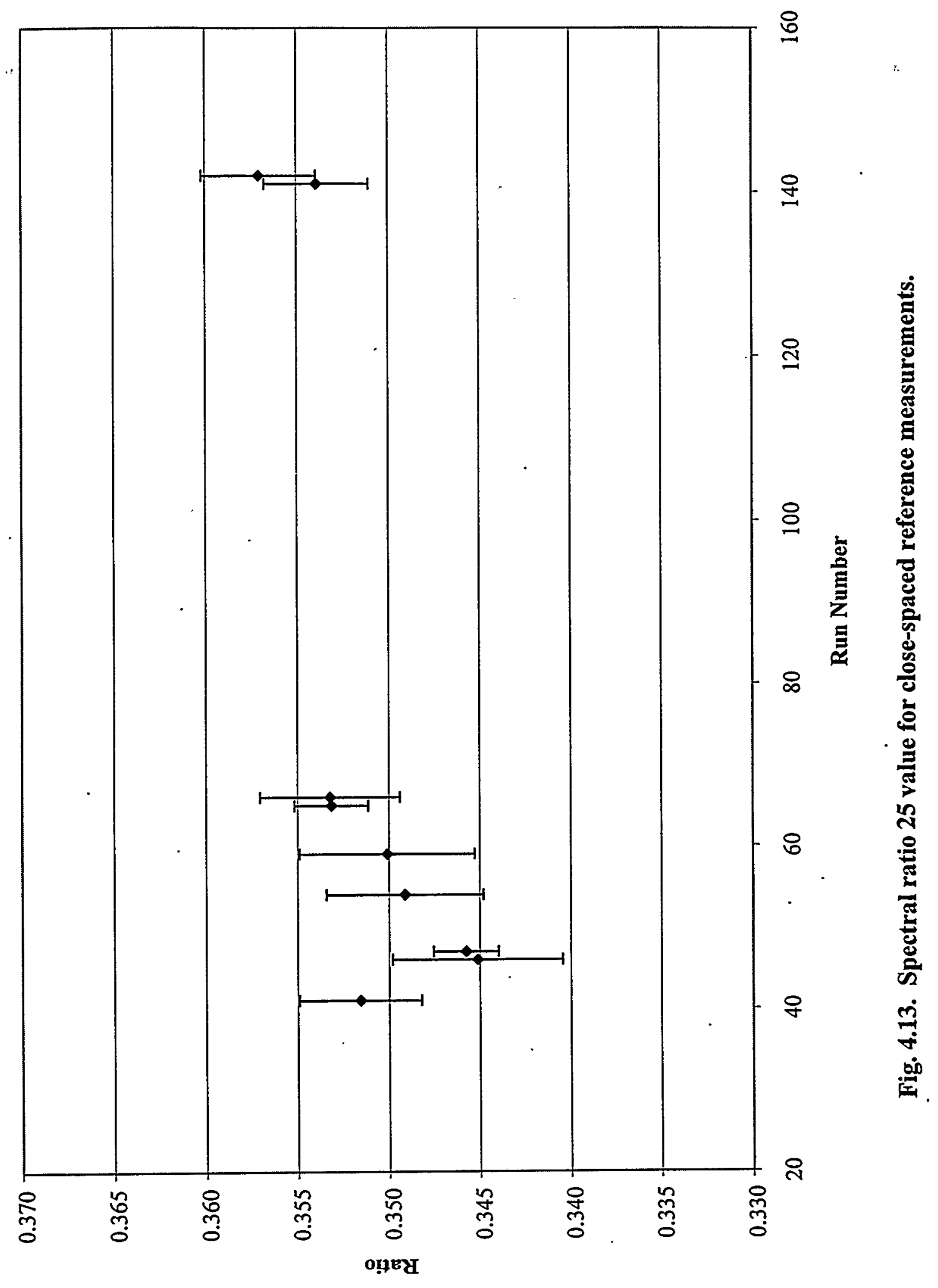




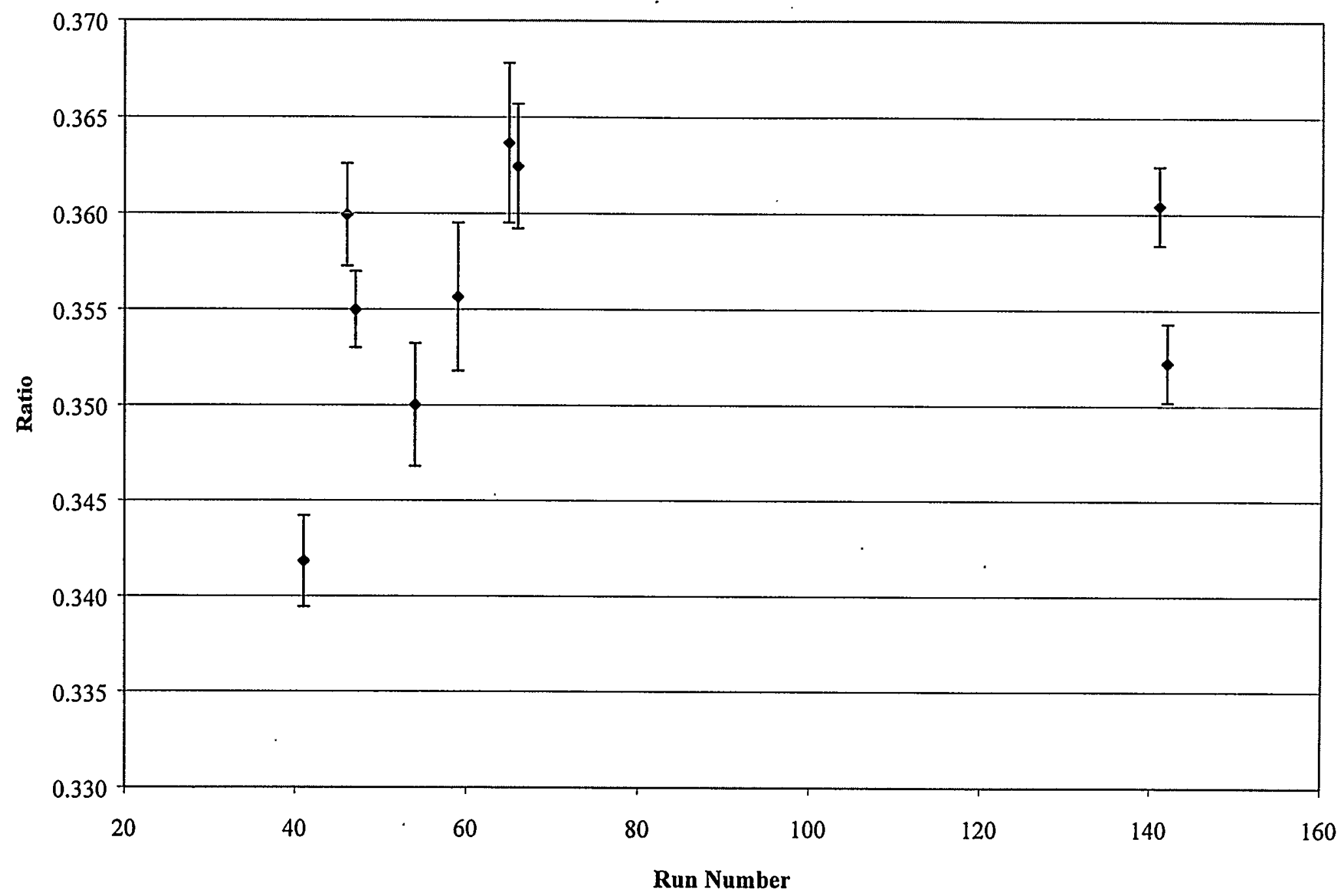

Fig. 4.14. Spectral ratio 34 value for close-spaced reference measurements. 


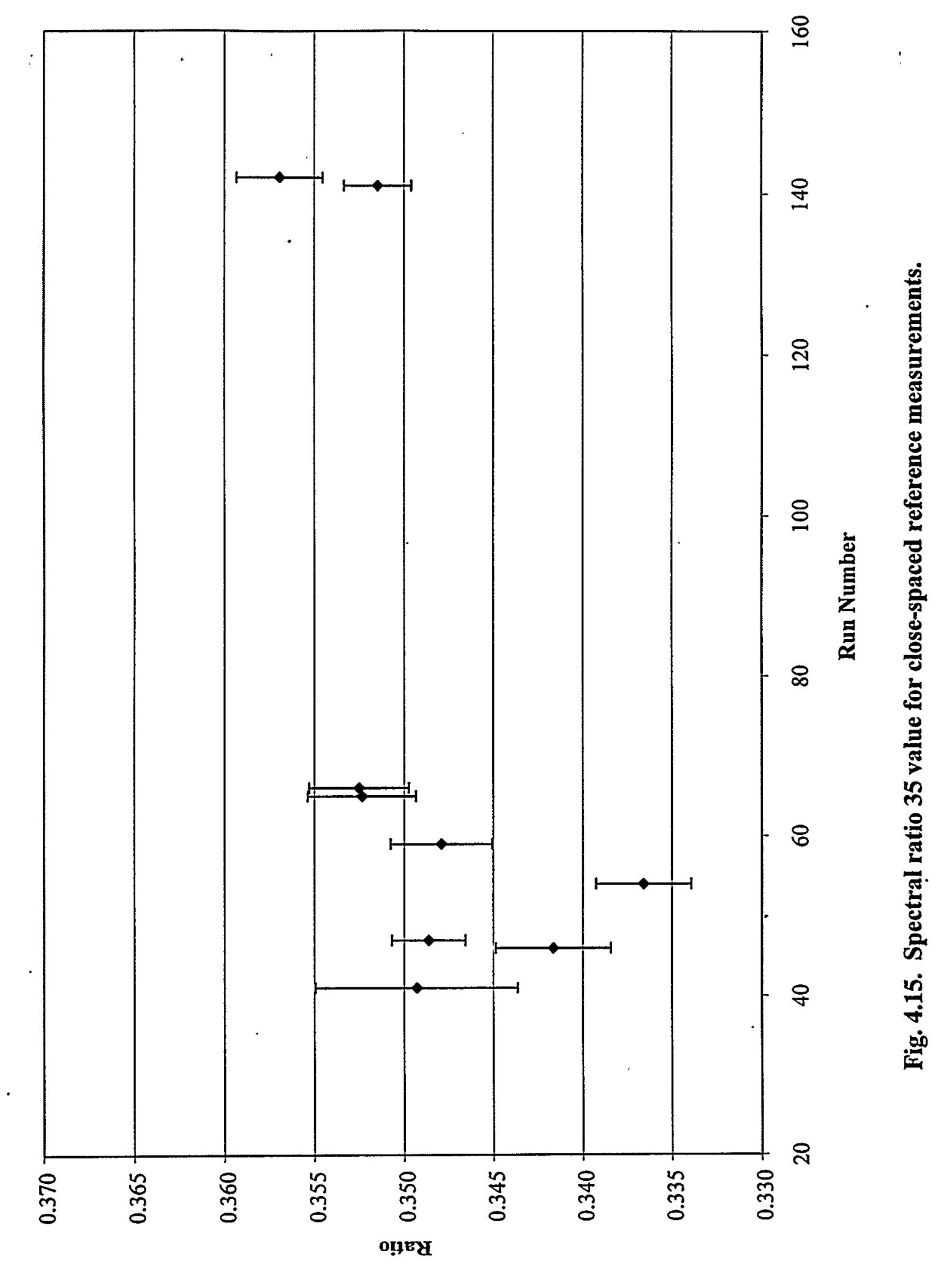




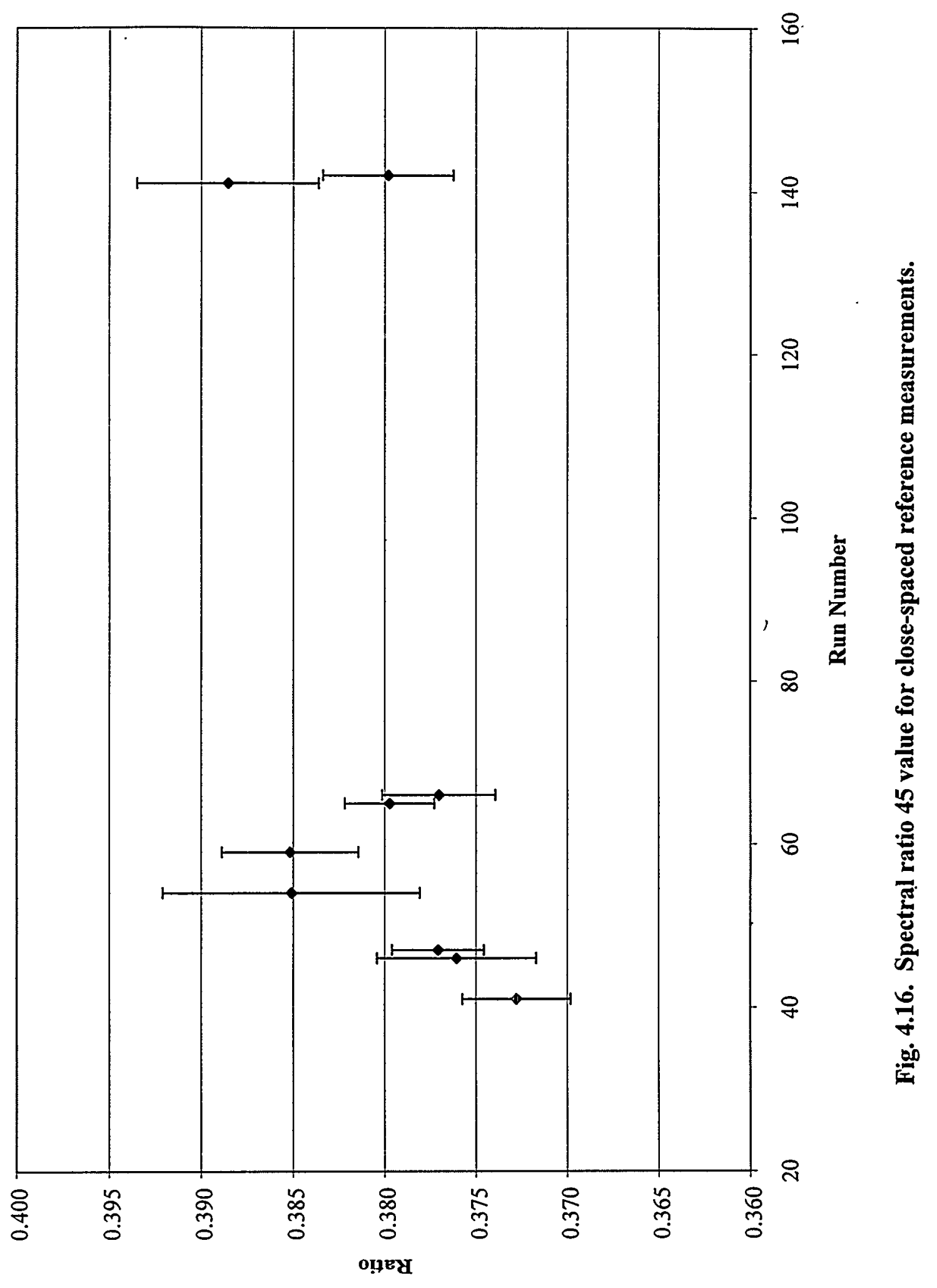




\subsection{FUEL ELEMENT SEPARATION MEASUREMENTS}

A series of measurements were performed in which the spacing between the fuel elements was varied. In some measurements, only one element was moved while in others all four elements were moved simultaneously.

\subsubsection{Movement of All Fuel Elements}

Two sets of measurements were performed in which all four elements were moved simultaneously with the difference between the sets being the starting position. The fuel elements were in the standard $A B A B$ orientation for both sets of measurements. The first set of measurements was performed beginning at the close-spaced configuration presented in the reproducibility measurement section. The fuel elements were then moved in $1-\mathrm{cm}$ increments. The assembly configuration for these measurements is provided in Table 4.13.

\begin{tabular}{|c|c|c|c|c|c|}
\hline \multicolumn{6}{|c|}{$\begin{array}{l}\text { Table 4.13. Fuel separation measurements beginning at close-spaced } \\
\text { reference position }\end{array}$} \\
\hline Average $^{a}$ & Run & \multicolumn{4}{|c|}{ Distance from center of assembly $(\mathrm{cm})$} \\
\hline $\begin{array}{c}\text { distance } \\
\text { change }(\mathrm{cm})\end{array}$ & no. & North $(\mathrm{A})$ & East (B) & South $(\mathrm{A})^{\circ}$ & West (B) \\
\hline 0 & 41 & 7.931 & 9.519 & 7.918 & 9.615 \\
\hline 0 & 46 & 7.931 & 9.519 & 7.918 & 9.615 \\
\hline 1.03 & 42 & 8.903 & 10.524 & 8.911 & 10.766 \\
\hline 1.03 & 43 & 8.903 & 10.524 & 8.911 & 10.766 \\
\hline 2.03 & 44 & 9.903 & 11.515 & 9.901 & 11.776 \\
\hline 3.03 & 45 & 10.903 & 12.505 & 10.898 & 12.782 \\
\hline
\end{tabular}

${ }^{a}$ Average distance change for all four elements.

${ }^{b}$ Orientation of fuel element in the assembly.

The spectral ratio values for the fuel traverse measurements are presented in Table 4.14. As expected, the spectral ratio values increased as the fuel elements were separated indicating that the system reactivity was decreasing. The interactions between the fuel elements decreased as the elements were moved apart. The spectral ratio values for detector combinations that were $180^{\circ}$ apart changed most significantly because the interaction between these fuel elements decreased the most. A plot of the spectral ratio values as a function of the average change in the distance from the original reference point is shown in Fig. 4.17. Spectral ratio values 23 and 45 changed the most while the other spectral ratio values essentially all changed the same amount. The spectral ratio values $24,25,34$, and 35 were all in close agreement as expected because of the essential symmetric configuration of the fuel elements. 
The spectral ratio values 23 and 45 changed $21 \%$ for a 1-cm move of the fuel elements while the spectral ratio values $24,25,34$, and 35 changed an average of $16 \%$. Further movement of the fuel elements from the center of the assembly produced larger changes in the spectral ratio values. The spectral ratio values 23 and 45 changed $45 \%$ and $50 \%$ respectively from the values for the starting position for the additional $1-\mathrm{cm}$ move of the fuel elements whereas the spectral ratio values $24,25,34$, and 35 only changed $\sim 29 \%$. The final $1-\mathrm{cm}$ movement of the fuel elements produced a $70 \%$ changed in spectral ratio values 23 and 45 relative to the values for the starting position. This change was almost a factor of two large than the change in spectral ratio values $24,25,34$, and 35 that only changed $40 \%$. These results demonstrated that spectral ratio values for detectors that were $180^{\circ}$ apart were more indicative of the overall interaction between fuel elements. Elements that were located $180^{\circ}$ apart had more water between the elements than adjacent detectors because the distance change was the greatest for these detectors. 


\begin{tabular}{|c|c|c|c|c|c|c|c|c|c|c|c|c|}
\hline \multicolumn{13}{|c|}{ Table 4.14. Spectral ratio values for fuel element traverse from close-spaced reference position } \\
\hline \multirow[b]{2}{*}{ No. } & \multicolumn{2}{|c|}{ Ratio 23} & \multicolumn{2}{|c|}{ Ratio 24} & \multicolumn{2}{|c|}{ Ratio 25} & \multicolumn{2}{|c|}{ Ratio 34} & \multicolumn{2}{|c|}{ Ratio 35} & \multicolumn{2}{|c|}{ Ratio 45 } \\
\hline & $\mathrm{R}^{\mathrm{a}}$ & $\sigma^{b}$ & $\mathbf{R}$ & $\sigma$ & $\overline{\mathrm{R}}$ & $\sigma$ & $\mathbf{R}$ & $\sigma$ & $\mathbf{R}$ & $\sigma$ & $\overline{\mathrm{R}}$ & $\bar{\sigma}$ \\
\hline 41 & 0.387 & 0.003 . & 0.352 & 0.003 & 0.352 & 0.003 & 0.342 & 0.002 & 0.349 & 0.006 & 0.373 & 0.003 \\
\hline 46 & 0.385 & 0.003 & 0.347 & 0.003 & 0.345 & 0.005 & 0.360 & 0.003 & 0.342 & 0.003 & 0.376 & 0.004 \\
\hline 42 & 0.471 & 0.003 & 0.405 & 0.004 & 0.402 & 0.005 & 0.411 & 0.004 & 0.404 & 0.004 & 0.456 & 0.006 \\
\hline 43 & 0.466 & 0.006 & 0.407 & 0.007 & 0.404 & 0.005 & 0.411 & 0.005 & 0.405 & 0.005 & 0.458 & 0.007 \\
\hline 44 & 0.561 & 0.004 & 0.454 & 0.004 & 0.438 & 0.003 & 0.466 & 0.002 & 0.449 & 0.004 & 0.566 & 0.005 \\
\hline 45 & 0.659 & 0.005 & 0.491 & 0.003 & 0.493 & 0.002 & 0.502 & 0.004 & 0.486 & 0.003 & 0.650 & 0.006 \\
\hline
\end{tabular}

${ }^{a}$ Low frequency average of spectral ratio.

${ }^{b}$ Standard deviation of the mean of the low frequency spectral ratio average. 


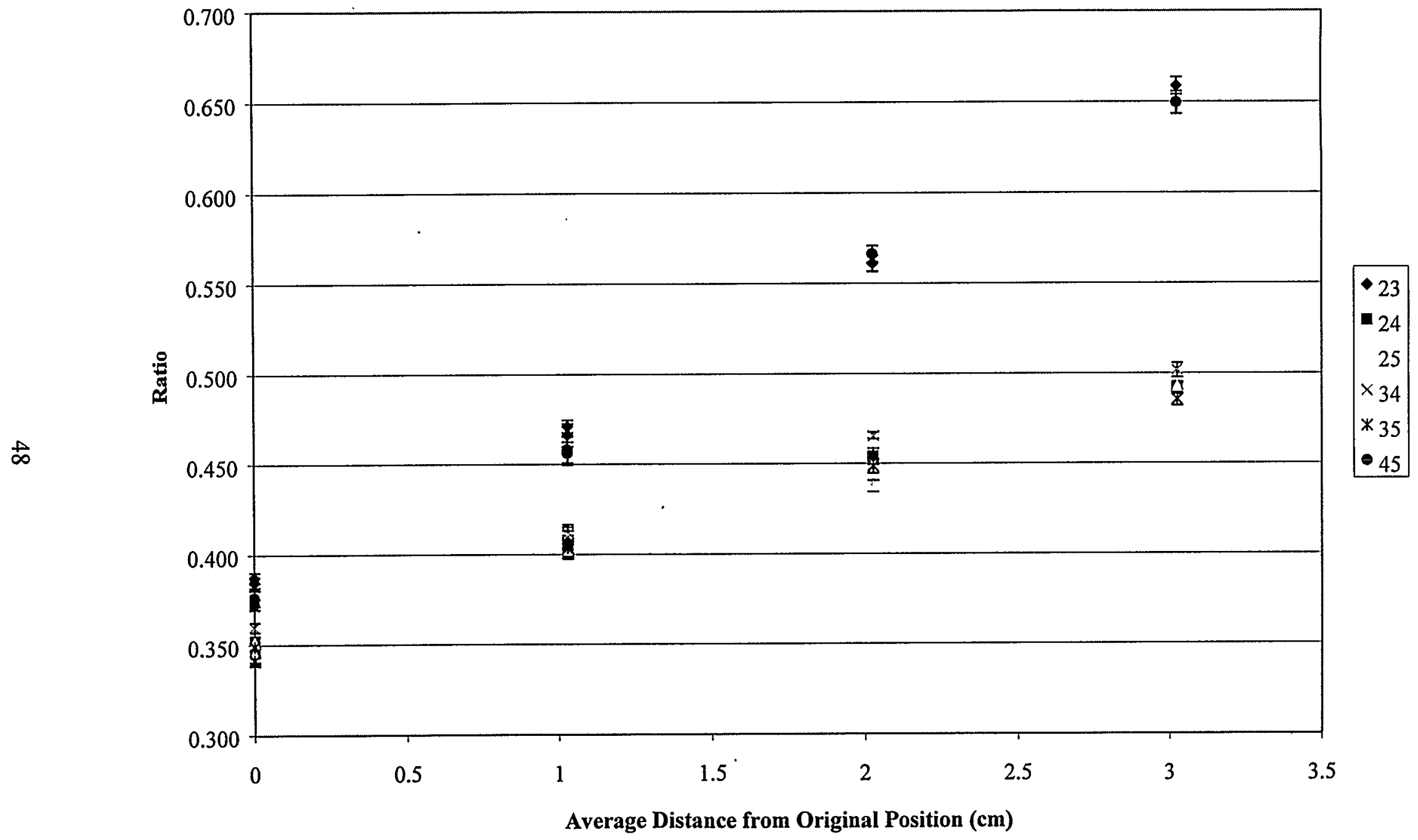

Fig. 4.17. Spectral ratio values for fuel element traverse measurements from close-spaced reference position. 
The second set of traverse measurements was performed with the fuel beginning at the incontact position. The fuel elements were moved in $\sim 0.5-\mathrm{cm}$ and $\sim 1.0-\mathrm{cm}$ increments from the in-contact position. The configuration of the fuel elements for these measurements is given in Table 4.15. In some instances, the measurements were essentially statistical repeats for a given configuration. For example, run numbers $162 \mathrm{a}$ and $162 \mathrm{~b}$ were statistical repeats for the same configuration without changing the experimental assembly. Therefore, the spectral signatures for these measurements were combined together and the spectral ratio values were the average of both measurements.

\begin{tabular}{|c|c|c|c|c|c|}
\hline \multicolumn{6}{|c|}{ Table 4.15. Fuel traverse measurements beginning at in-contact position } \\
\hline \multirow{2}{*}{$\begin{array}{c}\text { Average } \\
\text { distance } \\
\text { change (cm) }\end{array}$} & No. & \multicolumn{4}{|c|}{ Distance from center of assembly (cm) } \\
\cline { 3 - 6 } & & North (A) & East (B) & South (A) ${ }^{\mathrm{b}}$ & West (B) \\
\hline 0.000 & 160 & 6.745 & 8.109 & 6.712 & 8.299 \\
\hline 0.000 & 161 & 6.745 & 8.109 & 6.712 & 8.299 \\
\hline 0.511 & $162 \mathrm{a}$ & 7.239 & 8.634 & 7.215 & 8.822 \\
\hline 0.511 & $162 \mathrm{~b}$ & 7.239 & 8.634 & 7.215 & 8.822 \\
\hline 0.511 & $162^{\mathrm{c}}$ & 7.239 & 8.634 & 7.215 & 8.822 \\
\hline 0.993 & $163 \mathrm{a}$ & 7.835 & 9.125 & 7.717 & 9.263 \\
\hline 0.993 & $163 \mathrm{~b}$ & 7.835 & 9.125 & 7.717 & 9.263 \\
\hline 0.993 & $163^{\mathrm{c}}$ & 7.835 & 9.125 & 7.717 & 9.263 \\
\hline 1.999 & $164 \mathrm{a}$ & 8.703 & 10.122 & 8.713 & 10.324 \\
\hline 1.999 & $164 \mathrm{~b}$ & 8.703 & 10.122 & 8.713 & 10.324 \\
\hline 1.999 & $164^{\mathrm{c}}$ & 8.703 & 10.122 & 8.713 & 10.324 \\
\hline
\end{tabular}

Average distance change for all four elements.

${ }^{b}$ Orientation of fuel element in the assembly.

c Results for this run number-were obtained from the average of the two previous measurements.

The spectral ratio values for the fuel traverse measurements beginning at the in-contact position are provided in Table 4.16. The ratio values increased as the fuel elements were separated indicating that the system reactivity was decreasing. The interactions between the fuel elements decreased as the elements were moved apart. The spectral ratio values for detector combinations that were $180^{\circ}$ apart changed most significantly because the interaction between these fuel elements decreased the most. A plot of the spectral ratio values as a function of the average change in the distance from the original reference point is given in Fig. 4.17. Spectral ratio values 23 and 45 changed the most while the other spectral ratio values essentially changed the same amount. Again, the spectral ratio values $24,25,34$, and 35 were similar because of the nearly symmetric configuration of the fuel elements.

The spectral ratio values 23 and 45 changed $6 \%, 13 \%$, and $42 \%$ from the values for the in-contact reference position for the three movements of the fuel elements. The spectral ratio values $24,25,34$, and 35 changed on average $4.5 \%, 9 \%$, and $30 \%$ from the values 
for the in-contact reference position for the three movements of the fuel elements. As shown for the previous fuel movements, the spectral ratio values 23 and 45 changed slightly more than the spectral ratio values $24,25,34$, and 35 . These results further emphasize that the spectral ratio values for detectors $180^{\circ}$ apart were more indicative of the overall system reactivity and were more sensitive to changes in the assembly configuration. These changes in the spectral ratio values were smaller than those values for the close-spaced reference position because the fuel elements were closer together and the interactions between fuel elements remained high. 


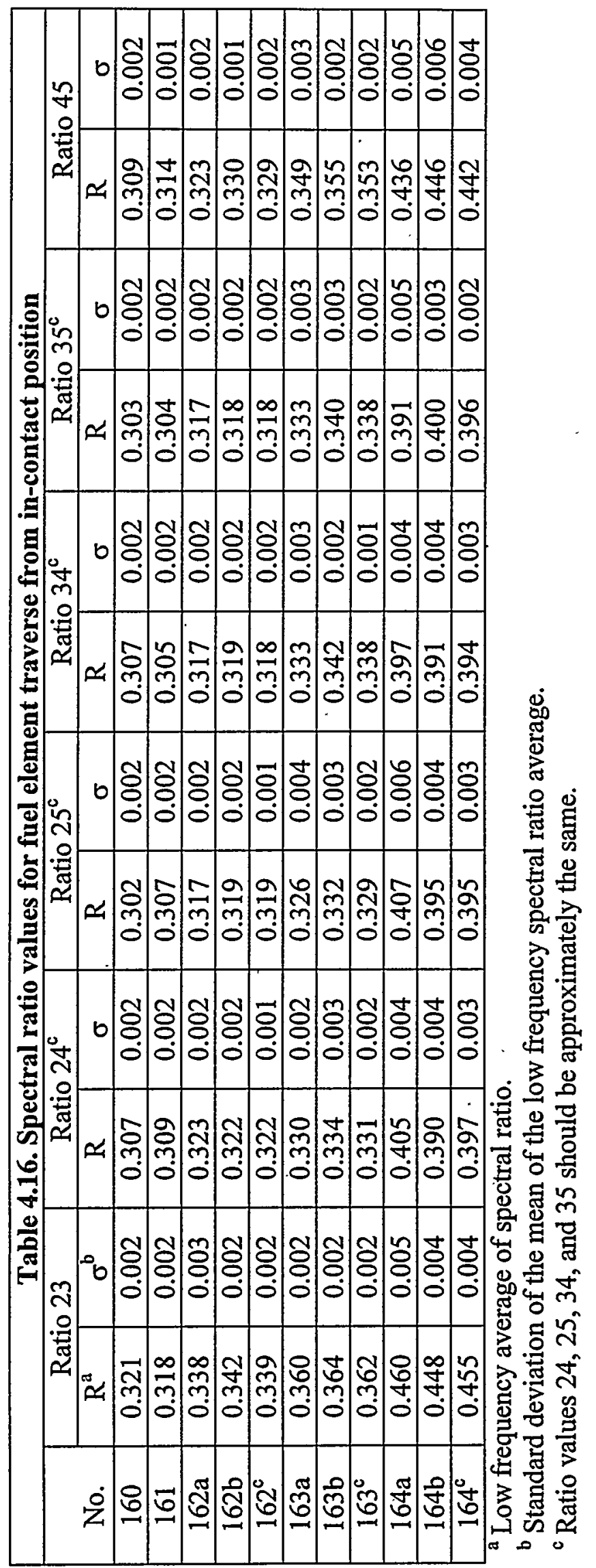




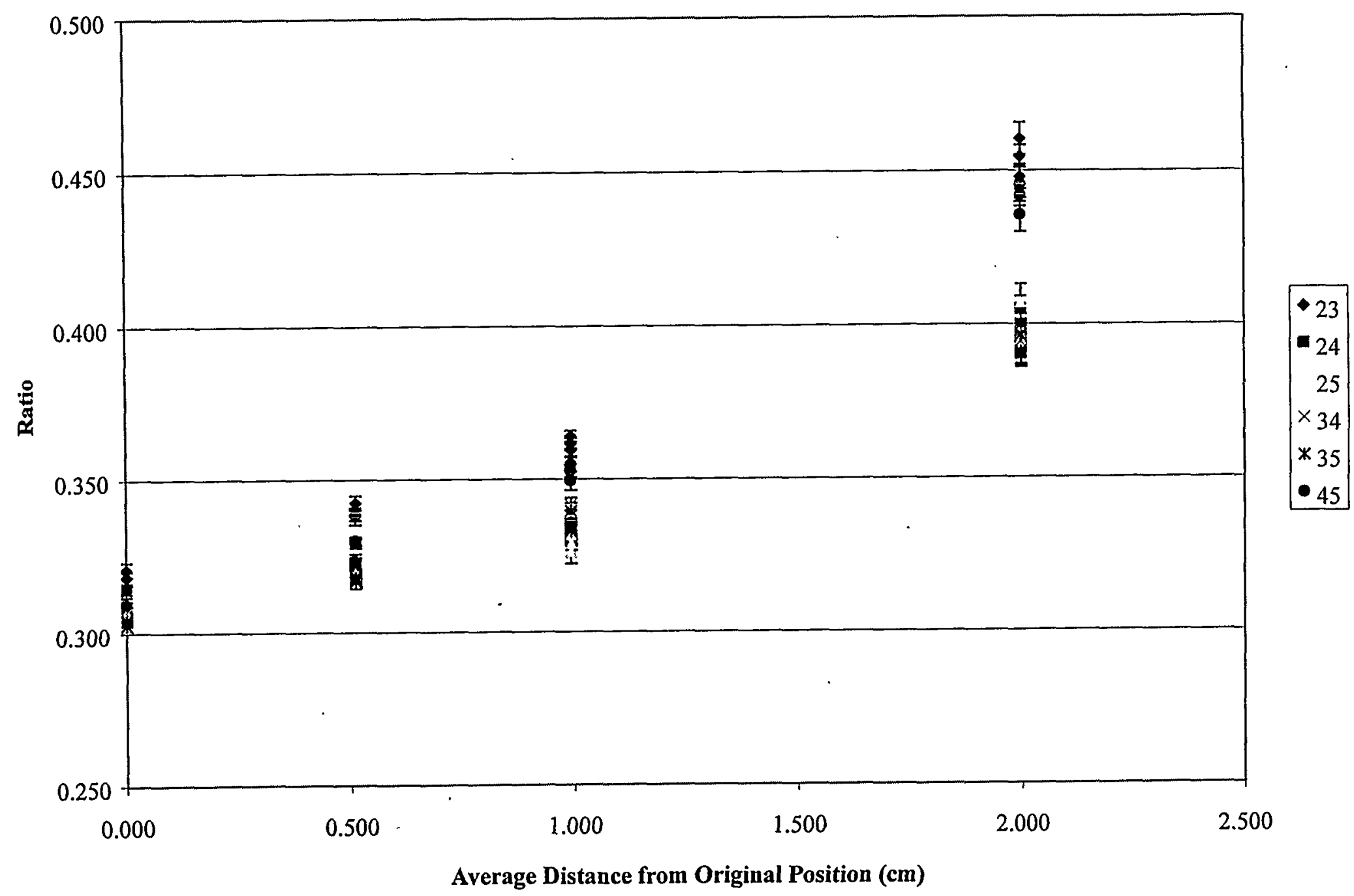

Fig. 4.18. Spectral ratio values for fuel element traverse measurements from in-contact position. 


\subsubsection{Movement of North Fuel Element}

Measurements were also performed in which only a single fuel element in the A orientation was moved to study the affects of spacing of the fuel elements. The north fuel element was moved in $\sim 1.0-\mathrm{cm}$ increments from the close-spaced reference position. The configuration of the fuel elements for these measurements is given in Table 4.17. The north fuel element was moved three different times as shown in Table 4.17.

\begin{tabular}{|c|c|c|c|c|c|}
\hline \multicolumn{6}{|c|}{ Table 4.17. Traverse of north fuel element beginning at close-spaced } \\
reference position \\
\cline { 3 - 6 } $\begin{array}{c}\text { Distance } \\
\text { change (cm) }\end{array}$ & No. & North $(\mathrm{A})^{\mathrm{a}}$ & ${\text { East }(\mathrm{B})^{\mathrm{a}}}^{\mathrm{a}}$ & South $(\mathrm{A})^{\mathrm{a}}$ & West $(\mathrm{B})^{\mathrm{a}}$ \\
\hline 0 & 46 & 7.931 & 9.519 & 7.918 & 9.615 \\
\hline 0 & 47 & 7.931 & 9.519 & 7.918 & 9.615 \\
\hline 0 & 54 & 7.931 & 9.519 & 7.918 & 9.615 \\
\hline 0.972 & 48 & 8.903 & 9.519 & 7.918 & 9.615 \\
\hline 0.972 & 49 & 8.903 & 9.519 & 7.918 & 9.615 \\
\hline 1.972 & 50 & 9.903 & 9.519 & .7 .918 & 9.615 \\
\hline 1.972 & 51 & 9.903 & 9.519 & 7.918 & 9.615 \\
\hline 3.972 & 52 & 11.903 & 9.519 & 7.918 & 9.615 \\
\hline 3.972 & 53 & 11.903 & 9.519 & 7.918 & 9.615 \\
\hline
\end{tabular}

${ }^{a}$ Orientation of fuel element in the assembly.

The spectral ratio values for these measurements are provided in Table 4.18. As shown previously, the spectral ratio values increased as the fuel element was moved away from the reference position. The spectral ratio 23 value increased $7 \%$ with a $0.972-\mathrm{cm}$ move of the north fuel element away from the center of the assembly. The spectral ratio value 45 changed $\sim 5 \%$ for the same movement of the north fuel element and the spectral ratio values $24,25,34$, and 35 changed an average of $\sim 3.5 \%$. Movement of the north fuel element another 1 -cm produced $11 \%$ and $12 \%$ changes in spectral ratio values 23 and 45 from those for the close-spaced reference position. The spectral ratio values $24,25,34$, and 35 changed an average of $\sim 8.7 \%$ from the reference values. The spectral ratio values decreased further with an additional 2-cm movement of the north fuel element. Again, the largest change was evident in spectral ratio values 23 and 45 that changed $22 \%$ and $26 \%$ respectively from the reference values. The spectral ratio values $24,25,34$, and 35 changed an average of $\sim 17.5 \%$ from the reference values. These results demonstrated the approximate reactivity worth of the north element. The essentially symmetric changes in spectral ratio values 23 and 45 demonstrated that the interaction between fuel elements was highly dependent on the assembly configuration. Fuel elements in the north and south positions had more fissile material closer to the assembly center because of the orientation of these elements.

These measurements were to be used to determine the reactivity worth for an element in orientation $\mathrm{A}$ as a function of position using the MCNP-DSP Monte Carlo code. 


\begin{tabular}{|c|c|c|c|c|c|c|c|c|c|c|c|c|}
\hline \multirow[b]{3}{*}{ No. } & \multirow{2}{*}{\multicolumn{2}{|c|}{ Ratio 23}} & \multirow{2}{*}{\multicolumn{2}{|c|}{ Ratio 24}} & rth & eleme & erse & m clo & ed & enc & ion & \\
\hline & & & & & \multicolumn{2}{|c|}{ Ratio 25} & \multicolumn{2}{|c|}{ Ratio 34} & \multicolumn{2}{|c|}{ Ratio 35} & \multicolumn{2}{|c|}{ Ratio 45} \\
\hline & $\mathrm{R}^{\mathrm{a}}$ & $\sigma^{b}$ & $\mathrm{R}$ & $\sigma$ & $\mathrm{R}$ & $\sigma$ & $\mathrm{R}$ & $\sigma$ & $\mathrm{R}$ & $\sigma$ & $\mathrm{R}$ & $\sigma$ \\
\hline 46 & 0.385 & 0.003 & 0.347 & 0.003 & 0.345 & 0.005 & 0.360 & 0.003 & 0.342 & 0.003 & 0.376 & 0.004 \\
\hline 47 & 0.389 & 0.002 & 0.351 & 0.002 & 0.346 & 0.002 & 0.355 & 0.002 & 0.349 & 0.002 & 0.377 & 0.003 \\
\hline 54 & 0.380 & 0.003 & 0.346 & 0.003 & 0.349 & 0.004 & 0.350 & 0.003 & 0.337 & 0.003 & 0.385 & 0.007 \\
\hline 48 & 0.414 & 0.005 & 0.367 & 0.004 & 0.355 & 0.003 & 0.377 & 0.003 & 0.363 & 0.003 & 0.400 & 0.004 \\
\hline 49 & 0.415 & 0.005 & 0.367 & 0.003 & 0.355 & 0.004 & 0.364 & 0.004 & 0.356 & 0.004 & 0.395 & 0.004 \\
\hline 50 & 0.427 & 0.005 & 0.379 & 0.005 & 0.378 & 0.003 & 0.389 & 0.003 & 0.378 & 0.005 & 0.411 & 0.002 \\
\hline 51 & 0.428 & 0.004 & 0.388 & 0.006 & 0.377 & 0.005 & 0.386 & 0.004 & 0.376 & 0.004 & 0.437 & 0.007 \\
\hline 52 & 0.471 & 0.004 & 0.408 & 0.005 & 0.401 & 0.006 & 0.415 & 0.004 & 0.401 & 0.004 & 0.480 & 0.006 \\
\hline 53 & 0.472 & 0.007 & 0.420 & 0.005 & 0.422 & 0.006 & 0.417 & 0.004 & 0.410 & 0.005 & 0.470 & 0.007 \\
\hline
\end{tabular}

${ }^{a}$ Low frequency average of spectral ratio.

${ }^{b}$ Standard deviation of the mean of the low frequency spectral ratio average. 


\subsubsection{Movement of East Fuel Element}

Measurements were also performed in which only a single fuel element in the B orientation was moved to allow the reactivity worth of this fuel element as a function of position to be determined. The fuel element was moved in $\sim 2.0-\mathrm{cm}$ increments from the close-spaced reference position. The configuration of the fuel elements for these measurements is given in Table 4.19. The spectral ratio values for these measurements are provided in Table 4.20. As shown previously, the spectral ratio values increased as the fuel element was moved away from the reference position. These measurements were to be used to determine the reactivity worth as a function of position for an element in the $B$ orientation. The change in the spectral ratio values for moving the east fuel element was essentially the same as the change in spectral ratio values for moving the north fuel element.

\begin{tabular}{|c|c|c|c|c|c|}
\hline \multicolumn{5}{|c|}{ Table 4.19. Traverse of east fuel element beginning at close-spaced } \\
reference position \\
\hline $\begin{array}{c}\text { Distance } \\
\text { change }(\mathrm{cm})\end{array}$ & No. & \multicolumn{4}{c|}{ Distance from center of assembly (cm) } \\
\cline { 3 - 6 } & North $(\mathrm{A})^{\mathrm{a}}$ & ${\text { East }(\mathrm{B})^{\mathrm{a}}}^{\mathrm{y}}$ & ${\text { South }(\mathrm{A})^{\mathrm{a}}}^{\mathrm{y}}$ & West $(\mathrm{B})^{\mathrm{a}}$ \\
\hline 0.000 & 54 & 7.931 & 9.519 & 7.918 & 9.615 \\
\hline 0.000 & 59 & 7.931 & 9.519 & 7.918 & 9.615 \\
\hline 1.996 & 55 & 7.931 & 11.515 & 7.918 & 9.615 \\
\hline 1.996 & 56 & 7.931 & 11.515 & 7.918 & 9.615 \\
\hline 3.990 & 57 & 7.931 & 13.509 & 7.918 & 9.615 \\
\hline 3.990 & 58 & 7.931 & 13.509 & 7.918 & 9.615 \\
\hline
\end{tabular}

${ }^{2}$ Orientation of fuel element in the assembly.

As with the movement of the north fuel element, the spectral ratio values increased as the east fuel element was moved away from the center of the assembly. The spectral ratio values 23 and 45 changed $\sim 12 \%$ and $23 \%$ from the reference values as the fuel element was moved away from the center of the assembly. The spectral ratio values $24,25,34$, and 35 changed on average $8 \%$ and $16 \%$ from the reference values as the fuel elements were moved away from the center of the assembly. These changes in the spectral ratio values were smaller than the changes observed for similar movements of a fuel element in the north position because the north and south fuel elements were closer to the center of the system than fuel elements in the east and west positions. The elements in the north and south positions had a greater impact on the overall system reactivity. 


\begin{tabular}{|c|c|c|c|c|c|c|c|c|c|c|c|c|}
\hline \multirow[b]{3}{*}{ No. } & \multicolumn{12}{|c|}{ Table 4.20. Spectral ratio values for east fuel element traverse from close-spaced reference position } \\
\hline & \multicolumn{2}{|c|}{ Ratio 23} & \multicolumn{2}{|c|}{ Ratio 24} & \multicolumn{2}{|c|}{ Ratio 25} & \multicolumn{2}{|c|}{ Ratio 34} & \multicolumn{2}{|c|}{ Ratio 35} & \multicolumn{2}{|c|}{ Ratio 45} \\
\hline & $\mathrm{R}^{\mathrm{a}}$ & $\sigma^{\mathrm{b}}$ & $\mathrm{R}$ & $\sigma$ & $\mathrm{R}$ & $\sigma$ & $\mathrm{R}$ & $\sigma$ & $\mathrm{R}$ & $\sigma$ & $\mathrm{R}$ & $\sigma$ \\
\hline 54 & 0.380 & 0.003 & 0.346 & 0.003 & 0.349 & 0.004 & 0.350 & 0.003 & 0.337 & 0.003 & 0.385 & 0.007 \\
\hline 59 & 0.382 & 0.004 & 0.353 & 0.003 & 0.350 & 0.005 & 0.356 & 0.004 & 0.348 & 0.003 & 0.385 & 0.004 \\
\hline 55 & 0.435 & 0.005 & 0.379 & 0.004 & 0.378 & 0.004 & 0.380 & 0.004 & 0.381 & 0.005 & 0.423 & 0.006 \\
\hline 56 & 0.429 & 0.005 & 0.382 & 0.004 & 0.374 & 0.003 & 0.382 & 0.004 & 0.379 & 0.005 & 0.423 & 0.006 \\
\hline 57 & 0.468 & 0.006 & 0.421 & 0.005 & 0.405 & 0.005 & 0.422 & 0.007 & 0.397 & 0.004 & 0.470 & 0.008 \\
\hline 58 & 0.481 & 0.006 & 0.425 & 0.006 & 0.410 & 0.005 & 0.427 & 0.004 & 0.393 & 0.005 & 0.470 & 0.010 \\
\hline
\end{tabular}

${ }^{\mathrm{a}}$ Low frequency average of spectral ratio.

${ }^{b}$ Standard deviation of the mean of the low frequency spectral ratio average. 


\subsection{FUEL ORIENTATION MEASUREMENTS}

Measurements were performed that can be used to investigate the changes associated with the orientation of the fuel elements in the assembly. The center-to-fuel spacing was selected to have the fuel elements close to each other. The configurations for these measurements are given in Table 4.21. The difference in the size of the inner and outer dimensions of the fuel elements limited the closeness to which the fuel elements could be placed in the $\mathrm{BBBB}$ configuration; therefore, this configuration cannot be directly compared to the $\mathrm{ABAB}$ or $\mathrm{AAAA}$ configurations.

\begin{tabular}{|c|c|c|c|c|}
\hline \multicolumn{5}{|c|}{ Table 4.21. Assembly configuration for different fuel orientation measurements } \\
\hline \multirow{2}{*}{$\begin{array}{c}\text { Fuel } \\
\text { orientation } \\
\text { (NESW) }\end{array}$} & North & East & South & West \\
\cline { 2 - 5 } & & 9.519 & 7.918 & 9.615 \\
\hline ABAB & 7.931 & 9.519 & 7.918 & 9.615 \\
\hline AAAA & 7.931 & 9.519 & 10.099 & 9.615 \\
\hline BBBB & 10.103 & &
\end{tabular}

${ }^{a}$ Orientation $\mathrm{A}$ corresponds to the small end of the fuel element closest to the center and orientation $\mathrm{B}$ corresponds to the large end of the fuel element closest to the center.

${ }^{\mathrm{b}}$ Spacing between fuel centerline and source dry well centerline.

The spectral ratio values for these measurement configurations are provided in Table 4.22. The $A B A B$ configuration was the standard close-spaced reference position, and the values that were reported in Table 4.22 for this configuration were the average values of all measurements in this configuration. The $A B A B$ configuration had lower spectral ratio values than the AAAA configuration by $8 \%$ for ratios with the detectors $180^{\circ}$ apart because the fissile material was closer together in with the $A B A B$ configuration. The $B B B B$ spectral ratio values were higher than the $A B A B$ spectral ratio values because of the separation between the fuel elements was greater. The most reactive configuration for this measurement assembly was the $A B A B$ configuration. 


\begin{tabular}{|c|c|c|c|c|c|c|c|c|c|c|c|c|}
\hline \multicolumn{10}{c|}{ Table 4.22. Spectral ratio values for different fuel element orientations } \\
\hline \multirow{2}{*}{ Orientation } & \multicolumn{2}{|c|}{ Ratio 23 } & \multicolumn{2}{c|}{ Ratio 24 } & \multicolumn{2}{c|}{ Ratio 25 } & \multicolumn{2}{c|}{ Ratio 34 } & \multicolumn{2}{c|}{ Ratio 35 } & \multicolumn{2}{c|}{ Ratio 45 } \\
\cline { 2 - 13 } & $\mathrm{R}^{\mathrm{a}}$ & $\sigma^{\mathrm{b}}$ & $\mathrm{R}$ & $\sigma$ & $\mathrm{R}$ & $\sigma$ & $\mathrm{R}$ & $\sigma$ & $\mathrm{R}$ & $\sigma$ & $\mathrm{R}$ & $\sigma$ \\
\hline $\mathrm{ABAB}$ & 0.387 & 0.005 & 0.352 & 0.004 & 0.351 & 0.004 & 0.355 & 0.007 & 0.349 & 0.006 & 0.379 & 0.005 \\
\hline $\begin{array}{c}\mathrm{AAAA} \\
(60)^{\mathrm{c}}\end{array}$ & 0.422 & 0.003 & 0.371 & 0.004 & 0.372 & 0.005 & 0.373 & 0.005 & 0.368 & 0.004 & 0.396 & 0.004 \\
\hline $\begin{array}{c}\text { AAAA } \\
(61)^{\mathrm{c}}\end{array}$ & 0.416 & 0.004 & 0.377 & 0.003 & 0.368 & 0.003 & 0.378 & 0.004 & 0.378 & 0.005 & 0.424 & 0.004 \\
\hline $\begin{array}{c}\text { BBBB } \\
(62)^{\mathrm{c}}\end{array}$ & 0.444 & 0.004 & 0.400 & 0.007 & 0.399 & 0.005 & 0.398 & 0.006 & 0.400 & 0.004 & 0.454 & 0.007 \\
\hline $\begin{array}{c}\text { BBBB } \\
(63)^{\mathrm{c}}\end{array}$ & 0.440 & 0.004 & 0.399 & 0.004 & 0.397 & 0.004 & 0.395 & 0.005 & 0.403 & 0.003 & 0.457 & 0.005 \\
\hline
\end{tabular}

${ }^{a}$ Low frequency average of spectral ratio.

${ }^{b}$ Standard deviation of the mean of the low frequency average of the spectral ratio.

${ }^{c}$ Measurement run number. 


\subsection{ALUMINUM PLATE MEASUREMENTS}

This section presents the results of measurements in which aluminum plates were positioned between the fuel elements. The aluminum plates were either $\sim 1 / 16$-or $\sim 1 / 8$ - inch thick. The plates all had the same lengths (48 inches) but had different widths. The plates positioned in the North and South position had the same width (4 7/8 inches), and those positioned in the East and West positions had the same width (11 7/8 inches). The plate guides were designed such that a maximum of four plates could be located in one guide. The plates $\sim 1 / 16$-and $\sim 1 / 8$-inch plates were used together to construct the $\sim 3 / 16$-and $\sim 1 / 4$-inch total thickness. The spectral ratio values obtainéd from these measurements are presented in Table 4.23 as a function of the number of 1/16-inch thick plates or equivalent that were used in the measurements. The individual measurement values were obtained by averaging the frequency dependent spectral ratio values over the low frequency range in which the spectral ratio was essentially constant for all reported spectral ratio values unless otherwise noted. The standard deviations of the individual measurement values are the standard deviations of the means of the low frequency averages for all spectral ratio values unless otherwise noted. Some of the individual measurements were simply statistical repeats in which a second set of data was obtained prior to changing the experimental assembly. These statistical repeat measurements were combined together and are also presented in Table 4.23.

The spectral ratio data presented in Table 4.23 are plotted as a function of the aluminum plate mass in Figs. 4.19 to 4.24 . The mass was determined using the density and dimensions of the plates. The individual spectral ratio values and the sums of statistical measurements are plotted as a function of the aluminum mass. The dashed lines indicate the one standard deviation spread of the reference measurements, i.e. the standard deviation of the sample set for the fifteen reference measurements. As evident in Figs. 4.19 through 4.24 , most of the data values were within one standard deviation of the reference measurements and all of the measurements were within two standard deviations of the reference measurements. The aluminum plates did not significantly affect the measured spectral ratio values, and thus did not change the subcriticality. 


\begin{tabular}{|c|c|c|c|c|c|c|c|c|c|c|c|c|c|c|c|c|}
\hline \multirow[b]{2}{*}{ No. } & \multicolumn{4}{|c|}{ Number of plates } & \multicolumn{2}{|c|}{ Ratio 23} & \multicolumn{2}{|c|}{ Ratio 24} & \multicolumn{2}{|c|}{ Ratio 25 } & \multicolumn{2}{|c|}{ Ratio 34} & \multicolumn{2}{|c|}{ Ratio 35} & \multicolumn{2}{|c|}{ Ratio 45} \\
\hline & $\mathrm{N}$ & $E$ & $\mathrm{~S}$ & $\mathrm{~W}$ & $\mathrm{R}^{\mathrm{a}}$ & $\sigma^{b}$ & $\mathrm{R}$ & $\sigma$ & $\mathrm{R}$ & $\sigma$ & $\mathrm{R}$ & $\sigma$ & $\mathrm{R}$ & 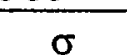 & $\mathrm{R}$ & 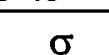 \\
\hline 70 & 1 & - & 1 & $\overline{-}$ & 0.559 & 0.010 & 0.470 & 0.005 & 0.448 & 0.006 & 0.474 & 0.007 & 0.439 & 0.004 & 0.523 & 0.008 \\
\hline 71 & 1 & - & 1 & - & 0.547 & 0.006 & 0.462 & 0.006 & 0.432 & 0.005 & 0.456 & 0.006 & 0.444 & 0.007 & 0.499 & 0.010 \\
\hline $\mathrm{Sum}^{\mathrm{c}}$ & 1 & - & 1 & $\overline{-}$ & 0.555 & 0.008 & 0.456 & 0.005 & 0.439 & 0.003 & 0.462 & 0.005 & 0.447 & 0.005 & 0.513 & 0.006 \\
\hline 72 & $2^{d}$ & - & 2 & - & 0.564 & 0.004 & 0.480 & 0.007 & 0.458 & 0.007 & 0.462 & 0.006 & 0.451 & 0.005 & 0.536 & 0.011 \\
\hline 73 & 2 & - & 2 & - & 0.550 & 0.007 & 0.455 & 0.007 & 0.444 & 0.005 & 0.455 & 0.008 & 0.446 & 0.006 & 0.520 & 0.015 \\
\hline Sum & 2 & - & 2 & - & 0.551 & 0.005 & 0.471 & 0.005 & 0.446 & 0.003 & 0.454 & 0.004 & 0.446 & 0.006 & 0.520 & 0.015 \\
\hline 74 & $3^{\mathrm{e}}$ & - & 3 & $\overline{-}$ & 0.533 & 0.006 & 0.444 & 0.008 & 0.448 & 0.006 & 0.448 & 0.006 & 0.456 & 0.004 & 0.511 & 0.005 \\
\hline 75 & 3 & - & 3 & - & 0.550 & 0.006 & 0.466 & 0.007 & 0.444 & 0.006 & 0.453 & 0.006 & 0.451 & 0.007 & 0.525 & 0.010 \\
\hline Sum & 3 & - & 3 & - & 0.542 & 0.005 & 0.453 & 0.005 & 0.448 & 0.004 & 0.457 & 0.004 & 0.451 & 0.004 & 0.519 & 0.006 \\
\hline 76 & 3 & 1 & 3 & 1 & 0.543 & 0.008 & 0.452 & 0.005 & 0.451 & 0.007 & 0.454 & 0.006 & 0.433 & 0.006 & 0.511 & 0.007 \\
\hline 77 & 3 & 1 & 3 & 1 & 0.556 & 0.006 & 0.464 & 0.007 & 0.445 & 0.006 & 0.463 & 0.006 & 0.448 & 0.007 & 0.525 & 0.010 \\
\hline Sum & 3 & 1 & 3 & 1 & 0.561 & 0.008 & 0.453 & 0.005 & 0.450 & 0.003 & 0.457 & 0.004 & 0.445 & 0.004 & 0.516 & 0.009 \\
\hline 78 & 2 & 1 & 2 & 1 & 0.535 & 0.008 & 0.447 & 0.006 & 0.445 & 0.006 & 0.453 & 0.005 & 0.436 & 0.007 & 0.502 & 0.010 \\
\hline 79 & 1 & 1 & 1 & 1 & 0.553 & 0.006 & 0.473 & 0.006 & 0.452 & 0.006 & 0.460 & 0.006 & 0.465 & 0.007 & 0.504 & 0.007 \\
\hline 80 & 1 & 2 & 1 & 2 & 0.535 & 0.008 & 0.446 & 0.005 & 0.435 & 0.006 & 0.471 & 0.006 & 0.442 & 0.005 & 0.515 & 0.011 \\
\hline 81 & 2 & 2 & 2 & 2 & 0.550 & 0.006 & 0.443 & 0.004 & 0.461 & 0.007 & 0.456 & 0.006 & 0.451 & 0.007 & 0.528 & 0.010 \\
\hline 82 & 3 & 2 & 3 & 2 & 0.549 & 0.007 & 0.451 & 0.005 & 0.437 & 0.006 & 0.455 & 0.007 & 0.456 & 0.008 & 0.524 & 0.009 \\
\hline 83 & 3 & 3 & 3 & 3 & 0.556 & 0.008 & 0.470 & 0.008 & 0.441 & 0.005 & 0.472 & 0.005 & 0.448 & 0.003 & 0.505 & 0.009 \\
\hline 84 & $4^{r}$ & 4 & 4 & 4 & 0.555 & 0.009 & 0.453 & 0.006 & 0.462 & 0.005 & 0.450 & 0.006 & 0.454 & 0.005 & 0.517 & 0.013 \\
\hline
\end{tabular}

${ }^{\mathrm{a}}$ Low frequency average of spectral ratio.

${ }^{b}$ Standard deviation of the mean of the low frequency spectral ratio average.

${ }^{c}$ Represents the summing of the spectral signatures of the two previous measurements.

${ }^{\mathrm{d}}$ Actual plate thickness is $\sim 1 / 8$ inch for measurements using two plates.

${ }^{\mathrm{e}}$ One $\sim 1 / 16$-inch and one $\sim 1 / 8$-inch thick plate are used to produce $\sim 3 / 16$-inch thick plate.

${ }^{\mathrm{f}}$ Two $\sim 1 / 8$-inch thick plates or one $\sim 1 / 8$-inch thick plate with two $\sim 1 / 16$-inch thick plates are used to construct $\sim 1 / 4$-inch thick plate. 


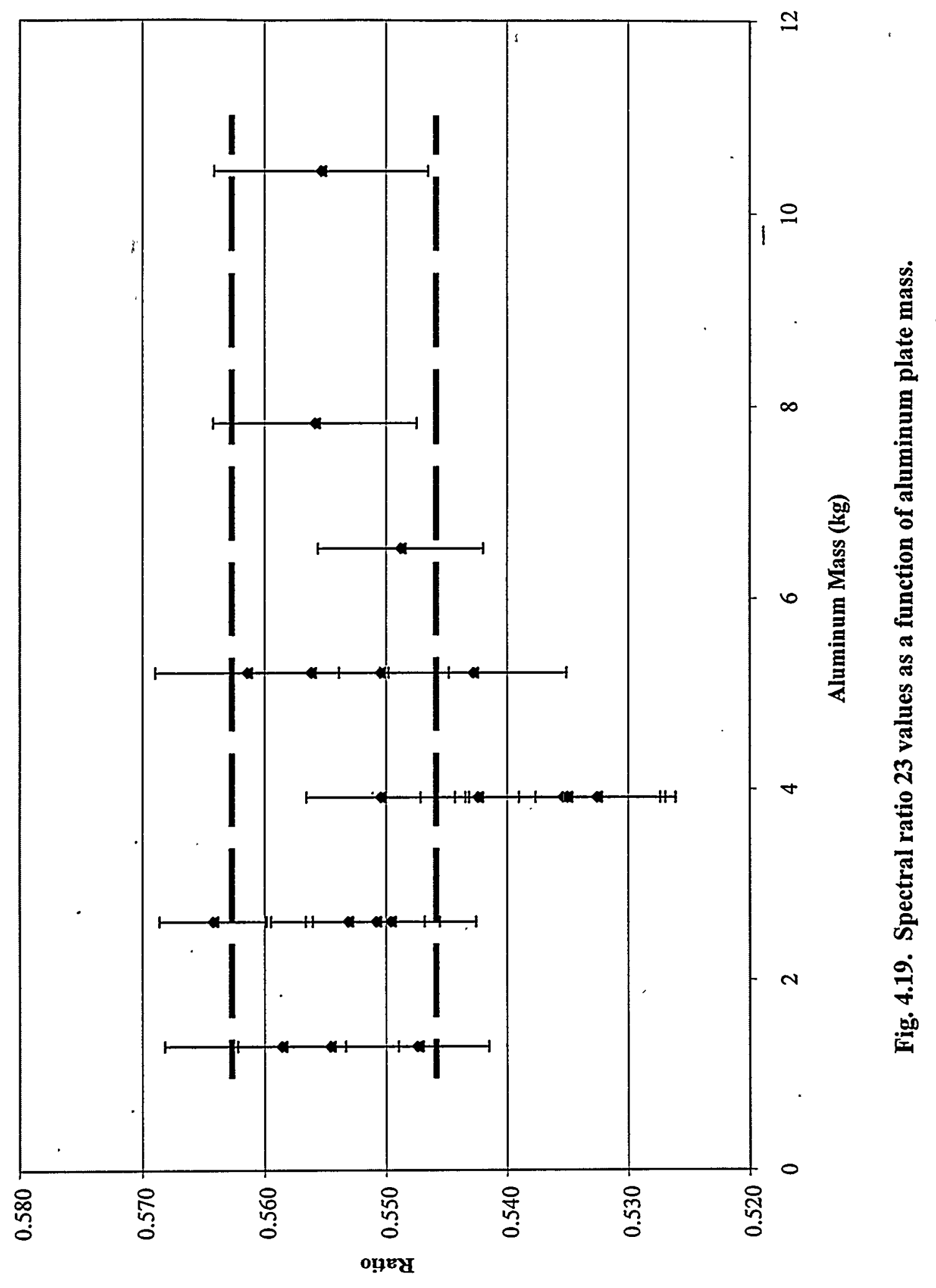




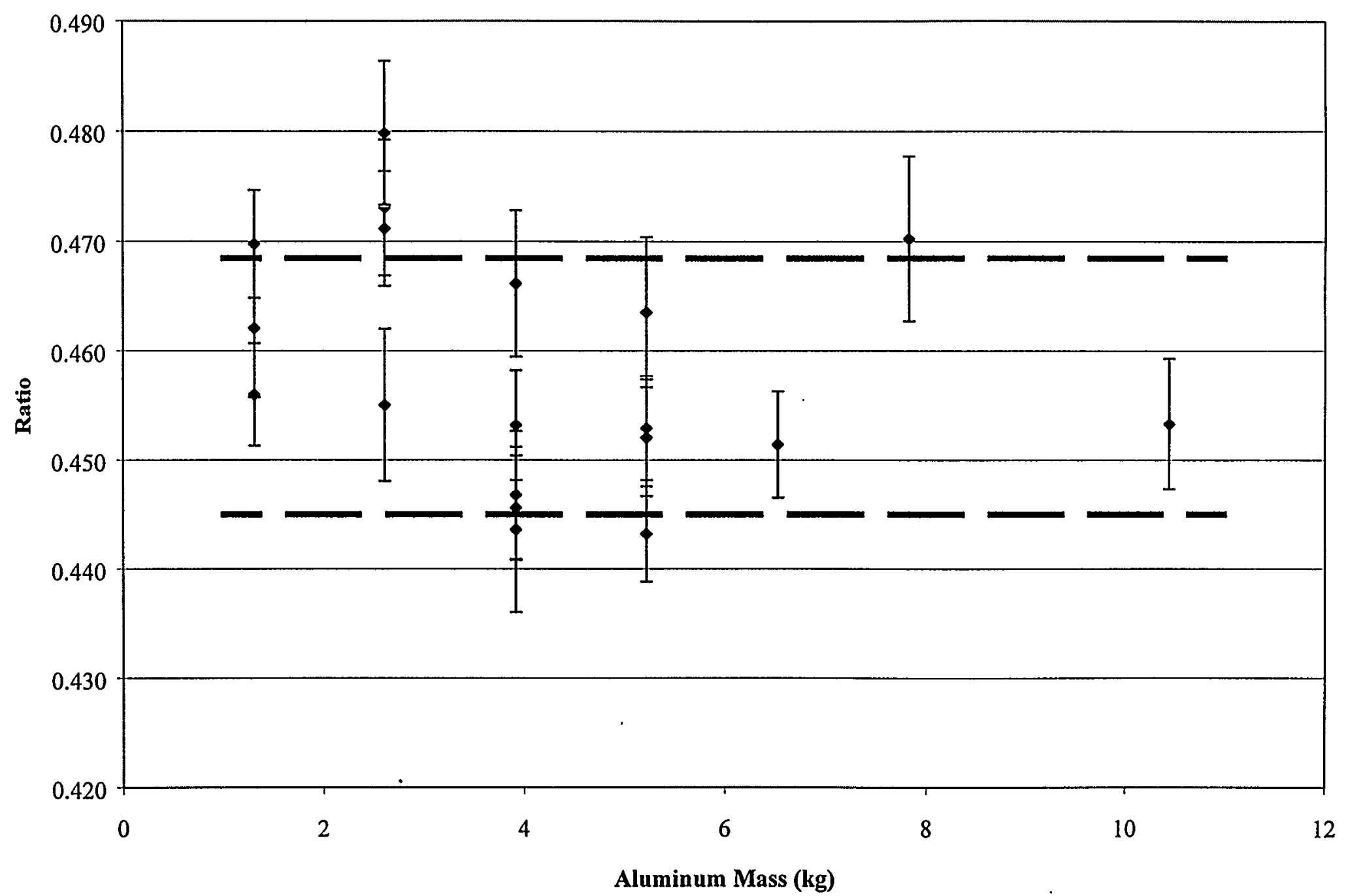

Fig. 4.20. Spectral ratio 24 values as a function of aluminum plate mass. 


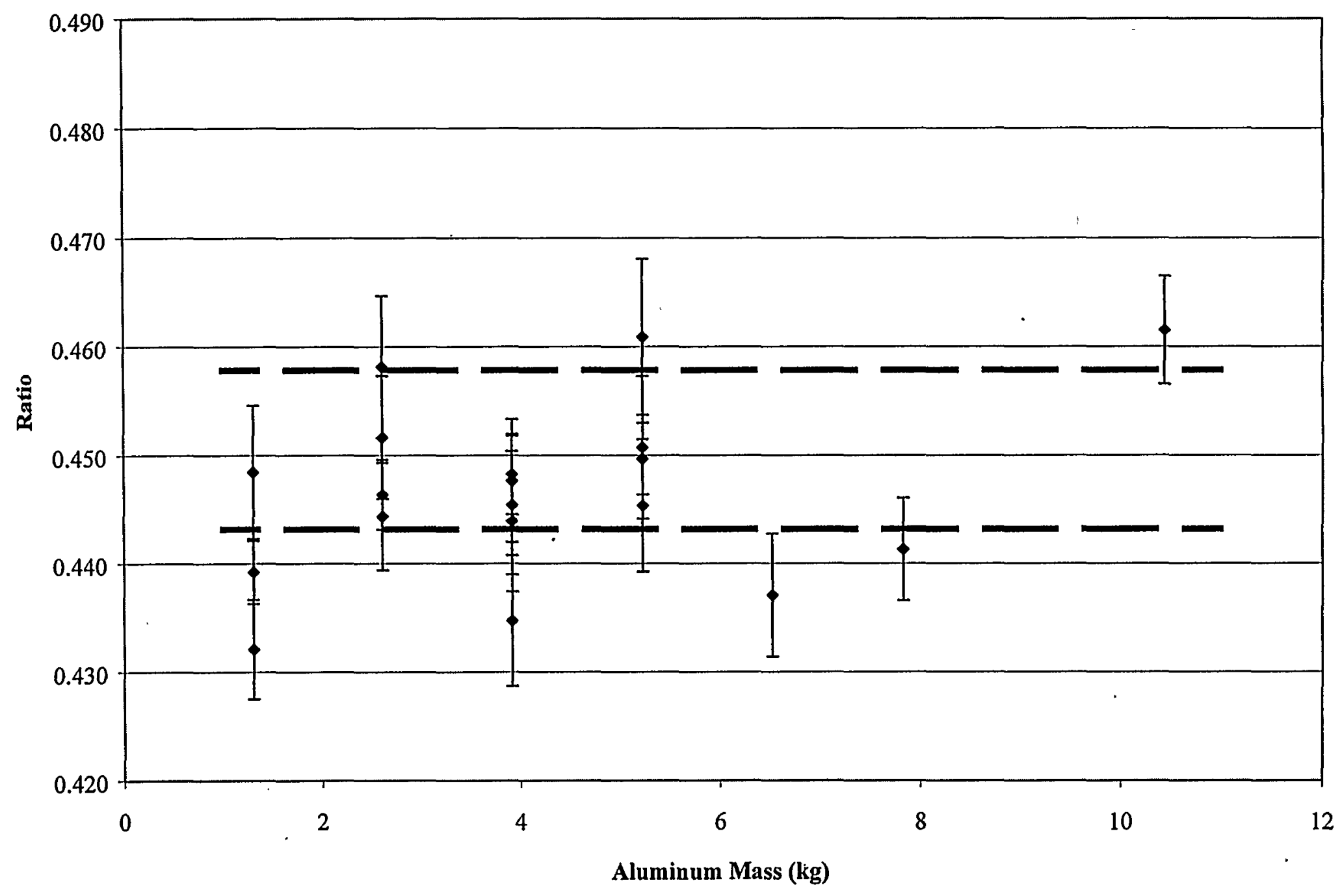

Fig. 4.21. Spectral ratio 25 values as a function of aluminum plate mass. 


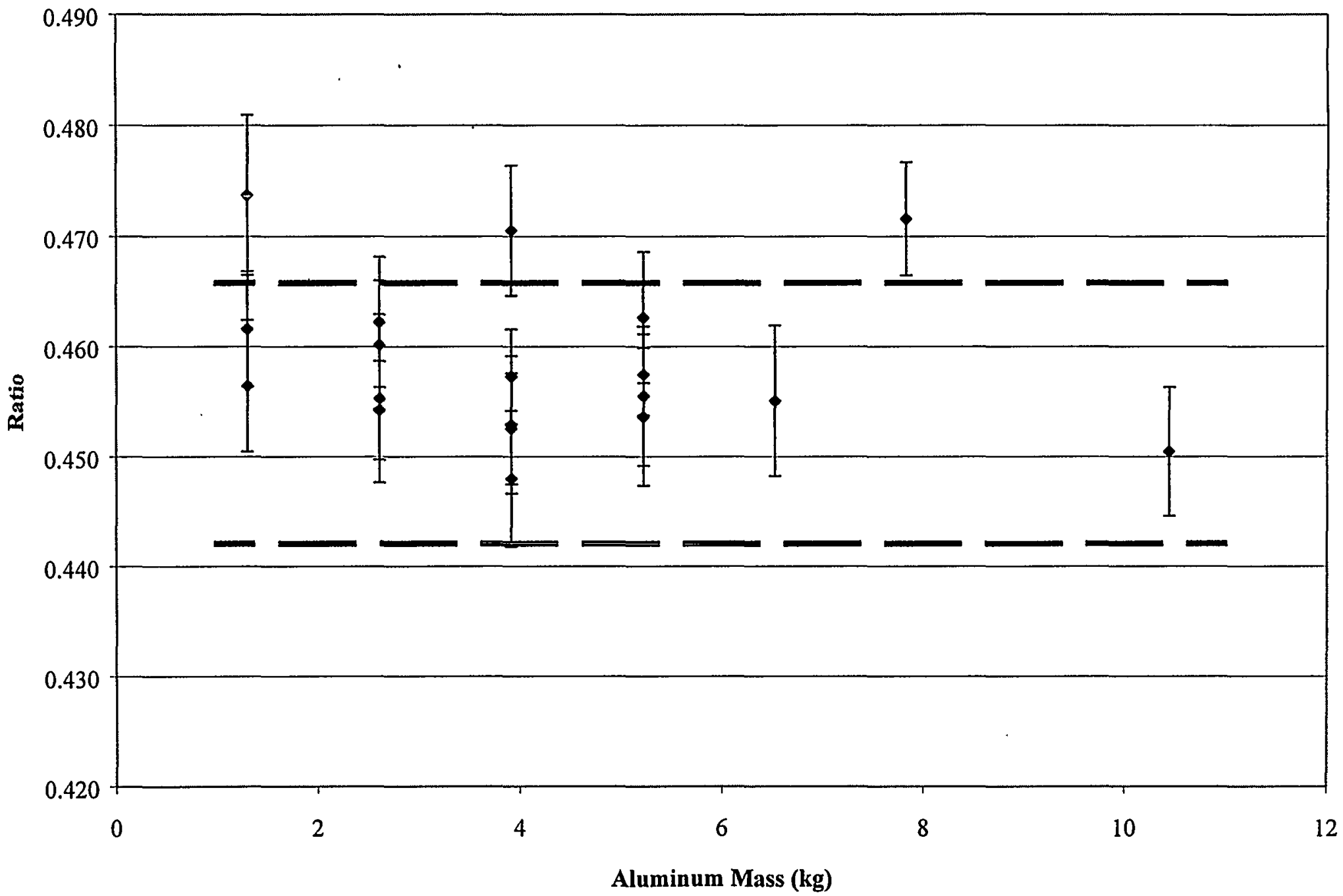

Fig. 4.22. Spectral ratio 34 values as a function of aluminum plate mass. 


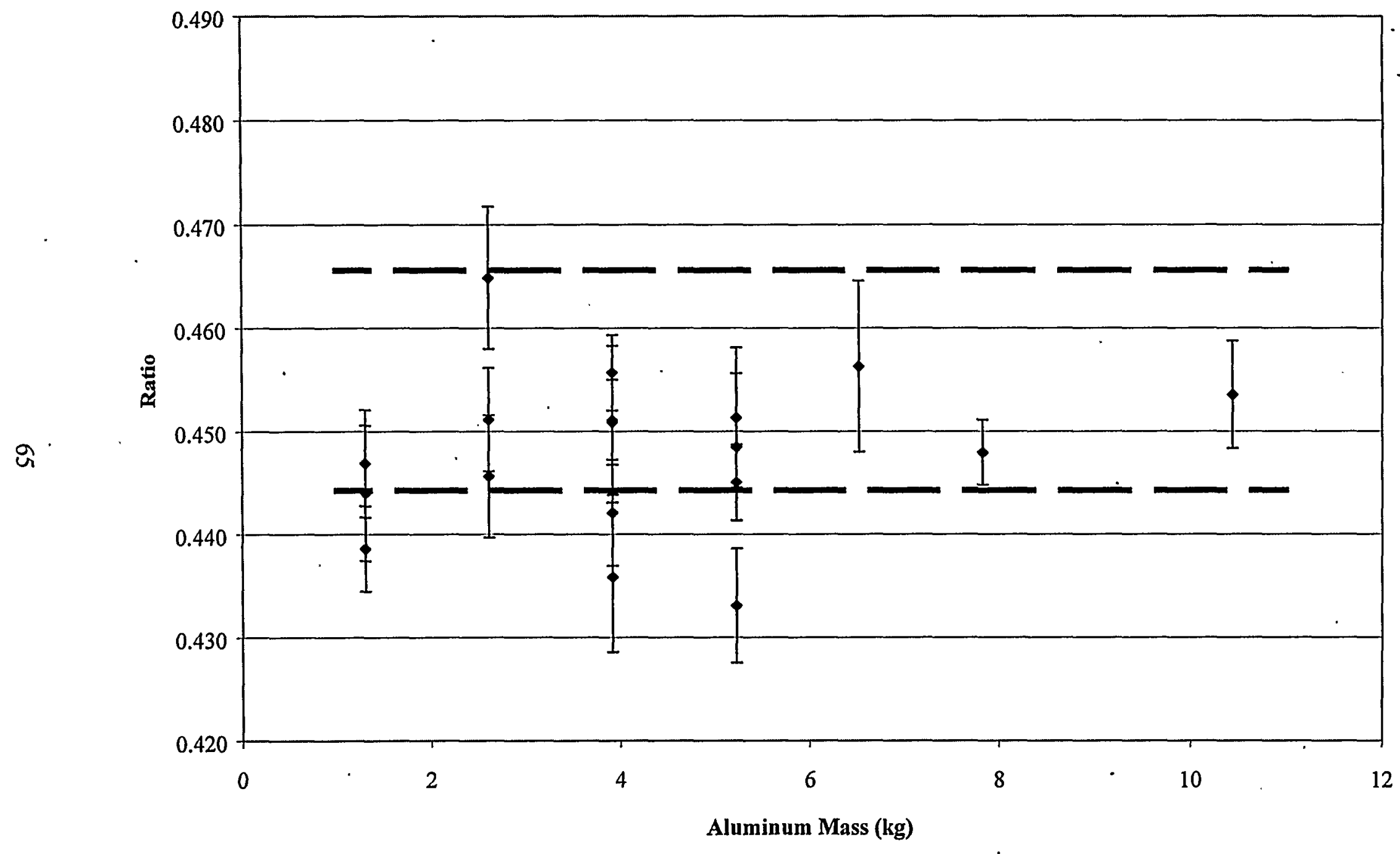

Fig. 4.23. Spectral ratio 35 values as a function of aluminum plate mass. 


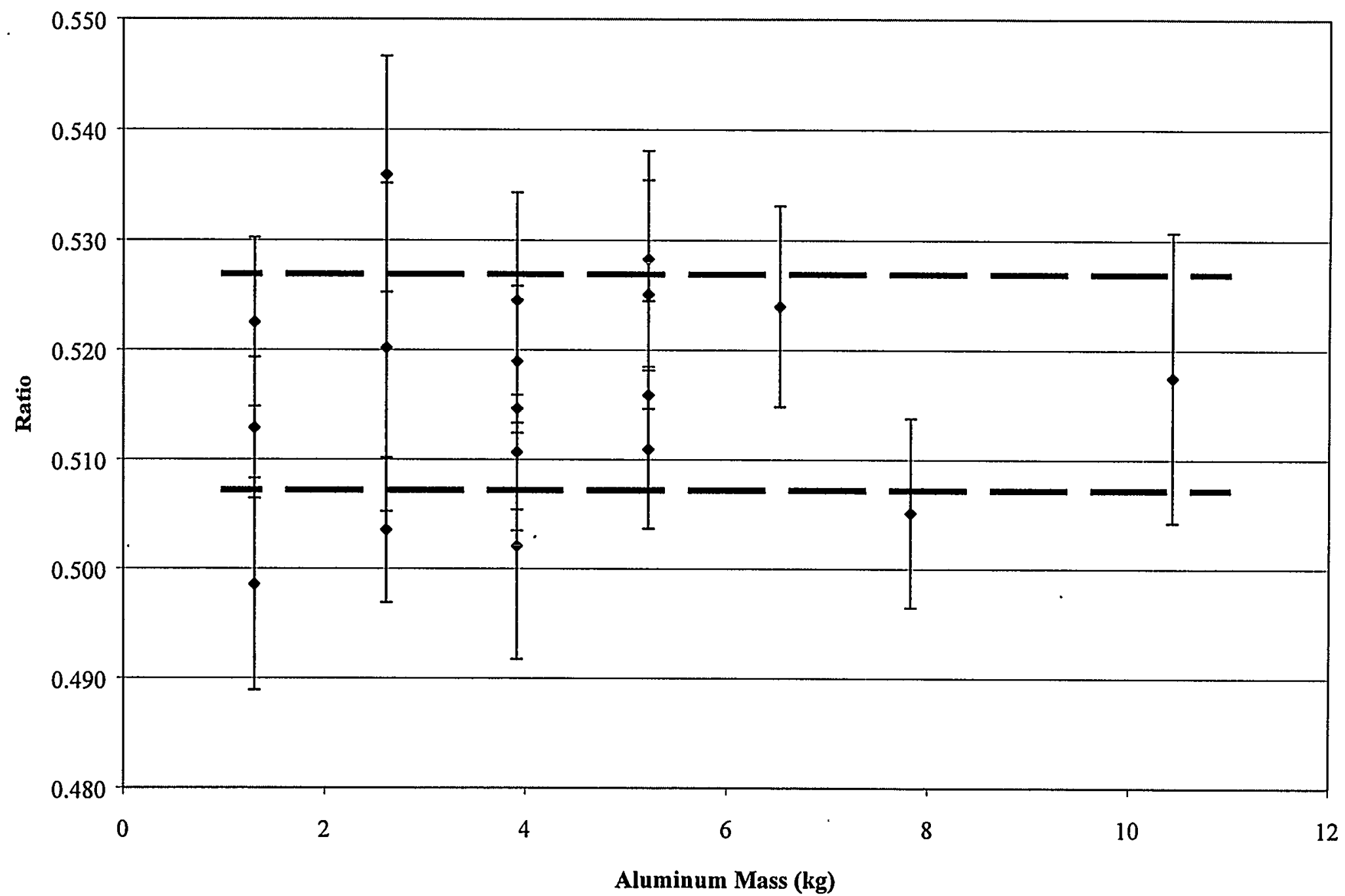

Fig. 4.24. Spectral ratio 45 values as a function of aluminum plate mass. 


\subsection{LEAD PLATE MEASUREMENTS}

This section presents the results of measurements in which lead plates were positioned between the fuel elements. The average spectral ratio values at low frequency obtained from these measurements are presented in Table 4.24 as a function of the number of plates. The statistical repeat measurements were combined together and are also presented in Table 4.24.

The sums of statistical measurements are plotted as a function of the lead mass in Figs. 4.25 through 4.30. The sums of the individual measurements were more statistically significant than individual measurements because the sums had twice as many data blocks. The dashed lines indicated the one standard deviation spread of the fifteen reference measurements. The results of the lead plate measurements were not significantly different from the reference measurements at the plate spacing. The spectral ratio values obtained from detectors 2 and 3 decreased slightly as a function of lead mass while the other spectral ratio values did not exhibit any clear pattern for changes in the lead mass. Except for the spectral ratio 23, a majority of the spectral ratio values were within two standard deviations of the reference plate measurements. The spectral ratio 23 values ranged from $3 \%$ to $7 \%$ less than the value for the reference measurements at the plate spacing. This was more than a factor of two greater than the uncertainty in the repeatability of the reference measurements. Although most of the spectral ratio values did not exhibit any particular trend with lead mass some of the spectral ratio values were consistent with each other. Consider the measurements with lead plates in the north and south positions (measurements 108 and 109). The spectral ratio values 24, 25, 34, and 35 were all the same because the plate configuration was symmetric. Likewise, the results of measurements with lead plates in the east and west positions (measurements 100 and 101) demonstrated consistent results. The spectral ratio values $24,25,34$, and 35 were all the same because again this was a symmetric configuration. One of the more interesting observations concerning this data was that the spectral ratio values were slightly lower than those for the reference plate measurements. This could indicate that the reactivity increased when adding lead plates. However, because most of the spectral ratio values were within two standard deviations of the reference measurements with no plates, the affects of the lead were considered small. 


\begin{tabular}{|c|c|c|c|c|c|c|c|c|c|c|c|c|c|c|c|c|}
\hline \multicolumn{17}{|c|}{ Table 4.24. Measured spectral ratio values with varying number of lead plates between the fuel elements } \\
\hline \multirow[b]{2}{*}{ No. } & \multicolumn{4}{|c|}{ Number of plates } & \multicolumn{2}{|c|}{ Ratio 23} & \multicolumn{2}{|c|}{ Ratio 24} & \multicolumn{2}{|c|}{ Ratio 25} & \multicolumn{2}{|c|}{ Ratio 34} & \multicolumn{2}{|c|}{ Ratio 35} & \multicolumn{2}{|c|}{ Ratio 45} \\
\hline & $\mathrm{N}$ & $\mathrm{E}$ & $\mathrm{S}$ & $\mathrm{W}$ & $\mathrm{R}^{\mathrm{a}}$ & $\sigma^{\mathrm{b}}$ & $\mathrm{R}$ & $\sigma$ & $\mathrm{R}$ & F & $\mathrm{R}$ & o & $\mathrm{R}$ & $\sigma$ & $\mathrm{R}$ & $\sigma$ \\
\hline 96 & 1 & 1 & 1 & 1 & 0.519 & 0.006 & 0.444 & 0.005 & 0.444 & 0.009 & 0.443 & 0.007 & 0.435 & 0.004 & 0.484 & 0.005 \\
\hline 97 & 1 & 1 & 1 & 1 & 0.516 & 0.008 & 0.420 & 0.005 & 0.425 & 0.006 & 0.438 & 0.004 & 0.424 & 0.007 & 0.496 & 0.009 \\
\hline Sum $^{c}$ & 1 & 1 & 1 & 1 & 0.516 & 0.004 & 0.432 & 0.004 & 0.434 & 0.005 & 0.438 & 0.003 & 0.425 & 0.003 & 0.487 & 0.007 \\
\hline 98 & & 1 & 1 & 1 & 0.525 & 0.007 & 0.422 & 0.007 & 0.418 & 0.006 & 0.442 & 0.006 & 0.419 & 0.004 & 0.470 & 0.007 \\
\hline 99 & & 1 & 1 & 1 & 0.530 & 0.007 & 0.435 & 0.005 & 0.435 & 0.006 & 0.446 & 0.008 & 0.443 & 0.005 & 0.506 & 0.007 \\
\hline Sum & & 1 & 1 & 1 & 0.522 & 0.007 & 0.435 & 0.005 & 0.435 & 0.006 & 0.446 & 0.008 & 0.443 & 0.005 & 0.506 & 0.007 \\
\hline 100 & & 1 & & 1 & 0.517 & 0.006 & 0.457 & 0.006 & 0.439 & 0.005 & 0.458 & 0.008 & 0.440 & 0.004 & 0.493 & 0.015 \\
\hline 101 & & 1 & & 1 & 0.536 & 0.005 & 0.462 & 0.005 & 0.443 & 0.006 & 0.434 & 0.007 & 0.450 & 0.007 & 0.502 & 0.008 \\
\hline Sum & & 1 & & 1 & 0.530 & 0.003 & 0.449 & 0.005 & 0.441 & 0.005 & 0.449 & 0.004 & 0.441 & 0.003 & 0.495 & 0.010 \\
\hline 102 & & 1 & & & 0.540 & 0.006 & 0.442 & 0.005 & 0.439 & 0.008 & 0.444 & 0.009 & 0.435 & 0.007 & 0.483 & 0.013 \\
\hline 103 & & 1 & & & 0.542 & 0.006 & 0.448 & 0.006 & 0.440 & 0.006 & 0.463 & 0.008 & 0.448 & 0.004 & 0.522 & 0.009 \\
\hline Sum & & 1 & & & 0.535 & 0.005 & 0.440 & 0.006 & 0.440 & 0.006 & 0.462 & 0.007 & 0.448 & 0.004 & 0.517 & 0.010 \\
\hline 104 & 1 & 1 & & & 0.544 & 0.007 & 0.446 & 0.004 & 0.435 & 0.005 & 0.455 & 0.006 & 0.429 & 0.006 & 0.538 & 0.017 \\
\hline 105 & 1 & 1 & & & 0.529 & 0.006 & 0.455 & 0.010 & 0.434 & 0.007 & 0.443 & 0.005 & 0.452 & 0.007 & 0.507 & 0.011 \\
\hline Sum & 1 & 1 & & & 0.535 & 0.003 & 0.442 & 0.003 & 0.429 & 0.004 & 0.446 & 0.004 & 0.442 & 0.004 & 0.522 & 0.010 \\
\hline 106 & 1 & 1 & 1 & & 0.521 & 0.008 & 0.444 & 0.006 & 0.437 & 0.005 & 0.454 & 0.008 & 0.446 & 0.006 & 0.506 & 0.014 \\
\hline 107 & 1 & 1 & 1 & & 0.528 & 0.005 & 0.448 & 0.005 & 0.434 & 0.005 & 0.445 & 0.006 & 0.452 & 0.006 & 0.497 & 0.012 \\
\hline Sum & 1 & 1 & 1 & & 0.526 & 0.006 & 0.447 & 0.003 & 0.431 & 0.004 & 0.446 & 0.005 & 0.448 & 0.003 & 0.487 & 0.011 \\
\hline 108 & 1 & & 1 & & 0.534 & 0.004 & 0.448 & 0.006 & 0.444 & 0.005 & 0.450 & 0.007 & 0.442 & 0.005 & 0.483 & 0.010 \\
\hline 109 & 1 & & 1 & & 0.534 & 0.006 & 0.441 & 0.008 & 0.452 & 0.005 & 0.458 & 0.011 & 0.446 & 0.005 & 0.510 & 0.009 \\
\hline Sum & 1 & & 1 & & 0.541 & 0.004 & 0.445 & 0.005 & 0.445 & 0.004 & 0.443 & 0.004 & 0.445 & 0.003 & 0.491 & 0.007 \\
\hline 110 & 1 & & & & 0.536 & 0.004 & 0.435 & 0.007 & 0.447 & 0.007 & 0.436 & 0.008 & 0.436 & 0.003 & 0.509 & 0.013 \\
\hline 111 & 1 & & & & 0.547 & 0.013 & 0.438 & 0.006 & 0.442 & 0.005 & 0.444 & 0.007 & 0.441 & 0.007 & 0.537 & 0.006 \\
\hline Sum & 1 & & & & 0.538 & 0.007 & 0.436 & 0.007 & 0.443 & 0.004 & 0.434 & 0.004 & 0.440 & 0.004 & 0.533 & 0.007 \\
\hline
\end{tabular}

${ }^{\mathrm{a}}$ Low frequency average of spectral ratio.

${ }^{b}$ Standard deviation of the mean of the low frequency spectral ratio average.

${ }^{\mathrm{c}}$ Represents the summing of the spectral signatures of the two previous measurements. 


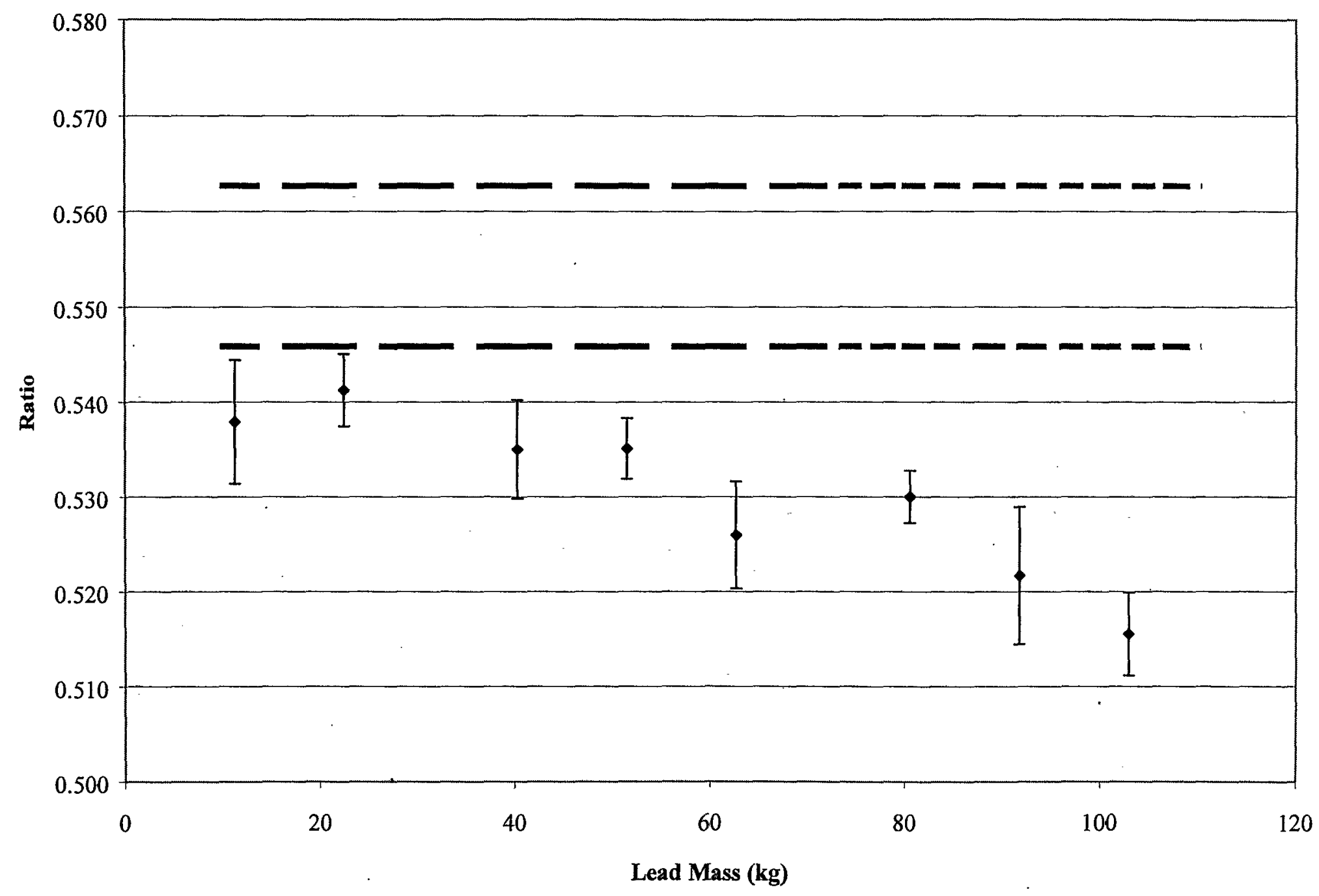

Fig. 4.25. Spectral ratio 23 values as a function of lead plate mass. 


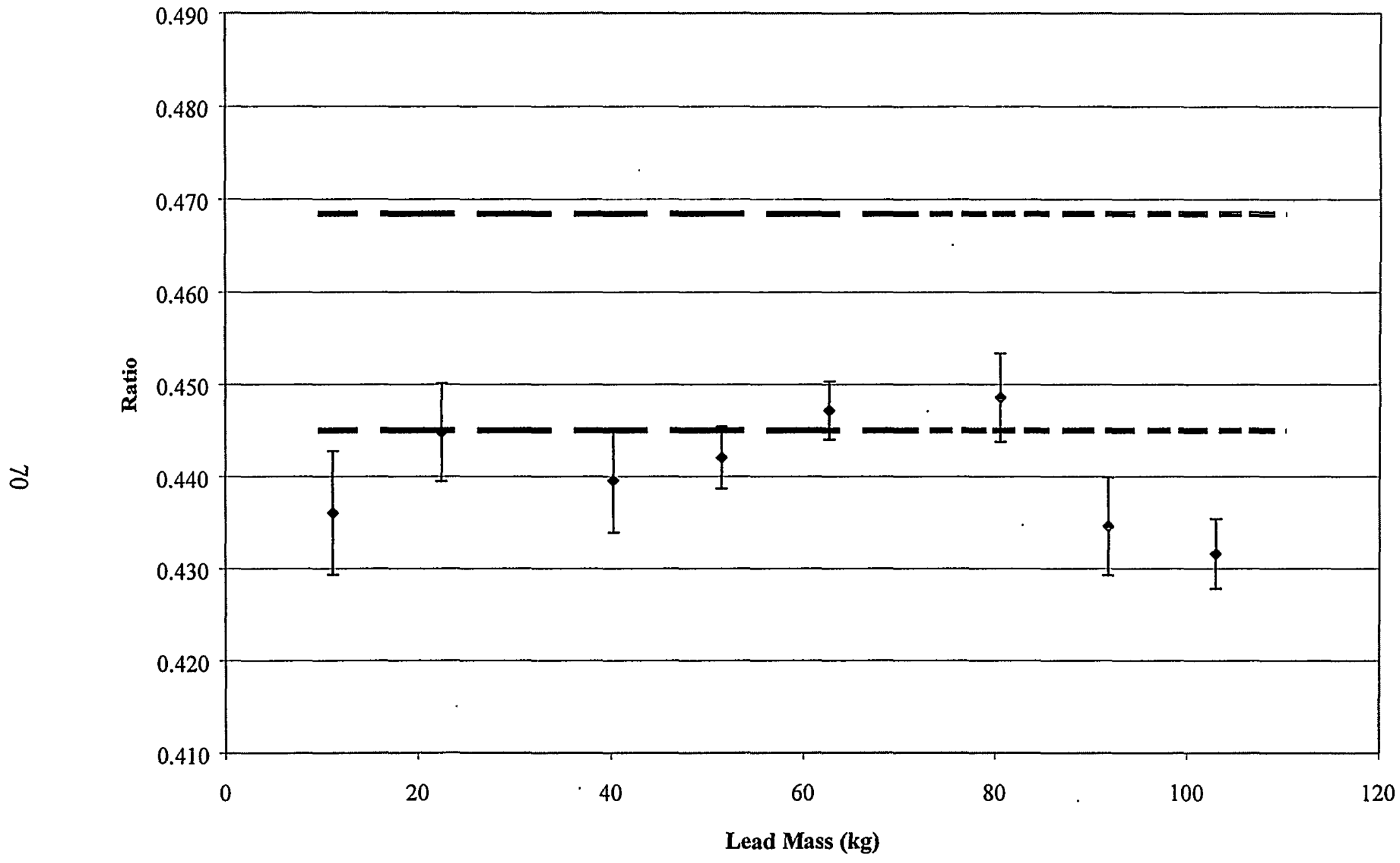

Fig. 4.26. Spectral ratio 24 values as a function of lead plate mass. 


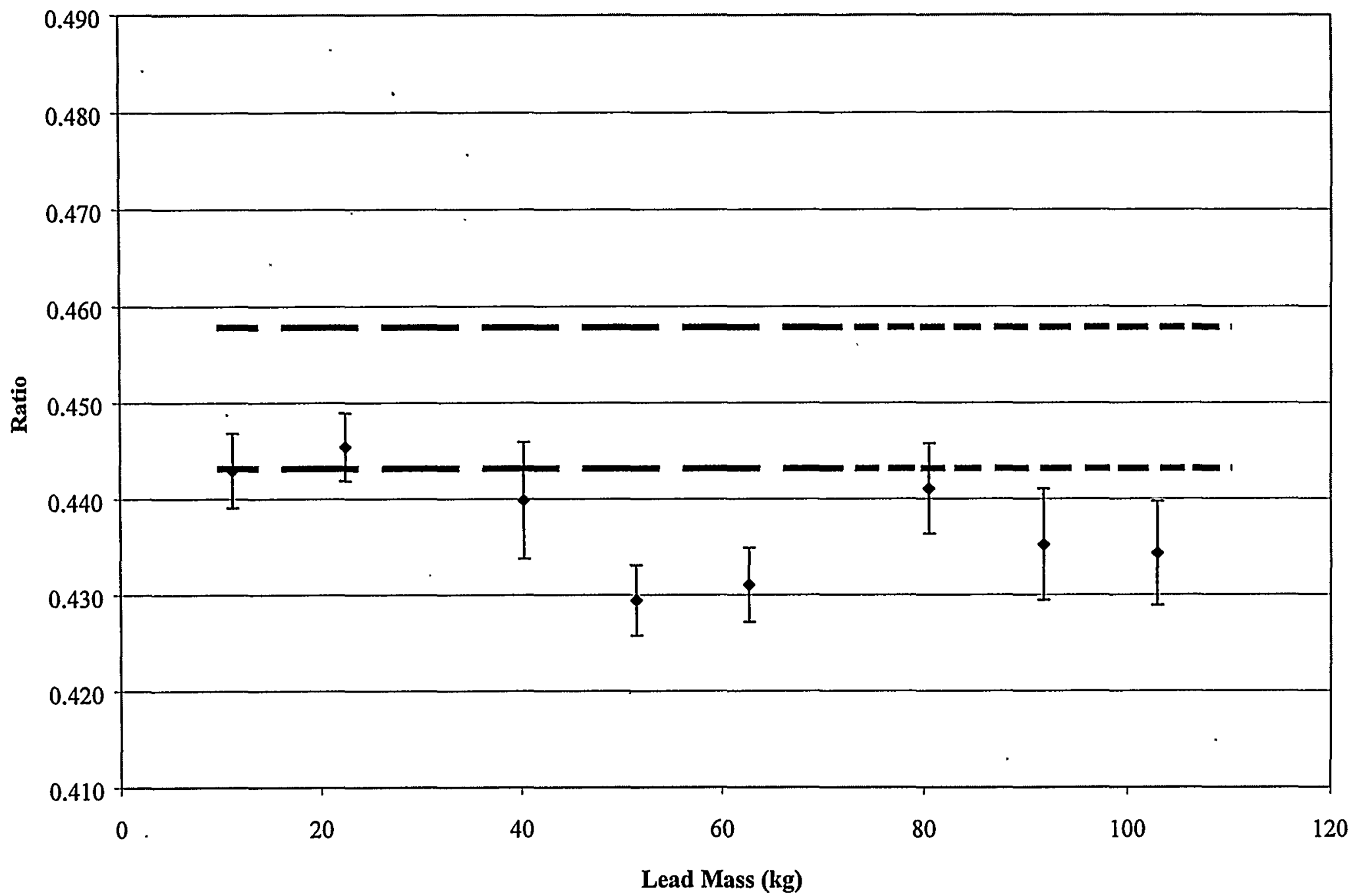

Fig. 4.27. Spectral ratio 25 values as a function of lead plate mass. 


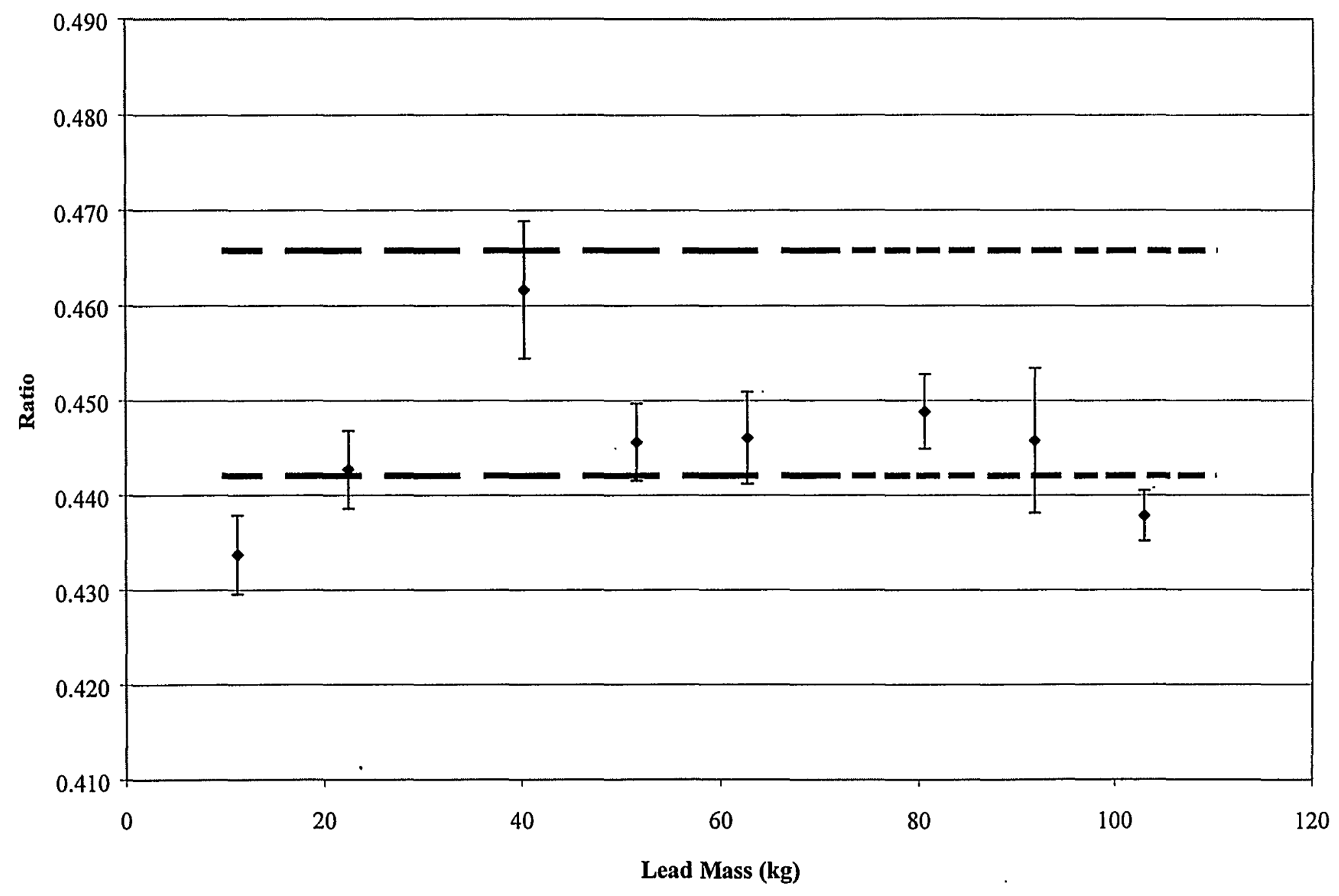

Fig. 4.28. Spectral ratio 34 values as a function of lead plate mass. 


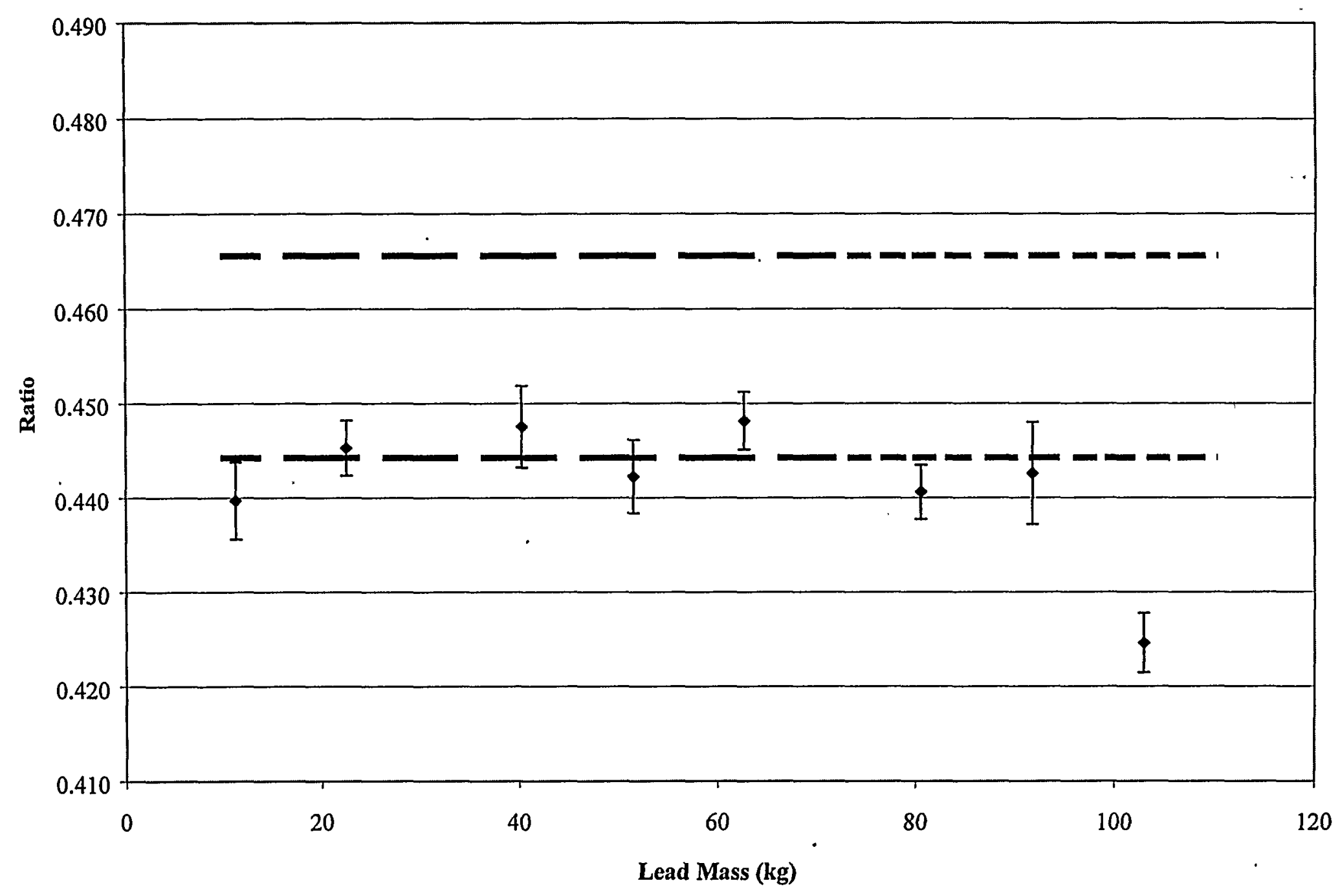

Fig. 4.29. Spectral ratio 35 values as a function of lead plate mass. 


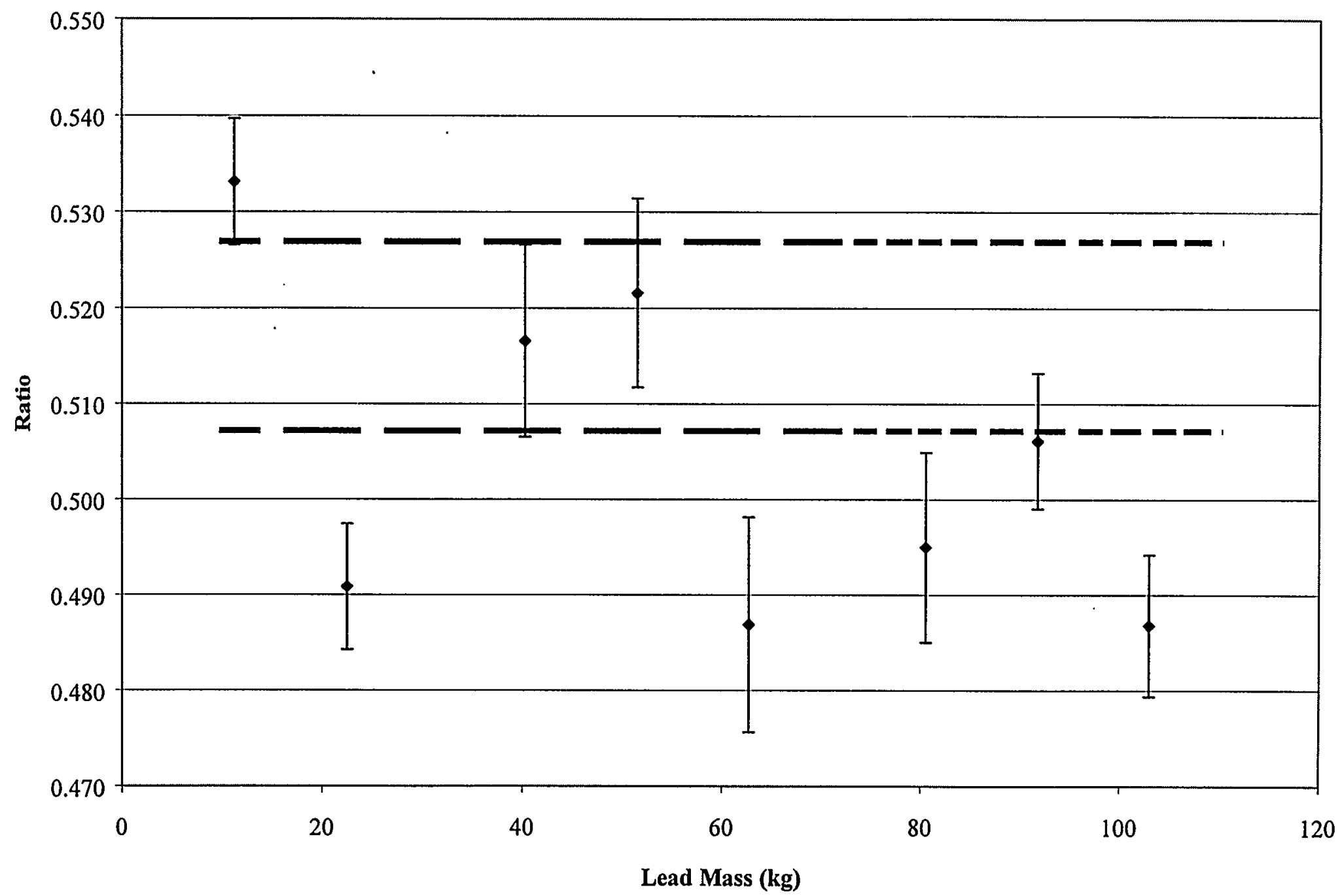

Fig. 4.30. Spectral ratio 45 values as a function of lead plate mass. 


\subsection{STAINLESS STEEL PLATE MEASUREMENTS}

This section presents the results of measurements in which stainless steel plates were positioned between the fuel elements. The stainless steel plates were either 0.06 -or 0.12 -inch thick. The plates all had the same lengths (48 inches) but had different widths. The plates positioned in the north and south position had the same width (4 7/8 inches), and those positioned in the east and west positions had the same width (11 7/8 inches). The plate guides were designed such that a maximum of four plates could be located in one guide. The plates were used together to construct the $\sim 3 / 16$-and $\sim 1 / 4$-inch total thickness. The spectral ratio values obtained from these measurements are presented as a function of the number of 0.06 -inch thick plates or equivalent that were used in the measurements in Table 4.25. Some of the individual measurements were simply statistical repeats in which additional sets of data were obtained prior to changing the experimental assembly. These statistical repeat measurements were combined together and are also presented in Table 4.25.

The data in Table 4.25 are presented as a function of the steel plate mass in Figs. 4.31 to 4.36. The sums of statistical measurements are plotted as a function of the steel mass. Repeat measurements not performed sequentially were not summed together because of the potential for very slight differences in the system configuration. These measurements are evident when two or more values were plotted for a given mass. The dashed lines indicate the one standard deviation spread of the fifteen reference measurements. As can be seen from the figures, the steel plates significantly changed the measured spectral ratio values. Measurement results with a single plate in the north and south positions were essentially the same as those obtained from the reference measurements except for spectral ratio value 23 . A single small plate in the north and south positions did not affect the interaction between adjacent elements and did not affect the interaction between elements located in the east and west positions. However, as the number of plates (mass) was increased the spectral ratio values increased significantly indicating that $k_{\text {eff }}$ was decreasing. This may have occurred because of a combination of water displacement near the fuel elements and because of the neutron absorption in the stainless steel. The sums of the spectral signatures were more statistically converged than the individual measurements. The results for these measurements showed very good repeatability when comparing the sums of two measurements.

Many measurements were performed with symmetric plate configurations. Consider the sum of measurements 112 and 113 with one steel plate in the north and south positions. This configuration was symmetric with respect to the north and south fuel elements. Therefore, the spectral ratios $24,25,34$, and 35 were in close agreement as can be seen from the data presented in Table 4.23. Likewise, the spectral ratios 24, 25, 34 and 35 were in close agreement for sum of measurements 116 and 117 and for the sum measurements 118 and 119. These measurements had symmetric plate configurations. The spectral ratios $24,25,34$, and 35 for the sum of measurements 116 and 117 did not differ from those for the sum of measurements 118 and 119 and indicated that the additional plate had a small affect on the interaction between adjacent fuel elements. 


\begin{tabular}{|c|c|c|c|c|c|c|c|c|c|c|c|c|c|c|c|c|}
\hline \multirow[b]{3}{*}{ No. } & \multicolumn{16}{|c|}{ rable 4.25. Measured spectral ratio values with varying number of stainle } \\
\hline & \multicolumn{4}{|c|}{ Number of plates } & \multicolumn{2}{|c|}{ Ratio 23} & \multicolumn{2}{|c|}{ Ratio 24} & \multicolumn{2}{|c|}{ Ratio 25} & \multicolumn{2}{|c|}{ Ratio 34} & \multicolumn{2}{|c|}{ Ratio 35} & \multicolumn{2}{|c|}{ Ratio 45} \\
\hline & $\mathrm{N}$ & $\mathrm{E}$ & $\mathrm{S}$ & $\mathrm{W}$ & $\mathrm{R}^{\mathrm{a}}$ & $\sigma^{\mathrm{b}}$ & $\mathrm{R}$ & $\sigma$ & $\mathrm{R}$ & 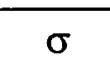 & $\overline{\mathrm{R}}$ & $\bar{\sigma}$ & $\mathrm{R}$ & $\bar{\sigma}$ & $\mathrm{R}$ & $\sigma$ \\
\hline 90 & 4 & 4 & 4 & 4 & 0.685 & 0.003 & 0.549 & 0.003 & 0.527 & 0.002 & 0.549 & 0.003 & 0.551 & 0.003 & 0.631 & 0.005 \\
\hline 91 & 3 & 3 & 3 & 3 & 0.654 & 0.004 & 0.533 & 0.003 & 0.526 & 0.003 & 0.529 & 0.003 & 0.527 & 0.003 & 0.636 & 0.005 \\
\hline 112 & 1 & & 1 & & 0.564 & 0.007 & 0.456 & 0.006 & 0.449 & 0.006 & 0.450 & 0.005 & 0.461 & 0.006 & 0.528 & 0.012 \\
\hline 113 & 1 & & 1 & & 0.569 & 0.007 & 0.461 & 0.007 & 0.456 & 0.004 & 0.454 & 0.005 & 0.456 & 0.004 & 0.535 & 0.018 \\
\hline $\mathrm{Sum}^{\mathrm{C}}$ & 1 & & 1 & & 0.570 & 0.004 & 0.458 & 0.003 & 0.451 & 0.003 & 0.453 & 0.005 & 0.457 & 0.004 & 0.505 & 0.010 \\
\hline 116 & 2 & & 2 & & 0.615 & 0.009 & 0.482 & 0.005 & 0.488 & 0.008 & 0.486 & 0.006 & 0.474 & 0.006 & 0.527 & 0.012 \\
\hline 117 & 2 & & 2 & & 0.604 & 0.006 & 0.465 & 0.005 & 0.476 & 0.007 & 0.489 & 0.008 & 0.511 & 0.007 & 0.554 & 0.010 \\
\hline Sum $^{\mathrm{c}}$ & 2 & & 2 & & 0.608 & 0.005 & 0.482 & 0.003 & 0.484 & 0.006 & 0.484 & 0.005 & 0.485 & 0.005 & 0.541 & 0.010 \\
\hline 118 & 3 & & 3 & & 0.615 & 0.007 & 0.466 & 0.006 & 0.473 & 0.006 & 0.475 & 0.006 & 0.494 & 0.008 & 0.546 & 0.008 \\
\hline 119 & 3 & & 3 & & 0.618 & 0.011 & 0.477 & 0.010 & 0.487 & 0.007 & 0.481 & 0.008 & 0.494 & 0.008 & 0.598 & 0.010 \\
\hline $\mathrm{Sum}^{\mathrm{c}}$ & 3 & & 3 & & 0.617 & 0.006 & 0.481 & 0.007 & 0.479 & 0.005 & 0.478 & 0.005 & 0.484 & 0.007 & 0.565 & 0.006 \\
\hline 120 & 3 & 1 & 3 & 1 & 0.631 & 0.004 & 0.503 & 0.004 & 0.508 & 0.004 & 0.513 & 0.004 & 0.509 & 0.004 & 0.607 & 0.006 \\
\hline 121 & 3 & 1 & 3 & 1 & 0.630 & 0.005 & 0.510 & 0.005 & 0.505 & 0.005 & 0.505 & 0.005 & 0.496 & 0.006 & 0.579 & 0.012 \\
\hline Sum $^{\mathrm{c}}$ & 3 & 1 & 3 & $\frac{2}{1}$ & 0.629 & 0.004 & 0.504 & 0.003 & 0.502 & 0.004 & 0.511 & 0.003 & 0.504 & 0.004 & 0.605 & 0.005 \\
\hline 122 & 2 & 1 & 2 & 1 & 0.628 & 0.005 & 0.502 & 0.005 & 0.497 & 0.004 & 0.504 & 0.005 & 0.507 & 0.005 & 0.559 & 0.009 \\
\hline 123 & 2 & 1 & 2 & 1 & 0.635 & 0.003 & 0.487 & 0.005 & 0.487 & 0.005 & 0.511 & 0.005 & 0.515 & 0.005 & 0.588 & 0.009 \\
\hline Sum $^{\mathrm{c}}$ & 2 & 1 & 2 & 1 & 0.628 & 0.003 & 0.496 & 0.003 & 0.488 & 0.003 & 0.508 & 0.003 & 0.506 & 0.003 & 0.568 & 0.007 \\
\hline 124 & 2 & 2 & 2 & 2 & 0.631 & \begin{tabular}{|l}
0.003 \\
\end{tabular} & 0.512 & 0.002 & 0.512 & 0.002 & 0.511 & 0.002 & 0.510 & 0.002 & 0.585 & 0.003 \\
\hline 131 & 1 & 1 & 1 & 1 & 0.608 & \begin{tabular}{|l|l|} 
\\
\end{tabular} & 0.491 & 0.004 & 0.488 & 0.004 & 0.500 & 0.003 & 0.491 & 0.003 & 0.559 & 0.005 \\
\hline 133 & 1 & 3 & 1 & 3 & 0.630 & \begin{tabular}{|l|l}
0.004 \\
\end{tabular} & 0.510 & 0.003 & 0.507 & 0.002 & 0.522 & 0.003 & 0.509 & 0.002 & 0.615 & 0.007 \\
\hline 134 & 1 & 3 & 1 & 3 & 0.631 & \begin{tabular}{|l}
0.003 \\
\end{tabular} & 0.511 & 0.003 & 0.506 & 0.003 & 0.523 & 0.002 & 0.503 & 0.002 & 0.605 & 0.008 \\
\hline $145 a$ & 4 & 4 & 4 & 4 & 0.674 & \begin{tabular}{|l|l|} 
\\
\end{tabular} & 0.556 & 0.004 & 0.526 & 0.004 & 0.546 & 0.004 & 0.552 & 0.004 & 0.640 & 0.013 \\
\hline $145 b$ & 4 & 4 & $\overline{4}$ & 4 & 0.661 & \begin{tabular}{|l|l}
0.007 \\
\end{tabular} & 0.551 & 0.003 & 0.531 & 0.003 & 0.541 & 0.005 & 0.537 & 0.005 & 0.577 & 0.005 \\
\hline Sum $^{\mathrm{c}}$ & 4 & 4 & 4 & 4 & 0.673 & \begin{tabular}{|l|l|}
0.004 \\
\end{tabular} & 0.554 & 0.003 & 0.532 & 0.003 & 0.548 & 0.003 & 0.543 & 0.003 & 0.615 & 0.007 \\
\hline
\end{tabular}

${ }^{\mathrm{a}}$ Low frequency average of spectral ratio.

${ }^{b}$ Standard deviation of the mean of the low frequency spectral ratio average.

${ }^{\mathrm{c}}$ Represents the sum of the spectral signatures of the two previous measurements. 


\begin{tabular}{|c|c|c|c|c|c|c|c|c|c|c|c|c|c|c|c|c|}
\hline \multicolumn{17}{|c|}{ Table 4.25 . (continued) } \\
\hline \multirow[b]{2}{*}{ No. } & \multicolumn{4}{|c|}{ Number of plates } & \multicolumn{2}{|c|}{ Ratio 23} & \multicolumn{2}{|c|}{ Ratio 24} & \multicolumn{2}{|c|}{ Ratio 25} & \multicolumn{2}{|c|}{ Ratio 34} & \multicolumn{2}{|c|}{ Ratio 35} & \multicolumn{2}{|c|}{ Ratio 45} \\
\hline & $\mathrm{N}$ & $E$ & $\mathrm{~S}$ & $\mathrm{~W}$ & $\mathrm{R}^{\mathrm{a}}$ & $\sigma^{b}$ & $\mathrm{R}$ & $\sigma$ & $\mathrm{R}$ & $\sigma$ & $\mathrm{R}$ & $\sigma$ & $\mathrm{R}$ & $\sigma$ & $\mathrm{R}$ & $\sigma$ \\
\hline $153 a$ & & 2 & & 2 & 0.606 & 0.005 & 0.490 & 0.004 & 0.498 & 0.004 & 0.501 & 0.003 & 0.490 & 0.003 & 0.563 & 0.005 \\
\hline $153 \mathrm{~b}$ & & 2 & & 2 & 0.614 & 0.004 & 0.487 & 0.004 & 0.488 & 0.003 & 0.502 & 0.004 & 0.495 & 0.004 & 0.575 & 0.005 \\
\hline Sum & & 2 & & 2 & 0.603 & 0.003 & 0.487 & 0.003 & 0.491 & 0.003 & 0.501 & 0.003 & 0.492 & 0.003 & 0.569 & 0.003 \\
\hline 155 & 1 & 2 & $\overline{1}$ & $\overline{2}$ & 0.610 & 0.005 & 0.501 & 0.004 & 0.506 & 0.004 & 0.507 & 0.003 & 0.510 & 0.003 & 0.608 & 0.009 \\
\hline 156 & 1 & 2 & 1 & 2 & 0.617 & 0.002 & 0.498 & 0.003 & 0.499 & 0.005 & 0.505 & 0.003 & 0.513 & 0.004 & 0.585 & 0.007 \\
\hline Sum $^{\mathrm{c}}$ & 1 & $\frac{2}{2}$ & 1 & 2 & 0.612 & 0.003 & 0.501 & 0.003 & 0.500 & 0.004 & 0.505 & 0.002 & 0.511 & 0.002 & 0.596 & 0.006 \\
\hline 157 & 3 & 2 & 3 & 2 & 0.640 & 0.005 & 0.508 & 0.004 & 0.510 & \begin{tabular}{|l|l}
0.004 \\
\end{tabular} & 0.516 & 0.003 & 0.520 & 0.005 & 0.601 & 0.008 \\
\hline 158 & 3 & 2 & 3 & 2 & 0.639 & 0.005 & 0.515 & 0.004 & 0.502 & 0.006 & 0.520 & \begin{tabular}{|l|l}
0.006 \\
\end{tabular} & 0.534 & \begin{tabular}{|l|l}
0.005 \\
\end{tabular} & 0.613 & 0.006 \\
\hline $159 \mathrm{a}$ & 2 & 3 & 2 & 3 & 0.646 & 0.005 & 0.524 & 0.004 & 0.514 & 0.006 & 0.525 & \begin{tabular}{|l|l|}
0.004 \\
\end{tabular} & 0.528 & \begin{tabular}{|l|l}
0.004 \\
\end{tabular} & 0.638 & 0.007 \\
\hline $159 \mathrm{~b}$ & 2 & 3 & 2 & 3 & 0.666 & 0.004 & 0.528 & 0.002 & 0.514 & 0.003 & 0.535 & 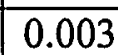 & 0.534 & \begin{tabular}{|l|l}
0.006 \\
\end{tabular} & 0.603 & 0.007 \\
\hline $159 \mathrm{c}$ & 2 & 3 & 2 & 3 & 0.662 & 0.004 & 0.529 & 0.004 & 0.522 & 0.004 & 0.527 & 0.003 & 0.536 & \begin{tabular}{|l|l|} 
\\
\end{tabular} & 0.601 & 0.005 \\
\hline Sum $^{\mathrm{d}}$ & 2 & 3 & 2 & 3 & 0.658 & 0.002 & 0.528 & 0.002 & 0.517 & 0.002 & 0.528 & 0.002 & 0.534 & 0.003 & 0.614 & 0.005 \\
\hline $166 a$ & 2 & 4 & 2 & 4 & 0.656 & 0.006 & 0.543 & 0.006 & 0.524 & 0.005 & 0.523 & 0.002 & 0.521 & 0.004 & 0.633 & 0.006 \\
\hline $166 \mathrm{~b}$ & 2 & 4 & 2 & 4 & 0.664 & 0.004 & 0.541 & 0.004 & 0.519 & 0.004 & 0.538 & 0.004 & 0.517 & 0.004 & 0.640 & 0.007 \\
\hline $166 c$ & 2 & 4 & 2 & $\overline{4}$ & 0.676 & 0.004 & 0.539 & 0.004 & 0.532 & 0.005 & 0.530 & 0.005 & 0.536 & \begin{tabular}{|l|}
0.005 \\
\end{tabular} & 0.590 & 0.006 \\
\hline $166 \mathrm{~d}$ & 2 & $\overline{4}$ & $\overline{2}$ & 4 & 0.645 & 0.007 & 0.543 & 0.004 & 0.527 & 0.004 & 0.551 & 0.005 & 0.540 & 0.004 & 0.624 & 0.019 \\
\hline Sum $^{\mathrm{e}}$ & 2 & 4 & 2 & 4 & \begin{tabular}{|l|l}
0.662 \\
\end{tabular} & 0.002 & 0.542 & 0.002 & 0.529 & 0.002 & 0.536 & 0.002 & 0.525 & \begin{tabular}{|l|l|}
0.003 \\
\end{tabular} & 0.623 & 0.007 \\
\hline
\end{tabular}

${ }^{a}$ Low frequency average of spectral ratio.

${ }^{b}$ Standard deviation of the mean of the low frequency spectral ratio average.

${ }^{c}$ Represents the sum of the spectral signatures of the two previous measurements.

${ }^{d}$ Represents the sum of the spectral signatures of the three previous measurements.

${ }^{\mathrm{e}}$ Represents the sum of the spectral signatures.of the four previous measurements. 
Table 4.25. (continued)

\begin{tabular}{|c|c|c|c|c|c|c|c|c|c|c|c|c|c|c|c|c|}
\hline \multicolumn{17}{|c|}{ Table 4.25. (continued) } \\
\hline No. & \multicolumn{4}{|c|}{ Number of plates } & \multicolumn{2}{|c|}{ Ratio 23} & \multicolumn{2}{|c|}{ Ratio 24} & \multicolumn{2}{|c|}{ Ratio 25} & \multicolumn{2}{|c|}{ Ratio 34} & \multicolumn{2}{|c|}{ Ratio 35} & \multicolumn{2}{|c|}{ Ratio 45} \\
\hline $167 \mathrm{a}$ & 4 & 4 & & & 0.606 & 0.004 & 0.518 & 0.003 & 0.485 & 0.002 & 0.514 & 0.003 & 0.488 & 0.003 & 0.581 & 0.005 \\
\hline $167 \mathrm{c}$ & 4 & 4 & & & 0.621 & 0.003 & 0.512 & 0.003 & 0.486 & 0.002 & 0.520 & 0.003 & 0.488 & 0.003 & 0.585 & 0.003 \\
\hline $167 d$ & 4 & 4 & & & 0.610 & 0.003 & 0.519 & 0.002 & 0.485 & 0.002 & 0.519 & 0.002 & 0.487 & 0.002 & 0.589 & 0.004 \\
\hline $167 \mathrm{e}$ & 4 & 4 & & & 0.617 & 0.003 & 0.516 & 0.003 & 0.486 & 0.002 & 0.514 & 0.002 & 0.483 & 0.002 & 0.602 & 0.006 \\
\hline $167 \mathrm{~g}$ & 4 & 4 & & & 0.620 & 0.003 & 0.515 & 0.002 & 0.489 & 0.003 & 0.514 & 0.003 & 0.486 & 0.002 & 0.571 & 0.003 \\
\hline $167 \mathrm{i}$ & 4 & 4 & & & 0.617 & 0.003 & 0.510 & 0.003 & 0.489 & 0.003 & 0.510 & 0.003 & 0.479 & 0.002 & 0.566 & 0.006 \\
\hline Sum $^{c}$ & 4 & 4 & & & 0.618 & 0.002 & 0.516 & 0.001 & 0.487 & 0.001 & 0.513 & 0.001 & 0.485 & 0.001 & 0.584 & 0.002 \\
\hline $168 \mathrm{a}$ & 1 & 4 & & & 0.606 & 0.004 & 0.519 & 0.004 & 0.477 & 0.003 & 0.514 & 0.005 & 0.474 & 0.002 & 0.581 & 0.008 \\
\hline $168 \mathrm{~b}$ & 1 & 4 & & & 0.601 & 0.004 & 0.512 & 0.004 & 0.473 & 0.002 & 0.505 & 0.003 & 0.481 & 0.004 & 0.548 & 0.008 \\
\hline Sum $^{d}$ & 1 & 4 & & & 0.600 & 0.003 & 0.517 & 0.003 & 0.471 & 0.002 & 0.507 & 0.002 & 0.478 & 0.003 & 0.570 & 0.005 \\
\hline $170 \mathrm{a}$ & 2 & 2 & & & 0.582 & 0.003 & 0.506 & 0.003 & 0.475 & 0.003 & 0.493 & 0.003 & 0.478 & 0.002 & 0.553 & 0.005 \\
\hline $170 \mathrm{~b}$ & 2 & 2 & & & 0.581 & 0.007 & 0.492 & 0.004 & 0.463 & 0.004 & 0.493 & 0.003 & 0.470 & 0.004 & 0.538 & 0.007 \\
\hline Sum $^{\mathrm{d}}$ & 2 & 2 & & & 0.581 & 0.004 & 0.499 & 0.002 & 0.469 & 0.002 & 0.493 & 0.002 & 0.479 & 0.002 & 0.544 & 0.004 \\
\hline
\end{tabular}

${ }^{\mathrm{a}}$ Low frequency average of spectral ratio.

${ }^{b}$ Standard deviation of the mean of the low frequency spectral ratio average.

${ }^{c}$ Represents the sum of the spectral signatures of the eight previous measurements.

${ }^{d}$ Represents the sum of the spectral signatures of the two previous measurements. 


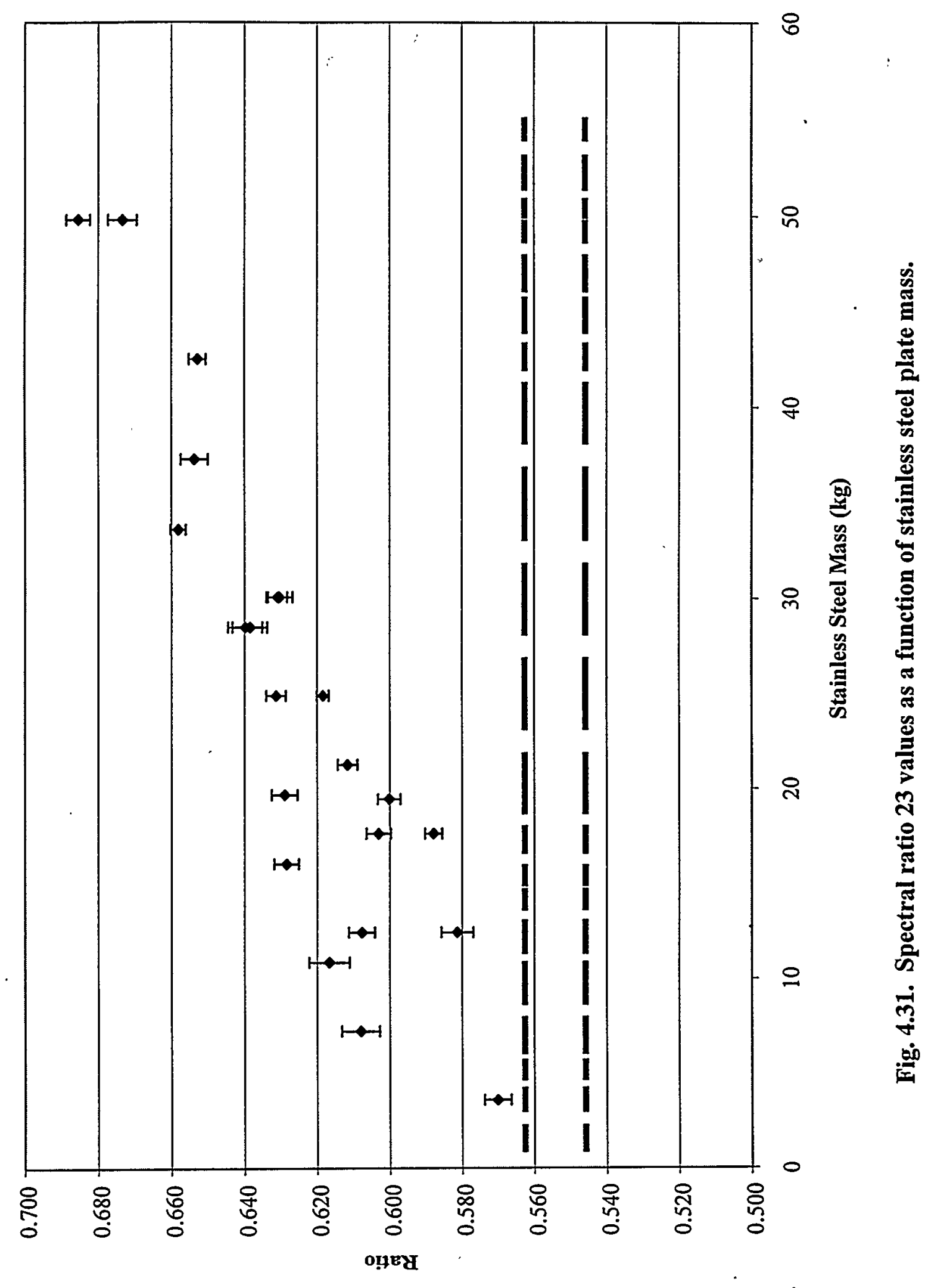




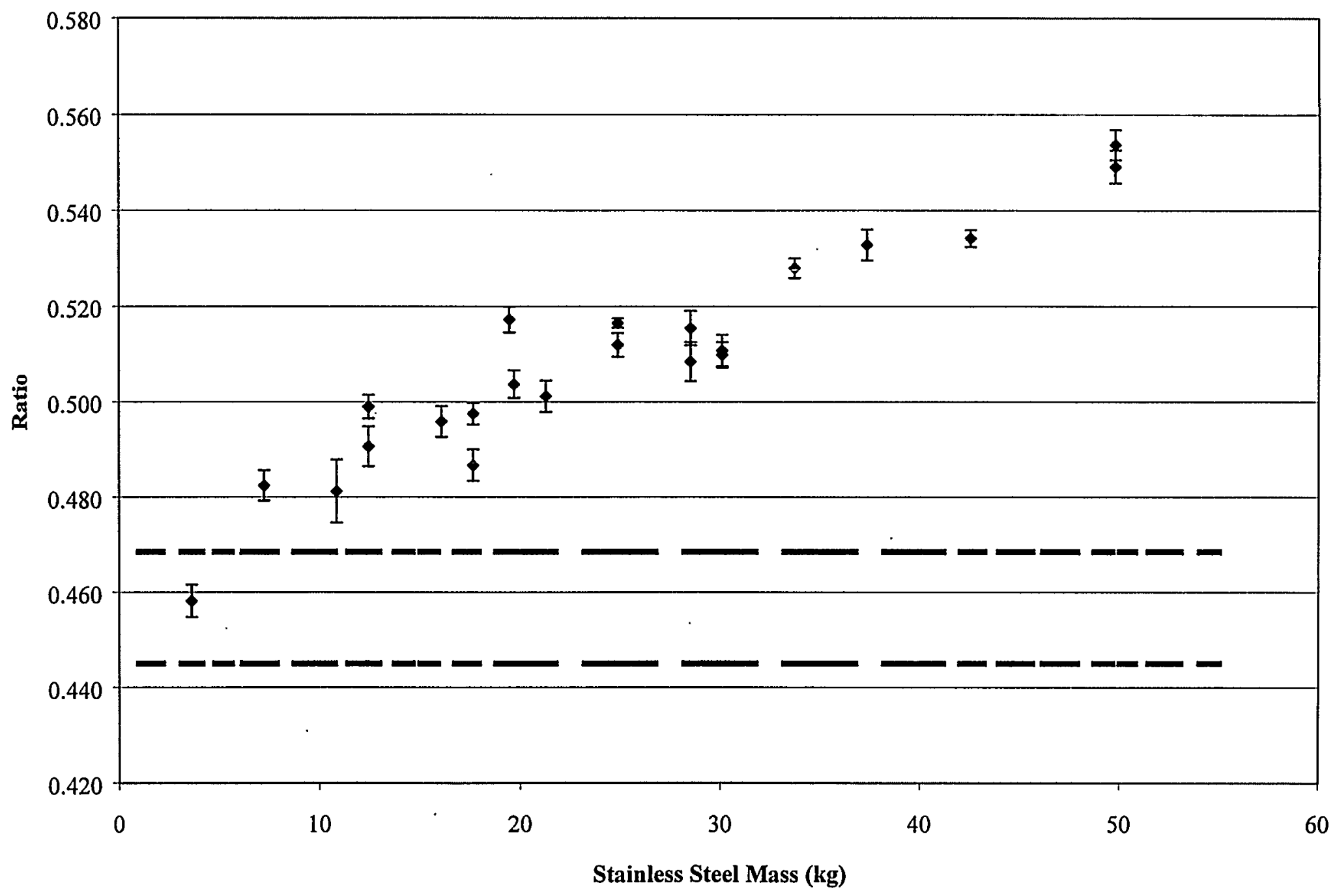

Fig. 4.32. Spectral ratio 24 values as a function of stainless steel plate mass. 


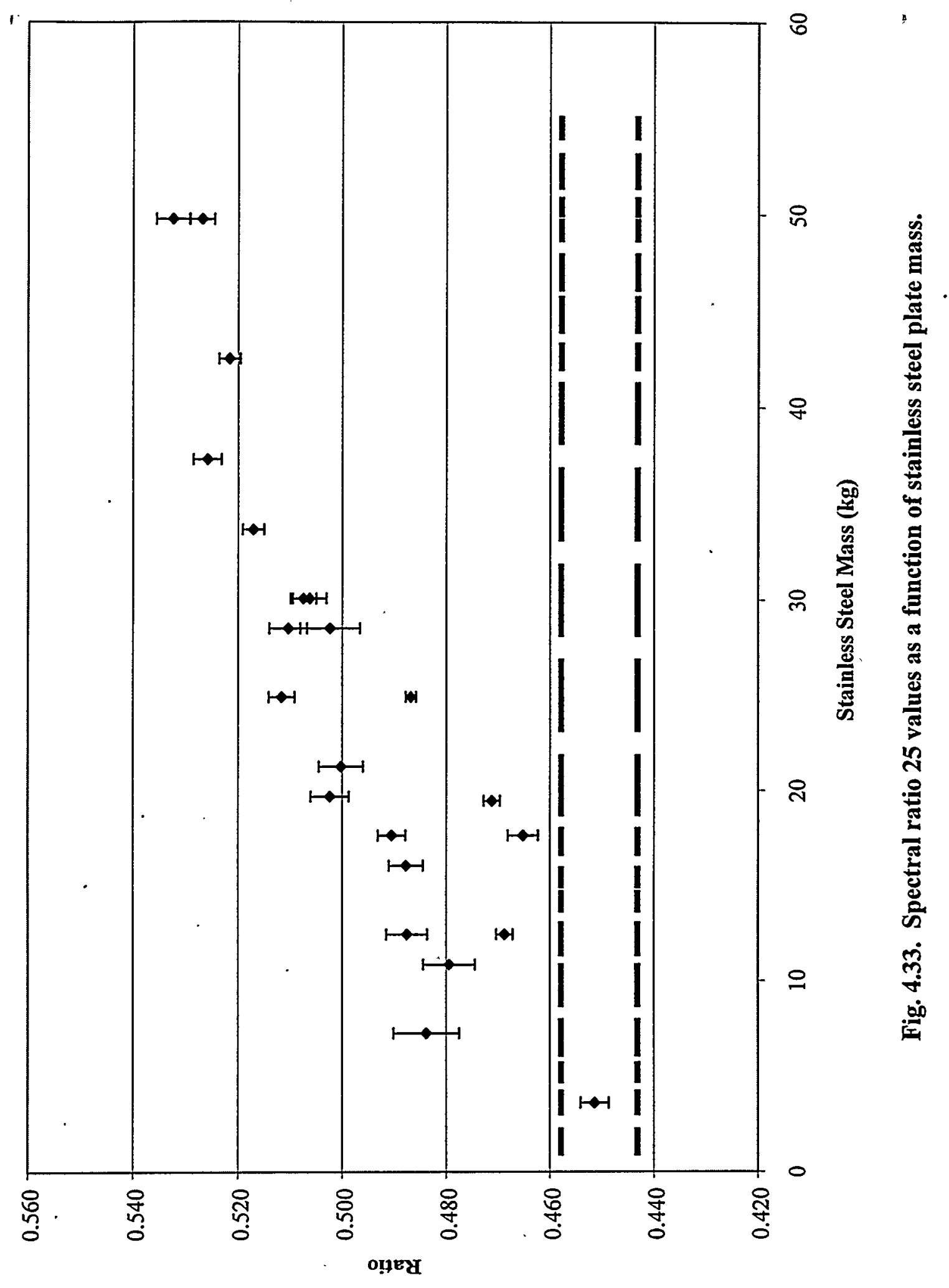




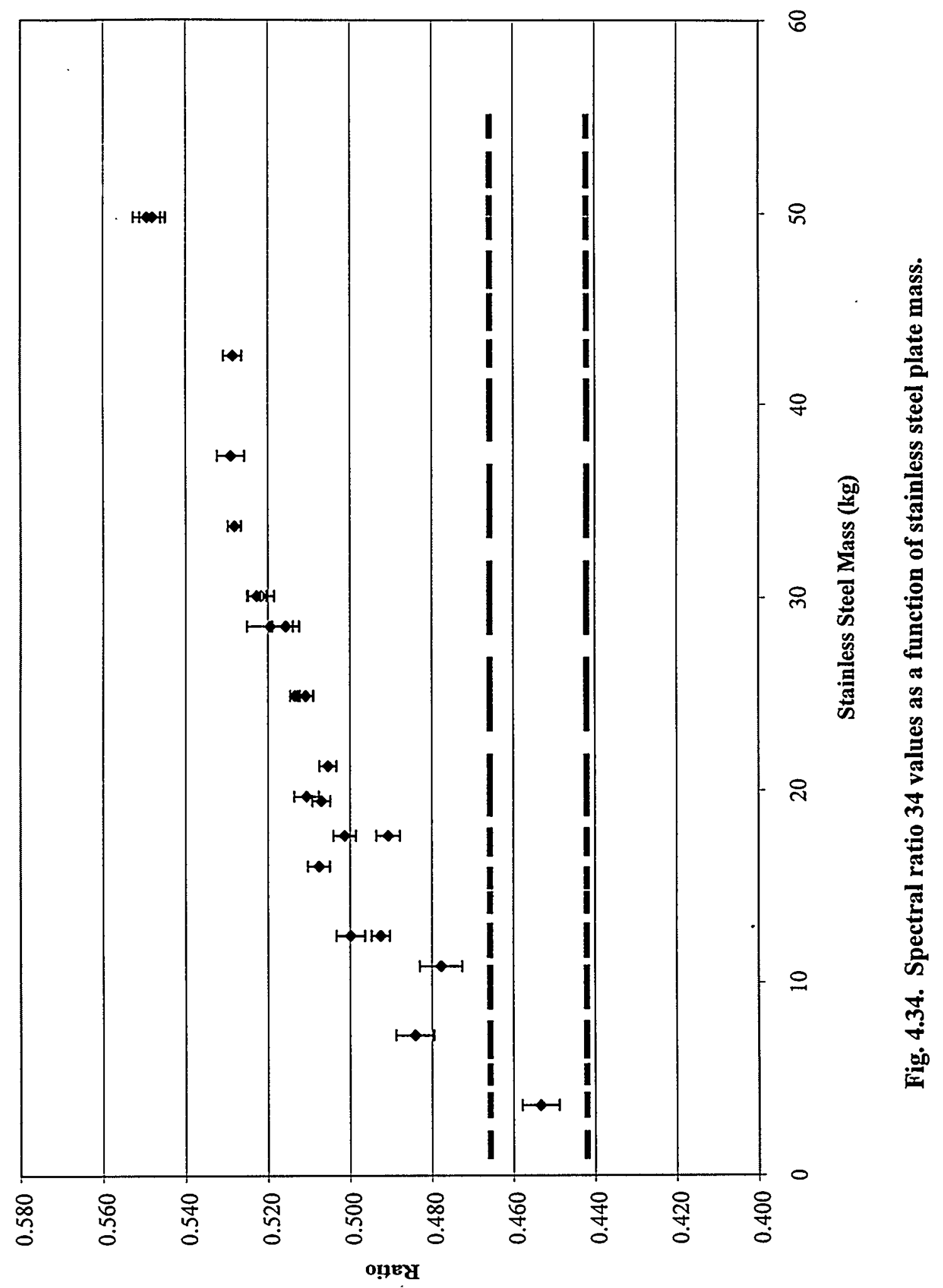




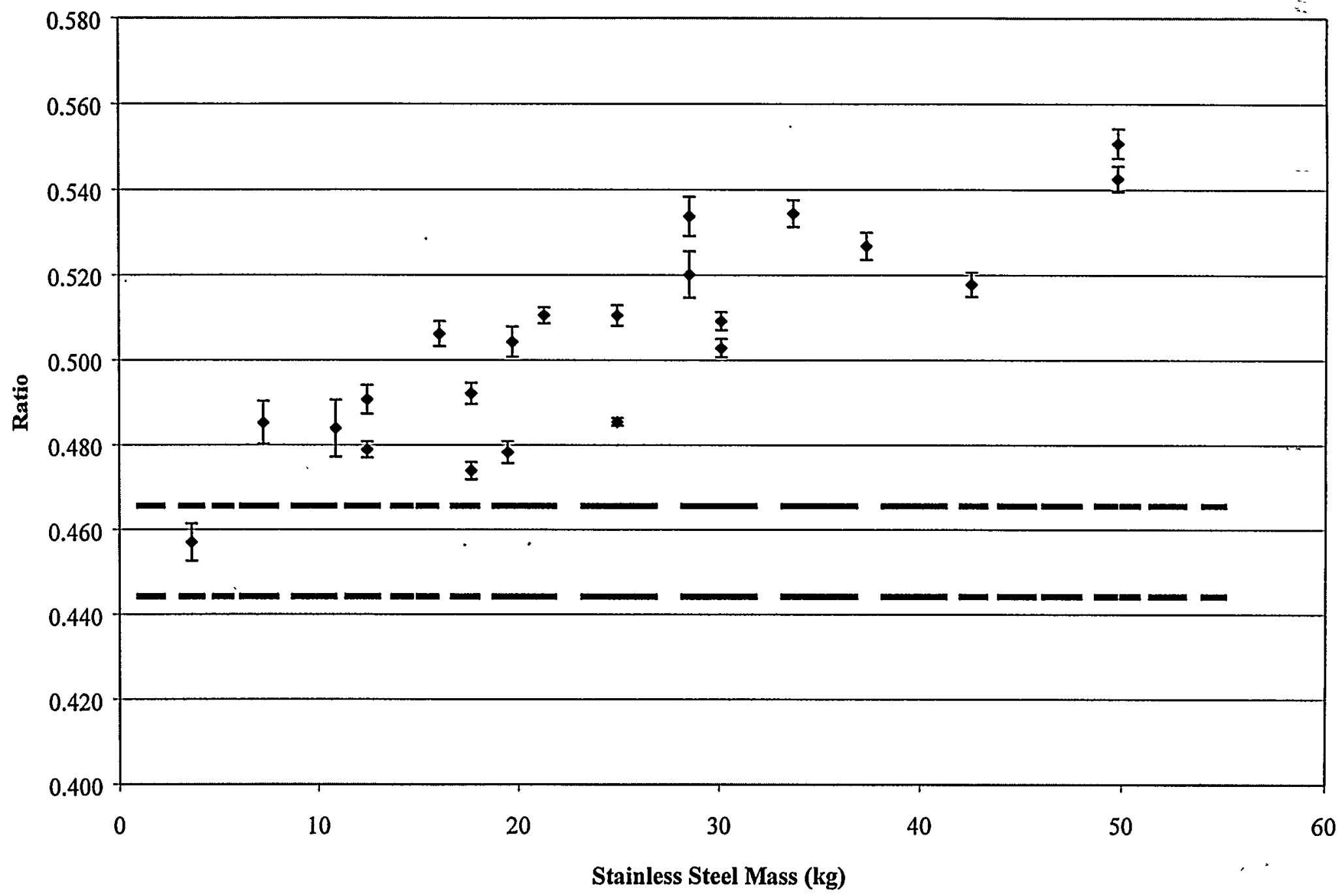

Fig. 4.35. Spectral ratio 35 values as a function of stainless steel plate mass. 


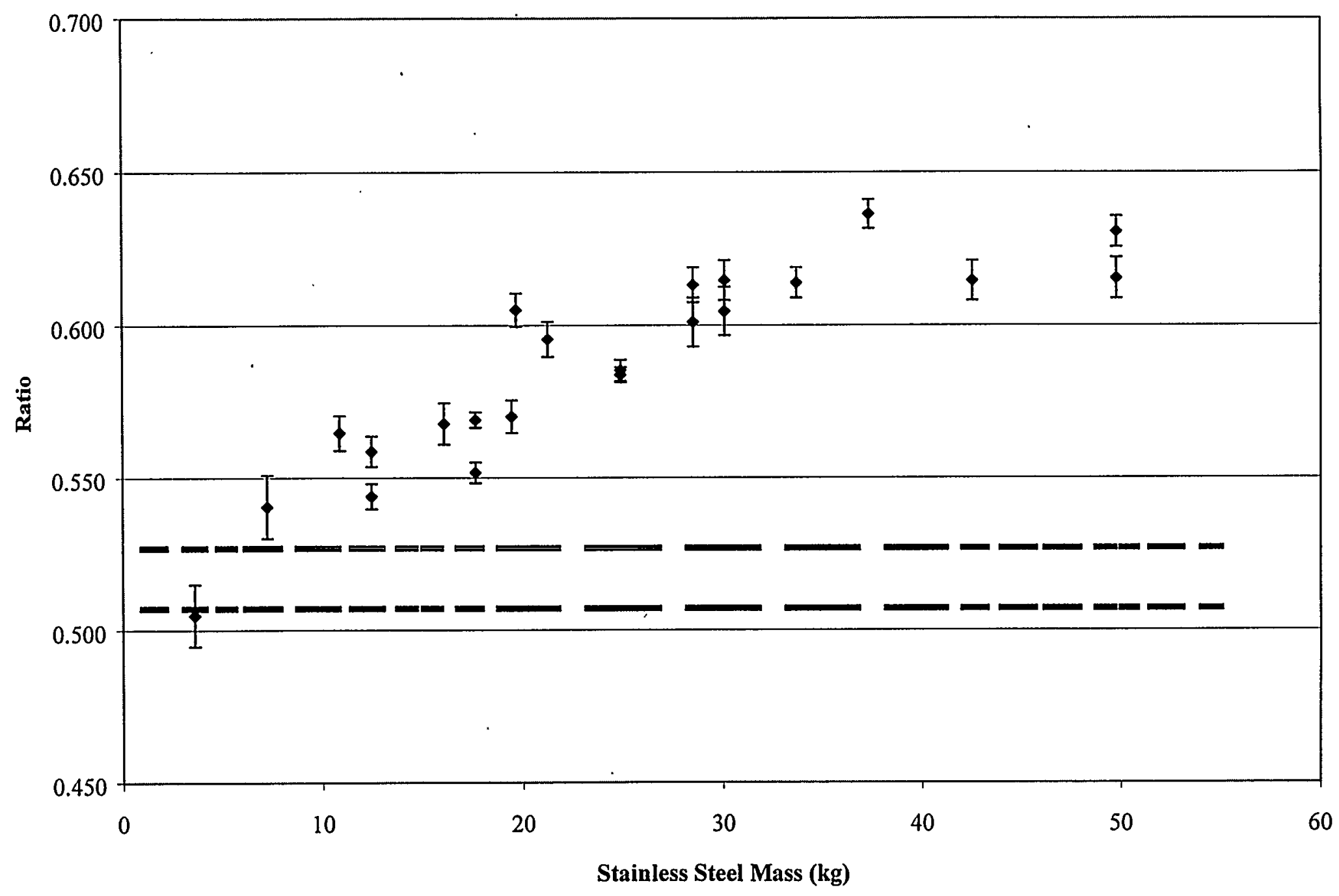

Fig. 4.36. Spectral ratio 45 values as a function of stainless steel plate mass. 
Spectral ratio 23 was most affected by addition of plates in the north and south positions with no plates in the east and west positions. Spectral ratio 23 changed from 0.57 to 0.62 for one to three plates in the north and south positions. Spectral ratio 45 changed from 0.51 to 0.57 for one to three plates in the north and south positions. The change in these spectral ratios occurred because the fuel elements in the north and south positions became more isolated from those in the east and west positions.

The magnitude of the change that was created when plates were added depends on the total number of plates in the system. Consider measurements in which one plate was in the east and west positions. The spectral ratio values $24,25,34$, and 35 statistically did not change when one, two, or three plates were placed in the north and south positions. The spectral value ratios $24,25,34$, and 35 varied only a few percent. The changes in spectral ratio 23 were quite small compared to the changes in spectral ratio 45 . Spectral ratio 23 changed from 0.61 to 0.63 for the addition of one to three plates in the north and south positions while the spectral ratio 45 changed from 0.56 to 0.61 . Plates in the east and west positions had a greater effect on the spectral ratio values, and this was to be expected because of the size of these plates. The same behavior was evident for measurements with two plates in the east and west positions with varying numbers of plates in the north and south positions.

Measurements were performed in which plates were placed in asymmetric positions in the system. These included measurements with four plates in the east position and varying number of plates in the north position (measurements 167,168 , and 169). The spectral ratio values involving detector 2 (north position) increased as the number of plates in the north position increased. Spectral ratio 23 values were $0.588 \pm 0.002,0.600$ \pm 0.003 , and $0.618 \pm 0.002$ for 0,1 , and 4 plates in the north position, respectively. The change in spectral ratio 45 was less significant because plates were only added to the north position. The spectral ratio values $24,25,34$, and 35 are non-symmetric because the plates were not symmetric. In general, the spectral ratio values increased the most as the number of plates in the system increased. As expected, the plates in the east and west positions had the greatest affect on the spectral ratios because of the size of these plates. Symmetric configurations of plates 'produced consistent results for symmetric combinations of detectors and the results of the asymmetric configurations also produced consistent results. Symmetric configurations of $1,2,3$, and 4 plates in all positions changed the spectral ratio 23 values $10 \%, 14 \%, 18 \%$, and $24 \%$, respectively with respect to the reference measurements without plates. These results indicate the change in the system reactivity because the spectral ratio is proportional to reactivity. 


\subsection{BORAL PLATE MEASUREMENTS}

This section presents the results of measurements in which BORAL plates were positioned between the fuel elements. The BORAL plates were 0.075 -inch thick. The plates all had the same lengths ( 48 inches) but had different widths. The plates positioned in the north and south position had the same width (4 7/8 inches), and those positioned in the east and west positions had the same width (11 7/8 inches). The spectral ratio values obtained from these measurements are presented as a function of the number of plates in Table 4.26. Some of the individual measurements were simply statistical repeats in which a second set of data was obtained prior to changing the experimental assembly. These statistical repeat measurements were combined together and are also presented in Table 4.26 .

The data presented in Table 4.26 are plotted as a function of the BORAL plate mass in Figs. 4.37 to 4.42 . The sums of statistical measurements were plotted as a function of the BORAL mass. The dashed lines indicate the one standard deviation spread of the reference measurements. As expected, the spectral ratio values changed significantly with the addition of the BORAL plates. These plates were strong absorbers that limited the interaction between fuel elements and reduced the overall reactivity of the system. When analyzing the results of the measurements it was important to not only consider the total mass of the absorber but also its location.

The position of the BORAL plates affected the six spectral ratio values differently. Symmetric placement of the BORAL plates produced spectral ratio values that were symmetric. Symmetric measurements with one BORAL plate in both the east and west positions produced symmetric spectral ratio values for combinations involving detectors 4 and 5 . The spectral ratio values $24,25,34$, and 35 were statistically the same and range from 0.578 to 0.585 . These values were well within the repeatability of the measurements and were considered the same. Likewise, symmetric measurements with one BORAL plate in both the north and south positions produced symmetric spectral ratio values for ratio combinations involving detectors 2 and 3. Additionally, measurements with one BORAL plate in all positions produce symmetric results. The spectral ratio values 24,25 , 34 , and 35 are within two percent of each other. The BORAL plates drastically changed the coupling between the fuel elements.

The results of measurements with plates positioned asymmetrically in the system produced expected results. Consider the sum of measurements 151a through 151d in which the BORAL plate was placed in the west position. Recalling that detectors 3, 4, and 5 are in the south, east, and west positions respectively, notice that the spectral ratio 34 was not changed as significantly as the spectral ratio 35 . The BORAL plate greatly affected ratio 35 because it limits the interactions between the south and west elements but only slightly affected the interaction between the south and east elements. The spectral ratio 34 value for this measurement was greater than the spectral ratio 34 for the reference measurement because of the coupling between all of the elements. The results for spectral ratio 24 were consistent with that for spectral ratio 34 , and likewise, the spectral ratio 25 was essentially the same as spectral ratio 35 for this measurement with a 
single BORAL plate in the west position. The measurements with one BORAL plate in the north position produced expected results. The spectral ratios 24 and 25 were within one percent of each other and the spectral ratios 34 and 35 were also within one percent of each other.

The BORAL plate measurements demonstrated how effective boron was in isolating the fuel elements from each other. The addition of a small BORAL plate drastically changed the spectral ratio values because the interaction between elements was dramatically affected. The impact of the BORAL plates depended on the number of plates and on the location of the plates. The addition of a large plate was more important than the addition of a small plate because of the additional amount of boron in the large plates. The change in the spectral ratio and hence the change in the reactivity ranged from $11 \%$ to $48 \%$. The $11 \%$ change occurred for a single BORAL plate in the north position, and the $48 \%$ change occurred when all four BORAL plates were placed in the assembly. 
Table 4.26. Measured spectral ratio values with varying number of BORAL plates between the fuel elements

\begin{tabular}{|c|c|c|c|c|c|c|c|c|c|c|c|c|c|c|c|c|}
\hline \multirow[b]{2}{*}{ No. } & \multicolumn{4}{|c|}{ Number of plates } & \multicolumn{2}{|c|}{ Ratio 23} & \multicolumn{2}{|c|}{ Ratio 24} & \multicolumn{2}{|c|}{ Ratio 25} & \multicolumn{2}{|c|}{ Ratio 34} & \multicolumn{2}{|c|}{ Ratio 35} & \multicolumn{2}{|c|}{ Ratio 45} \\
\hline & $\mathrm{N}$ & $\mathrm{E}$ & $\mathrm{S}$ & W & $\mathrm{R}^{\mathrm{a}}$ & $\sigma^{b}$ & $\mathrm{R}$ & $\sigma$ & $\mathrm{R}$ & $\sigma$ & $\overline{\mathrm{R}}$ & $\sigma$ & $\mathrm{R}$ & $\sigma$ & $\mathrm{R}$ & $\sigma$ \\
\hline 125 & 1 & 1 & 1 & 1 & 0.822 & 0.007 & 0.637 & 0.005 & 0.635 & 0.005 & 0.657 & 0.005 & 0.635 & 0.007 & 0.782 & 0.011 \\
\hline 135 & 1 & 1 & 1 & 1 & 0.822 & 0.004 & 0.627 & 0.003 & 0.633 & 0.004 & 0.646 & 0.006 & 0.638 & 0.004 & 0.758 & 0.007 \\
\hline $136 a$ & 1 & & & & 0.621 & 0.005 & 0.512 & 0.004 & 0.502 & 0.003 & 0.487 & 0.002 & 0.476 & 0.003 & 0.584 & 0.006 \\
\hline $136 \mathrm{~b}$ & 1 & & & & 0.617 & 0.004 & 0.519 & 0.004 & 0.505 & 0.004 & 0.494 & 0.004 & 0.480 & 0.004 & 0.574 & 0.010 \\
\hline Sum $^{c}$ & 1 & & & & 0.619 & 0.004 & 0.512 & 0.003 & 0.503 & 0.002 & 0.488 & 0.002 & 0.478 & 0.003 & 0.576 & 0.006 \\
\hline $146 \mathrm{a}$ & 1 & 1 & & 1 & 0.755 & 0.004 & 0.623 & 0.004 & 0.620 & 0.005 & 0.592 & 0.003 & 0.603 & 0.004 & 0.702 & 0.024 \\
\hline $146 b$ & 1 & 1 & & 1 & 0.765 & 0.007 & 0.616 & 0.008 & 0.614 & 0.009 & 0.577 & 0.007 & 0.598 & 0.005 & 0.765 & 0.019 \\
\hline $146 c$ & 1 & 1 & & 1 & 0.762 & 0.005 & 0.620 & 0.006 & 0.626 & 0.004 & 0.599 & 0.004 & 0.601 & 0.004 & 0.714 & 0.007 \\
\hline $146 \mathrm{~d}$ & 1 & 1 & & 1 & 0.761 & 0.007 & 0.610 & 0.007 & 0.616 & 0.006 & 0.607 & 0.006 & 0.600 & 0.005 & 0.743 & 0.010 \\
\hline Sum $^{d}$ & 1 & 1 & & 1 & 0.762 & 0.001 & 0.609 & 0.006 & 0.613 & 0.004 & 0.595 & 0.002 & 0.597 & 0.003 & 0.739 & 0.007 \\
\hline 147 & 1 & & 1 & & 0.702 & 0.005 & 0.530 & 0.004 & 0.522 & 0.003 & 0.545 & 0.005 & 0.537 & 0.003 & 0.657 & 0.009 \\
\hline 148 & 1 & & 1 & 1 & 0.753 & 0.006 & 0.546 & 0.005 & 0.590 & 0.013 & 0.560 & 0.006 & 0.634 & 0.010 & 0.690 & 0.018 \\
\hline $149 a$ & 1 & & 1 & 1 & 0.746 & 0.007 & 0.540 & 0.003 & 0.616 & 0.006 & 0.555 & 0.004 & 0.633 & 0.005 & 0.730 & 0.022 \\
\hline $149 b$ & 1 & & 1 & 1 & 0.770 & 0.009 & 0.556 & 0.004 & 0.576 & 0.004 & 0.548 & 0.004 & 0.631 & 0.006 & 0.692 & 0.011 \\
\hline $149 c$ & 1 & & 1 & 1 & 0.735 & 0.007 & 0.549 & 0.005 & 0.607 & 0.008 & 0.554 & 0.004 & 0.661 & 0.010 & 0.651 & 0.014 \\
\hline $149 d$ & 1 & & 1 & 1 & 0.757 & 0.007 & 0.548 & 0.006 & 0.581 & 0.011 & 0.545 & 0.002 & 0.594 & 0.006 & 0.707 & 0.016 \\
\hline Sum & 1 & & 1 & 1 & 0.752 & 0.005 & 0.544 & 0.004 & 0.607 & 0.004 & 0.555 & 0.003 & 0.633 & 0.005 & 0.696 & 0.009 \\
\hline $150 a$ & 1 & & & 1 & 0.714 & 0.005 & 0.538 & 0.006 & 0.581 & 0.005 & 0.498 & 0.006 & 0.577 & 0.005 & 0.709 & 0.014 \\
\hline $150 \mathrm{~b}$ & 1 & & & 1 & 0.707 & 0.005 & 0.536 & 0.005 & 0.597 & 0.007 & 0.505 & 0.003 & 0.575 & 0.005 & 0.641 & 0.009 \\
\hline $150 \mathrm{c}$ & 1 & & & 1 & 0.703 & 0.008 & 0.536 & 0.004 & 0.611 & 0.005 & 0.500 & 0.006 & 0.583 & 0.004 & 0.652 & 0.012 \\
\hline $150 \mathrm{~d}$ & 1 & & & 1 & 0.689 & 0.014 & 0.526 & 0.005 & 0.605 & 0.008 & 0.496 & 0.003 & 0.565 & 0.006 & 0.631 & 0.011 \\
\hline Sum $^{\mathrm{d}}$ & 1 & & & 1 & 0.707 & 0.003 & 0.530 & 0.003 & 0.597 & 0.003 & 0.497 & 0.002 & 0.576 & 0.003 & 0.661 & 0.006 \\
\hline
\end{tabular}

${ }^{a}$ Low frequency average of spectral ratio.

${ }^{b}$ Standard deviation of the mean of the low frequency spectral ratio average.

${ }^{c}$ Represents the summing of the spectral signatures of the two previous measurements.

${ }^{\mathrm{d}}$ Represents the summing of the spectral signatures of the four previous measurements. 
Table 4.26. (continued)

\begin{tabular}{|c|c|c|c|c|c|c|c|c|c|c|c|c|c|c|c|c|}
\hline \multicolumn{17}{|c|}{ Table 4.26. (continued) } \\
\hline \multirow[b]{2}{*}{ No. } & \multicolumn{4}{|c|}{ Number of plates } & \multicolumn{2}{|c|}{ Ratio 23} & \multicolumn{2}{|c|}{ Ratio 24} & \multicolumn{2}{|c|}{ Ratio 25} & \multicolumn{2}{|c|}{ Ratio 34} & \multicolumn{2}{|c|}{ Ratio 35} & \multicolumn{2}{|c|}{ Ratio 45} \\
\hline & $\mathrm{N}$ & $\mathrm{E}$ & $S$ & W & $\mathrm{R}^{\mathrm{a}}$ & $\sigma^{\mathrm{b}}$ & $\mathrm{R}$ & $\sigma$ & $\mathrm{R}$ & $\sigma$ & $\mathrm{R}$ & $\sigma$ & $\mathrm{R}$ & $\sigma$ & $\overline{\mathbf{R}}$ & $\sigma$ \\
\hline $151 \mathrm{a}$ & & & & 1 & 0.625 & 0.004 & 0.493 & 0.004 & 0.540 & 0.006 & 0.477 & 0.003 & 0.545 & 0.005 & 0.608 & 0.007 \\
\hline $151 b$ & & & & 1 & 0.617 & 0.005 & 0.478 & 0.003 & 0.542 & 0.008 & 0.486 & 0.005 & 0.545 & 0.005 & 0.606 & 0.009 \\
\hline $151 \mathrm{c}$ & & & & 1 & 0.624 & 0.003 & 0.480 & 0.005 & 0.527 & 0.006 & 0.474 & 0.003 & 0.561 & 0.006 & 0.589 & 0.007 \\
\hline $151 \mathrm{~d}$ & & & & 1 & 0.610 & 0.005 & 0.492 & 0.002 & 0.543 & 0.005 & 0.477 & 0.004 & 0.546 & 0.004 & 0.591 & 0.009 \\
\hline Sum $^{c}$ & & & & 1 & 0.631 & 0.003 & 0.484 & 0.001 & 0.540 & 0.003 & 0.480 & 0.002 & 0.547 & 0.003 & 0.598 & 0.004 \\
\hline $154 a$ & & 1 & & 1 & 0.716 & 0.007 & 0.575 & 0.005 & 0.583 & 0.006 & 0.582 & 0.004 & 0.592 & 0.006 & 0.685 & 0.007 \\
\hline $154 \mathrm{~b}$ & & 1 & & 1 & 0.706 & 0.004 & 0.579 & 0.004 & 0.573 & 0.005 & 0.580 & 0.006 & 0.579 & 0.005 & 0.667 & 0.011 \\
\hline $154 \mathrm{c}$ & & 1 & & 1 & 0.715 & 0.004 & 0.579 & 0.005 & 0.570 & 0.006 & 0.583 & 0.004 & 0.595 & 0.004 & 0.670 & 0.009 \\
\hline $154 \mathrm{~d}$ & & 1 & & 1 & 0.720 & 0.004 & 0.571 & 0.005 & 0.578 & 0.004 & 0.583 & 0.004 & 0.588 & 0.004 & 0.668 & 0.008 \\
\hline $154 \mathrm{e}$ & & 1 & & 1 & 0.713 & 0.005 & 0.565 & 0.006 & 0.580 & 0.004 & 0.579 & 0.003 & 0.582 & 0.003 & 0.671 & 0.012 \\
\hline $154 \mathrm{f}$ & & 1 & & 1 & 0.692 & 0.006 & 0.576 & 0.006 & 0.580 & 0.006 & 0.579 & 0.004 & 0.600 & 0.005 & 0.692 & 0.015 \\
\hline $154 \mathrm{~g}$ & & 1 & & 1 & 0.701 & 0.004 & 0.591 & 0.005 & 0.570 & 0.006 & 0.581 & 0.004 & 0.591 & 0.005 & 0.683 & 0.009 \\
\hline $154 \mathrm{~h}$ & & 1 & & 1 & 0.702 & 0.005 & 0.583 & 0.005 & 0.574 & 0.004 & 0.593 & 0.005 & 0.581 & 0.004 & 0.670 & 0.009 \\
\hline Sum $^{d}$ & & 1 & & 1 & 0.714 & 0.003 & 0.582 & 0.002 & 0.578 & 0.002 & 0.585 & 0.002 & 0.585 & 0.002 & 0.678 & 0.004 \\
\hline
\end{tabular}

${ }^{\mathrm{a}}$ Low frequency average of spectral ratio.

b Standard deviation of the mean of the low frequency spectral ratio average.

${ }^{c}$ Represents the sum of the spectral signatures of the four previous measurements.

d Represents the sum of the spectral signatures of the eight previous measurements. 


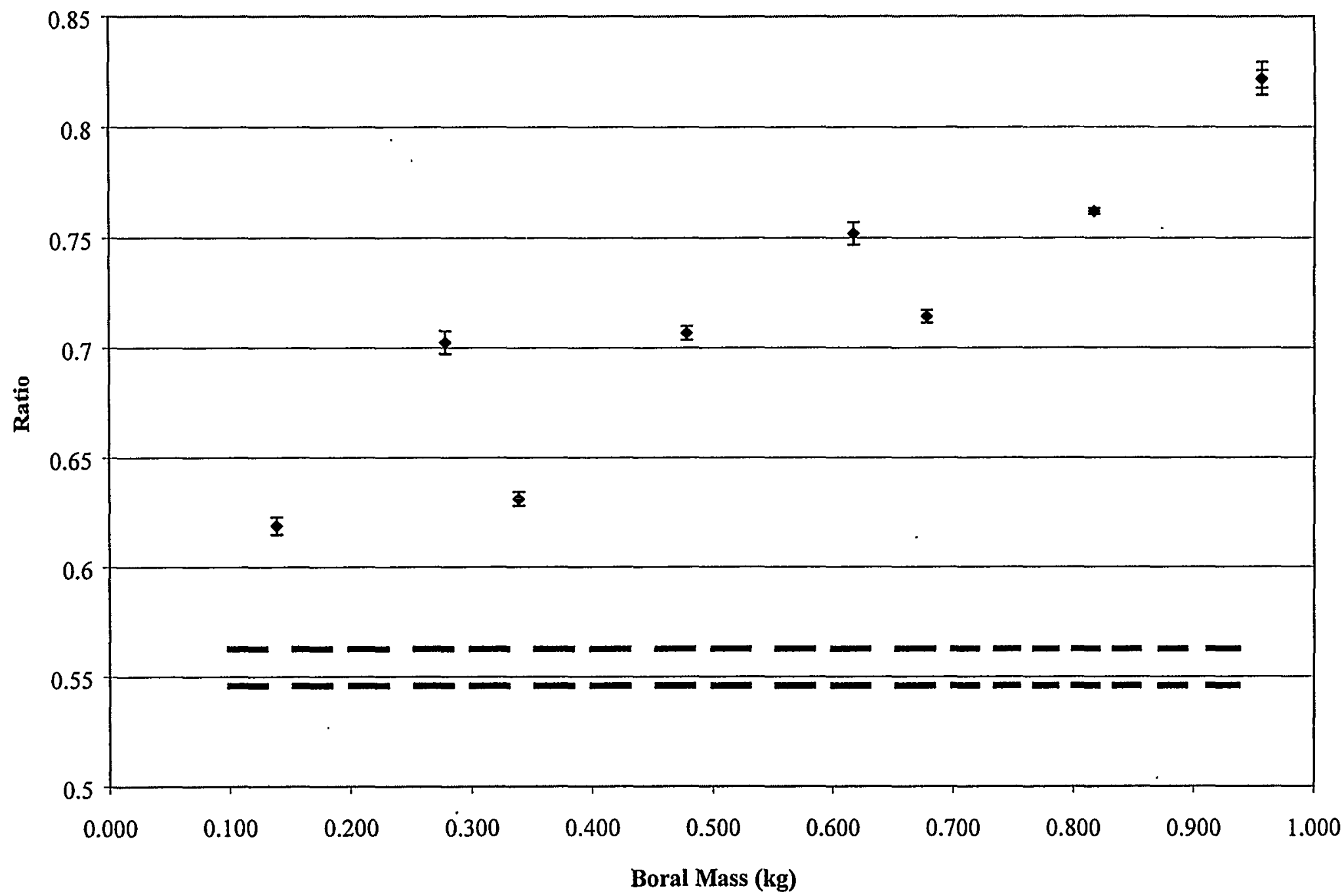

Fig. 4.37. Spectral ratio 23 values as a function of BORAL plate mass. 


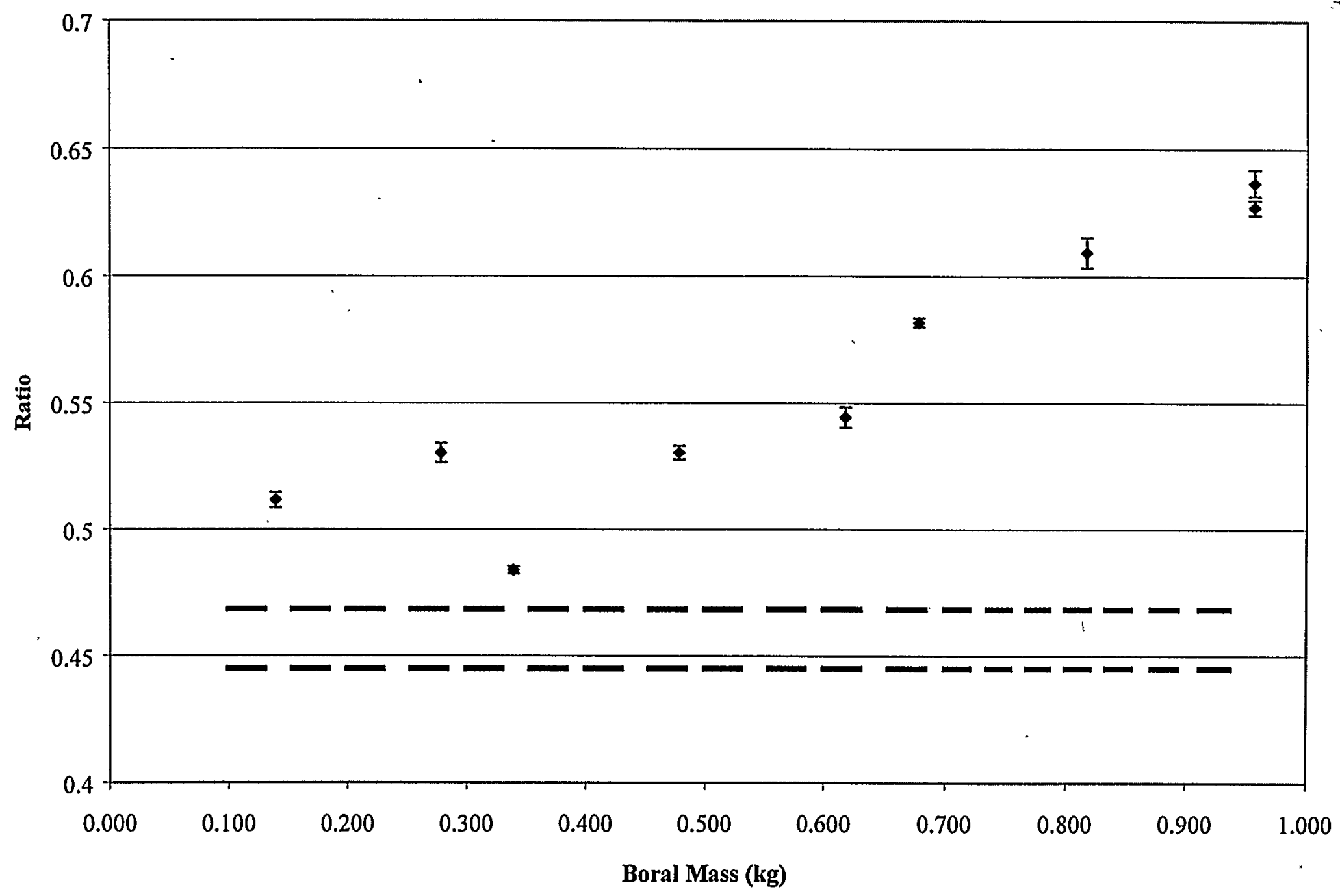

Fig. 4.38. Spectral ratio 24 values as a function of BORAL plate mass. 


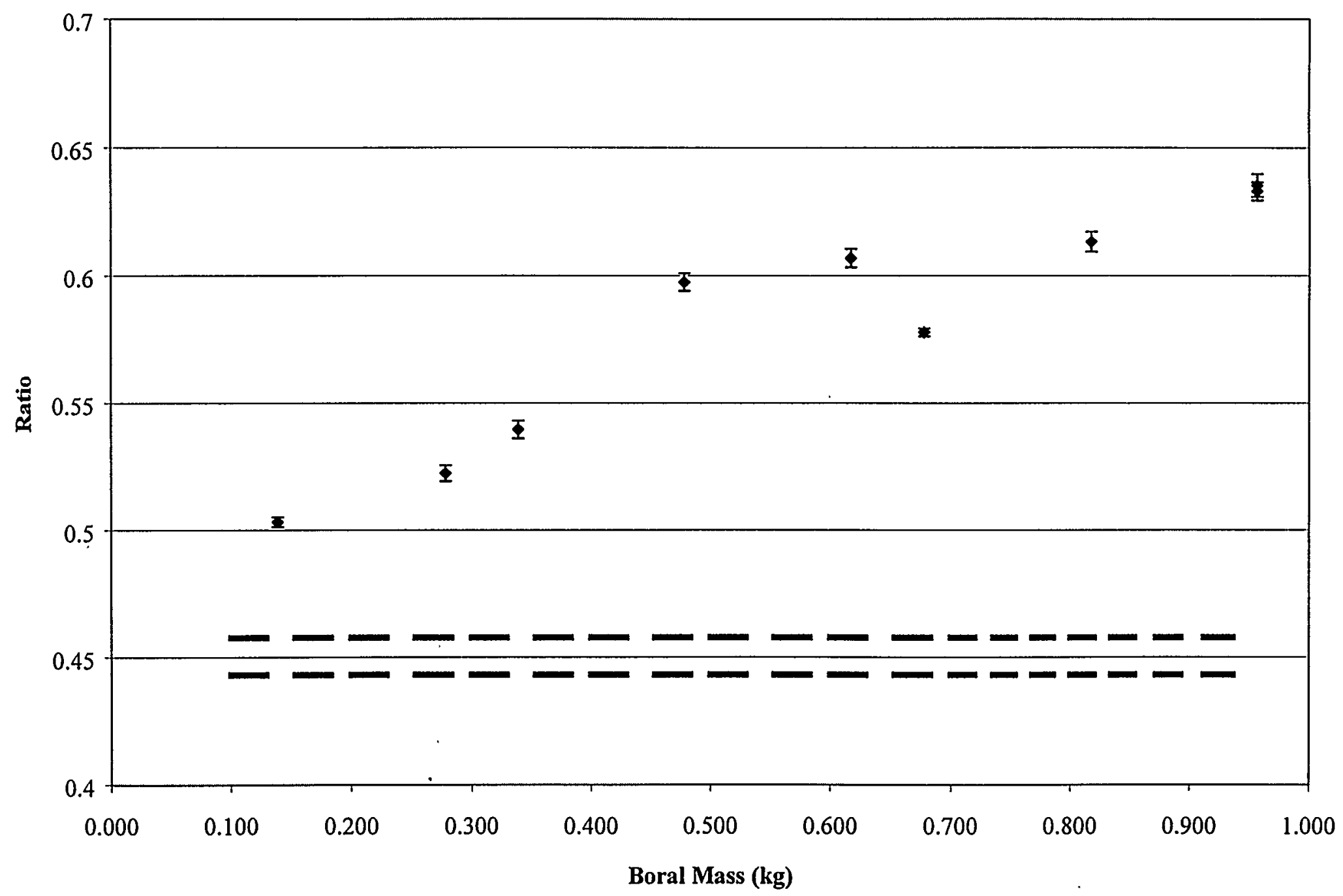

Fig. 4.39. Spectral ratio 25 values as a function of BORAL plate mass. 


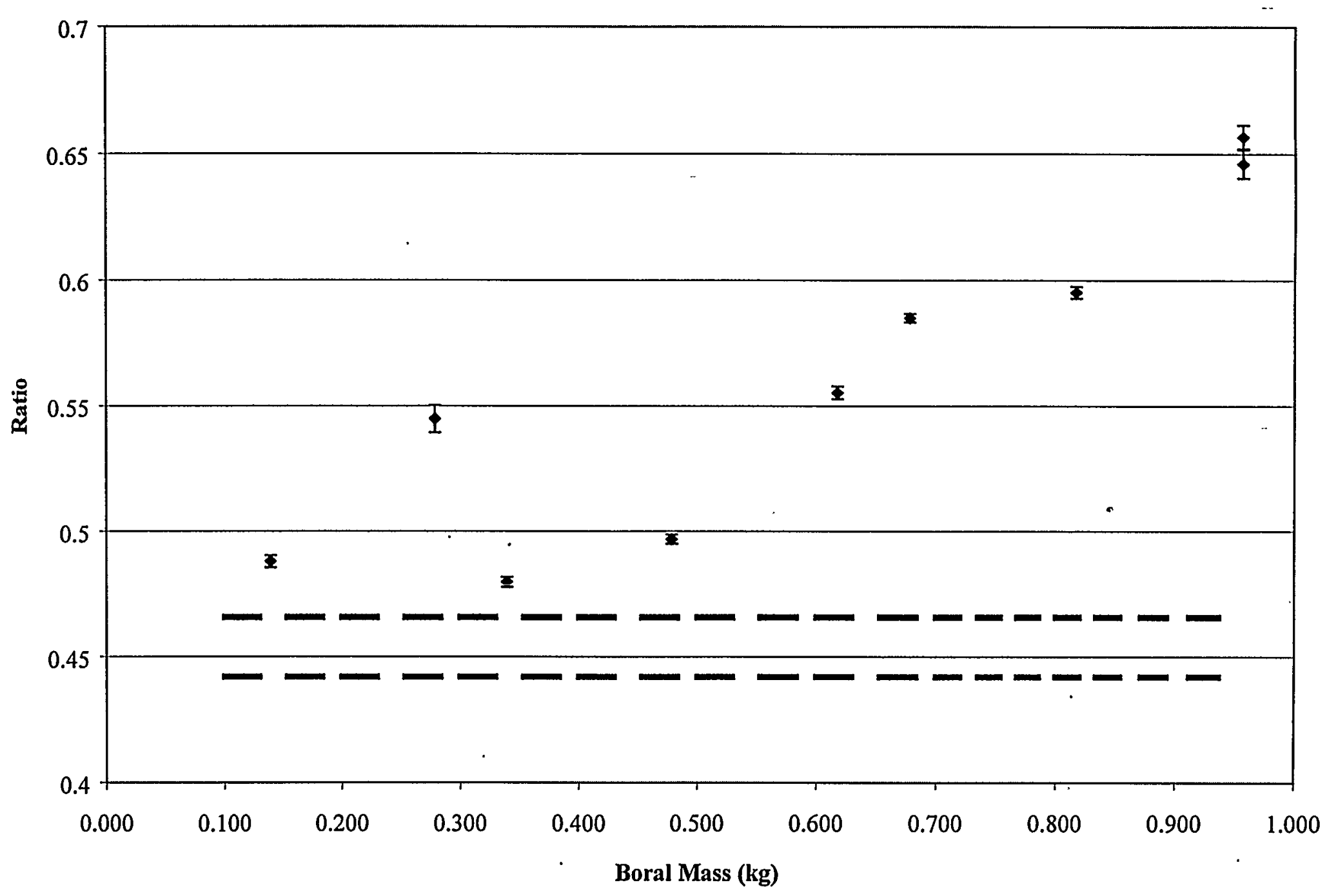

Fig. 4.40. Spectral ratio 34 values as a function of BORAL plate mass. 


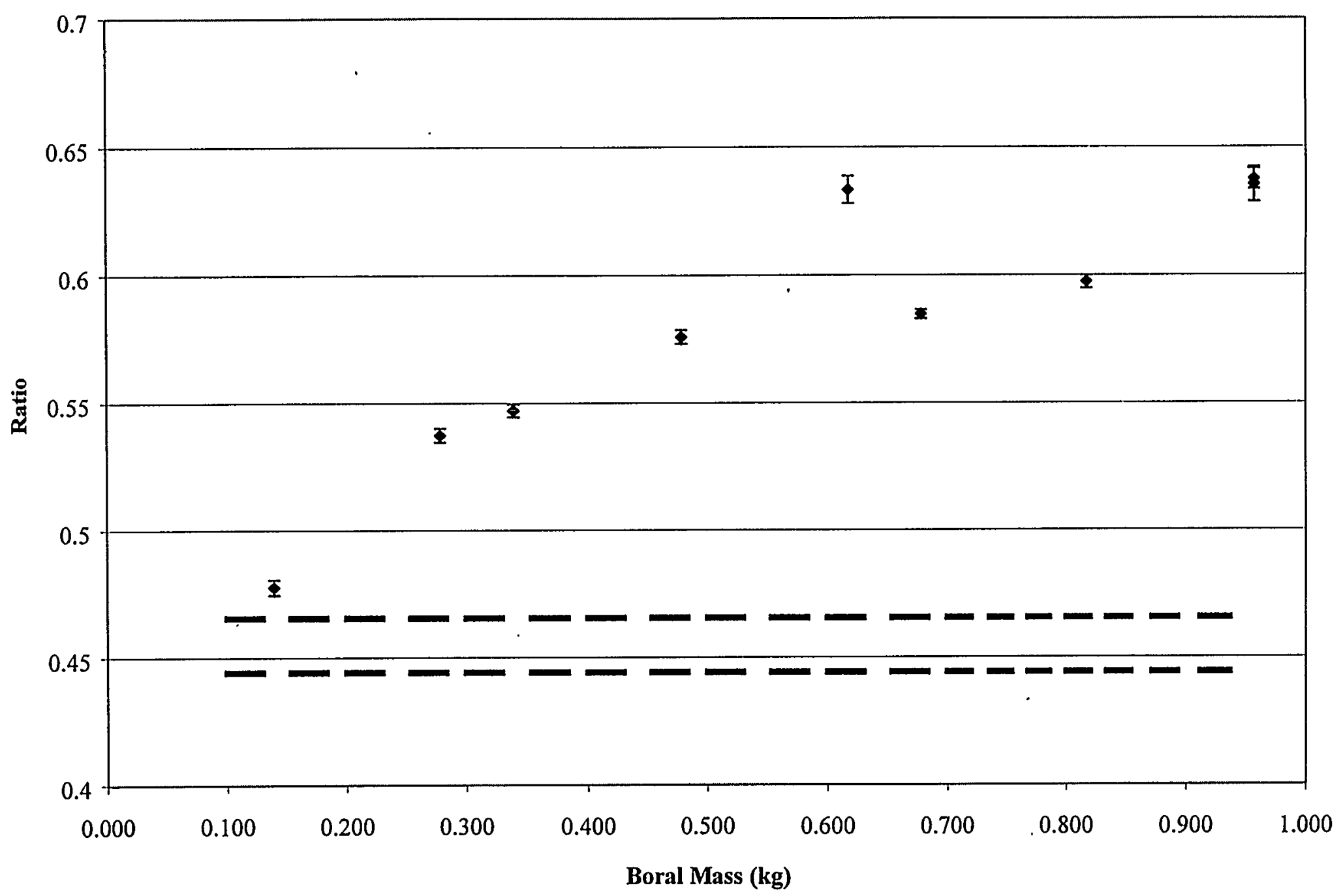

Fig. 4.41. Spectral ratio 35 values as a function of BORAL plate mass. 


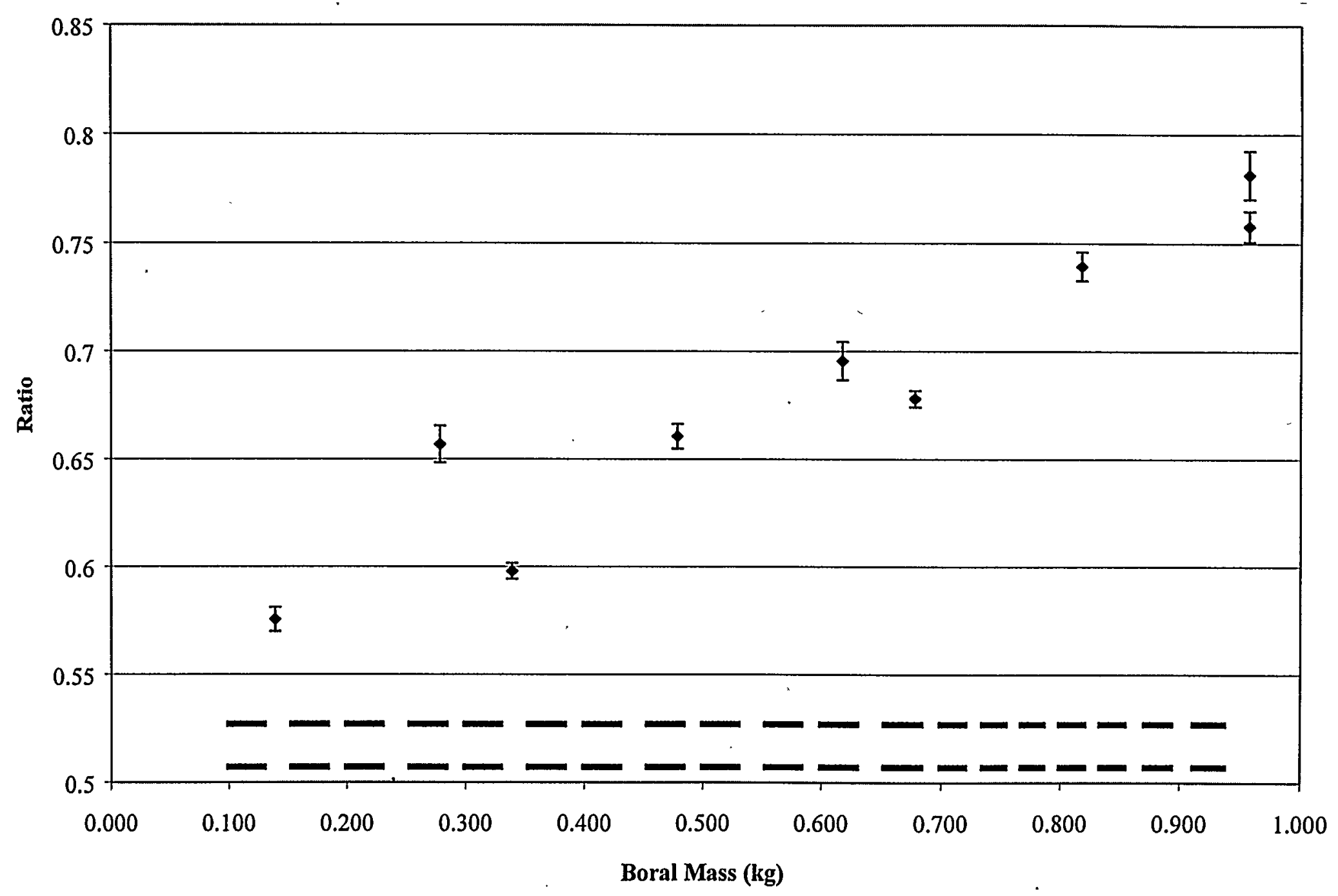

Fig. 4.42. Spectral ratio 45 values as a function of BORAL plate mass. 


\section{SPENT FUEL MEASUREMENTS}

Limited exploratory spent fuel measurements were performed in the MURR weir pool that was adjacent to the reactor pool. The experimental assembly was modified by replacing the 7-ft dry-wells with 18-ft dry-wells and lead plugs were used in place of the aluminum plugs in the bottom of the dry wells for additional shielding. As previously stated, 2.54-cm-thick lead shields were placed around the detectors on the exterior of the dry wells. The lead shields were encased in aluminum and were 24-in. long. In these measurements, the $1-\mathrm{atm}-{ }^{3} \mathrm{He}$ detectors in the east and west positions were input as channels 2 and 3 into the frequency analyzer. The detector in the south position was input as channel 4 into the frequency analyzer. Although the dry well was present, a detector was not placed in the north position because of the high gamma radiation field at this location. The orientation and configuration of the fuel elements for these measurements is given in Table 5.1 and a photograph of the assembly is given in Fig. 5.1.

\begin{tabular}{|c|c|c|c|c|}
\hline \multicolumn{5}{|c|}{ Table 5.1. Assembly configuration for spent fuel measurements } \\
\hline Parameter & North & East & South & West \\
\hline Fuel Orientation $^{2}$ & $\bar{A}$ & $\bar{B}$ & $\mathrm{~A}$ & B \\
\hline $\begin{array}{l}\text { Center-to-Fuel } \\
\text { Spacing }(\mathrm{cm})^{b}\end{array}$ & 6.745 & 8.109 & 6.712 & 8.299 \\
\hline $\begin{array}{l}\text { Detector-to-Fuel } \\
\text { Spacing }(\mathrm{cm})^{\mathrm{c}}\end{array}$ & 10.5 & 10.5 & 10.5 & 10.5 \\
\hline
\end{tabular}

${ }^{a}$ Orientation A corresponds to the small end of the fuel element closest to the center and orientation B corresponds to the large end of the fuel element closest to the center.

${ }^{\mathrm{b}}$ Spacing between fuel centerline and source dry well centerline.

${ }^{\mathrm{c}}$ Spacing between fuel element centerline and detector dry well centerline.

Measurements were performed with four fresh fuel elements, one spent and three fresh fuel elements, and two fresh and two spent fuel elements. The fuel element assembly identifiers for these measurements are provided in Table 5.2. Spent fuel elements MO-461 and MO-463 had an estimated burnup of 143 MWD with approximately 6 months of cooling time.

\begin{tabular}{|c|c|c|c|}
\hline \multicolumn{4}{|c|}{ Table 5.2. Fuel element identifiers for spent fuel measurements } \\
\hline $\begin{array}{c}\text { Fuel element } \\
\text { location }\end{array}$ & Four fresh & $\begin{array}{c}\text { Three fresh and } \\
\text { one spent }\end{array}$ & $\begin{array}{c}\text { Two fresh and } \\
\text { two spent }\end{array}$ \\
\hline North & MO-517 & MO-461 & MO-461 \\
\hline East & MO-519 & MO-519 & MO-519 \\
\hline South & MO-518 & MO-518 & MO-463 \\
\hline West & MO-520 & MO-520 & MO-520 \\
\hline
\end{tabular}




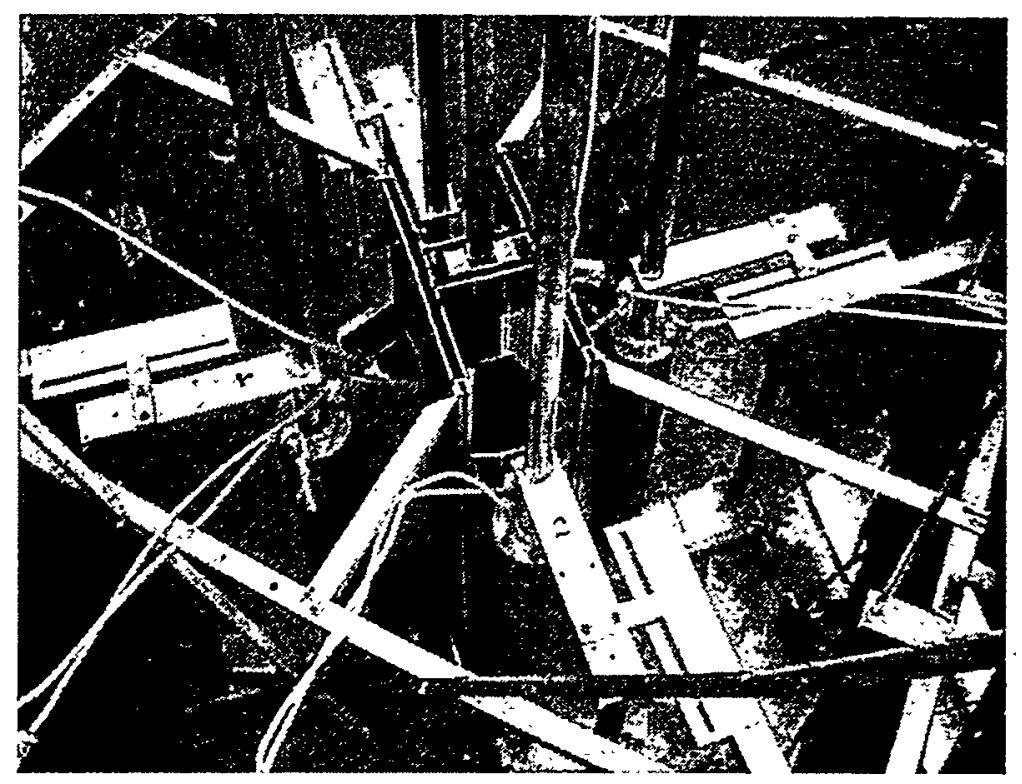

Fig. 5.1. Spent fuel measurement configuration.

The assembly was lowered into the weir pool using a crane whose hook and steel cables were between the detector dry wells. The hook remained in placed during these measurements and put tension on the dry wells. The dry. wells may not have remained perpendicular although a rope was used to try to keep the detectors perpendicular. Furthermore, there was know way to estimate the effects of raising and lowering the test assembly into the weir pool. Variations to the assembly geometry were to be investigated when analyzing these measurements. Furthermore, the affects of slight rotations in the fuel elements were to be investigated in the analyses. No measurement device was used to ensure that the elements did not rotate during the placement of the fuel elements in the test assembly; visual inspections were adequate to ensure that the elements were not rotated about their center. The assembly in the weir pool is shown in Fig. 5.2. 


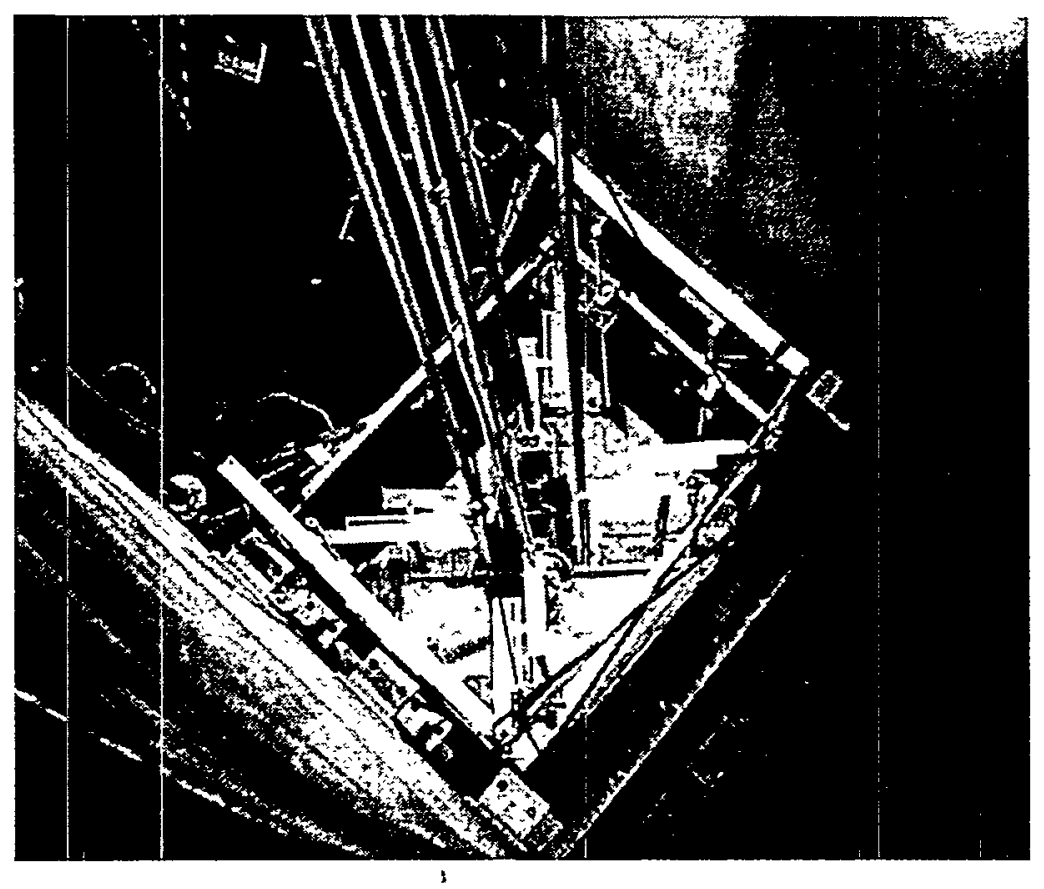

Fig. 5.2. Assembly in reactor weir pool.

The detector in the south position remained in its position for all measurements, but its high voltage was turned off for the two spent fuel element measurements. The high gamma ray background would have saturated the response of this detector. The results of the measurements are provided in Table 5.3. As can be seen from the data provided in Table 5.3, the spectral ratio values increased as more spent fuel elements were used in the measurements and indicated that the reactivity was decreasing. The spectral ratio values presented in Table 5.3 were corrected because only $98.5 \%$ of the spontaneous fission events of the source were counted for the spent fuel measurements. The temperature varied approximately $4^{\circ} \mathrm{F}$ over the period of these measurements. Fresh fuel measurements were performed with two different detector threshold settings. Measurement number 192 corresponded to a high threshold setting that was used for the spent fuel measurements whereas number 193 had a 1 volt threshold that was the same as measurements performed in the fresh water tank. The spectral ratio values for the fresh fuel measurements did not depend on the detector threshold values because the spectral ratio is essentially independent of detection efficiency. The measurements with a single spent fuel element were repeated at different times. The results for the two measurements with a single spent fuel element were in good agreement with each other although the temperature varied $4^{\circ} \mathrm{F}$ from one measurement to another. This indicated that the small change in temperature did not drastically affect the results of the measurements. However, these measurement files were not averaged together because the fuel elements were removed between the measurements and changes in the spectral ratio values due to temperature could be masked by changes in the apparatus. The spectral ratio value 23 changed approximately $5 \%$ as a result of replacing one fresh element in the north position 
with one spent fuel element. The spectral ratio values 24 and 34 were essentially the same as evident from the results in Table 5.3. The average of spectral ratio values 24 and 34 changed approximately $5 \%$ as a result of replacing one fresh fuel element in the north position with a spent fuel element. The results of the two measurements with two spent and two fresh elements were combined together because these measurements represented statistical repeats for the same fuel element configuration. Only a single spectral ratio value was obtained because the detector in the south position was turned off due to the high gamma ray background at the detector. The spectral ratio value 23 changed approximately $11 \%$ when two fresh fuel elements in the north and south positions were replaced with spent fuel elements. 
Table 5.3. Measured spectral ratio values for spent fuel measurements

\begin{tabular}{|c|c|c|c|c|c|c|c|c|}
\hline \multicolumn{9}{|c|}{ Table 5.3. Measured spectral ratio values for spent fuel measurements } \\
\hline \multirow[t]{2}{*}{ Configuration } & \multirow[t]{2}{*}{ Number } & \multirow{2}{*}{$\begin{array}{c}\text { Temperature } \\
\cdot\left({ }^{\circ} \mathrm{F}\right)\end{array}$} & \multicolumn{2}{|c|}{ Ratio 23} & \multicolumn{2}{|c|}{ Ratio 24} & \multicolumn{2}{|c|}{ Ratio 34} \\
\hline & & & $\mathrm{R}^{\mathrm{a}}$ & $\sigma^{\mathrm{b}}$ & $\mathrm{R}^{\mathrm{a}}$ & $\sigma^{\mathrm{b}}$ & $\mathrm{R}^{\mathrm{a}}$ & $\sigma^{\mathrm{b}}$ \\
\hline 4 fresh & 192 & 106.5 & 0.298 & 0.003 & 0.289 & 0.002 & 0.290 & 0.003 \\
\hline 4 fresh & 193 & 106.8 & 0.301 & 0.003 & 0.286 & 0.003 & 0.288 & 0.003 \\
\hline $\begin{array}{l}3 \text { fresh, } \\
1 \text { spent }\end{array}$ & 189 & $\begin{array}{l}103.3- \\
104.1\end{array}$ & 0.313 & 0.003 & 0.307 & 0.002 & 0.299 & 0.003 \\
\hline $\begin{array}{l}3 \text { fresh, } \\
1 \text { spent }\end{array}$ & 194 & $\begin{array}{l}107.1- \\
107.5\end{array}$ & 0.315 & 0.003 & 0.304 & 0.002 & 0.304 & 0.002 \\
\hline $\begin{array}{l}2 \text { fresh, } \\
2 \text { spent } \\
\end{array}$ & 190 & $\begin{array}{c}104.4- \\
105.5 \\
\end{array}$ & 0.331 & 0.006 & & & & \\
\hline $\begin{array}{l}2 \text { fresh, } \\
2 \text { spent }\end{array}$ & 191 & $\begin{array}{l}105.5- \\
106.2\end{array}$ & 0.322 & 0.006 & & & & \\
\hline $\begin{array}{c}\text { Average of } 2 \\
\text { fresh and } 2 \text { spent }\end{array}$ & Avg. & - & 0.331 & 0.004 & & & & \\
\hline
\end{tabular}


Count rate data was also obtained during these measurements. These count rates are presented in Table 5.4. The count rates for detectors in the east and west positions decreased with the addition of the spent fuel elements because fewer fission events were occurring in the fuel elements as a result of the reduced uranium content in the spent fuel elements and because of the reduced detection efficiency. Lowering the threshold for the fresh fuel measurements further increased the detector count rates for the fresh fuel measurements.

\begin{tabular}{|c|c|c|c|c|c|}
\hline \multicolumn{6}{|c|}{ Table 5.4. Detector count rate values for spent fuel measurements } \\
\hline Configuration & No. & $\begin{array}{c}\text { Temperature } \\
\left({ }^{\circ} \mathrm{F}\right)\end{array}$ & $\begin{array}{c}\text { South } \\
\text { (counts/sec) }\end{array}$ & $\begin{array}{c}\text { East } \\
\text { (counts/sec) }\end{array}$ & $\begin{array}{c}\text { West } \\
\text { (counts/sec) }\end{array}$ \\
\hline 4 fresh & 192 & 10.6 .5 & 4085 & 2996 & 2429 \\
\hline 4 fresh & 193 & 106.8 & 6726 & 7503 & 7377 \\
\hline $\begin{array}{l}3 \text { fresh, } \\
1 \text { spent }\end{array}$ & $\cdot 189$ & $\begin{array}{c}103.3- \\
104.1\end{array}$ & 4025 & 2949 & 2384 \\
\hline $\begin{array}{l}3 \text { fresh, } \\
1 \text { spent }\end{array}$ & 194 & $\begin{array}{l}107.1- \\
107.5\end{array}$ & 3052 & 2884 & 2403 \\
\hline $\begin{array}{l}2 \text { fresh, } \\
2 \text { spent }\end{array}$ & 190 & $\begin{array}{c}104.4- \\
105.5\end{array}$ & & 1456 & 841 \\
\hline $\begin{array}{l}2 \text { fresh, } \\
2 \text { spent }\end{array}$ & 191 & $\begin{array}{c}105.5- \\
106.2\end{array}$ & & 1462 & 845 \\
\hline
\end{tabular}

Additional count rate measurements were performed with one spent fuel element and three fresh fuel elements with the ${ }^{252} \mathrm{Cf}$ source removed. The average detector count rates were 256, 167 and 128 counts per second for detectors in the south, east, and west positions respectively. The counts were approximately $5 \%$ of the count rate with the source present. The detector thresholds were set such that mostly neutron events contributed to the detector response; therefore, some of these counts without the source present must be attributed to an inherent source in the spent fuel element and some fraction of gamma ray counts. The count rate measurements without the ${ }^{252} \mathrm{Cf}$ source were repeated for measurements with two spent fuel elements. The average detector count rates were 198 and 98 counts per second for the east and west detectors, respectively. This was approximately $12 \%$ of the count rate with the source present. Again, these counts can be attributed to an inherent source in the spent fuel elements and counting some gamma rays. As expected the percentage doubled when two spent fuel elements were used instead of one spent fuel element.

Additional spent fuel measurements were to be performed in which the affects of the elements are heightened. These measurements were only preliminary and were performed as an addition to the fresh fuel measurements. 


\section{SUMMARY AND CONCLUSIONS}

Subcritical noise analysis measurements were successfully performed with a variety of configurations of research reactor fuel elements at the Missouri University Research Reactor (MURR) in July 1998. These measurements were performed to assess the subcriticality of research reactor fuel elements separated by neutron absorbing materials and to determine the reactivity worth of spent (irradiated) fuel elements. This collaborative program between Oak Ridge National Laboratory, Westinghouse Safety Management Solutions, Inc., and the University of Missouri was undertaken to obtain benchmark subcritical measurements that address the excess conservatism associated with the transportation and storage of research reactor fuel elements at the Savannah River Technology Center.

Measurements were performed to determine the optimum source axial location, the optimum detector location, and the repeatability of the measurements. The results demonstrated that the optimum source location was near the axial center of the active region of the fuel elements and that the optimum detector location was a $9.0-\mathrm{cm}$ separation between the fuel centerline and the detector centerline. Two sets of reference measurements were performed to investigate the repeatability of the measurements. The results of the measurements demonstrated that the uncertainty in the measured spectral ratio values was approximately $1 \%$ to $2 \%$. This uncertainty represented the sample set standard deviation obtained from the two reference sets. The standard deviation of the sample set did not differ significantly from the standard deviation of the mean of the individual spectral ratio values thereby indicating that the variation between measurements was not significant. The standard deviation of the sample set should be used when comparing measured and calculated spectral ratio values.

The results also demonstrated that the selected configuration of the fuel elements had the highest reactivity. Fuel element traverse measurements were performed in which all fuel elements or a single fuel element was moved from a reference position. The results indicated that the reactivity of the system decreased as the fuel elements were moved apart and that the detectors located $180^{\circ}$ apart were the most sensitive to changes in system reactivity. The fuel elements in the north and south positions had a greater reactivity worth than fuel elements in the east and west positions as demonstrated by the fuel traverse measurements in which only one fuel element was moved.

Measurements were performed with a variety of plates positioned between the fuel element to simulate isolation of fuel elements from each other. In general, symmetric arrangements of plates produced expected results in that symmetric spectral ratio values were essentially the same. Asymmetric arrangements of plates produced spectral ratio values as expected. The magnitude of the change that was created when plates were added depended on the total number of plates in the system. The aluminum plates did not significantly affect the measured spectral ratio values. Most of the data values fell within one standard deviation of the reference measurements and all of the measurements fell within two standard deviations of the reference measurements for these measurements. 
The majority of the lead plate measurements demonstrated that lead had little affect on the system reactivity. The spectral ratio values obtained from detectors 2 and 3 decreased slightly as a function of lead mass while the other spectral ratio values did not exhibit any clear pattern for changes in the lead mass. Except for the spectral ratio 23, a majority of the spectral ratio values were within two standard deviations of the reference plate measurements. The spectral ratio 23 values differed from $2 \%$ to $6 \%$ from the reference measurements. This difference is greater than the uncertainty in the reproducibility of the measurements. However, the remaining spectral ratio values were consistent with each other and were within two standard deviations of the reference measurements and hence demonstrated that lead has little affect on the system reactivity.

The stainless steel plates had a significant impact on the reactivity of the system and performed well in isolating the fuel elements from each other. Measurement results with a single plate in the north and south position were statistically the same as those obtained from the reference measurements. However, as the number of plates (mass) was increased the spectral ratio values increased significantly indicating that $\mathrm{k}_{\text {eff }}$ was decreasing. This may have occurred because of a combination of water displacement near the fuel elements and because of the neutron absorption in the stainless steel. As expected, the plates in the east and west positions had the greatest affect on the spectral ratios because of the size of these plates. Symmetric configurations of plates produced predictable results for symmetric combinations of detectors and the results of the asymmetric configurations also produced expected results. The change in the spectral ratio values and hence the approximate change in reactivity from the reference measurements varied from $2 \%$ to $24 \%$.

The BORAL plates produced the largest changes in the spectral ratio values and in the reactivity of the system. The BORAL plate measurements demonstrated how effective boron was in isolating the fuel elements from each other. The addition of a small BORAL plate drastically changed the spectral ratio values because the interaction between elements was dramatically affected. The impact of the BORAL plates depended on the number of plates and on the location of the plates. The addition of a large plate was more important than the addition of a small plate because of the size of the large plates. The change in the spectral ratio values and hence the approximate change in reactivity from the reference measurements ranged from $11 \%$ to $48 \%$.

The spent fuel measurements were only preliminary measurements. The results indicated that a measurable change could be determined when one or two fresh fuel elements were replaced by spent fuel elements. The spectral ratio value for detectors $180^{\circ}$ apart changed $5 \%$ when one fresh fuel element was replaced with a spent fuel element and changed $11 \%$ when two fresh fuel elements were replaced with spent fuel elements. The detector count rates also decreased when the fresh-fuel elements were replaced with spent fuel elements. Count rate measurements performed without the ${ }^{252} \mathrm{Cf}$ source present indicated that an inherent source was present in the spent fuel assemblies and some gamma ray events were probably counted. This inherent source cannot be estimated based on the 
detector count rates without the ${ }^{252} \mathrm{Cf}$ source, because some gamma ray events were probably counted.

The results of these fresh fuel measurements can be used as a subcritical benchmark for Monte Carlo transport codes. Measurements with and without plates provide data that can be used to benchmark Monte Carlo codes. The results of the spent fuel measurements cannot be used as benchmark data unless destructive analyses of the fuel elements are performed and the contribution of the inherent source to the spectral ratio values can be determined. However, the reactivity of the spent fuel configurations can still be estimated even without detailed knowledge of the fission product content. Additional spent fuel measurements are needed in which large perturbations to the system can be made by replacing all fresh elements with spent fuel elements. 


\section{REFERENCES}

1. V. K. Paré and J. T Mihalczo, "Reactivity from Power Spectral Density Measurements with Californium-252," Nucl. Sci. Eng. 56, 213 (1975).

2. J. T. Mihalczo, V. K. Paré, G. L. Regan, M. V. Mathis, and G. C. Tillett, "Determination of Reactivity from Power Spectral Density Measurements with ${ }^{252}$ Cf," Nucl. Sci. Eng. 60, 29 (1978).

3. J. T. Mihalczo, "The Use of Californium-252 as a Randomly Pulsed Neutron Source for Prompt Neutron Decay Measurements," Nucl. Sci. Eng., 53, 393-414 (1974).

4. J. D. Orndoff, "Prompt Neutron Periods of Metal Critical Assemblies," Nucl. Sci. Eng., 2, 450 (1957).

5. "WSMS - Subcritical Measurements", Q:A.-2512, University of Missouri Research Reactor Facility, December 18, 1998.

6. J. F. Zino, "Technical Report - Experimental Subcritical Measurements Using Fresh and Spent MURR Assemblies (U)", WSMS-CRT-98-0068, September 1998.

7. Drawings 409406 and 409407, "University of Missouri at Columbia Test Research Training Reactor 4", EG\&G Idaho, Inc., September 1977. 


\section{APPENDIX A}

\section{FRESH FUEL CONTENT DATA}

Babcox and Wilcox in Tables A.1 through A.4 provided the fuel content data for the four fresh assemblies.

\begin{tabular}{|c|c|c|c|c|c|c|c|}
\hline \multicolumn{7}{|c|}{ Table A.1. Fuel contents for MO-517 } \\
\hline Plate & Volume & Total U & $\begin{array}{c}\text { UAl } 3 \\
\text { weight }\end{array}$ & $\begin{array}{c}\mathrm{Al} \text { in } \\
\text { matrix }\end{array}$ & U-235 & U-238 & Al \\
\hline & $\mathrm{cm}^{3}$ & $\mathrm{~g} /$ plate & & $\begin{array}{c}\text { excluding } \\
\text { bound }\end{array}$ & $\mathrm{g} /$ plate & $\mathrm{g} /$ plate & $\mathrm{g} /$ plate \\
\hline 1 & 13.51 & 20.62 & 28.95 & 21.09 & 19.20 & 1.42 & 29.42 \\
\hline 2 & 14.31 & 21.84 & 31.08 & 22.00 & 20.35 & 1.50 & 31.23 \\
\hline 3 & 15.12 & 23.06 & 32.81 & 23.21 & 21.48 & 1.58 & 32.96 \\
\hline 4 & 15.92 & 24.27 & 34.53 & 24.83 & 22.61 & 1.66 & 35.09 \\
\hline 5 & 16.73 & 25.50 & 36.26 & 26.12 & 23.76 & 1.75 & 36.87 \\
\hline 6 & 17.53 & 26.70 & 37.98 & 27.60 & 24.87 & 1.83 & 38.88 \\
\hline 7 & 18.33 & 27.90 & 39.70 & 28.82 & 25.99 & 1.92 & 40.63 \\
\hline 8 & 19.13 & 29.13 & 41.43 & 29.50 & 27.14 & 1.99 & 41.80 \\
\hline 9 & 19.94 & 30.34 & 43.15 & 31.46 & 28.27 & 2.08 & 44.27 \\
\hline 10 & 20.74 & 31.59 & 44.90 & 32.56 & 29.43 & 2.16 & 45.87 \\
\hline 11 & 21.55 & 32.77 & 46.62 & 33.85 & 30.53 & 2.24 & 47.70 \\
\hline 12 & 22.35 & 33.99 & 48.33 & 35.35 & 31.67 & 2.34 & 49.68 \\
\hline 13 & 23.15 & 35.18 & 50.08 & 36.49 & 32.77 & 2.41 & 51.39 \\
\hline 14 & 23.95 & 36.42 & 51.81 & 37.72 & 33.93 & 2.49 & 53.12 \\
\hline 15 & 24.76 & 37.66 & 53.53 & 38.29 & 35.08 & 2.58 & 54.16 \\
\hline 16 & 25.56 & 38.87 & 55.26 & 40.31 & 36.21 & 2.66 & 56.70 \\
\hline 17 & 26.36 & 40.10 & 56.99 & 40.80 & 37.36 & 2.75 & 57.69 \\
\hline 18 & 27.17 & 41.27 & 58.69 & 42.30 & 38.44 & 2.82 & 59.72 \\
\hline 19 & 27.97 & 42.50 & 60.43 & 43.31 & 39.59 & 2.91 & 61.24 \\
\hline 20 & 28.77 & 43.71 & 62.17 & 44.56 & 40.72 & 2.99 & 63.03 \\
\hline 21 & 29.58 & 44.94 & 63.87 & 46.08 & 41.86 & 3.08 & 65.01 \\
\hline 22 & 30.38 & 46.14 & 65.60 & 47.34 & 42.98 & 3.16 & 66.80 \\
\hline 23 & 31.18 & 47.37 & 67.35 & 48.41 & 44.12 & 3.25 & 68.39 \\
\hline 24 & 31.99 & 48.58 & 69.07 & 49.59 & 45.25 & 3.33 & 70.08 \\
\hline Total & 545.99 & 830.48 & 1180.59 & 851.59 & 773.60 & 56.88 & 1201.70 \\
\hline & & & & & & & \\
\hline
\end{tabular}




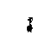

\begin{tabular}{|c|c|c|c|c|c|c|c|}
\hline \multicolumn{7}{|c|}{ Table A.2. Fuel contents for MO-518 } \\
\hline Plate & Volume & Total U & $\begin{array}{c}\text { UAl3 } \\
\text { weight }\end{array}$ & $\begin{array}{c}\text { Al in } \\
\text { matrix }\end{array}$ & U-235 & U-238 & Al \\
\hline & cm $^{3}$ & g/plate & & $\begin{array}{c}\text { excluding } \\
\text { bound }\end{array}$ & g/plate & g/plate & g/plate \\
\hline 1 & 13.51 & 20.64 & 28.95 & 21.09 & 19.22 & 1.42 & 29.39 \\
\hline 2 & 14.31 & 21.84 & 31.08 & 22.00 & 20.34 & 1.50 & 31.24 \\
\hline 3 & 15.12 & 23.06 & 32.80 & 23.35 & 21.48 & 1.58 & 33.09 \\
\hline 4 & 15.92 & 24.27 & 34.53 & 24.83 & 22.61 & 1.66 & 35.09 \\
\hline 5 & 16.73 & 25.50 & 36.26 & 26.12 & 23.75 & 1.75 & 36.88 \\
\hline 6 & 17.53 & 26.69 & 37.98 & 27.60 & 24.87 & 1.82 & 38.89 \\
\hline 7 & 18.33 & 27.88 & 39.70 & 28.82 & 25.97 & 1.91 & 40.64 \\
\hline 8 & 19.14 & 29.13 & 41.44 & 29.50 & 27.13 & 1.99 & 41.81 \\
\hline 9 & 19.94 & 30.35 & 43.15 & 31.46 & 28.27 & 2.08 & 44.26 \\
\hline 10 & 20.74 & 31.57 & 44.90 & 32.56 & 29.41 & 2.16 & 45.89 \\
\hline 11 & 21.55 & 32.76 & 46.62 & 33.85 & 30.52 & 2.24 & 47.71 \\
\hline 12 & 22.34 & 33.99 & 48.33 & 35.35 & 31.67 & 2.33 & 49.69 \\
\hline 13 & 23.15 & 35.21 & 50.08 & 36.49 & 32.79 & 2.42 & 51.36 \\
\hline 14 & 23.95 & 36.41 & 51.80 & 37.72 & 33.91 & 2.49 & 53.11 \\
\hline 15 & 24.76 & 37.66 & 53.53 & 38.29 & 35.08 & 2.58 & 54.16 \\
\hline 16 & 25.56 & 38.86 & 55.26 & 40.31 & 36.20 & 2.66 & 56.70 \\
\hline 17 & 26.36 & 40.08 & 56.98 & 40.80 & 37.33 & 2.74 & 57.70 \\
\hline 18 & 27.17 & 41.27 & 58.69 & 42.30 & 38.44 & $2: 82$ & 59.72 \\
\hline 19 & 27.97 & 42.52 & 60.45 & 43.31 & 39.61 & 2.91 & 61.24 \\
\hline 20 & 28.77 & 43.710 & 62.17 & 44.56 & 40.71 & 2.99 & 63.02 \\
\hline 21 & 29.58 & 44.95 & 63.80 & 46.07 & 41.87 & 3.08 & 64.99 \\
\hline 22 & 30.38 & 46.14 & 65.60 & 47.34 & 42.98 & 3.16 & 66.80 \\
\hline 23 & 31.18 & 47.39 & 67.35 & 48.41 & 44.13 & 3.25 & 68.37 \\
\hline 24 & 31.99 & 48.49 & 69.07 & 49.59 & 45.17 & 3.32 & 70.17 \\
\hline Total & 545.99 & 830.36 & 1180.59 & 851.72 & 773.48 & 56.88 & 1201.95 \\
\hline
\end{tabular}




\begin{tabular}{|c|c|c|c|c|c|c|c|}
\hline \multicolumn{7}{|c|}{ Table A.3. Fuel contents for MO-519 } \\
\hline Plate & Volume & Total U & $\begin{array}{c}\text { UAl3 } \\
\text { weight }\end{array}$ & $\begin{array}{c}\text { Al in } \\
\text { matrix }\end{array}$ & U-235 & U-238 & Al \\
\hline & $\mathrm{cm}^{3}$ & $\mathrm{~g} /$ plate & & $\begin{array}{c}\text { excluding } \\
\text { bound }\end{array}$ & $\mathrm{g} /$ plate & g/plate & g/plate \\
\hline 1 & 13.51 & 20.63 & 28.95 & 21.09 & 19.21 & 1.42 & 29.41 \\
\hline 2 & 14.31 & 21.85 & 31.09 & 22.00 & 20.35 & 1.50 & 31.24 \\
\hline 3 & 15.12 & 23.04 & 32.80 & 23.35 & 21.46 & 1.58 & 33.11 \\
\hline 4 & 15.92 & 24.27 & .34 .52 & 24.97 & 22.61 & 1.66 & 35.22 \\
\hline 5 & 16.73 & 25.50 & 36.26 & 26.12 & 23.76 & 1.75 & 36.88 \\
\hline 6 & 17.53 & 26.70 & 37.98 & 27.60 & 24.88 & 1.83 & 38.88 \\
\hline 7 & 18.33 & 27.92 & 39.70 & 28.82 & 26.01 & 1.91 & 40.60 \\
\hline 8 & 19.14 & 29.12 & 41.44 & 29.50 & 27.12 & 1.99 & 41.82 \\
\hline 9 & 19.94 & 30.33 & 43.15 & 31.46 & 28.25 & 2.08 & 44.29 \\
\hline 10 & 20.74 & 31.58 & 44.90 & 32.56 & 29.41 & 2.16 & 45.88 \\
\hline 11 & 21.55 & 32.75 & 46.62 & 33.85 & 30.51 & 2.24 & 47.72 \\
\hline 12 & 22.34 & 33.99 & 48.33 & 35.35 & 31.66 & 2.33 & 49.69 \\
\hline 13 & 23.15 & 35.21 & 50.08 & 36.49 & 32.80 & 2.42 & 51.36 \\
\hline 14 & 23.95 & 36.42 & 51.80 & 37.72 & 33.92 & 2.49 & 53.10 \\
\hline 15 & 24.76 & 37.66 & 53.53 & 38.29 & 35.08 & 2.58 & 54.16 \\
\hline 16 & 25.56 & 38.88 & 55.26 & 40.31 & 36.22 & 2.66 & 56.69 \\
\hline 17 & 26.36 & 40.07 & 56.98 & 40.80 & 37.33 & 2.74 & 57.71 \\
\hline 18 & 27.17 & 41.27 & 58.69 & 42.30 & 38.44 & 2.82 & 59.72 \\
\hline 19 & 27.97 & 42.49 & 60.44 & 43.31 & 39.58 & 2.91 & 61.26 \\
\hline 20 & 28.77 & 43.74 & 62.15 & 44.82 & 40.75 & 2.99 & 63.22 \\
\hline 21 & 29.58 & 44.94 & 63.87 & 46.08 & 41.87 & 3.08 & 65.01 \\
\hline 22 & 30.38 & 46.15 & 65.60. & 47.33 & 42.99 & 3.16 & 66.78 \\
\hline 23 & 31.18 & 47.30 & 67.35 & 48.41 & 44.05 & 3.25 & 68.46 \\
\hline 24 & 31.99 & 48.57 & 69.07 & 49.59 & 45.25 & 3.33 & 70.09 \\
\hline Total & 545.99 & 830.39 & 1180.56 & 852.12 & 773.52 & 56.88 & 1202.29 \\
\hline
\end{tabular}




\begin{tabular}{|c|c|c|c|c|c|c|c|}
\hline \multicolumn{7}{|c|}{ Table A.4. Fuel contents for MO-520 } \\
\hline Plate & Volume & Total U & $\begin{array}{c}\text { UAl3 } \\
\text { weight }\end{array}$ & $\begin{array}{c}\text { Al in } \\
\text { matrix }\end{array}$ & U-235 & U-238 & Al \\
\hline & $\mathrm{cm}^{3}$ & $\mathrm{~g} /$ plate & & $\begin{array}{c}\text { excluding } \\
\text { bound }\end{array}$ & $\mathrm{g} /$ plate & $\mathrm{g} /$ plate & $\mathrm{g} /$ plate \\
\hline 1 & 13.51 & 20.63 & 28.95 & 21.09 & 19.21 & 1.42 & 29.41 \\
\hline 2 & 14.31 & 21.84 & 31.07 & 22.09 & 20.35 & 1.50 & 31.32 \\
\hline 3 & 15.12 & 23.07 & 32.80 & 23.35 & 21.49 & 1.58 & 33.08 \\
\hline 4 & 15.92 & 24.28 & 34.52 & 24.97 & 22.62 & 1.66 & 35.21 \\
\hline 5 & 16.73 & 25.51 & 36.25 & 26.27 & 23.76 & 1.75 & 37.01 \\
\hline 6 & 17.53 & 26.72 & 37.98 & 27.60 & 24.89 & 1.83 & 38.86 \\
\hline 7 & 18.33 & 27.91 & 39.70 & 28.82 & 26.00 & 1.91 & 40.61 \\
\hline 8 & 19.14 & 29.14 & 41.43 & 29.67 & 27.15 & 1.99 & 41.96 \\
\hline 9 & 19.94 & 30.35 & 43.15 & 31.46 & 28.27 & 2.08 & 44.26 \\
\hline 10 & 20.74 & 31.59 & 44.60 & 33.16 & 29.42 & 2.16 & 46.17 \\
\hline 11 & 21.55 & 32.77 & 46.62 & 33.85 & 30.52 & 2.24 & 47.70 \\
\hline 12 & 22.35 & 33.99 & 48.03 & 35.80 & 31.67 & 2.33 & 49.84 \\
\hline 13 & 23.15 & 35.23 & 49.74 & 37.09 & 32.82 & 2.41 & 51.60 \\
\hline 14 & 23.95 & 36.43 & 51.46 & 38.41 & 33.94 & 2.49 & 53.44 \\
\hline 15 & 24.76 & 37.66 & 53.11 & 39.51 & 35.08 & 2.58 & 54.96 \\
\hline 16 & 25.56 & 38.90 & 54.89 & 41.05 & 36.24 & 2.66 & 57.04 \\
\hline 17 & 26.36 & 40.08 & 56.60 & 41.56 & 37.33 & 2.74 & 58.08 \\
\hline 18 & 27.17 & 41.25 & 58.69 & 42.30 & 38.43 & 2.82 & 59.74 \\
\hline 19 & 27.97 & 42.53 & 60.04 & 44.12 & 39.62 & 2.91 & 61.63 \\
\hline 20 & 28.77 & 43.74 & 62.15 & 44.82 & 40.75 & 2.99 & 63.23 \\
\hline 21 & 29.58 & 44.95 & 63.87 & 46.08 & 41.88 & 3.08 & 65.00 \\
\hline 22 & 30.38 & 46.11 & 65.60 & 47.34 & 42.96 & 3.16 & 66.83 \\
\hline 23 & 31.18 & 47.35 & 67.35 & 48.41 & 44.10 & 3.25 & 68.41 \\
\hline 24 & 31.99 & 48.59 & 68.54 & 51.16 & 45.26 & 3.33 & 71.11 \\
\hline Total & 545.99 & 830.62 & 1177.14 & 859.98 & 773.73 & 56.89 & 1206.50 \\
\hline
\end{tabular}




\section{APPENDIX B}

\section{ASSEMBLY CALIBRATION DATA}

A series of measurements were performed to calibrate the slide counters with the actual separation between the fuel centerline and the source dry well that was located in the center of the assembly. The data for these measurements were as given in Table B.1.

\begin{tabular}{|c|c|c|c|c|c|c|c|}
\hline \multicolumn{2}{|c|}{ Table B.1. Slide calibration data } \\
\hline \multicolumn{2}{|c|}{ North } & \multicolumn{2}{|c|}{ South } & \multicolumn{2}{c|}{ East } & \multicolumn{2}{c|}{ West } \\
\hline $\begin{array}{c}\text { Counter } \\
\text { reading }\end{array}$ & $\begin{array}{c}\text { Center- } \\
\text { to-center } \\
\text { spacing } \\
\text { (cm) }\end{array}$ & $\begin{array}{c}\text { Counter } \\
\text { reading }\end{array}$ & $\begin{array}{c}\text { Center- } \\
\text { to-center } \\
\text { spacing } \\
(\mathrm{cm})\end{array}$ & $\begin{array}{c}\text { Counter } \\
\text { reading }\end{array}$ & $\begin{array}{c}\text { Center- } \\
\text { to-center } \\
\text { spacing } \\
(\mathrm{cm})\end{array}$ & $\begin{array}{c}\text { Counter } \\
\text { reading }\end{array}$ & $\begin{array}{c}\text { Center- } \\
\text { to-center } \\
\text { spacing } \\
(\mathrm{cm})\end{array}$ \\
\hline 58 & 6.623 & 55 & 6.712 & 39 & 6.584 & 30 & 6.584 \\
\hline 60 & 6.745 & 175 & 7.918 & 194 & 8.109 & 210 & 8.299 \\
\hline 180 & 7.931 & 195 & 8.127 & 239 & 8.584 & 233 & 8.584 \\
\hline 200 & 8.114 & 242 & 8.584 & 334 & 9.519 & 350 & 9.615 \\
\hline 252 & 8.623 & 444 & 10.584 & 440 & 10.584 & 432 & 10.584 \\
\hline 452 & 10.623 & 642 & 12.584 & 642 & 12.584 & 630 & 12.584 \\
\hline 652 & 12.623 & 843 & 14.584 & 841 & 14.584 & 832 & 14.584 \\
\hline 854 & 14.623 & & & & & & \\
\hline
\end{tabular}




\section{APPENDIX C \\ SYSTEM CONFIGURATION FOR ALL MEASUREMENTS}

The source, detector, and fuel assembly configurations for the measurements were as provided in Table C.1. The detector position was given in terms of the center of the detector dry well to the center of the fuel element spacing. The source position was provided in terms of the distance from the centerline of the active region of the fuel. In measurements 172 through 187, the source was placed in the north dry well whose centerline was $9.0-\mathrm{cm}$ from the fuel element centerline. 


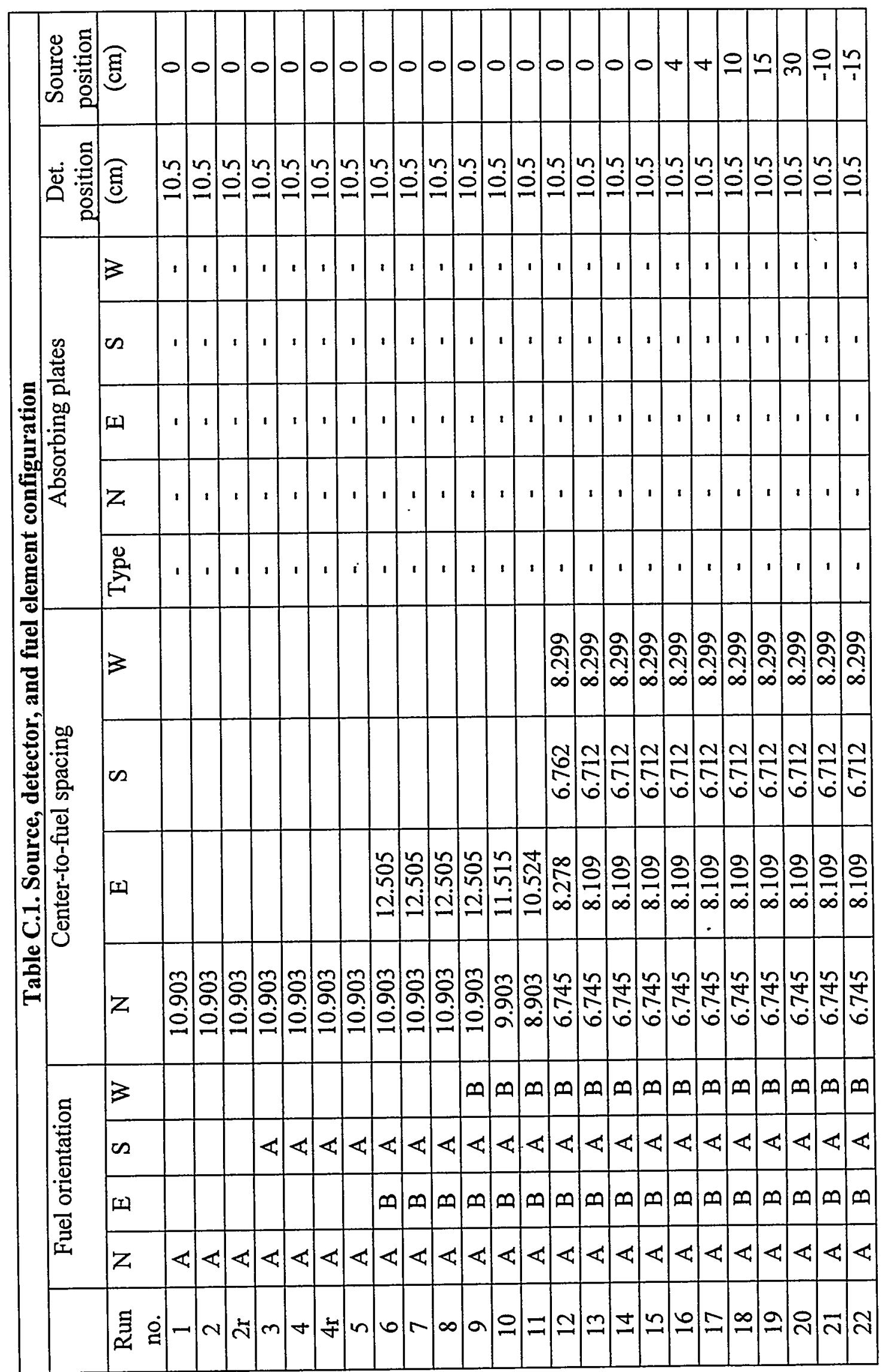




\begin{tabular}{|c|c|c|c|c|c|c|c|c|c|c|c|c|c|c|c|}
\hline \multicolumn{16}{|c|}{ Table C.1. (continued) } \\
\hline & \multicolumn{4}{|c|}{ Fuel orientation } & \multicolumn{4}{|c|}{ Center-to-fuel spacing } & \multicolumn{5}{|c|}{ Absorbing plates } & \multirow{2}{*}{$\begin{array}{c}\begin{array}{c}\text { Det. } \\
\text { position }\end{array} \\
(\mathrm{cm})\end{array}$} & \multirow{2}{*}{$\begin{array}{c}\begin{array}{c}\text { Source } \\
\text { position }\end{array} \\
\frac{(\mathrm{cm})}{}\end{array}$} \\
\hline $\begin{array}{l}\text { Run } \\
\text { no. }\end{array}$ & $\mathrm{N}$ & $\mathrm{E}$ & $\mathrm{S}$ & $\mathrm{W}$ & $\mathrm{N}$ & $E$ & $\mathrm{~S}$ & $\mathrm{~W}$ & Type & $\mathrm{N}$ & $\mathrm{E}$ & $\mathrm{s}$ & $\bar{W}$ & & \\
\hline 23 & $\mathrm{~A}$ & $\mathrm{~B}$ & $\overline{\mathrm{A}}$ & $\mathrm{B}$ & 6.745 & 8.109 & 6.712 & 8.299 & - & - & - & - & - & 10.5 & -30 \\
\hline 24 & $\mathrm{~A}$ & $\mathrm{~B}$ & $\mathrm{~A}$ & $\mathrm{~B}$ & 6.745 & 8.109 & 6.712 & 8.299 & - & - & - & - & - & 10.5 & 0 \\
\hline 25 & A & $\mathrm{B}$ & $\mathrm{A}$ & $\mathrm{B}$ & 7.931 & 9.519 & 7.918 & 9.615 & - & - & - & - & - & 10.5 & 0 \\
\hline 26 & $\bar{A}$ & $\bar{B}$ & $\bar{A}$ & $\mathrm{~B}$ & 10.903 & 12.505 & 10.898 & 12.782 & - & - & - & - & - & 10.5 & 0 \\
\hline 27 & $\mathrm{~A}$ & $\mathrm{~B}$ & $\mathrm{~A}$ & $\mathrm{~B}$ & 10.903 & 12.505 & 10.898 & 12.782 & - & - & - & - & - & 10.5 & 0 \\
\hline 28 & $\mathrm{~A}$ & $\mathrm{~B}$ & $\mathrm{~A}$ & $\mathrm{~B}$ & 7.931 & 9.519 & 7.918 & 9.615 & - & - & - & - & - & 10.5 & 0 \\
\hline 29 & $\bar{A}$ & $\bar{A}$ & $\overline{\mathrm{A}}$ & $\overline{\mathrm{A}}$ & 8.603 & 8.732 & 8.614 & 8.910 & - & - & - & - & - & 10.5 & 0 \\
\hline 30 & $\bar{A}$ & $\mathrm{~A}$ & $\mathrm{~A}$ & $\bar{A}$ & 8.603 & 8.732 & 8.614 & 8.910 & - & - & - & - & - & 10.5 & 0 \\
\hline 31 & $\mathrm{~A}$ & B & $\mathrm{A}$ & $\mathrm{B}$ & 8.114 & 12.665 & 8.127 & 12.941 & - & - & - & $=$ & - & 10.5 & 0 \\
\hline 32 & $\mathrm{~A}$ & $\mathrm{~B}$ & $\mathrm{~A}$ & B & 8.114 & 12.665 & 8.127 & 12.941 & - & - & - & - & - & 10.5 & 0 \\
\hline 33 & $\mathrm{~A}$ & $B$ & $\mathrm{~A}$ & B & 8.114 & 12.665 & 8.127 & 12.941 & - & - . & - & - & - & 10.5 & 0 \\
\hline 34 & A & B & $\mathrm{A}$ & $\mathrm{B}$ & 8.114 & 12.665 & 8.127 & 12.941 & - & - & - & - & - & 9 & 0 \\
\hline 35 & $\mathrm{~A}$ & B & $\mathrm{A}$ & $\mathrm{B}$ & 8.114 & 12.665 & 8.127 & 12.941 & - & - & - & - & - & 9 & 0 \\
\hline 36 & $\mathrm{~A}$ & $\mathrm{~B}$ & $\mathrm{~A}$ & $\mathrm{~B}$ & 8.114 & 12.665 & 8.127 & 12.941 & - & - & - & - & - & 7.5 & 0 \\
\hline 37 & $\bar{A}$ & $\bar{B}$ & $\bar{A}$ & $\mathrm{~B}^{\circ}$ & 8.114 & 12.665 & 8.127 & 12.941 & - & - & - & - & - & 12 & 0 \\
\hline 38 & $\mathrm{~A}$ & $\mathrm{~B}$ & $\mathrm{~A}$ & $\mathrm{~B}$ & 8.114 & 12.665 & 8.127 & 12.941 & - & - & - & - & - & 12 & 0 \\
\hline 39 & $\mathrm{~A}$ & B & $\mathrm{A}$ & B & 8.114 & 12.665 & 8.127 & 12.941 & - & - & - & - & - & 13.5 & 0 \\
\hline 40 & $\mathrm{~A}$ & B & A & $\mathrm{B}$ & 8.114 & 12.665 & 8.127 & 12.941 & - & - & - & - & - & 9 & 0 \\
\hline 41 & $\mathrm{~A}$ & $\mathrm{~B}$ & $\mathrm{~A}$ & $\mathrm{~B}$ & 7.931 & 9.519 & 7.918 & 9.615 & - & - & - & - & - & 9 & $\overline{0}$ \\
\hline 42 & $\mathrm{~A}$ & B & $\mathrm{A}$ & $\mathrm{B}$ & 8.903 & 10.524 & 8.911 & 10.766 & - & - & - & - & - & 9 & 0 \\
\hline 43 & $\mathrm{~A}$ & $\mathrm{~B}$ & $\mathrm{~A}$ & B & 8.903 & 10.524 & 8.911 & 10.766 & - & - & - & - & - & 9 & 0 \\
\hline 44 & $\mathrm{~A}$ & $\mathrm{~B}$ & $\mathrm{~A}$ & $\mathrm{~B}$ & 9.903 & 11.515 & 9.901 & 11.776 & - & - & - & - & - & 9 & 0 \\
\hline 45 & $\mathrm{~A}$ & $\bar{B}$ & $\mathrm{~A}$ & B & 10.903 & 12.505 & 10.898 & 12.782 & - & - & - & - & - & 9 & 0 \\
\hline 46 & $\bar{A}$ & B & $\overline{\mathrm{A}}$ & $\bar{B}$ & 7.931 & 9.519 & 7.918 & 9.615 & - & - & - & - & - & 9 & 0 \\
\hline
\end{tabular}


Table C.1. (continued)

\begin{tabular}{|c|c|c|c|c|c|c|c|c|c|c|c|c|c|c|c|}
\hline & & & & & & & Table ( & (contin & & & & & & & \\
\hline & & 10 & ntat & & & enter-to-1 & spacin & & & & & & & Det. & Source \\
\hline $\begin{array}{l}\text { Run } \\
\text { no. }\end{array}$ & $\bar{N}$ & $\bar{E}$ & $S$ & W & $\mathrm{N}$ & $\mathrm{E}$. & $\mathrm{S}$ & $\mathrm{W}$ & Type & $\mathrm{N}$ & $E$ & $S$ & $\mathrm{~W}$ & $(\mathrm{~cm})$ & $(\mathrm{cm})$ \\
\hline 47 & A & B & A & B & $7.931^{\circ}$ & 9.519 & 7.918 & 9.615 & - & - & - & - & - & 9 & 0 \\
\hline 48 & A & B & A & $B$ & 8.903 & 9.519 & 7.918 & 9.615 & - & - & - & - & - & 9 & 0 \\
\hline 49 & $\mathrm{~A}$ & $\mathrm{~B}$ & $\mathrm{~A}$ & B & 8.903 & 9.519 & 7.918 & 9.615 & - & - & - & - & - & 9 & 0 \\
\hline 50 & A & B & A & B & 9.903 & 9.519 & 7.918 & 9.615 & - & - & - & - & - & 9 & 0 \\
\hline 51 & A & B & $\mathrm{A}$ & B & 9.903 & 9.519 & 7.918 & 9.615 & - & - & - & - & - & 9 & 0 \\
\hline 52 & $\mathrm{~A}$ & B & $\mathrm{A}$ & $\mathrm{B}$ & 11.903 & 9.519 & 7.918 & 9.615 & - & - & - & - & - & 9 & 0 \\
\hline 53 & A & B & A & B & 11.903 & 9.519 & 7.918 & 9.615 & - & - & - & - & - & 9 & 0 \\
\hline 54 & A & B & A & B & 7.931 & 9.519 & 7.918 & 9.615 & - & - & - & - & - & 9 & 0 \\
\hline 55 & $\mathrm{~A}$ & $B$ & A & B & 7.931 & 11.515 & 7.918 & 9.615 & - & - & - & - & - & 9 & 0 \\
\hline 56 & A & B & A & $\mathrm{B}$ & 7.931 & 11.515 & 7.918 & 9.615 & - & - & - & - & - & 9 & 0 \\
\hline 57 & $\mathrm{~A}$ & $\bar{B}$ & $\bar{A}$ & $\bar{B}$ & 7.931 & 13.509 & 7.918 & 9.615 & - & - & - & - & - & 9 & 0 \\
\hline 58 & A & $\mathrm{B}$ & A & $\mathrm{B}$ & 7.931 & 13.509 & 7.918 & 9.615 & - & - & - & - & - & 9 & 0 \\
\hline 59 & $\mathrm{~A}$ & B & A & B & 7.931 & 9.519 & 7.918 & 9.615 & - & - & - & - & - & 9 & 0 \\
\hline 60 & $\mathrm{~A}$ & $\mathrm{~A}$ & $\mathrm{~A}$ & $\mathrm{~A}$ & 7.931 & 9.519 & 7.918 & 9.615 & - & - & - & - & - & 9 & 0 \\
\hline 61 & A & A & A & A & 7.931 & 9.519 & 7.918 & 9.615 & - & - & - & - & - & 9 & 0 \\
\hline 62 & $\mathrm{~B}$ & B & B & B & 10.103 & 9.519 & 10.099 & 9.615 & - & - & - & - & - & 9 & 0 \\
\hline 63 & B & B & B & B & 10.103 & 9.519 & 10.099 & 9.615 & - & - & - & - & - & 9 & 0 \\
\hline 64 & $\mathrm{~A}$ & $B$ & $\mathrm{~A}$ & $\mathrm{~B}$ & 7.931 & 9.519 & 7.918 & 9.615 & - & - & - & - & - & 9 & 0 \\
\hline 65 & A & B & A & B & 7.931 & 9.519 & 7.918 & 9.615 & - & - & - & - & - & 9 & 0 \\
\hline 66 & $\mathrm{~A}$ & $B$ & $\mathrm{~A}$ & $\mathrm{~B}$ & 7.931 & 9.519 & 7.918 & 9.615 & - & - & - & - & - & 9 & 0 \\
\hline 67 & A & B & A & B & 7.931 & 9.519 & 7.918 & 9.615 & - & - & $=$ & - & 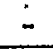 & 9 & 0 \\
\hline 68 & $\mathrm{~A}$ & B & A & $\mathrm{B}$ & 7.931 & 9.519 & 7.918 & 9.615 & $=$ & - & - & - & - & 9 & 0 \\
\hline 69 & $\mathrm{~A}$ & B & A & B & 8.114 & 12.665 & 8.127 & 12.941 & - & - & - & - & - & 9 & 0 \\
\hline 70 & A & B & A & B & 8.114 & 12.665 & 8.127 & 12.941 & $\mathrm{Al}$ & 1 & - & 1 & - & 9 & 0 \\
\hline
\end{tabular}




\begin{tabular}{|c|c|c|c|c|c|c|c|c|c|c|c|c|c|c|c|}
\hline \multicolumn{16}{|c|}{ Table C.1. (continued) } \\
\hline & \multicolumn{4}{|c|}{ Fuel orientation } & \multicolumn{4}{|c|}{ Center-to-fuel spacing } & \multicolumn{5}{|c|}{ Absorbing plates } & \multirow{2}{*}{$\begin{array}{c}\begin{array}{c}\text { Det. } \\
\text { position }\end{array} \\
(\mathrm{cm})\end{array}$} & \multirow{2}{*}{$\begin{array}{c}\begin{array}{c}\text { Source } \\
\text { position }\end{array} \\
(\mathrm{cm})\end{array}$} \\
\hline $\begin{array}{l}\text { Run } \\
\text { no. }\end{array}$ & $\mathrm{N}$ & $\mathrm{E}$ & $\mathrm{S}$ & $\bar{W}$ & $\bar{N}$ & $\mathrm{E}$ & $\mathrm{S}$ & $\mathrm{W}$ & Type & $\mathrm{N}$ & $\mathrm{E}$ & $\mathrm{S}$ & $\mathrm{W}$ & & \\
\hline 71 & $\mathrm{~A}$ & $\mathrm{~B}$ & $\mathrm{~A}$ & $\mathrm{~B}$ & 8.114 & 12.665 & 8.127 & 12.941 & $\overline{\mathrm{Al}}$ & 1 & - & 1 & - & 9 & 0 \\
\hline 72 & $\mathrm{~A}$ & $\mathrm{~B}$ & A & $\mathrm{B}$ & 8.114 & 12.665 & 8.127 & 12.941 & $\overline{\mathrm{Al}}$ & 2 & - & 2 & - & 9 & 0 \\
\hline 73 & A & $\mathrm{B}$ & A & $\mathrm{B}$ & 8.114 & 12.665 & 8.127 & 12.941 & $\overline{\mathrm{Al}}$ & 2 & - & 2 & $\overline{-}$ & 9 & 0 \\
\hline 74 & A & $\mathrm{B}$ & A & $\mathrm{B}$ & 8.114 & 12.665 & 8.127 & 12.941 & $\mathrm{Al}$ & 3 & - & 3 & - & 9 & 0 \\
\hline 75 & $\mathrm{~A}$ & $\bar{B}$ & $\mathrm{~A}$ & $\bar{B}$ & 8.114 & 12.665 & 8.127 & 12.941 & $\mathrm{Al}$ & 3 & - & 3 & - & 9 & 0 \\
\hline 76 & $\mathrm{~A}$ & $\mathrm{~B}$ & A & $\bar{B}$ & 8.114 & 12.665 & 8.127 & 12.941 & $\overline{\mathrm{Al}}$ & 3 & 1 & 3 & 1 & 9 & 0 \\
\hline 77 & $\mathrm{~A}$ & $\bar{B}$ & $\overline{\mathrm{A}}$ & $\mathrm{B}$ & 8.114 & 12.665 & 8.127 & 12.941 . & $\mathrm{Al}$ & 3 & 1 & 3 & 1 & 9 & 0 \\
\hline 78 & A & $\mathrm{B}$ & $\mathrm{A}$ & $\mathrm{B}$ & 8.114 & 12.665 & 8.127 & 12.941 & $\mathrm{Al}$ & 2 & 1 & 2 & 1 & 9 & 0 \\
\hline 79 & A & B & $\mathrm{A}$ & $\mathrm{B}$ & 8.114 & 12.665 & 8.127 & 12.941 & $\mathrm{Al}$ & 1 & 1 & 1 & 1 & 9 & 0 \\
\hline .80 & $\mathrm{~A}$ & B & A & B & 8.114 & 12.665 & 8.127 & 12.941 & $\mathrm{Al}$ & 1 & 2 & 1 & 2 & 9 & 0 \\
\hline 81 & $\mathrm{~A}$ & B & $\bar{A}$ & $\bar{B}$ & 8.114 & 12.665 & 8.127 & 12.941 & $\overline{\mathrm{Al}}$ & 2 & 2 & 2 & 2 & 9 & 0 \\
\hline 82 & $\mathrm{~A}$ & B & A & B & 8.114 & 12.665 & 8.127 & 12.941 & $\mathrm{Al}$ & 3 & 2 & 3 & 2 & 9 & 0 \\
\hline 83 & $\mathrm{~A}$ & B & $\mathrm{A}$ & B & 8.114 & 12.665 & 8.127 & 12.941 & $\mathrm{Al}$ & 3 & 3 & 3 & 3 & 9 & 0 \\
\hline 84 & $\mathrm{~A}$ & B & $\mathrm{A}$ & B & 8.114 & 12.665 & 8.127 & 12.941 & $\overline{\mathrm{Al}}$ & 4 & 4 & 4 & 4 & 9 & 0 \\
\hline 85 & $\mathrm{~A}$ & B & $\mathrm{A}$ & B & 8.114 & 12.665 & 8.127 & 12.941 & - & - & - & - & - & 9 & 0 \\
\hline 86 & $\mathrm{~A}$ & B & A & B & 8.114 & 12.665 & 8.127 & 12.941 & - & - & - & - & - & 9 & 0 \\
\hline 87 & $\mathrm{~A}$ & B & $\mathrm{A}$ & $\mathrm{B}$ & 8.114 & 12.665 & 8.127 & 12.941 & - & - & - & - & - & 9 & $\overline{0}$ \\
\hline 88 & $\mathrm{~A}$ & B & A & $\mathrm{B}$ & 8.114 & 12.665 & 8.127 & 12.941 & - & - & - & - & - & 9 & 0 \\
\hline 89 & $\mathrm{~A}$ & B & $\mathrm{A}$ & B & 8.114 & 12.665 & 8.127 & 12.941 & - & - & - & - & - & 9 & 0 \\
\hline 90 & $\mathrm{~A}$ & $\mathrm{~B}$ & $\mathrm{~A}$ & $\mathrm{~B}$ & 8.114 & 12.665 & 8.127 & 12.941 & SS & 4 & 4 & 4 & 4 & 9 & 0 \\
\hline 91 & $\mathrm{~A}$ & $\mathrm{~B}$ & $\mathrm{~A}$ & $\mathrm{~B}$ & 8.114 & 12.665 & 8.127 & 12.941 & SS & 3 & 3 & 3 & 3 & 9 & 0 \\
\hline 92 & $\mathrm{~A}$ & $\bar{B}$ & $\mathrm{~A}$ & $\mathrm{~B}$ & 8.114 & 12.665 & 8.127 & 12.941 & Boral & 1 & 1 & 1. & 1 & 9 & 0 \\
\hline 93 & $\mathrm{~A}$ & $\mathrm{~B}$ & $\overline{\mathrm{A}}$ & $B$ & 8.114 & 12.665 & 8.127 & 12.941 & Boral & 1 & 1 & 1 & 1 & 9 & 0 \\
\hline 94 & $\mathrm{~A}$ & B & $\mathrm{A}$ & $\mathrm{B}$ & 8.114 & 12.665 & 8.127 & 12.941 & - & - & - & - & - & 9 & 0 \\
\hline
\end{tabular}




\begin{tabular}{|c|c|c|c|c|c|c|c|c|c|c|c|c|c|c|c|}
\hline \multicolumn{16}{|c|}{ Table C.1. (continued) } \\
\hline & \multicolumn{4}{|c|}{ Fuel orientation } & \multicolumn{4}{|c|}{ Center-to-fuel spacing } & \multicolumn{5}{|c|}{ Absorbing plates } & \multirow{2}{*}{$\begin{array}{c}\begin{array}{c}\text { Det. } \\
\text { position }\end{array} \\
(\mathrm{cm})\end{array}$} & \multirow{2}{*}{$\begin{array}{c}\begin{array}{c}\text { Source } \\
\text { position }\end{array} \\
(\mathrm{cm})\end{array}$} \\
\hline $\begin{array}{l}\text { Run } \\
\text { no. }\end{array}$ & $\mathrm{N}$ & $\mathrm{E}$ & $\mathrm{S}$ & $\mathrm{W}$ & $\mathrm{N}$ & $\mathrm{E}$ & $\mathrm{S}$ & $\mathrm{W}$ & Type & $\mathrm{N}$ & E & $\mathrm{S}$ & $\mathrm{W}$ & & \\
\hline 95 & A & B & $\mathrm{A}$ & $\mathrm{B}$ & 8.114 & 12.665 & 8.127 & 12.941 & Lead & - & - & - & 1 & 9 & 0 \\
\hline 96 & $\mathrm{~A}$ & $\mathrm{~B}$ & $\mathrm{~A}$ & $\mathrm{~B}$ & 8.114 & $12: 665$ & 8.127 & 12.941 & Lead & 1 & 1 & 1 & 1 & 9 & 0 \\
\hline 97 & $\mathrm{~A}$ & $\mathrm{~B}$ & $\mathrm{~A}$ & $\mathrm{~B}$ & 8.114 & 12.665 & 8.127 & 12.941 & Lead & 1 & 1 & 1 & 1 & 9 & 0 \\
\hline 98 & $\bar{A}$ & $\mathrm{~B}$ & $\mathrm{~A}$ & $\mathrm{~B}$ & 8.114 & 12.665 & 8.127 & 12.941 & Lead & - & 1 & 1 & 1 & 9 & 0 \\
\hline 99 & $\bar{A}$ & $\mathrm{~B}$ & $\mathrm{~A}$ & $\mathrm{~B}$ & 8.114 & 12.665 & 8.127 & 12.941 & Lead & - & 1 & 1 & 1 & 9 & 0 \\
\hline 100 & $\mathrm{~A}$ & $\mathrm{~B}$ & $\mathrm{~A}$ & $\mathrm{~B}$ & 8.114 & 12.665 & 8.127 & 12.941 & Lead & - & 1 & - & 1 & 9 & 0 \\
\hline 101 & $\overline{\mathrm{A}}$ & $\mathrm{B}$ & $\mathrm{A}$ & $\mathrm{B}$ & 8.114 & 12.665 & 8.127 & 12.941 & Lead & - & 1 & - & 1 & 9 & 0 \\
\hline 102 & $\mathrm{~A}$ & $\mathrm{~B}$ & $\mathrm{~A}$ & $\mathrm{~B}$ & 8.114 & 12.665 & 8.127 & 12.941 & Lead & - & 1 & - & - & 9 & 0 \\
\hline 103 & A & B & A & $\mathrm{B}$ & 8.114 & 12.665 & 8.127 & 12.941 & Lead & - & 1 & - & - & 9 & 0 \\
\hline 104 & A & $\mathrm{B}$ & $\mathrm{A}$ & $\mathrm{B}$ & 8.114 & 12.665 & 8.127 & 12.941 & Lead & 1 & 1 & - & - & 9 & 0 \\
\hline 105 & $\mathrm{~A}$ & $\bar{B}$ & $\mathrm{~A}$ & $\mathrm{~B}$ & 8.114 & 12.665 & 8.127 & 12.941 & Lead & 1 & 1 & - & - & 9 & 0 \\
\hline 106 & $\mathrm{~A}$ & B & $\mathrm{A}$ & $\mathrm{B}$ & 8.114 & 12.665 & 8.127 & 12.941 & Lead & 1 & 1 & 1 & - & 9 & 0 \\
\hline 107 & $\mathrm{~A}$ & $\mathrm{~B}$ & $\mathrm{~A}$ & B & 8.114 & 12.665 & 8.127 & 12.941 & Lead & 1 & 1 & 1 & - & 9 & 0 \\
\hline 108 & $\bar{A}$ & B & $\mathrm{A}$ & B & 8.114 & 12.665 & 8.127 & 12.941 & Lead & 1 & - & 1 & - & 9 & 0 \\
\hline 109 & $\mathrm{~A}$ & B & $\overline{\mathrm{A}}$ & $\mathrm{B}$ & 8.114 & 12.665 & 8.127 & 12.941 & Lead & 1 & - & 1 & - & 9 & 0 \\
\hline 110 & $\mathrm{~A}$ & B & $\mathrm{A}$ & B & 8.114 & 12.665 & 8.127 & 12.941 & Lead & 1 & - & - & - & 9 & 0 \\
\hline 111 & $\mathrm{~A}$ & $\bar{B}$ & $\mathrm{~A}$ & $\mathrm{~B}$ & 8.114 & 12.665 & 8.127 & 12.941 & Lead & 1 & - & - & - & 9 & 0 \\
\hline 112 & $\mathrm{~A}$ & $\mathrm{~B}$ & $\mathrm{~A}$ & $\mathrm{~B}$ & 8.114 & 12.665 & 8.127 & 12.941 & SS & 1 & - & 1 & - & 9 & 0 \\
\hline 113 & $\mathrm{~A}$ & B & $\mathrm{A}$ & $\mathrm{B}$ & 8.114 & 12.665 & 8.127 & 12.941 & SS & 1 & - & 1 & - & 9 & 0 \\
\hline 114 & $\mathrm{~A}$ & $\mathrm{~B}$ & $\mathrm{~A}$ & $\mathrm{~B}$ & 8.114 & 12.665 & 8.127 & 12.941 & - & - & - & - & - & 9 & 0 \\
\hline 115 & $\overline{\mathrm{A}}$ & $\mathrm{B}$ & $\mathrm{A}$ & $\mathrm{B}$ & 8.114 & 12.665 & 8.127 & 12.941 & - & - & - & - & - & 9 & 0 \\
\hline 116 & $\mathrm{~A}$ & B & $\mathrm{A}$ & B & 8.114 & 12.665 & 8.127 & 12.941 & SS & 2 & - & 2 & - & 9 & 0 \\
\hline 117 & $\mathrm{~A}$ & B & $\mathrm{A}$ & $B$ & 8.114 & 12.665 & 8.127 & 12.941 & SS & 2 & - & 2 & - & 9 & 0 \\
\hline 118 & $\mathrm{~A}$ & $\mathrm{~B}$ & $\mathrm{~A}$ & $B$ & 8.114 & 12.665 & 8.127 & 12.941 & SS & 3 & - & 3 & - & 9 & 0 \\
\hline
\end{tabular}




\begin{tabular}{|c|c|c|c|c|c|c|c|c|c|c|c|c|c|c|c|}
\hline \multicolumn{16}{|c|}{ Table C.1. (continued) } \\
\hline & \multicolumn{4}{|c|}{ Fuel orientation } & \multicolumn{4}{|c|}{ Center-to-fuel spacing } & \multicolumn{5}{|c|}{ Absorbing plates } & \multirow{2}{*}{$\frac{\begin{array}{c}\text { Det. } \\
\text { position }\end{array}}{(\mathrm{cm})}$} & \multirow{2}{*}{$\begin{array}{c}\begin{array}{c}\text { Source } \\
\text { position }\end{array} \\
(\mathrm{cm})\end{array}$} \\
\hline $\begin{array}{c}\text { Run } \\
\text { no. }\end{array}$ & $\mathrm{N}$ & $\mathrm{E}$ & $\mathrm{S}$ & $\bar{W}$ & $\bar{N}$ & $\overline{E^{\prime}}$ & $\bar{S}$ & $\bar{W}$ & Type & $\mathrm{N}$ & $\bar{E}$ & $\mathrm{~S}$ & $\mathrm{~W}$ & & \\
\hline 119 & $\mathrm{~A}$ & $\mathrm{~B}$ & $\mathrm{~A}$ & $\mathrm{~B}$ & 8.114 & 12.665 & 8.127 & 12.941 & SS & 3 & - & 3 & - & 9 & 0 \\
\hline 120 & $\mathrm{~A}$ & B & $\mathrm{A}$ & B & 8.114 & 12.665 & 8.127 & 12.941 & SS & 3 & 1 & 3 & 1 & 9 & 0 \\
\hline 121 & $\mathrm{~A}$ & $\mathrm{~B}$ & $\mathrm{~A}$ & $\mathrm{~B}$ & 8.114 & 12.665 & 8.127 & 12.941 & SS & 3 & 1 & 3 & 1 & 9 & 0 \\
\hline 122 & $\bar{A}$ & $\mathrm{~B}$ & $\mathrm{~A}$ & $\mathrm{~B}$ & 8.114 & 12.665 & 8.127 & 12.941 & SS & 2 & 1 & 2 & 1 & 9 & 0 \\
\hline 123 & $\mathrm{~A}$ & $\mathrm{~B}$ & $\mathrm{~A}$ & $\mathrm{~B}$ & 8.114 & 12.665 & 8.127 & 12.941 & SS & 2 & 1 & 2 & 1 & 9 & 0 \\
\hline 124 & $\mathrm{~A}$ & $\mathrm{~B}$ & $\mathrm{~A}$ & B & 8.114 & 12.665 & 8.127 & 12.941 & SS & 2 & 2 & 2 & 2 & 9 & 0 \\
\hline 125 & $\mathrm{~A}$ & B & $\mathrm{A}$ & B & 8.114 & 12.665 & 8.127 & 12.941 & Boral & 1 & 1 & 1 & 1 & 9 & 0 \\
\hline 126 & $\mathrm{~A}$ & B & $\mathrm{A}$ & B & 8.114 & 12.665 & 8.127 & 12.941 & - & - & - & - & - & 9 & 0 \\
\hline 127 & $\mathrm{~A}$ & B & $\mathrm{A}$ & B & 8.114 & 12.665 & 8.127 & 12.941 & - & - & - & - & - & 9 & 0 \\
\hline 128 & $\mathrm{~A}$ & $\bar{B}$ & $\mathrm{~A}$ & $\mathrm{~B}$ & 7.931 & 9.519 & 7.918 & 9.615 & - & - & - & - & - & 9 & 0 \\
\hline 129 & $\mathrm{~A}$ & $\mathrm{~B}$ & $\mathrm{~A}$ & B & 7.931 & 9.519 & 7.918 & 9.615 & - & - & - & - & - & 9 & 0 \\
\hline 130 & $\mathrm{~A}$ & B & $\mathrm{A}$ & B & 8.114 & 12.665 & 8.127 & 12.941 & - & - & - & - & - & 9 & 0 \\
\hline 131 & $\mathrm{~A}$ & $\bar{B}$ & $\mathrm{~A}$ & B & 8.114 & 12.665 & 8.127 & 12.941 & SS & 1 & 1 & 1 & 1 & 9 & 0 \\
\hline 132 & $\mathrm{~A}$ & $\mathrm{~B}$ & $\mathrm{~A}$ & B & 8.114 & 12.665 & 8.127 & 12.941 & SS & 1 & 1 & 1 & 1 & 9 & 0 \\
\hline 133 & $\mathrm{~A}$ & B & $\mathrm{A}$ & B & 8.114 & 12.665 & 8.127 & 12.941 & SS & 1 & 3 & 1 & 3 & 9 & 0 \\
\hline 134 & $\mathrm{~A}$ & B & $\mathrm{A}$ & B & 8.114 & 12.665 & 8.127 & 12.941 & SS & $\overline{1}$ & 3 & 1 & 3 & 9 & 0 \\
\hline 135 & $\mathrm{~A}$ & B & $\mathrm{A}$ & B & 8.114 & 12.665 & 8.127 & 12.941 & Boral & 1 & 1 & $\overline{1}$ & $\frac{1}{1}$ & 9 & 0 \\
\hline $136 \mathrm{a}$ & $\bar{A}$ & $\bar{B}$ & $\mathrm{~A}$ & B & 8.114 & 12.665 & 8.127 & 12.941 & Boral & 1 & - & - & - & 9 & 0 \\
\hline $136 \mathrm{~b}$ & $\mathrm{~A}$ & B & $\mathrm{A}$ & B & 8.114 & 12.665 & 8.127 & 12.941 & Boral & 1 & - & - & - & 9 & 0 \\
\hline 137 & $\mathrm{~A}$ & B & $\mathrm{A}$ & B & 8.114 & 12.665 & 8.127 & 12.941 & - & - & - & - & - & 9 & 0 \\
\hline 138 & $\mathrm{~A}$ & B & $\mathrm{A}$ & B & 7.931 & 9.519 & 7.918 & 9.615 & - & - & - & - & - & 9 & 0 \\
\hline $139 a$ & A & B & $\mathrm{A}$ & B & 7.931 & 9.519 & 7.918 & 9.615 & - & - & - & - & $\therefore-$ & 9 & 0 \\
\hline $139 b$ & $\overline{\mathrm{A}}$ & $\bar{B}$ & $\mathrm{~A}$ & $\mathrm{~B}$ & 7.931 & 9.519 & 7.918 & 9.615 & - & - & - & - & - & 9 & 0 \\
\hline $139 c$ & $\mathrm{~A}$ & B & $\mathrm{A}$ & $\bar{B}$ & 7.931 & 9.519 & 7.918 & 9.615 & - & - & - & - & - & 9 & 0 \\
\hline
\end{tabular}


Table C.1. (continued)

\begin{tabular}{|c|c|c|c|c|c|c|c|c|c|c|c|c|c|c|c|}
\hline \multicolumn{16}{|c|}{ Table C.1. (continued) } \\
\hline & \multicolumn{4}{|c|}{ Fuel orientation } & \multicolumn{4}{|c|}{ Center-to-fuel spacing } & \multicolumn{5}{|c|}{ Absorbing plates } & \multirow{2}{*}{$\frac{\begin{array}{c}\text { Det. } \\
\text { position }\end{array}}{(\mathrm{cm})}$} & \multirow{2}{*}{$\begin{array}{c}\begin{array}{c}\text { Source } \\
\text { position }\end{array} \\
(\mathrm{cm})\end{array}$} \\
\hline $\begin{array}{c}\text { Run } \\
\text { no. }\end{array}$ & $\mathrm{N}$ & $\mathrm{E}$ & $\mathrm{S}$ & $\mathrm{W}$ & $\mathrm{N}$ & $\mathrm{E}$ & $\bar{S}$ & $\bar{W}$ & Type & $\mathrm{N}$ & $\bar{E}$ & $\bar{S}$ & $\bar{W}$ & & \\
\hline $139 d$ & $\mathrm{~A}$ & $B$ & $\mathrm{~A}$ & B & 7.931 & 9.519 & 7.918 & 9.615 & - & - & - & - & - & 9 & 0 \\
\hline $139 \mathrm{e}$ & A & $\mathrm{B}$ & $\mathrm{A}$ & $\mathrm{B}$ & 7.931 & 9.519 & 7.918 & 9.615 & - & - & - & - & - & 9 & 0 \\
\hline 140 & A & $\mathrm{B}$ & $\overline{\mathrm{A}}$ & B & 7.931 & 9.519 & 7.918 & 9.615 & - & - & - & - & - & 9 & 0 \\
\hline 141 & $\mathrm{~A}$ & $B$ & $\mathrm{~A}$ & B & 8.114 & 12.665 & 8.127 & 12.941 & - & - & - & - & - & 9 & 0 \\
\hline 142 & $\mathrm{~A}$ & $\mathrm{~B}$ & A & B & 8.114 & 12.665 & 8.127 & 12.941 & - & - & - & - & - & 9 & 0 \\
\hline 143 & $\mathrm{~A}$ & $\mathrm{~B}$ & $\mathrm{~A}$ & B & 8.114 & 12.665 & 8.127 & 12.941 & - & - & - & - & - & 9 & 0 \\
\hline $144 a$ & $\mathrm{~A}$ & B & $\mathrm{A}$ & B & 8.114 & 12.665 & 8.127 & 12.941 & SS & 4 & 4 & 4 & 4 & 9 & 0 \\
\hline $144 b$ & $\mathrm{~A}$ & B & $\mathrm{A}$ & $B$ & 8.114 & 12.665 & 8.127 & 12.941 & SS & 4 & 4 & 4 & 4 & 9 & 0 \\
\hline $144 c$ & A & B & $\mathrm{A}$ & B & 8.114 & 12.665 & 8.127 & 12.941 & SS & 4 & 4 & 4 & 4 & 9 & 0 \\
\hline $145 a$ & $\mathrm{~A}$ & $B$ & $\mathrm{~A}$ & B & 8.114 & 12.665 & 8.127 & 12.941 & SS & 4 & 4 & 4 & 4 & 9 & 0 \\
\hline $145 b$ & $\mathrm{~A}$ & $\mathrm{~B}$ & $\bar{A}$ & B & 8.114 & 12.665 & 8.127 & 12.941 & SS & 4 & 4 & 4 & 4 & 9 & 0 \\
\hline $146 a$ & $\overline{\mathrm{A}}$ & $\bar{B}$ & $\overline{\mathrm{A}}$ & B & 8.114 & 12.665 & 8.127 & 12.941 & Boral & 1 & 1 & - & 1 & 9 & 0 \\
\hline $146 \mathrm{~b}$ & $A$ & $\mathrm{~B}$ & $\mathrm{~A}$ & $B$ & 8.114 & 12.665 & 8.127 & 12.941 & Boral & 1 & 1 & - & 1 & 9 & 0 \\
\hline $146 \mathrm{c}$ & $\mathrm{A}$ & B & $\mathrm{A}$ & B & 8.114 & 12.665 & 8.127 & 12.941 & Boral & 1 & 1 & - & 1 & 9 & 0 \\
\hline $146 \mathrm{~d}$ & $\overline{\mathrm{A}}$ & B & $\mathrm{A}$ & B & 8.114 & 12.665 & 8.127 & 12.941 & Boral & 1 & 1 & - & 1 & 9 & 0 \\
\hline 147 & $\mathrm{~A}$ & B & $\mathrm{A}$ & B & 8.114 & 12.665 & 8.127 & 12.941 & Boral & 1 & - & 1 & - & 9 & 0 \\
\hline 148 & $\mathrm{~A}$ & $\mathrm{~B}$ & $\mathrm{~A}$ & B & 8.114 & 12.665 & 8.127 & 12.941 & Boral & 1 & - & 1 & 1 & 9 & 0 \\
\hline $149 a$ & $\mathrm{~A}$ & $\mathrm{~B}$ & $\mathrm{~A}$ & B & 8.114 & 12.665 & 8.127 & 12.941 & Boral & 1 & - & 1 & 1 & 9 & 0 \\
\hline $149 b$ & $\overline{\mathrm{A}}$ & $\mathrm{B}$ & $\bar{A}$ & $\mathrm{~B}$ & 8.114 & 12.665 & 8.127 & 12.941 & Boral & 1 & - & 1 & 1 & 9 & 0 \\
\hline $149 \mathrm{c}$ & $A$ & $\mathrm{~B}$ & $\mathrm{~A}$ & $B$ & 8.114 & 12.665 & 8.127 & 12.941 & Boral & 1 & - & $\overline{1}$ & $\overline{1}$ & 9 & 0 \\
\hline $149 d$ & $\mathrm{~A}$ & B & A & $B$ & 8.114 & 12.665 & 8.127 & 12.941 & Boral & 1 & - & 1 & 1 & 9 & 0 \\
\hline $150 \mathrm{a}$ & $\overline{\mathrm{A}}$ & $\mathrm{B}$ & $\mathrm{A}$ & B & 8.114 & 12.665 & 8.127 & 12.941 & Boral & 1 & - & - & 1 & 9 & 0 \\
\hline $150 \mathrm{~b}$ & $\bar{A}$ & $\mathrm{~B}$ & $\overline{\mathrm{A}}$ & B & 8.114 & 12.665 & 8.127 & 12.941 & Boral & 1 & - & - & 1 & 9 & 0 \\
\hline $150 c$ & $\mathrm{~A}$ & B & $\mathrm{A}$ & B & 8.114 & 12.665 & 8.127 & 12.941 & Boral & 1 & - & - & 1 & 9 & 0 \\
\hline
\end{tabular}




\begin{tabular}{|c|c|c|c|c|c|c|c|c|c|c|c|c|c|c|c|}
\hline \multicolumn{16}{|c|}{ Table C.1. (continued) } \\
\hline & \multicolumn{4}{|c|}{ Fuel orientation } & \multicolumn{4}{|c|}{ Center-to-fuel spacing } & \multicolumn{5}{|c|}{ Absorbing plates } & \multirow{2}{*}{$\begin{array}{c}\begin{array}{c}\text { Det. } \\
\text { position }\end{array} \\
\text { (cm) }\end{array}$} & \multirow{2}{*}{$\begin{array}{c}\begin{array}{c}\text { Source } \\
\text { position }\end{array} \\
(\mathrm{cm})\end{array}$} \\
\hline $\begin{array}{c}\text { Run } \\
\text { no. }\end{array}$ & $\mathrm{N}$ & $\bar{E}$ & $S$ & $\mathrm{~W}$ & $\mathrm{~N}$ & $\mathrm{E}$ & $\mathrm{S}$ & $\mathrm{W}$ & Type & $\mathrm{N}$ & $\bar{E}$ & $\mathrm{~S}$ & $\mathrm{~W}$ & & \\
\hline $150 \mathrm{~d}$ & $\mathrm{~A}$ & $\mathrm{~B}$ & $\mathrm{~A}$ & $\mathrm{~B}$ & 8.114 & 12.665 & 8.127 & 12.941 & Boral & 1 & - & - & 1 & 9 & 0 \\
\hline $151 \mathrm{a}$ & $\mathrm{A}$ & $\mathrm{B}$ & $\mathrm{A}$ & $\mathrm{B}$ & 8.114 & $12: 665$ & 8.127 & 12.941 & Boral & - & - & - & 1 & 9 & 0 \\
\hline $151 \mathrm{~b}$ & $\mathrm{~A}$ & $\mathrm{~B}$ & A & B & 8.114 & 12.665 & 8.127 & 12.941 & Boral & - & - & - & 1 & 9 & 0 \\
\hline $151 \mathrm{c}$ & $\mathrm{A}$ & $\mathrm{B}$ & $\bar{A}$ & $\mathrm{~B}$ & 8.114 & 12.665 & 8.127 & 12.941 & Boral & - & - & - & 1 & 9 & 0 \\
\hline $151 \mathrm{~d}$ & $\mathrm{~A}$ & $\bar{B}$ & $\overline{\mathrm{A}}$ & $\mathrm{B}$ & 8.114 & 12.665 & 8.127 & 12.941 & Boral & - & - & - & 1 & 9 & 0 \\
\hline 152 & $\bar{A}$ & $\mathrm{~B}$ & $\overline{\mathrm{A}}$ & $\mathrm{B}$ & 8.114 & 12.665 & 8.127 & 12.941 & - & - & - & - & - & 9 & 0 \\
\hline $153 a$ & $\mathrm{~A}$ & $\mathrm{~B}$ & $\mathrm{~A}$ & $\mathrm{~B}$ & 8.114 & 12.665 & 8.127 & 12.941 & SS & - & 2 & - & 2 & 9 & 0 \\
\hline $153 \mathrm{~b}$ & $\mathrm{~A}$ & $\mathrm{~B}$ & $\mathrm{~A}$ & B & 8.114 & 12.665 & 8.127 & 12.941 & SS & - & 2 & - & 2 & 9 & 0 \\
\hline $154 \mathrm{a}$ & A & B & A & B & 8.114 & 12.665 & 8.127 & 12.941 & Boral & - & 1 & - & 1 & 9 & 0 \\
\hline $154 \mathrm{~b}$ & A & $B$ & $\mathrm{~A}$ & B & 8.114 & 12.665 & 8.127 & 12.941 & Boral & - & 1 & - & 1 & 9 & 0 \\
\hline $154 c$ & $\mathrm{~A}$ & $B$ & $\mathrm{~A}$ & B & 8.114 & 12.665 & 8.127 & 12.941 & Boral & - & 1 & - & 1 & 9 & 0 \\
\hline $154 d$ & $\mathrm{~A}$ & $\bar{B}$ & $\mathrm{~A}$ & B & 8.114 & 12.665 & 8.127 & 12.941 & Boral & - & 1 & - & 1 & 9 & 0 \\
\hline $154 \mathrm{e}$ & $\mathrm{A}$ & $B$ & $\mathrm{~A}$ & B & 8.114 & 12.665 & 8.127 & 12.941 & Boral & - & 1 & - & 1 & 9 & 0 \\
\hline $154 \mathrm{f}$ & $\bar{A}$ & B & $\bar{A}$ & $\bar{B}$ & 8.114 & 12.665 & 8.127 & 12.941 & Boral & - & 1 & - & 1 & 9 & 0 \\
\hline $154 \mathrm{~g}$ & $\bar{A}$ & B & $\bar{A}$ & $\mathrm{~B}$ & 8.114 & 12.665 & 8.127 & 12.941 & Boral & - & 1 & $\because$ & 1 & 9 & 0 \\
\hline $154 \mathrm{~h}$ & $\mathrm{~A}$ & $\mathrm{~B}$ & $\mathrm{~A}$ & B & 8.114 & 12.665 & 8.127 & 12.941 & Boral & - & 1 & - & 1 & 9 & 0 \\
\hline 155 & $\mathrm{~A}$ & B & $\mathrm{A}$ & B & 8.114 & 12.665 & 8.127 & 12.941 & SS & 1 & 2 & 1 & 2 & 9 & 0 \\
\hline 156 & $\overline{\mathrm{A}}$ & B & $\overline{\mathrm{A}}$ & B & 8.114 & 12.665 & 8.127 & 12.941 & SS & 1 & 2 & 1 & 2 & 9 & 0 \\
\hline 157 & $\bar{A}$ & $\bar{B}$ & $\mathrm{~A}$ & B & 8.114 & 12.665 & 8.127 & 12.941 & SS & 3 & 2 & 3 & 2 & 9 & 0 \\
\hline 158 & $\mathrm{~A}$ & B & $\mathrm{A}$ & B & 8.114 & 12.665 & 8.127 & 12.941 & SS & 3 & 2 & 3 & 2 & 9 & 0 \\
\hline $159 a$ & $\mathrm{~A}$ & B & $\mathrm{A}$ & B & 8.114 & 12.665 & 8.127 & 12.941 & SS & 2 & 3 & 2 & 3 & 9 & 0 \\
\hline $159 \mathrm{~b}$ & $\mathrm{~A}$ & $\bar{B}$ & $\mathrm{~A}$ & B & 8.114 & 12.665 & 8.127 & 12.941 & SS & 2 & 3 & 2 & 3 & 9 & 0 \\
\hline $159 \mathrm{c}$ & $\mathrm{A}$ & B & $\mathrm{A}$ & B & 8.114 & 12.665 & 8.127 & 12.941 & SS & 2 & 3 & 2 & 3 & 9 & 0 \\
\hline 160 & $\mathrm{~A}$ & B & $\mathrm{A}$ & $\mathrm{B}$ & 6.745 & 8.109 & 6.712 & 8.299 & - & - & - & - & - & 9 & $\overline{0}$ \\
\hline
\end{tabular}


Table C.1. (continued)

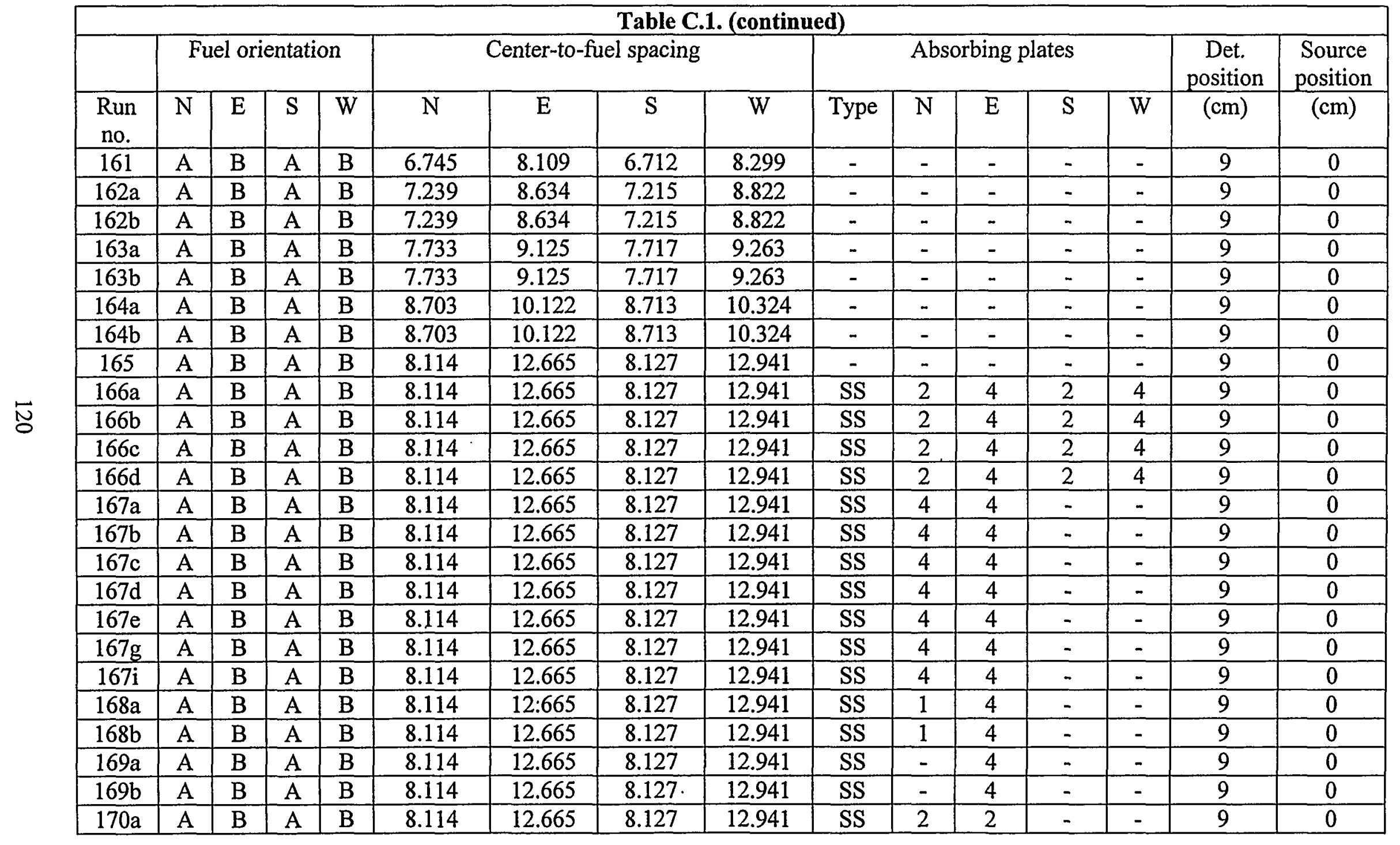




\begin{tabular}{|c|c|c|c|c|c|c|c|c|c|c|c|c|c|c|c|}
\hline \multicolumn{16}{|c|}{ Table C.1. (continued) } \\
\hline & \multicolumn{4}{|c|}{ Fuel orientation } & \multicolumn{4}{|c|}{ Center-to-fuel spacing } & \multicolumn{5}{|c|}{ Absorbing plates } & \multirow{2}{*}{$\begin{array}{c}\begin{array}{c}\text { Det. } \\
\text { position }\end{array} \\
(\mathrm{cm})\end{array}$} & \multirow{2}{*}{$\begin{array}{c}\begin{array}{c}\text { Source } \\
\text { position }\end{array} \\
(\mathrm{cm})\end{array}$} \\
\hline $\begin{array}{l}\text { Run } \\
\text { no. }\end{array}$ & $\mathrm{N}$ & $\mathrm{E}$ & $\mathrm{S}$ & $\bar{W}$ & $\bar{N}$ & $\mathrm{E}$ & $S$ & $\mathrm{~W}$ & Type & $\mathrm{N}$ & $\mathrm{E}$ & $\overline{\mathrm{S}}$ & $\bar{W}$ & & \\
\hline $170 \mathrm{~b}$ & $\mathrm{~A}$ & $\mathrm{~B}$ & $\mathrm{~A}$ & $\mathrm{~B}$ & 8.114 & 12.665 & 8.127 & 12.941 & SS & 2 & 2 & - & - & 9 & 0 \\
\hline 171 & $\mathrm{~A}$ & $\mathrm{~B}$ & $\mathrm{~A}$ & $\mathrm{~B}$ & 8.114 & 12.665 & 8.127 & 12.941 & - & - & - & - & - & 9 & 0 \\
\hline $172 a$ & $\mathrm{~A}$ & $\mathrm{~B}$ & $\mathrm{~A}$ & $\mathrm{~B}$ & 6.745 & 8.109 & 6.712 & 8.299 & - & - & - & - & - & 10.5 & $0(N)$ \\
\hline $172 b$ & $\mathrm{~A}$ & $\mathrm{~B}$ & $\mathrm{~A}$ & $\mathrm{~B}$ & 6.745 & 8.109 & 6.712 & 8.299 & - & - & - & - & - & 10.5 & $0(\mathrm{~N})$ \\
\hline $172 \mathrm{c}$ & $\mathrm{A}$ & $\mathrm{B}$ & $\mathrm{A}$ & $\mathrm{B}$ & 6.745 & 8.109 & 6.712 & 8.299 & - & - & - & - & - & 10.5 & $0(\mathrm{~N})$ \\
\hline $172 \mathrm{~d}$ & $\mathrm{~A}$ & $\mathrm{~B}$ & $\mathrm{~A}$ & $\mathrm{~B}$ & 6.745 & 8.109 & 6.712 & 8.299 & - & - & - & - & - & 10.5 & $0(\mathrm{~N})$ \\
\hline $173 a$ & $\mathrm{~A}$ & $\mathrm{~B}$ & $\mathrm{~A}$ & $\mathrm{~B}$ & 6.745 & 8.109 & 6.712 & 8.299 & - & - & - & - & - & 10.5 & $0(\mathrm{~N})$ \\
\hline $173 b$ & $\mathrm{~A}$ & $\mathrm{~B}$ & $\mathrm{~A}$ & $\mathrm{~B}$ & 6.745 & 8.109 & 6.712 & 8.299 & - & - & - & - & - & 10.5 & $0(\mathrm{~N})$ \\
\hline $174 a$ & $\mathrm{~A}$ & $\mathrm{~B}$ & $\mathrm{~A}$ & B & 6.745 & 8.109 & 6.712 & 8.299 & - & - & - & - & - & 10.5 & $0(\mathrm{~N})$ \\
\hline $174 b$ & $\mathrm{~A}$ & $\mathrm{~B}$ & $\mathrm{~A}$ & $\mathrm{~B}$ & 6.745 & 8.109 & 6.712 & 8.299 & - & - & - & - & - & 10.5 & $0(\mathrm{~N})$ \\
\hline $174 \mathrm{c}$ & $\mathrm{A}$ & $\mathrm{B}$ & $\mathrm{A}$ & $\mathrm{B}$ & 6.745 & 8.109 & 6.712 & 8.299 & - & - & - & - & - & 10.5 & $0(\mathrm{~N})$ \\
\hline $175 \mathrm{a}$ & $\mathrm{A}$ & $\mathrm{B}$ & $\mathrm{A}$ & $\mathrm{B}$ & 6.745 & 8.109 & 6.712 & 8.299 & - & - & - & - & - & 10.5 & $0(\mathrm{~N})$ \\
\hline $175 b$ & $\mathrm{~A}$ & $\mathrm{~B}$ & $\mathrm{~A}$ & $\mathrm{~B}$ & 6.745 & 8.109 & 6.712 & 8.299 & - & $\therefore$ & - & - & - & 10.5 & $0(\mathrm{~N})$ \\
\hline 176 & $\mathrm{~A}$ & $\mathrm{~B}$ & $\mathrm{~A}$ & $\mathrm{~B}$ & 6.745 & 8.109 & 6.712 & 8.299 & - & - & - & - & - & 10.5 & $0(\mathrm{~N})$ \\
\hline 177 & $\mathrm{~A}$ & B & $\mathrm{A}$ & $\mathrm{B}$ & 6.745 & 8.109 & 6.712 & 8.299 & - & - & - & - & - & 10.5 & $0(\mathrm{~N})$ \\
\hline $178 a$ & $\mathrm{~A}$ & $\mathrm{~B}$ & $\mathrm{~A}$ & $\mathrm{~B}$ & 6.745 & 8.109 & 6.712 & 8.299 & - & - & - & - & - & 10.5 & $0(\mathrm{~N})$ \\
\hline $178 \mathrm{~b}$ & $\mathrm{~A}$ & $\mathrm{~B}$ & $\mathrm{~A}$ & $\mathrm{~B}$ & 6.745 & 8.109 & 6.712 & 8.299 & - & - & - & - & - & 10.5 & $0(\mathrm{~N})$ \\
\hline 179 & $\mathrm{~A}$ & $\bar{B}$ & $\mathrm{~A}$ & $\mathrm{~B}$ & 6.745 & 8.109 & 6.712 & 8.299 & - & - & - & - & - & 10.5 & $0(\mathrm{~N})$ \\
\hline 180 & $\mathrm{~A}$ & $\mathrm{~B}$ & $\mathrm{~A}$ & B & 6.745 & 8.109 & 6.712 & 8.299 & - & - & - & - & - & 10.5 & $0(\mathrm{~N})$ \\
\hline 181 & $\mathrm{~A}$ & $\mathrm{~B}$ & $\mathrm{~A}$ & B & 6.745 & 8.109 & 6.712 & 8.299 & - & - & - & - & - & 10.5 & $0(\mathrm{~N})$ \\
\hline 183 & $\mathrm{~A}$ & $\mathrm{~B}$ & $\mathrm{~A}$ & $\mathrm{~B}$ & 6.745 & 8.109 & 6.712 & 8.299 & - & - & - & - & - & 10.5 & $0(\mathrm{~N})$ \\
\hline 185 & $\mathrm{~A}$ & $\mathrm{~B}$ & $\mathrm{~A}$ & B & 6.745 & 8.109 & 6.712 & 8.299 & - & - & - & - & - & 10.5 & $0(\mathrm{~N})$ \\
\hline 186 & $\mathrm{~A}$ & B & $\mathrm{A}$ & B & 6.745 & 8.109 & 6.712 & 8.299 & - & - & - & - & - & 10.5 & $0(\mathrm{~N})$ \\
\hline 187 & $\mathrm{~A}$ & B & $\mathrm{A}$ & B & 6.745 & 8.109 & 6.712 & 8.299 & - & - & - & - & - & 10.5 & $0(N)$ \\
\hline
\end{tabular}


Table C.1. (continued)

\begin{tabular}{|c|c|c|c|c|c|c|c|c|c|c|c|c|c|c|c|c|}
\hline \multicolumn{10}{c|}{ Table C.1. (continued) } \\
\hline \multicolumn{10}{|c|}{ Fuel orientation } & \multicolumn{9}{c|}{ Center-to-fuel spacing } & \multicolumn{3}{c|}{ Absorbing plates } & $\begin{array}{c}\text { Det. } \\
\text { position }\end{array}$ & $\begin{array}{c}\text { Source } \\
\text { position }\end{array}$ \\
\hline $\begin{array}{c}\text { Run } \\
\text { no. }\end{array}$ & N & E & S & W & N & E & S & W & Type & N & E & S & W & (cm) & $(\mathrm{cm})$ \\
\hline 189 & A & B & A & B & 6.745 & 8.109 & 6.712 & 8.299 & - & - & - & - & - & 10.5 & 0 \\
\hline 190 & A & B & A & B & 6.745 & 8.109 & 6.712 & 8.299 & - & - & - & - & - & 10.5 & 0 \\
\hline 191 & A & B & A & B & 6.745 & 8.109 & 6.712 & 8.299 & - & - & - & - & - & 10.5 & 0 \\
\hline 192 & A & B & A & B & 6.745 & 8.109 & 6.712 & 8.299 & - & - & - & - & - & 10.5 & 0 \\
\hline 193 & A & B & A & B & 6.745 & 8.109 & 6.712 & 8.299 & - & - & - & - & - & 10.5 & 0 \\
\hline 194 & A & B & A & B & 6.745 & 8.109 & 6.712 & 8.299 & - & - & - & - & - & 10.5 & 0 \\
\hline
\end{tabular}




\section{APPENDIX D}

\section{FOURIER ANALYSIS SYSTEMS SETTINGS}

The settings for the RC units, sampling rates, block size, and number of data blocks acquired for each run were as specified in Table D.1.

\begin{tabular}{|c|c|c|c|c|c|c|c|c|c|}
\hline \multicolumn{10}{|c|}{ Table D.1. Electronic systems configuration } \\
\hline \multirow{2}{*}{$\begin{array}{c}\text { Run } \\
\text { no. }\end{array}$} & 1 & 2 & 3 & 4 & 5 & $\begin{array}{c}\text { RC } \\
\text { gain }\end{array}$ & $\begin{array}{c}\text { Block } \\
\text { size }\end{array}$ & $\begin{array}{c}\text { Band } \\
\text { width } \\
(\mathrm{kHz})\end{array}$ & $\begin{array}{c}\text { Blocks } \\
(\mathrm{k})\end{array}$ \\
\hline 1 & 50 & 50 & 50 & 50 & 50 & 1.75 & 1024 & 10 & 10 \\
\hline 2 & 50 & 50 & 50 & 50 & 50 & 1.75 & 512 & 10 & 30 \\
\hline $2 \mathrm{r}$ & 50 & 50 & 50 & 50 & 50 & 1.75 & 512 & 10 & 30 \\
\hline 3 & 50 & 50 & 50 & 50 & 50 & 1.75 & 1024 & 10 & 10 \\
\hline 4 & 50 & 50 & 50 & 50 & 50 & 1.75 & 512 & 10 & 30 \\
\hline $4 \mathrm{r}$ & 50 & 50 & 50 & 50 & 50 & 1.75 & 512 & 10 & 30 \\
\hline 5 & 20 & 20 & 20 & 20 & 20 & 1.75 & 1024 & 5 & 30 \\
\hline 6 & 50 & 50 & 50 & 50 & 50 & 1.75 & 1024 & 10 & 10 \\
\hline 7 & 50 & 50 & 50 & 50 & 50 & 1.75 & 512 & 10 & 30 \\
\hline 8 & 20 & 20 & 20 & 20 & 20 & 1.75 & 1024 & 5 & 10 \\
\hline 9 & 50 & 50 & 50 & 50 & 50 & 1.75 & 1024 & 10 & 10 \\
\hline 10 & 50 & 50 & 50 & 50 & 50 & 1.75 & 1024 & 10 & 10 \\
\hline 11 & 50 & 50 & 50 & 50 & 50 & 1.75 & 1024 & 10 & 10 \\
\hline 12 & 50 & 50 & 50 & 50 & 50 & 1.75 & 1024 & 10 & 10 \\
\hline 13 & 50 & 50 & 50 & 50 & 50 & 1.75 & 1024 & 10 & 10 \\
\hline 14 & 20 & 20 & 20 & 20 & 20 & 1.75 & 512 & 5 & 10 \\
\hline 15 & 20 & 20 & 20 & 20 & 20 & 1.75 & 512 & 5 & 10 \\
\hline 16 & 20 & 20 & 20 & 20 & 20 & 1.75 & 512 & 5 & 10 \\
\hline 17 & 20 & 20 & 20 & 20 & 20 & 1.75 & 512 & 5 & 10 \\
\hline 18 & 20 & 20 & 20 & 20 & 20 & 1.75 & 512 & 5 & 10 \\
\hline 19 & 20 & 20 & 20 & 20 & 20 & 1.75 & 512 & 5 & 10 \\
\hline 20 & 20 & 20 & 20 & 20 & 20 & 1.75 & 512 & 5 & 10 \\
\hline 21 & 20 & 20 & 20 & 20 & 20 & 1.75 & 512 & 5 & 10 \\
\hline 22 & 20 & 20 & 20 & 20 & 20 & 1.75 & 512 & 5 & 10 \\
\hline 23 & 20 & 20 & 20 & 20 & 20 & 1.75 & 512 & 5 & 10 \\
\hline 24 & 20 & 20 & 20 & 20 & 20 & 1.75 & 512 & 5 & 10 \\
\hline 25 & 20 & 20 & 20 & 20 & 50 & 1.75 & 512 & 5 & 10 \\
\hline 26 & 20 & 20 & 20 & 20 & 50 & 1.75 & 512 & 5 & 10 \\
\hline 27 & 20 & 20 & 20 & 20 & 50 & 1.75 & 512 & 5 & 10 \\
\hline 28 & 20 & 20 & 20 & 20 & 50 & 1.75 & 512 & 5 & 10 \\
\hline 29 & 20 & 20 & 20 & 20 & 50 & 1.75 & 512 & 5 & 10 \\
\hline
\end{tabular}




\begin{tabular}{|c|c|c|c|c|c|c|c|c|c|}
\hline \multicolumn{10}{|c|}{ Table D.1. (continued) } \\
\hline \multirow[b]{2}{*}{$\begin{array}{c}\text { Run } \\
\text { no. }\end{array}$} & \multicolumn{5}{|c|}{$\mathrm{RC}$ frequency $(\mathrm{kHz})$} & \multirow[b]{2}{*}{$\begin{array}{l}\mathrm{RC} \\
\text { gain }\end{array}$} & \multirow[b]{2}{*}{$\begin{array}{c}\text { Block } \\
\text { size }\end{array}$} & \multirow{2}{*}{$\begin{array}{l}\text { Band } \\
\text { width } \\
(\mathrm{kHz})\end{array}$} & \multirow[b]{2}{*}{$\begin{array}{c}\text { Blocks } \\
\text { (k) }\end{array}$} \\
\hline & 1 & 2 & 3 & 4 & 5 & & & & \\
\hline 30 & 20 & 20 & 20 & 20 & 50 & 1.75 & 512 & 5 & 10 \\
\hline 31 & 20 & 20 & 20 & 20 & 50 & 1.75 & 512 & 5 & 10 \\
\hline 32 & 20 & 20 & 20 & 20 & 50 & 1.75 & 512 & 5 & 10 \\
\hline 33 & 20 & 20 & 20 & 20 & 50 & 1.75 & 512 & 5 & 10 \\
\hline 34 & 20 & 20 & 20 & 20 & 20 & 1.75 & 512 & 5 & 10 \\
\hline 35 & 20 & 20 & 20 & 20 & 20 & 1.75 & 512 & 5 & 10 \\
\hline 36 & 20 & 20 & 20 & 20 & 20 & 1.75 & 512 & 5 & 10 \\
\hline 37 & 20 & 20 & 20 & 20 & 20 & 1.75 & 512 & 5 & 10 \\
\hline 38 & 20 & 20 & 20 & 20 & 20 & 1.75 & 512 & 5 & 10 \\
\hline 39 & 20 & 20 & 20 & 20 & 20 & 1.75 & 512 & 5 & 100 \\
\hline 40 & 20 & 20 & 20 & 20 & 20 & 1.75 & 512 & 5 & 10 \\
\hline 41 & 20 & 20 & 20 & 20 & 20 & 1.75 & $\overline{512}$ & 5 & 10 \\
\hline 42 & 20 & 20 & 20 & 20 & 20 & 1.75 & $\overline{512}$ & 5 & 10 \\
\hline 43 & 20 & 20 & 20 & 20 & 20 & 1.75 & 512 & 5 & 10 \\
\hline 44 & 20 & 20 & 20 & 20 & 20 & 1.75 & 512 & 5 & 10 \\
\hline 45 & 20 & 20 & 20 & 20 & 20 & 1.75 & 512 & 5 & 10 \\
\hline 46 & 20 & 20 & 20 & 20 & 20 & 1.75 & 512 & 5 & 10 \\
\hline 47 & 20 & 20 & 20 & 20 & 20 & 1.75 & 1024 & 2 & 5 \\
\hline 48 & 20 & 20 & 20 & 20 & 20 & 1.75 & 512 & 5 & 10 \\
\hline 49 & 20 & 20 & 20 & 20 & 20 & 1.75 & 512 & 5 & 10 \\
\hline 50 & 20 & 20 & 20 & 20 & 20 & 1.75 & $\overline{512}$ & 5 & 10 \\
\hline 51 & 20 & 20 & 20 & 20 & 20 & 1.75 & 512 & 5 & 10 \\
\hline 52 & 20 & 20 & 20 & 20 & 20 & 1.75 & 512 & 5 & 10 \\
\hline 53 & 20 & 20 & 20 & 20 & 20 & 1.75 & 512 & 5 & 10 \\
\hline 54 & 20 & 20 & 20 & 20 & 20 & 1.75 & 512 & 5 & 10 \\
\hline 55 & 20 & 20 & 20 & 20 & 20 & 1.75 & 512 & 5 & 10 \\
\hline 56 & 20 & 20 & 20 & 20 & 20 & 1.75 & 512 & 5 & 10 \\
\hline 57 & 20 & 20 & 20 & 20 & 20 & 1.75 & 512 & 5 & 10 \\
\hline 58 & 20 & 20 & 20 & 20 & 20 & 1.75 & 512 & 5 & 10 \\
\hline 59 & 20 & 20 & 20 & 20 & 20 & 1.75 & 512 & 5 & 10 \\
\hline 60 & 20 & 20 & 20 & 20 & 20 & 1.75 & 512 & 5 & 10 \\
\hline 61 & 20 & 20 & 20 & 20 & 20 & 1.75 & 512 & 5 & 10 \\
\hline 62 & 20 & 20 & 20 & 20 & 20 & 1.75 & 512 & 5 & 10 \\
\hline 63 & 20 & 20 & 20 & 20 & 20 & 1.75 & 512 & 5 & 10 \\
\hline 64 & 20 & 20 & 20 & 20 & 20 & 1.75 & 512 & 5 & 350 \\
\hline 65 & 20 & 20 & 20 & 20 & 20 & 1.75 & 512 & 5 & 10 \\
\hline 66 & 20 & 20 & 20 & 20 & 20 & 1.75 & 512 & 5 & 10 \\
\hline 67 & 20 & 20 & 20 & 20 & 20 & 1.75 & 512 & 5 & 10 \\
\hline 68 & 20 & 20 & 20 & 20 & 20 & 1.75 & 512 & 5 & 10 \\
\hline
\end{tabular}




\begin{tabular}{|c|c|c|c|c|c|c|c|c|c|}
\hline \multicolumn{10}{|c|}{ Table D.1. (continued) } \\
\hline \multirow[b]{2}{*}{$\begin{array}{l}\text { Run } \\
\text { no. }\end{array}$} & \multicolumn{5}{|c|}{$\mathrm{RC}$ frequency $(\mathrm{kHz})$} & \multirow[b]{2}{*}{$\begin{array}{l}\mathrm{RC} \\
\text { gain }\end{array}$} & \multirow[b]{2}{*}{$\begin{array}{c}\text { Block } \\
\text { size }\end{array}$} & \multirow{2}{*}{$\begin{array}{l}\text { Band } \\
\text { width } \\
(\mathrm{kHz})\end{array}$} & \multirow[b]{2}{*}{$\begin{array}{l}\text { Blocks } \\
\text { (k) }\end{array}$} \\
\hline & 1 & 2 & 3 & 4 & 5 & & & & \\
\hline 69 & 20 & 20 & 20 & 20 & 20 & 1.75 & 512 & 5 & 10 \\
\hline 70 & 20 & 20 & 20 & 20 & 20 & 1.75 & 512 & 5 & 10 \\
\hline 71 & 20 & 20 & 20 & 20 & 20 & 1.75 & 512 & 5 & 10 \\
\hline 72 & 20 & 20 & 20 & 20 & 20 & 1.75 & 512 & 5 & 10 \\
\hline 73 & 20 & 20 & 20 & 20 & 20 & 1.75 & 512 & 5 & 10 \\
\hline 74 & 20 & 20 & 20 & 20 & 20 & 1.75 & 512 & 5 & 10 \\
\hline 75 & 20 & 20 & 20 & 20 & 20 & 1.75 & 512 & 5 & 10 \\
\hline 76 & 20 & 20 & 20 & 20 & 20 & 1.75 & 512 & 5 & 10 \\
\hline 77 & 20 & 20 & 20 & 20 & 20 & 1.75 & 512 & 5 & 10 \\
\hline 78 & 20 & 20 & 20 & 20 & 20 & 1.75 & 512 & 5 & 10 \\
\hline 79 & 20 & 20 & 20 & 20 & 20 & 1.75 & 512 & 5 & 10 \\
\hline 80 & 20 & 20 & 20 & 20 & 20 & 1.75 & 512 & 5 & 10 \\
\hline 81 & 20 & 20 & 20 & 20 & 20 & 1.75 & 512 & 5 & 10 \\
\hline 82 & 20 & 20 & 20 & 20 & 20 & 1.75 & 512 & 5 & 10 \\
\hline 83 & 20 & 20 & 20 & 20 & 20 & 1.75 & 512 & 5 & 10 \\
\hline 84 & 20 & 20 & 20 & 20 & 20 & 1.75 & 512 & 5 & 10 \\
\hline 85 & 20 & 20 & 20 & 20 & 20 & 1.75 & 512 & 5 & 10 \\
\hline 86 & 20 & 20 & 20 & 20 & 20 & 1.75 & 512 & 5 & 10 \\
\hline 87 & 20 & 20 & 20 & 20 & 20 & 1.75 & 512 & 5 & 10 \\
\hline 88 & 20 & 20 & 20 & 20 & 20 & 1.75 & 512 & 5 & 10 \\
\hline 89 & 20 & 20 & 20 & 20 & 20 & 1.75 & 512 & 5 & 10 \\
\hline 90 & 20 & 20 & 20 & 20 & 20 & 1.75 & 512 & 5 & 100 \\
\hline 91 & 20 & 20 & 20 & 20 & 20 & 1.75 & 512 & 5 & 75 \\
\hline 92 & 20 & 20 & 20 & 20 & 20 & 1.75 & 512 & 5 & 10 \\
\hline 93 & 20 & 20 & 20 & 20 & 20 & 1.75 & 512 & 5 & 10 \\
\hline 94 & 20 & 20 & 20 & 20 & 20 & 1.75 & 512 & 5 & 10 \\
\hline 95. & 20 & 20 & 20 & 20 & 20 & 1.75 & 512 & 5 & 10 \\
\hline 96 & 20 & 20 & 20 & 20 & 20 & 1.75 & 512 & 5 & 10 \\
\hline 97 & 20 & 20 & 20 & 20 & 20 & 1.75 & 512 & 5 & 10 \\
\hline 98 & 20 & 20 & 20 & 20 & 20 & 1.75 & 512 & 5 & 10 \\
\hline 99 & 20 & 20 & 20 & 20 & 20 & 1.75 & 512 & 5 & 10 \\
\hline 100 & 20 & 20 & 20 & 20 & 20 & 1.75 & 512 & 5 & 10 \\
\hline 101 & 20 & 20 & 20 & 20 & 20 & 1.75 & 512 & 5 & 10 \\
\hline 102 & 20 & 20 & 20 & 20 & 20 & 1.75 & 512 & 5 & 10 \\
\hline 103 & 20 & 20 & 20 & 20 & 20 & 1.75 & 512 & 5 & 10 \\
\hline 104 & 20 & 20 & 20 & 20 & 20 & 1.75 & 512 & 5 & 10 \\
\hline 105 & 20 & 20 & 20 & 20 & 20 & 1.75 & 512 & 5 & 10 \\
\hline 106 & 20 & 20 & 20 & 20 & 20 & 1.75 & 512 & 5 & 10 \\
\hline 107 & 20 & 20 & 20 & 20 & 20 & 1.75 & 512 & 5 & 10 \\
\hline
\end{tabular}




\begin{tabular}{|c|c|c|c|c|c|c|c|c|c|}
\hline \multicolumn{10}{|c|}{ Table D.1. (continued) } \\
\hline \multirow{2}{*}{$\begin{array}{c}\text { Run } \\
\text { no. }\end{array}$} & 1 & 2 & 3 & 4 & 5 & $\begin{array}{c}\text { RC } \\
\text { gain }\end{array}$ & $\begin{array}{c}\text { Block } \\
\text { size }\end{array}$ & $\begin{array}{c}\text { Band } \\
\text { width } \\
(\mathrm{kHz})\end{array}$ & $\begin{array}{c}\text { Blocks } \\
\text { (k) }\end{array}$ \\
\hline 108 & 20 & 20 & 20 & 20 & 20 & 1.75 & 512 & 5 & 10 \\
\hline 109 & 20 & 20 & 20 & 20 & 20 & 1.75 & 512 & 5 & 10 \\
\hline 110 & 20 & 20 & 20 & 20 & 20 & 1.75 & 512 & 5 & 10 \\
\hline 111 & 20 & 20 & 20 & 20 & 20 & 1.75 & 512 & 5 & 10 \\
\hline 112 & 20 & 20 & 20 & 20 & 20 & 1.75 & 512 & 5 & 10 \\
\hline 113 & 20 & 20 & 20 & 20 & 20 & 1.75 & 512 & 5 & 10 \\
\hline 114 & 20 & 20 & 20 & 20 & 20 & 1.75 & 512 & 5 & 10 \\
\hline 115 & 20 & 20 & 20 & 20 & 20 & 1.75 & 512 & 5 & 10 \\
\hline 116 & 20 & 20 & 20 & 20 & 20 & 1.75 & 512 & 5 & 10 \\
\hline 117 & 20 & 20 & 20 & 20 & 20 & 1.75 & 512 & 5 & 10 \\
\hline 118 & 20 & 20 & 20 & 20 & 20 & 1.75 & 512 & 5 & 10 \\
\hline 119 & 20 & 20 & 20 & 20 & 20 & 1.75 & 512 & 5 & 10 \\
\hline 120 & 20 & 20 & 20 & 20 & 20 & 1.75 & 512 & 5 & 50 \\
\hline 121 & 20 & 20 & 20 & 20 & 20 & 1.75 & 512 & 5 & 50 \\
\hline 122 & 20 & 20 & 20 & 20 & 20 & 1.75 & 512 & 5 & 50 \\
\hline 123 & 20 & 20 & 20 & 20 & 20 & 1.75 & 512 & 5 & 50 \\
\hline 124 & 20 & 20 & 20 & 20 & 20 & 1.75 & 512 & 5 & 150 \\
\hline 125 & 20 & 20 & 20 & 20 & 20 & 1.75 & 512 & 5 & 1000 \\
\hline 126 & 20 & 20 & 20 & 20 & 20 & 1.75 & 512 & 5 & 10 \\
\hline 127 & 20 & 20 & 20 & 20 & 20 & 1.75 & 512 & 5 & 10 \\
\hline 128 & 20 & 20 & 20 & 20 & 20 & 1.75 & 512 & 5 & 10 \\
\hline 129 & 20 & 20 & 20 & 20 & 20 & 1.75 & 512 & 5 & 10 \\
\hline 130 & 20 & 20 & 20 & 20 & 20 & 1.75 & 512 & 5 & 10 \\
\hline 131 & 20 & 20 & 20 & 20 & 20 & 1.75 & 512 & 5 & 50 \\
\hline 132 & 20 & 20 & 20 & 20 & 20 & 1.75 & 512 & 5 & 50 \\
\hline 133 & 20 & 20 & 20 & 20 & 20 & 1.75 & 512 & 5 & 100 \\
\hline 134 & 20 & 20 & 20 & 20 & 20 & 1.75 & 512 & 5 & 100 \\
\hline 135 & 50 & 50 & 50 & 50 & 50 & 1.75 & 1024 & 10 & 1000 \\
\hline $136 \mathrm{a}$ & 50 & 50 & 50 & 50 & 50 & 1.75 & 1024 & 10 & 50 \\
\hline $136 \mathrm{~b}$ & 50 & 50 & 50 & 50 & 50 & 1.75 & 1024 & 10 & 50 \\
\hline 137 & 20 & 20 & 20 & 20 & 20 & 1.75 & 512 & 5 & 10 \\
\hline 138 & 20 & 20 & 20 & 20 & 20 & 1.75 & 512 & 5 & 10 \\
\hline $139 \mathrm{a}$ & 20 & 20 & 20 & 20 & 20 & 1.75 & 512 & 5 & 2 \\
\hline $139 \mathrm{~b}$ & 20 & 20 & 20 & 20 & 20 & 1.75 & 512 & 5 & 2 \\
\hline $139 \mathrm{c}$ & 20 & 20 & 20 & 20 & 20 & 1.75 & 512 & 5 & 2 \\
\hline $139 \mathrm{~d}$ & 20 & 20 & 20 & 20 & 20 & 1.75 & 512 & 5 & 2 \\
\hline $139 \mathrm{e}$ & 20 & 20 & 20 & 20 & 20 & 1.75 & 512 & 5 & 2 \\
\hline 140 & 20 & 20 & 20 & 20 & 20 & 1.75 & 512 & 5 & 10 \\
\hline 141 & 20 & 20 & 20 & 20 & 20 & 1.75 & 512 & 5 & 10 \\
\hline
\end{tabular}




\begin{tabular}{|c|c|c|c|c|c|c|c|c|c|}
\hline \multicolumn{10}{|c|}{ Table D.1. (continued) } \\
\hline \multirow[b]{2}{*}{$\begin{array}{l}\text { Run } \\
\text { no. }\end{array}$} & \multicolumn{5}{|c|}{$\overline{\mathrm{RC}}$ frequency $(\mathrm{kHz})$} & \multirow[b]{2}{*}{$\begin{array}{l}R C \\
\text { gain }\end{array}$} & \multirow[b]{2}{*}{$\begin{array}{c}\text { Block } \\
\text { size }\end{array}$} & \multirow{2}{*}{$\begin{array}{l}\text { Band } \\
\text { width } \\
(\mathrm{kHz})\end{array}$} & \multirow[b]{2}{*}{$\begin{array}{c}\text { Blocks } \\
\text { (k) }\end{array}$} \\
\hline & 1 & 2 & 3 & 4 & 5 & & & & \\
\hline 142 & 20 & 20 & 20 & 20 & 20 & 1.75 & 512 & 5 & 10 \\
\hline 143 & 20 & 20 & 20 & 20 & 20 & 1.75 & 512 & 5 & 5 \\
\hline $144 a$ & 20 & 20 & 20 & 20 & 20 & 1.75 & 1024 & 10 & 50 \\
\hline $144 b$ & 20 & 20 & 20 & 20 & 20 & 1.75 & 1024 & 10 & 50 \\
\hline $144 \mathrm{c}$ & 20 & 20 & 20 & 20 & 20 & 1.75 & 1024 & 10 & 50 \\
\hline $145 a$ & 20 & 20 & $\overline{20}$ & 20 & 20 & 1.75 & 1024 & 10 & 50 \\
\hline $145 \mathrm{~b}$ & 20 & 20 & 20 & 20 & 20 & 1.75 & 1024 & 10 & 50 \\
\hline $146 a$ & 20 & 20 & 20 & 20 & 20 & 1.75 & 1024 & 10 & 100 \\
\hline $146 \mathrm{~b}$ & 20 & 20 & 20 & 20 & 20 & 1.75 & 1024 & 10 & 100 \\
\hline $146 \mathrm{c}$ & 20 & 20 & 20 & 20 & 20 & 1.75 & 1024 & 10 & 100 \\
\hline $146 d$ & 20 & 20 & 20 & 20 & 20 & 1.75 & 1024 & 10 & 100 \\
\hline 147 & 20 & 20 & 20 & 20 & 20 & 1.75 & 1024 & 10 & 100 \\
\hline 148 & 20 & 20 & 20 & 20 & 20 & 1.75 & 1024 & 10 & 50 \\
\hline $149 a$ & 20 & 20 & 20 & 20 & 20 & 1.75 & 1024 & 10 & 50 \\
\hline $149 \mathrm{~b}$ & 20 & 20 & 20 & 20 & 20 & 1.75 & 1024 & 10 & 50 \\
\hline $149 c$ & 20 & 20 & 20 & 20 & .20 & 1.75 & 1024 & 10 & 50 \\
\hline $149 d$ & 20 & 20 & 20 & 20 & 20 & 1.75 & 1024 & 10 & 50 \\
\hline $150 \mathrm{a}$ & 20 & 20 & 20 & 20 & 20 & 1.75 & 1024 & 10 & 50 \\
\hline $150 \mathrm{~b}$ & 20 & 20 & 20 & 20 & 20 & 1.75 & 1024 & $\overline{10}$ & 50 \\
\hline $150 c$ & 20 & 20 & 20 & 20 & 20 & 1.75 & 1024 & 10 & 50 \\
\hline $150 \mathrm{~d}$ & 20 & 20 & 20 & 20 & 20 & 1.75 & 1024 & 10 & 50 \\
\hline $151 a$ & 20 & 20 & 20 & 20 & 20 & 1.75 & 1024 & 10 & 50 \\
\hline $151 \mathrm{~b}$ & 20 & 20 & 20 & 20 & 20 & 1.75 & 1024 & 10 & 50 \\
\hline $151 \mathrm{c}$ & 20 & 20 & 20 & 20 & 20 & 1.75 & 1024 & 10 & 50 \\
\hline $151 \mathrm{~d}$ & 20 & 20 & 20 & 20 & 20 & 1.75 & 1024 & 10 & 50 \\
\hline 152 & 20 & 20 & 20 & 20 & 20 & 1.75 & 512 & 5 & 350 \\
\hline $153 a$ & 20 & 20 & 20 & 20 & 20 & 1.75 & 512 & 5 & 50 \\
\hline $153 \mathrm{~b}$ & 20 & 20 & 20 & 20 & 20 & 1.75 & 1024 & 10 & 50 \\
\hline $154 a$ & 20 & 20 & 20 & 20 & 20 & 1.75 & 1024 & 10 & 95 \\
\hline $154 \mathrm{~b}$ & 20 & 20 & 20 & 20 & 20 & 1.75 & 1024 & 10 & 95 \\
\hline $154 \mathrm{c}$ & 20 & 20 & 20 & 20 & 20 & 1.75 & 1024 & 10 & 95 \\
\hline $154 d$ & 20 & 20 & 20 & 20 & 20 & 1.75 & 1024 & 10 & 95 \\
\hline $154 \mathrm{e}$ & 20 & 20 & 20 & 20 & 20 & 1.75 & 1024 & 10 & 95 \\
\hline $154 \mathrm{f}$ & 20 & 20 & 20 & 20 & 20 & 1.75 & 1024 & 10 & 95 \\
\hline $154 \mathrm{~g}$ & 20 & 20 & 20 & 20 & 20 & 1.75 & 1024 & 10 & 95 \\
\hline $154 \mathrm{~h}$ & 20 & 20 & 20 & 20 & 20 & 1.75 & 1024 & 10 & 95 \\
\hline 155 & 20 & 20 & 20 & 20 & 20 & 1.75 & 512 & 5 & 50 \\
\hline 156 & 20 & 20 & 20 & 20 & 20 & 1.75 & 512 & 5 & 50 \\
\hline 157 & 20 & 20 & 20 & 20 & $\overline{20}$ & 1.75 & 512 & 5 & 50 \\
\hline
\end{tabular}




\begin{tabular}{|c|c|c|c|c|c|c|c|c|c|}
\hline \multicolumn{10}{|c|}{ Table D.1. (continued) } \\
\hline \multirow[b]{2}{*}{$\begin{array}{l}\text { Run } \\
\text { no. }\end{array}$} & \multicolumn{5}{|c|}{$\mathrm{RC}$ frequency $(\mathrm{kHz})$} & \multirow[b]{2}{*}{$\begin{array}{l}\mathrm{RC} \\
\text { gain }\end{array}$} & \multirow[b]{2}{*}{$\begin{array}{c}\text { Block } \\
\text { size }\end{array}$} & \multirow{2}{*}{$\begin{array}{l}\text { Band } \\
\text { width } \\
\text { (kHz) }\end{array}$} & \multirow[b]{2}{*}{$\begin{array}{l}\text { Blocks } \\
\text { (k) }\end{array}$} \\
\hline & 1 & 2 & 3 & 4 & 5 & & & & \\
\hline 158 & 20 & 20 & 20 & 20 & 20 & 1.75 & 512 & 5 & 50 \\
\hline $159 a$ & 20 & 20 & 20 & 20 & 20 & 1.75 & 512 & 5 & 50 \\
\hline $159 \mathrm{~b}$ & 20 & 20 & 20 & 20 & 20 & 1.75 & 512 & 5 & 50 \\
\hline $159 \mathrm{c}$ & 20 & 20 & 20 & 20 & 20 & 1.75 & 512 & 5 & 50 \\
\hline 160 & 20 & 20 & 20 & 20 & 20 & 1.75 & 512 & 5 & 10 \\
\hline 161 & 20 & 20 & 20 & 20 & 20 & 1.75 & 512 & 5 & 10 \\
\hline $162 a$ & 20 & 20 & 20 & 20 & 20 & 1.75 & 512 & 5 & 10 \\
\hline $162 \mathrm{~b}$ & 20 & 20 & 20 & 20 & 20 & 1.75 & 512 & 5 & 10 \\
\hline $163 a$ & 20 & 20 & 20 & 20 & 20 & 1.75 & 512 & 5 & 10 \\
\hline $163 b$ & 20 & 20 & 20 & 20 & 20 & 1.75 & 512 & 5 & 10 \\
\hline $164 a$ & 20 & 20 & 20 & 20 & 20 & 1.75 & 512 & 5 & 10 \\
\hline $164 \mathrm{~b}$ & 20 & 20 & 20 & 20 & 20 & 1.75 & 512 & 5 & 10 \\
\hline 165 & 20 & 20 & 20 & 20 & 20 & 1.75 & 512 & 5 & 10 \\
\hline $166 a$ & 20 & 20 & 20 & 20 & 20 & 1.75 & 512 & 5 & 45 \\
\hline $166 \mathrm{~b}$ & 20 & 20 & 20 & 20 & 20 & 1.75 & 512 & 5 & 45 \\
\hline $166 \mathrm{c}$ & 20 & 20 & 20 & 20 & 20 & 1.75 & 512 & 5 & 45 \\
\hline $166 d$ & 20 & 20 & 20 & 20 & 20 & 1.75 & 512 & 5 & 45 \\
\hline $167 \mathrm{a}$ & 20 & 20 & 20 & 20 & 20 & 1.75 & 512 & 5 & 100 \\
\hline $167 \mathrm{~b}$ & 20 & 20 & 20 & 20 & 20 & 1.75 & 512 & 5 & 100 \\
\hline $167 \mathrm{c}$ & 20 & 20 & 20 & 20 & 20 & 1.75 & 512 & 5 & 100 \\
\hline $167 d$ & 20 & 20 & 20 & 20 & 20 & 1.75 & 512 & 5 & 100 \\
\hline $167 \mathrm{e}$ & 20 & 20 & 20 & 20 & 20 & 1.75 & 512 & 5 & 100 \\
\hline $167 \mathrm{~g}$ & 20 & 20 & 20 & 20 & 20 & 1.75 & 512 & 5 & 100 \\
\hline $167 \mathrm{i}$ & 20 & 20 & 20 & 20 & 20 & 1.75 & 512 & 5 & 100 \\
\hline $168 \mathrm{a}$ & 20 & 20 & 20 & 20 & 20 & 1.75 & 512 & 5 & 50 \\
\hline $168 \mathrm{~b}$ & 20 & 20 & 20 & 20 & 20 & 1.75 & 512 & 5 & 50 \\
\hline $169 a$ & 20 & 20 & 20 & 20 & 20 & 1.75 & 512 & 5 & 50 \\
\hline $169 b$ & 20 & 20 & 20 & 20 & 20 & 1.75 & 512 & 5 & 50 \\
\hline $170 \mathrm{a}$ & 20 & 20 & 20 & 20 & 20 & 1.75 & 512 & 5 & 50 \\
\hline $170 \mathrm{~b}$ & 20 & 20 & 20 & 20 & 20 & 1.75 & 512 & 5 & 50 \\
\hline 171 & 20 & 20 & 20 & 20 & 20 & 1.75 & 512 & 5 & 10 \\
\hline $172 a$ & 20 & 20 & 20 & 20 & 20 & 1.75 & 1024 & 5 & 100 \\
\hline $172 \mathrm{~b}$ & 20 & 20 & 20 & 20 & 20 & 1.75 & 1024 & 5 & 100 \\
\hline $172 \mathrm{c}$ & 20 & 20 & 20 & 20 & 20 & 1.75 & 1024 & 5 & 100 \\
\hline $172 d$ & 20 & 20 & 20 & 20 & 20 & 1.75 & 1024 & 5 & 100 \\
\hline $173 a$ & 20 & 20 & 20 & 20 & 20 & 1.75 & 1024 & 5 & 50 \\
\hline $173 b$ & 20 & 20 & 20 & 20 & 20 & 1.75 & 1024 & 5 & 25 \\
\hline $174 a$ & 20 & 20 & 20 & 20 & 20 & 1.75 & 1024 & 5 & 15 \\
\hline $174 \mathrm{~b}$ & 20 & 20 & 20 & 20 & 20 & 1.75 & 1024 & 5 & 15 \\
\hline
\end{tabular}




\begin{tabular}{|c|c|c|c|c|c|c|c|c|c|}
\hline \multicolumn{10}{|c|}{ Table D.1. (continued) } \\
\hline \multirow{2}{*}{$\begin{array}{c}\text { Run } \\
\text { no. }\end{array}$} & 1 & 2 & 3 & 4 & 5 & $\begin{array}{c}\text { RC } \\
\text { gain }\end{array}$ & $\begin{array}{c}\text { Block } \\
\text { size }\end{array}$ & $\begin{array}{c}\text { Band } \\
\text { width. } \\
(\mathrm{kHz})\end{array}$ & $\begin{array}{c}\text { Blocks } \\
(\mathrm{k})\end{array}$ \\
\hline $174 \mathrm{c}$ & 20 & 20 & 20 & 20 & 20 & 1.75 & 1024 & 5 & 15 \\
\hline $175 \mathrm{a}$ & 20 & 20 & 20 & 20 & 20 & 1.75 & 512 & 4 & 50 \\
\hline $175 \mathrm{~b}$ & 20 & 20 & 20 & 20 & 20 & 1.75 & 512 & 4 & 50 \\
\hline 176 & 20 & 20 & 20 & 20 & 20 & 1.75 & 512 & 4 & 100 \\
\hline 177 & 20 & 20 & 20 & 20 & 20 & 1.75 & 512 & 4 & 50 \\
\hline $178 \mathrm{a}$ & 20 & 20 & 20 & 20 & 20 & 1.75 & 512 & 4 & 20 \\
\hline $178 \mathrm{~b}$ & 20 & 20 & 20 & 20 & 20 & 1.75 & 512 & 4 & 20 \\
\hline 179 & 20 & 20 & 20 & 20 & 20 & 1.75 & 512 & 4 & 100 \\
\hline 180 & 20 & 20 & 20 & 20 & 20 & 1.75 & 2048 & 5 & $?$ \\
\hline 181 & 20 & 20 & 20 & 20 & 20 & 1.75 & 2048 & 5 & 10 \\
\hline 183 & 20 & 20 & 20 & 20 & 20 & 1.75 & 2048 & 5 & 10 \\
\hline 185 & 20 & 20 & 20 & 20 & 20 & 1.75 & 2048 & 5 & 40 \\
\hline 186 & 20 & 20 & 20 & 20 & 20 & 1.75 & 2048 & 5 & 40 \\
\hline 187 & 20 & 20 & 20 & 20 & 20 & 1.75 & 2048 & 5 & 40 \\
\hline 188 & 20 & 20 & 20 & 20 & 20 & 1.75 & 2048 & 5 & 3.37 \\
\hline 189 & 20 & 20 & 20 & 20 & .20 & 1.75 & 2048 & 5 & 40 \\
\hline 190 & 20 & 20 & 20 & 20 & 20 & 1.75 & 2048 & 5 & 40 \\
\hline 191 & 20 & 20 & 20 & 20 & 20 & 1.75 & 2048 & 5 & 40 \\
\hline 192 & 20 & 20 & 20 & 20 & 20 & 1.75 & 2048 & 5 & 20 \\
\hline 193 & 20 & 20 & 20 & 20 & 20 & 1.75 & 2048 & 5 & 5 \\
\hline 194 & 20 & 20 & 20 & 20 & 20 & 1.75 & 2048 & 5 & 40 \\
\hline
\end{tabular}




\section{APPENDIX E}

\section{SOURCE AND DETECTOR COUNT RATES}

The source and detector count rates for each measurement were as provided in Table E.1.

\begin{tabular}{|c|c|c|c|c|c|c|}
\hline \multicolumn{7}{|c|}{ Table E.1. Source and detector count rates } \\
\hline $\begin{array}{c}\text { Run } \\
\text { no. }\end{array}$ & $\begin{array}{c}\text { Source } \\
1\end{array}$ & 2 & 3 & 4 & 5 & $\begin{array}{c}\text { Fraction of } \\
\text { source events } \\
\text { counted }\end{array}$ \\
\hline 1 & 65221 & 2396 & 570 & 532 & 519 & 0.986 \\
\hline 2 & 65221 & 2396 & 570 & 532 & 519 & 0.986 \\
\hline 2 r & 65221 & 2396 & 570 & 532 & 519 & 0.986 \\
\hline 3 & 65214 & 2513 & 2295 & 638 & 630 & 0.986 \\
\hline 4 & 65214 & 2513 & 2295 & 638 & 630 & 0.986 \\
\hline $4 \mathrm{r}$ & 65214 & 2513 & 2295 & 638 & 630 & 0.986 \\
\hline 5 & 65238 & 2514 & 2303 & 638 & 630 & 0.987 \\
\hline 6 & 65218 & 2938 & 2708 & 2564 & 676 & 0.986 \\
\hline 7 & 65218 & 2938 & 2708 & 2564 & 676 & 0.986 \\
\hline 8 & 65238 & 2938 & 2705 & 2566 & 676 & 0.987 \\
\hline 9 & 65238 & 3457 & 3174 & 2748 & 2710 & 0.987 \\
\hline 10 & 65214 & 4872 & 4479 & 3930 & 3840 & 0.986 \\
\hline 11 & 65238 & 7173 & 6589 & 5850 & 5729 & 0.987 \\
\hline 12 & 65170 & 15881 & 14517 & 13215 & 13119 & 0.986 \\
\hline 13 & 65290 & 15917 & 14523 & 13393 & 13144 & 0.987 \\
\hline 14 & 65213 & 15913 & 14517 & 13385 & 13132 & 0.986 \\
\hline 15 & 65213 & 15913 & 14517 & 13385 & 13132 & 0.986 \\
\hline 16 & 65405 & 15631 & 15104 & 13163 & 12939 & 0.989 \\
\hline 17 & 65405 & 15631 & 15104 & 13163 & 12939 & 0.989 \\
\hline 18 & 65425 & 14376 & 14937 & 12117 & 11867 & 0.989 \\
\hline 19 & 65408 & 12494 & 13886 & 10530 & 10310 & 0.989 \\
\hline 20 & 65414 & 7090 & 9147 & 6007 & 5860 & 0.989 \\
\hline 21 & 65422 & 14476 & 11538 & 12170 & 12036 & 0.989 \\
\hline 22 & 65550 & 12747 & 9482 & 10710 & 10637 & 0.991 \\
\hline 23 & 65421 & 5106 & 3316 & 4307 & 4332 & 0.989 \\
\hline 24 & 65503 & 15916 & 15719 & 13396 & 13225 & 0.991 \\
\hline 25 & 65592 & 10697 & 10645 & 8786 & 8628 & 0.993 \\
\hline 26 & 65593 & 3476 & 3436 & 2764 & 2722 & 0.993 \\
\hline 27 & 65540 & 3455 & 3428 & 2745 & 2687 & 0.992 \\
\hline 28 & 65607 & 10729 & 10642 & 8788 & 8658 & 0.993 \\
\hline 29 & 65541 & 9263 & 9351 & 9344 & 9137 & 0.992 \\
\hline & & & & & & \\
\hline
\end{tabular}




\begin{tabular}{|c|c|c|c|c|c|c|}
\hline \multicolumn{7}{|c|}{ Table E.1. Source and detector count rates (continued) } \\
\hline $\begin{array}{c}\text { Run } \\
\text { no. }\end{array}$ & $\begin{array}{c}\text { Source } \\
1\end{array}$ & 2 & 3 & 4 & 5 & $\begin{array}{c}\text { Fraction of } \\
\text { source events } \\
\text { counted }\end{array}$ \\
\hline 30 & 65558 & 9271 & 9346 & 9349 & 9151 & 0.992 \\
\hline 31 & 65510 & 6646 & 6628 & 3883 & 3847 & 0.991 \\
\hline 32 & 65533 & 6654 & 6640 & 3881 & 3855 & 0.992 \\
\hline 33 & 65564 & 6653 & 6636 & 3886 & 3859 & 0.992 \\
\hline 34 & 65563 & 7868 & 7864 & 4603 & 4587 & 0.992 \\
\hline 35 & 65563 & 7868 & 7864 & 4603 & 4587 & 0.992 \\
\hline 36 & 65532 & 8419 & 8519 & 4967 & 4954 & 0.992 \\
\hline 37 & 65568 & 5341 & 5212 & 3058 & 3047 & 0.992 \\
\hline 38 & 65568 & 5341 & 5212 & 3058 & 3047 & 0.992 \\
\hline 39 & 65541 & 4056 & 3965 & 2320 & 2325 & 0.992 \\
\hline 40 & 65519 & 7917 & 7867 & 4622 & 4627 & 0.992 \\
\hline 41 & 65561 & 12724 & 12647 & 10578 & 10475 & 0.992 \\
\hline 42 & 65521 & 8496 & 8438 & 6981 & 6907 & 0.992 \\
\hline 43 & 65521 & 8496 & 8438 & 6981 & 6907 & 0.992 \\
\hline 44 & 65549 & 5786 & 5781 & 4713 & 4649 & 0.992 \\
\hline 45 & 65152 & 4117 & 4127 & 3314 & 3251 & 0.986 \\
\hline 46 & 65622 & 12739 & 12638 & 10571 & 10459 & 0.993 \\
\hline 47 & 65541 & 12742 & 12648 & 10567 & 10455 & 0.992 \\
\hline 48 & 65506 & 10580 & 11758 & 9725 & 9605 & 0.991 \\
\hline 49 & 65557 & 10578 & 11759 & 9720 & 9600 & 0.992 \\
\hline 50 & 65519 & 8679 & 11015 & 8945 & 8841 & 0.992 \\
\hline 51 & 65546 & 8675 & 11018 & 8961 & 8838 & 0.992 \\
\hline 52 & 65525 & 5690 & 9950 & 7801 & 7691 & 0.992 \\
\hline 53 & 65521 & 5700 & 9961 & 7811 & 7696 & 0.992 \\
\hline 54 & 65506 & 12678 & 12633 & 10559 & 10437 & 0.991 \\
\hline 55 & 65496 & 10862 & 10861 & 7092 & 9227 & 0.991 \\
\hline 56 & 65496 & 10862 & 10861 & 7092 & 9227 & 0.991 \\
\hline 57 & 65160 & 9577 & 9612 & 4594 & 8440 & 0.986 \\
\hline 58 & 65160 & 9577 & 9612 & 4594 & 8440 & 0.986 \\
\hline 59 & 65145 & 12688 & 12631 & 10563 & 10446 & 0.986 \\
\hline 60 & 65153 & 11438 & 11653 & 10117 & 9989 & 0.986 \\
\hline 61 & 65153 & 11438 & 11653 & 10117 & 9989 & 0.986 \\
\hline 62 & 65149 & 7342 & 7295 & 7966 & 7775 & 0.986 \\
\hline 63 & 65149 & 7342 & 7295 & 7966 & 7775 & 0.986 \\
\hline 64 & 65142 & & & 10478 & 10339 & 0.986 \\
\hline 65 & 65133 & 12658 & 12518 & 10480 & 10355 & 0.986 \\
\hline 66 & 65133 & 12658 & 12518 & 10480 & 10355 & 0.986 \\
\hline 67 & 65133 & 12658 & 12518 & 10480 & 10355 & 0.986 \\
\hline 68 & 65133 & 12658 & 12518 & 10480 & 10355 & 0.986 \\
\hline
\end{tabular}




\begin{tabular}{|c|c|c|c|c|c|c|}
\hline \multicolumn{7}{|c|}{ Table E.1. Source and detector count rates (continued) } \\
\hline $\begin{array}{l}\text { Run } \\
\text { no. }\end{array}$ & $\begin{array}{c}\text { Source } \\
1\end{array}$ & 2 & 3 & 4 & 5 & $\begin{array}{c}\text { Fraction. of } \\
\text { source events } \\
\text { counted }\end{array}$ \\
\hline 69 & 65135 & 7786 & 7699 & 4527 & 4514 & 0.986 \\
\hline 70 & 65136 & 7891 & 7789 & 4579 & 4569 & 0.986 \\
\hline 71 & 65136 & 7891 & 7789 & 4579 & 4569 & 0.986 \\
\hline 72 & 65114 & 7983 & 7907 & 4648 & 4652 & 0.986 \\
\hline 73 & 65114 & 7983 & 7907 & 4648 & 4652 & 0.986 \\
\hline 74 & 65127 & 8061 & 7992 & 4710 & 4677 & 0.986 \\
\hline 75 & 65127 & 8061 & 7992 & 4710 & 4677 & 0.986 \\
\hline 76 & 65107 & 8122 & 8061 & 4708 & 4735 & 0.986 \\
\hline 77 & 65107 & 8122 & 8061 & 4708 & 4735 & 0.986 \\
\hline 78 & 65122 & 8054 & 7979 & 4640 & 4693 & 0.986 \\
\hline 79 & 65120 & 7988 & 7920 & 4610 & 4645 & 0.986 \\
\hline 80 & 65118 & 8053 & 8007 & 4684 & 4733 & 0.986 \\
\hline 81 & 65116 & 8142 & 8086 & 4746 & 4771 & 0.986 \\
\hline 82 & 65582 & 8214 & 8173 & 4801 & 4828 & 0.993 \\
\hline 83 & 65127 & 8292 & 8235 & 4861 & 4898 & 0.986 \\
\hline 84 & 65200 & 8413 & 8405 & 4995 & 5004 & 0.987 \\
\hline 85 & 65188 & 7864 & 7802 & 4496 & 4552 & 0.987 \\
\hline 86 & 65136 & 7853 & 7782 & 4501 & 4545 & 0.986 \\
\hline 87 & 65136 & 7853 & 7782 & 4501 & 4545 & 0.986 \\
\hline 88 & 65136 & 7853 & 7782 & 4501 & 4545 & 0.986 \\
\hline 89 & 65136 & 7853 & 7782 & 4501 & 4545 & 0.986 \\
\hline 90 & 65118 & 5661 & 5602 & 3169 & 3147 & 0.986 \\
\hline 91 & 65116 & 5844 & 5783 & 3277 & 3264 & 0.986 \\
\hline 92 & 65103 & 3897 & 3720 & 2232 & 1886 & 0.986 \\
\hline 93 & 65100 & 3918 & 3738 & 1871 & 1873 & 0.986 \\
\hline 94 & 65100 & 7922 & 7801 & 4526 & 4566 & 0.987 \\
\hline 95 & 65100 & 7734 & 7368 & 4422 & 1530 & 0.987 \\
\hline 96 & 65118 & 9165 & 8959 & 5390 & 5456 & 0.987 \\
\hline 97 & 65118 & 9165 & 8959. & 5390 & 5456 & 0.987 \\
\hline 98 & 65450 & 8843 & 8742 & 5193 & 5243 & 0.992 \\
\hline 99 & 65450 & 8843 & 8742 & 5193 & 5243 & 0.992 \\
\hline 100 & 65129 & 8606 & 8440 & 5015 & 5072 & 0.987 \\
\hline 101 & 65129 & 8606 & 8440 & 5015 & 5072 & 0.987 \\
\hline 102 & 65088 & 8154 & 7993 & 4878 & 4582 & 0.986 \\
\hline 103 & 65088 & 8154 & 7993 & 4878 & 4582 & 0.986 \\
\hline 104 & 65092 & 8433 & 8191 & 5046 & 4737 & 0.986 \\
\hline 105 & 65092 & 8433 & 8191 & 5046 & 4737 & 0.986 \\
\hline 106 & 65083 & 8663 & 8513 & 5249 & 4912 & 0.986 \\
\hline 107 & 65083 & 8663 & 8513 & 5249 & 4912 & 0.986 \\
\hline
\end{tabular}




\begin{tabular}{|c|c|c|c|c|c|c|}
\hline \multicolumn{7}{|c|}{ Table E.1. Source and detector count rates (continued) } \\
\hline $\begin{array}{c}\text { Run } \\
\text { no. }\end{array}$ & $\begin{array}{c}\text { Source } \\
1\end{array}$ & 2 & 3 & 4 & 5 & $\begin{array}{c}\text { Fraction of } \\
\text { source events } \\
\text { counted }\end{array}$ \\
\hline 108 & 65515 & 8319 & 8147 & 4614 & 4812 & 0.993 \\
\hline 109 & 65515 & 8319 & 8147 & 4614 & 4812 & 0.993 \\
\hline 110 & 65088 & 8113 & 7858 & 4456 & 4662 & 0.986 \\
\hline 111 & 65088 & 8113 & 7858 & 4456 & 4662 & 0.986 \\
\hline 112 & 65090 & 7237 & 7117 & 3963 & 4210 & 0.986 \\
\hline 113 & 65090 & 7237 & 7117 & 3963 & 4210 & 0.986 \\
\hline 114 & 65081 & 7815 & 7683 & 4305 & 4512 & 0.986 \\
\hline 115 & 65093 & 7781 & 7607 & 4280 & 4485 & 0.986 \\
\hline 116 & 65092 & 6982 & 6849 & 3893 & 3962 & 0.986 \\
\hline 117 & 65092 & 6983 & 6842 & 3894 & 3961 & 0.986 \\
\hline 118 & 65101 & 6807 & 6667 & 3773 & 3867 & 0.987 \\
\hline 119 & 65101 & 6807 & 6667 & 3773 & 3867 & 0.987 \\
\hline 120 & 65089 & 6355 & 6235 & 3421 & 3551 & 0.986 \\
\hline 121 & 65078 & 6498 & 6372 & 3482 & 3639 & 0.986 \\
\hline 122 & 65078 & 6499 & 6372 & 3482 & 3640 & 0.986 \\
\hline 123 & 65084 & 6494 & 5377 & 3478 & 3636 & 0.986 \\
\hline 124 & 65077 & 6239 & 6116 & 3295 & 3451 & 0.986 \\
\hline 125 & 65066 & 3705 & 3626 & 1760 & 1835 & 0.986 \\
\hline 126 & 65055 & 7837 & 7704 & 4315 & 4513 & 0.987 \\
\hline 127 & 65055 & 7837 & 7704 & 4315 & 4513 & 0.987 \\
\hline 128 & 65052 & 12617 & 12383 & 9851 & 10317 & 0.987 \\
\hline 129 & 65081 & 12436 & 12095 & 9656 & 10133 & 0.987 \\
\hline 130 & 65055 & 7886 & 7750 & 4342 & 4557 & 0.987 \\
\hline 131 & 65245 & 6711 & 6633 & 3638 & 3766 & 0.990 \\
\hline 132 & 65245 & 6711 & 6633 & 3638 & 3766 & 0.990 \\
\hline 133 & 65190 & 6225 & 6139 & 3239 & 3418 & 0.989 \\
\hline 134 & 65101 & 6221 & 6135 & 3237 & 3418 & 0.987 \\
\hline 135 & 65083 & 3779 & 3590 & 1816 & 1897 & 0.987 \\
\hline $136 \mathrm{a}$ & 65061 & 5687 & 6533 & 3391 & 3527 & 0.987 \\
\hline $136 \mathrm{~b}$ & 65061 & 5687 & 6533 & 3391 & 3527 & 0.987 \\
\hline 137 & 65049 & 7866 & 7729 & 4317 & 4536 & 0.987 \\
\hline 138 & 65049 & 12681 & 12418 & 9853 & 10346 & 0.987 \\
\hline $139 \mathrm{a}$ & 65055 & 12550 & 12174 & 9676 & 10246 & 0.987 \\
\hline $139 \mathrm{~b}$ & 65055 & 12550 & 12174 & 9676 & 10246 & 0.987 \\
\hline $139 \mathrm{c}$ & 65055 & 12550 & 12174 & 9676 & 10246 & 0.987 \\
\hline $139 \mathrm{~d}$ & 65055 & 12550 & 12174 & 9676 & 10246 & 0.987 \\
\hline $139 \mathrm{e}$ & 65055 & 12550 & 12174 & 9676 & 10246 & 0.987 \\
\hline 140 & 65118 & 12580 & 12255 & 9782 & 10160 & 0.988 \\
\hline 141 & 65075 & 12512 & 12271 & 10178 & 10139 & 0.988 \\
\hline
\end{tabular}




\begin{tabular}{|c|c|c|c|c|c|c|}
\hline \multicolumn{7}{|c|}{ Table E.1. Source and detector count rates (continued) } \\
\hline $\begin{array}{c}\text { Run } \\
\text { no. }\end{array}$ & $\begin{array}{c}\text { Source } \\
1\end{array}$ & 2 & 3 & 4 & 5 & $\begin{array}{c}\text { Fraction of } \\
\text { source events } \\
\text { counted }\end{array}$ \\
\hline 142 & 65075 & 12291 & 12024 & 10166 & 9832 & 0.988 \\
\hline 143 & 65105 & 7676 & 7500 & 4475 & 4258 & 0.988 \\
\hline $144 \mathrm{a}$ & 65078 & 5680 & 5513 & 3114 & 3054 & 0.988 \\
\hline $144 \mathrm{~b}$ & 65078 & 5680 & 5513 & 3114 & 3054 & 0.988 \\
\hline $144 \mathrm{c}$ & 65078 & 5680 & 5513 & 3114 & 3054 & 0.988 \\
\hline $145 \mathrm{a}$ & 65002 & 5633 & 5493 & 3098 & 3056 & 0.987 \\
\hline $145 \mathrm{~b}$ & 65106 & 5699 & 5552 & 3080 & 3085 & 0.988 \\
\hline $146 \mathrm{a}$ & 65097 & 3806 & 3844 & 2046 & 1938 & 0.988 \\
\hline $146 \mathrm{~b}$ & 65097 & 3806 & 3844 & 2046 & 1938 & 0.988 \\
\hline $146 \mathrm{c}$ & 65097 & 3806 & 3844 & 2046 & 1938 & 0.988 \\
\hline $146 \mathrm{~d}$ & 65097 & 3806 & 3844 & 2046 & 1938 & 0.988 \\
\hline 147 & 65104 & 4962 & 4901 & 2825 & 2864 & 0.989 \\
\hline 148 & 65110 & 4238 & 4163 & 2677 & 1877 & 0.989 \\
\hline $149 \mathrm{a}$ & 65085 & 4235 & 4167 & 2675 & 1874 & 0.988 \\
\hline $149 \mathrm{~b}$ & 65085 & 4235 & 4167 & 2675 & 1874 & 0.988 \\
\hline $149 \mathrm{c}$ & 65085 & 4235 & 4167 & 2675 & 1874 & 0.988 \\
\hline $149 \mathrm{~d}$ & 65085 & 4235 & 4167 & 2675 & 1874 & 0.988 \\
\hline $150 \mathrm{a}$ & 65072 & 3397 & 4270 & 3255 & 2089 & 0.988 \\
\hline $150 \mathrm{~b}$ & 65072 & 3397 & 4270 & 3255 & 2089 & 0.988 \\
\hline $150 \mathrm{c}$ & 65072 & 3397 & 4270 & 3255 & 2089 & 0.988 \\
\hline $150 \mathrm{~d}$ & 65072 & 3397 & 4270 & 3255 & 2089 & 0.988 \\
\hline $151 \mathrm{a}$ & 65067 & 6109 & 6070 & 4021 & 2425 & 0.988 \\
\hline $151 \mathrm{~b}$ & 65067 & 6109 & 6070 & 4021 & 2425 & 0.989 \\
\hline $151 \mathrm{c}$ & 65067 & 6109 & 6070 & 4021 & 2425 & 0.988 \\
\hline $151 \mathrm{~d}$ & 65067 & 6109 & 6070 & 4021 & 2425 & 0.989 \\
\hline 152 & 65068 & 7636 & 7551 & 4462 & 4269 & 0.988 \\
\hline $153 \mathrm{a}$ & 65070 & 6607 & 6579 & 3798 & 3592 & 0.988 \\
\hline $153 \mathrm{~b}$ & 65070 & 6607 & 6579 & 3798 & 3592 & 0.988 \\
\hline $154 \mathrm{a}$ & 65054 & 4871 & 4837 & 2287 & 2205 & 0.988 \\
\hline $154 \mathrm{~b}$ & 65054 & 4871 & 4837 & 2287 & 2205 & 0.988 \\
\hline $154 \mathrm{c}$ & 65054 & 4871 & 4837 & 2287 & 2205 & 0.988 \\
\hline $154 \mathrm{~d}$ & 65054 & 4871 & 4837 & 2287 & 2205 & 0.988 \\
\hline $154 \mathrm{e}$ & 65054 & 4871 & 4837 & 2287 & 2205 & 0.988 \\
\hline $154 \mathrm{f}$ & 65054 & 4871 & 4837 & 2287 & 2205 & 0.988 \\
\hline $154 \mathrm{~g}$ & 65054 & 4871 & 4837 & 2287 & 2205 & 0.988 \\
\hline $154 \mathrm{~h}$ & 65054 & 4871 & 4837 & 2287 & 2205 & 0.988 \\
\hline 155 & 65066 & 6295 & 6248 & 3517 & 3384 & 0.989 \\
\hline 156 & 65036 & 6296 & 6249 & 3515 & 3382 & 0.988 \\
\hline 157 & 65046 & 5984 & 5925 & 3355 & 3217 & 0.989 \\
\hline & & & & & & \\
\hline
\end{tabular}




\begin{tabular}{|c|c|c|c|c|c|c|}
\hline \multicolumn{7}{|c|}{ Table E.1. Source and detector count rates (continued) } \\
\hline $\begin{array}{c}\text { Run } \\
\text { no. }\end{array}$ & $\begin{array}{c}\text { Source } \\
1\end{array}$ & 2 & 3 & 4 & 5 & $\begin{array}{c}\text { Fraction of } \\
\text { source events } \\
\text { counted }\end{array}$ \\
\hline 158 & 65046 & 5984 & 5926 & 3356 & 3215 & 0.989 \\
\hline $159 \mathrm{a}$ & 65040 & 5921 & 5861 & 3298 & 3132 & 0.989 \\
\hline $159 \mathrm{~b}$ & 65040 & 5921 & 5861 & 3298 & 3132 & 0.989 \\
\hline $159 \mathrm{c}$ & 65040 & 5921 & 5861 & 3298 & 3132 & 0.989 \\
\hline 160 & 65029 & 18321 & 18004 & 15479 & 15216 & 0.988 \\
\hline 161 & 65027 & 18331 & 18016 & 15458 & 15211 & 0.988 \\
\hline $162 \mathrm{a}$ & 65040 & 16553 & 16265 & 13958 & 13786 & 0.988 \\
\hline $162 \mathrm{~b}$ & 65040 & 16553 & 16265 & 13958 & 13786 & 0.989 \\
\hline $163 \mathrm{a}$ & 65049 & 13945 & 13731 & 11713 & 11580 & 0.989 \\
\hline $163 \mathrm{~b}$ & 65049 & 13945 & 13731 & 11713 & 11580 & 0.989 \\
\hline $164 \mathrm{a}$ & 65019 & 9306 & 9176 & 7298 & 7608 & 0.988 \\
\hline $164 \mathrm{~b}$ & 65019 & 9306 & 9176 & 7298 & 7608 & 0.988 \\
\hline 165 & 65021 & 7627 & 7644 & 4457 & 4383 & 0.988 \\
\hline $166 \mathrm{a}$ & 64877 & 5797 & 5673 & 3200 & 3131 & 0.986 \\
\hline $166 \mathrm{~b}$ & 64877 & 5797 & 5673 & 3200 & 3131 & 0.986 \\
\hline $166 \mathrm{c}$ & 64877 & 5797 & 5673 & 3200 & 3131 & 0.986 \\
\hline $166 \mathrm{~d}$ & 64877 & 5797 & 5673 & 3200 & 3131 & 0.986 \\
\hline $167 \mathrm{a}$ & 65013 & 6254 & 6586 & 3412 & 3856 & 0.988 \\
\hline $167 \mathrm{~b}$ & 65013 & 6254 & 6586 & 3412 & 3856 & 0.988 \\
\hline $167 \mathrm{c}$ & 65013 & 6254 & 6586 & 3412 & 3856 & 0.988 \\
\hline $167 \mathrm{~d}$ & 65013 & 6254 & 6586 & 3412 & 3856 & 0.988 \\
\hline $167 \mathrm{e}$ & 65013 & 6254 & 6586 & 3412 & 3856 & 0.988 \\
\hline $167 \mathrm{~g}$ & 65013 & 6254 & 6586 & 3412 & 3856 & 0.988 \\
\hline $167 \mathrm{i}$ & 65013 & 6254 & 6586 & 3412 & 3856 & 0.988 \\
\hline $168 \mathrm{a}$ & 65005 & 6608 & 6728 & 3517 & 4009 & 0.989 \\
\hline $168 \mathrm{~b}$ & 65005 & 6608 & 6728 & 3517 & 4009 & 0.989 \\
\hline $169 \mathrm{a}$ & 64979 & 6911 & 6871 & 3610 & 4151 & 0.988 \\
\hline $169 \mathrm{~b}$ & 64979 & 6911 & 6871 & 3610 & 4151 & 0.988 \\
\hline $170 \mathrm{a}$ & 65008 & 6688 & 6970 & 3695 & 4025 & 0.989 \\
\hline $170 \mathrm{~b}$ & 65008 & 6688 & 6970 & 3695 & 4025 & 0.989 \\
\hline 171 & 65006 & 7683 & 7697 & 4510 & 4388 & 0.989 \\
\hline $172 \mathrm{a}$ & 64955 & 7067 & 7087 & 9405 & & 0.988 \\
\hline $172 \mathrm{~b}$ & 64955 & 7067 & 7087 & 9405 & & 0.988 \\
\hline $172 \mathrm{c}$ & 64955 & 7067 & 7087 & 9405 & & 0.988 \\
\hline $172 \mathrm{~d}$ & 64955 & 7067 & 7087 & 9405 & & 0.988 \\
\hline $173 \mathrm{a}$ & 64924 & 2613 & 2844 & 2856 & & 0.988 \\
\hline $173 \mathrm{~b}$ & 64924 & 2613 & 2844 & 2856 & & 0.988 \\
\hline $174 \mathrm{a}$ & 64920 & 5183 & 5667 & 5715 & & 0.988 \\
\hline $174 \mathrm{~b}$ & 64920 & 5183 & 5667 & 5715 & & 0.988 \\
\hline & & & & & & \\
\hline
\end{tabular}




\begin{tabular}{|c|c|c|c|c|c|c|}
\hline \multicolumn{7}{|c|}{ Table E.1. Source and detector count rates (continued) } \\
\hline $\begin{array}{c}\text { Run } \\
\text { no. }\end{array}$ & $\begin{array}{c}\text { Source } \\
1\end{array}$ & 2 & 3 & 4 & 5 & $\begin{array}{c}\text { Fraction of } \\
\text { source events } \\
\text { counted }\end{array}$ \\
\hline $174 \mathrm{c}$ & 64920 & 5183 & 5667 & 5715 & & 0.988 \\
\hline $175 \mathrm{a}$ & 64933 & 677 & 727 & 718 & & 0.988 \\
\hline $175 \mathrm{~b}$ & 64933 & 677 & 727 & 718 & & 0.988 \\
\hline 176 & 64942 & 678 & 726 & 716 & & 0.988 \\
\hline 177 & 64948 & 680 & 727 & 738 & & 0.989 \\
\hline $178 \mathrm{a}$ & 64935 & 2661 & 2851 & 2864 & & 0.988 \\
\hline $178 \mathrm{~b}$ & 65933 & 2658 & 2851 & 2865 & & 0.988 \\
\hline 179 & 64750 & 2620 & 2853 & 2864 & & 0.986 \\
\hline 180 & & 32 & 26 & & & \\
\hline 181 & 64503 & 2957 & 3009 & & & 0.985 \\
\hline 183 & 64492 & 2953 & 3004 & & & 0.984 \\
\hline 185 & 64467 & 947 & 990 & & & 0.984 \\
\hline 186 & 64495 & 916 & 959 & & & 0.984 \\
\hline 187 & 64466 & 926 & 986 & & & 0.984 \\
\hline 188 & 64179 & 2959 & 4054 & 2396 & & 0.985 \\
\hline 189 & 64177 & 2949 & 4025 & 2384 & & 0.985 \\
\hline 190 & 64154 & 1456 & & 841 & & 0.984 \\
\hline 191 & 64155 & 1462 & & 845 & & 0.984 \\
\hline 192 & 64192 & 2996 & 4085 & 2429 & & 0.985 \\
\hline 193 & 64182 & 7503 & 6726 & 7377 & & 0.985 \\
\hline 194 & 64167 & 2884 & 3052 & 2403 & & 0.984 \\
\hline
\end{tabular}




\section{APPENDIX F \\ EVALUATION OF BUBBLES IN ASSEMBLY}

The formation of bubbles in the experimental was a concern because no actions were taken to ensure that bubble formation would be minimized. The affects of voids in the assembly were analyzed by forcing air at various flow rates up through the bottom of the fuel element in the south position. The fuel elements were designed such that water was between the individual fuel plates. The results of the forced-air flow measurements are provided in Table F.1. All of the spectral ratio values were within one standard deviation of the case with no forced-air flow. The values for the no forced-air flow were the average values for the plate-spacing reference measurement. As can be seen from these results, formation of bubbles in the test assembly was not a measurable affect because the fuel elements were over-moderated. 
Table F.1. Spectral ratio values for different forced air flow rates

\begin{tabular}{|c|c|c|c|c|c|c|c|c|c|c|c|c|}
\hline \multicolumn{13}{|c|}{ Table F.1. Spectral ratio values for different forced air flow rates } \\
\hline Flow rate & \multicolumn{2}{|c|}{ Ratio 23} & \multicolumn{2}{|c|}{ Ratio 24} & \multicolumn{2}{|c|}{ Ratio 25} & \multicolumn{2}{|c|}{ Ratio 34} & \multicolumn{2}{|c|}{ Ratio 35} & \multicolumn{2}{|c|}{ Ratio 45} \\
\hline (liter/min) & $\mathrm{R}^{\mathrm{a}}$ & $\sigma^{6}$ & $\overline{\mathrm{R}}$ & $\bar{\sigma}$ & $\overline{\mathrm{R}}$ & $\bar{\sigma}$ & $\overline{\mathrm{R}}$ & $\sigma$ & $\mathrm{R}$ & $\sigma$ & $\overline{\mathrm{R}}$ & $\bar{\sigma}$ \\
\hline 0 & 0.554 & 0.008 & 0.457 & 0.012 & 0.451 & 0.007 & 0.454 & 0.012 & 0.455 & 0.011 & 0.517 & 0.010 \\
\hline 0.1 & 0.556 & 0.005 & 0.453 & 0.007 & 0.447 & 0.006 & 0.471 & 0.005 & 0.465 & 0.009 & 0.509 & 0.011 \\
\hline 0.5 & 0.562 & 0.007 & 0.460 & 0.006 & 0.451 & 0.002 & 0.461 & 0.009 & 0.449 & 0.010 & 0.532 & 0.011 \\
\hline
\end{tabular}

${ }^{a}$ Low frequency average of spectral ratio.

${ }^{b}$ Standard deviation of the mean of the low frequency spectral ratio average. 


\section{APPENDIX G}

\section{FUEL TILTING MEASUREMENTS}

The affects of tilting the fuel elements was investigated because the spacing of the fuel elements significantly affected the results of the measurements. Measurements were performed in which the top fuel elements were pulled inward approximately $1 / 16$ to $1 / 8$ in. and pulled outward approximately $3 / 16$ to $1 / 4$ in. Ropes were tied to the top of the fuel elements to apply tension to the element. The results of the measurements are provided in Table G.1. These measurements were performed with the assembly in the close-spaced reference configuration. The spectral ratio values changed an average of $6 \%$ for both the inward and outward tilts of the fuel elements. This change was considered significant because it was greater than the uncertainty in the measurements 


\begin{tabular}{|c|c|c|c|c|c|c|c|c|c|c|c|c|}
\hline \multicolumn{13}{|c|}{ Table G.1. Spectral ratio values for tilting of fuel elements } \\
\hline Tilt & \multicolumn{2}{|c|}{ Ratio 23} & \multicolumn{2}{|c|}{ Ratio 24} & \multicolumn{2}{|c|}{ Ratio 25} & \multicolumn{2}{|c|}{ Ratio 34} & \multicolumn{2}{|c|}{ Ratio 35} & \multicolumn{2}{|c|}{ Ratio 45} \\
\hline (in) & $\mathrm{R}^{\mathrm{a}}$ & $\sigma^{b}$ & $\overline{\mathrm{R}}$ & $\sigma$ & $\overline{\mathrm{R}}$ & $\sigma$ & $\overline{\mathrm{R}}$ & $\sigma$ & $\overline{\mathrm{R}}$ & $\sigma$ & $\overline{\mathrm{R}}$ & $\sigma$ \\
\hline 0 & 0.383 & 0.005 & 0.348 & 0.004 & 0.347 & 0.003 & 0.351 & $0 . \overline{006}$ & $0 . \overline{345}$ & 0.005 & 0.374 & 0.005 \\
\hline 0.635 & 0.398 & 0.003 & 0.372 & 0.004 & 0.363 & 0.003 & 0.367 & 0.003 & 0.370 & 0.002 & 0.401 & 0.004 \\
\hline-0.3175 & 0.361 & 0.003 & 0.342 & 0.004 & 0.338 & 0.003 & 0.332 & 0.003 & 0.329 & 0.003 & 0.350 & 0.004 \\
\hline
\end{tabular}

${ }^{a}$ Low frequency average of spectral ratio.

${ }^{b}$ Standard deviation of the mean of the low frequency spectral ratio average. 


\section{APPENDIX H \\ SPECTRAL SIGNATURES FOR FRESH FUEL REFERENCE MEASUREMENTS AT PLATE.SPACING}

This appendix contains average spectral signatures for the reference measurements with the fuel elements separated at the position for the plate measurements. These signatures show the frequency dependence of these quantities. The average at each frequency point and the standard deviation of the mean at each frequency point were calculated for the fifteen reference measurements. The average spectral ratio values are shown in Fig. H.1 to H.6. The average spectral ratio values were essentially constant over the low-frequency range. Except for the spectral ratio signatures, the spectral functions were normalized by dividing by the source auto spectrum. The average source auto spectrum is shown in Fig. H.7. The average detector auto spectra for one of the detectors is shown in Fig. H.8. The detector auto spectra decreased as a function of frequency and could be fitted to determine the prompt neutron decay constant. An average source-detector cross spectra was estimated from the fifteen measurements The real and imaginary parts of the sourcedetector cross spectra are shown in Figs. H.9 and H.10. The source-detector cross spectrum consisted of both a real and an imaginary component. These spectra could also be fitted to obtain the prompt neutron decay constant using a calibration spectrum. A detector-detector cross spectrum was also obtained for the fifteen reference measurements. The real and imaginary components of the detector-detector cross spectra are shown in Figs. H.11 and H.12. The imaginary component of the detector-detector cross spectrum was essentially zero. 


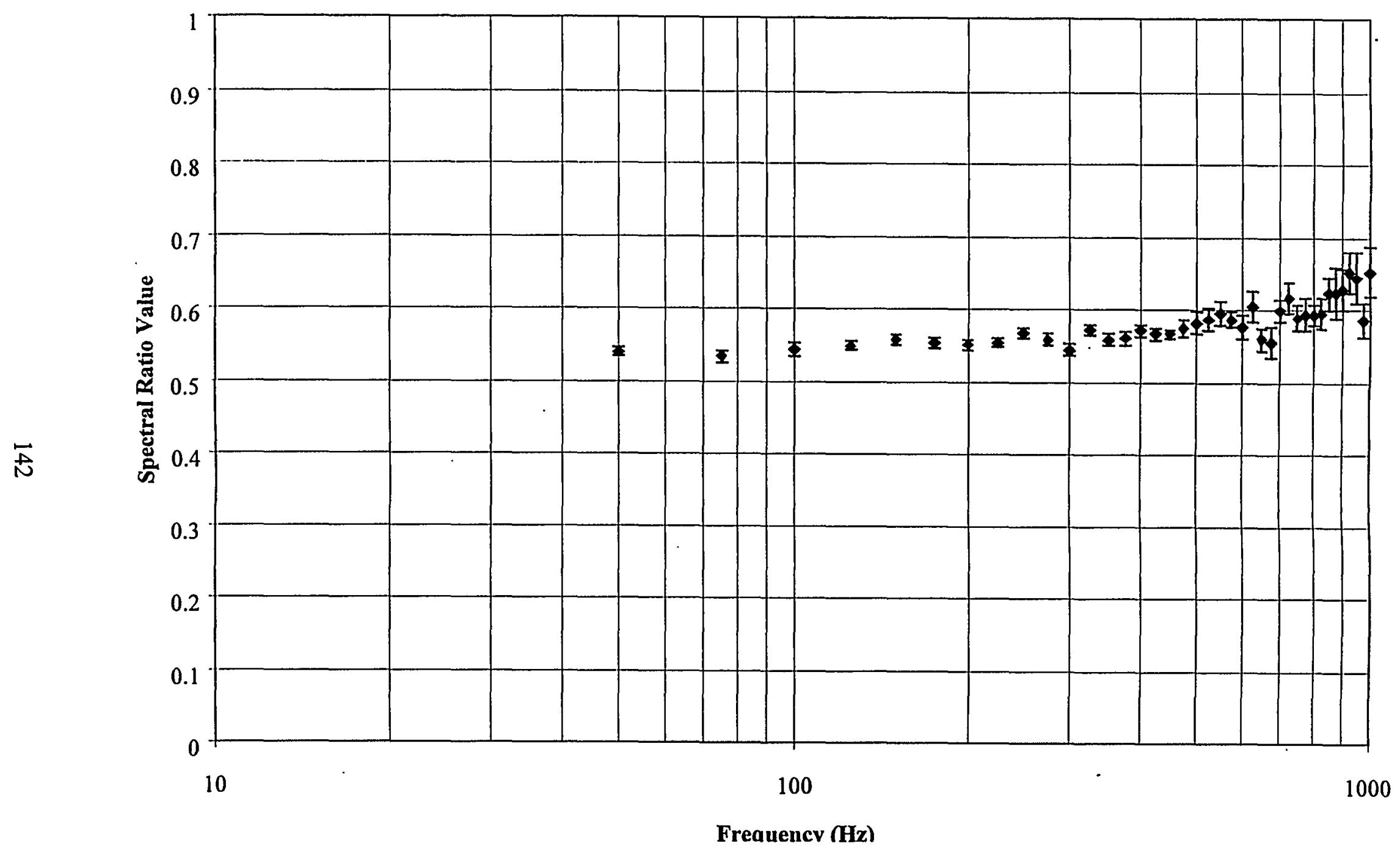

Fig. H.1. Frequency-dependent average spectral ratio 23 for reference measurements at plate spacing. 


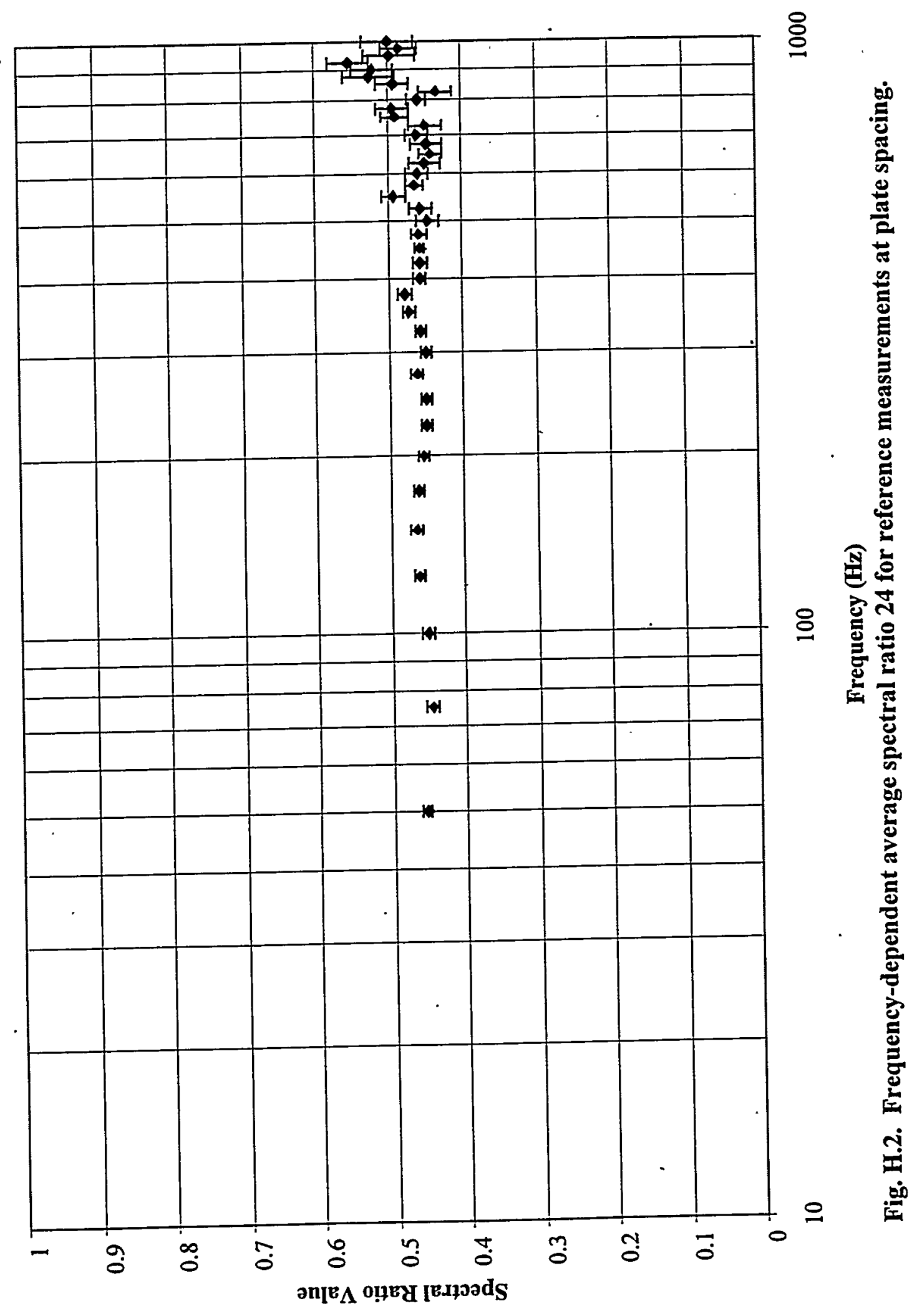




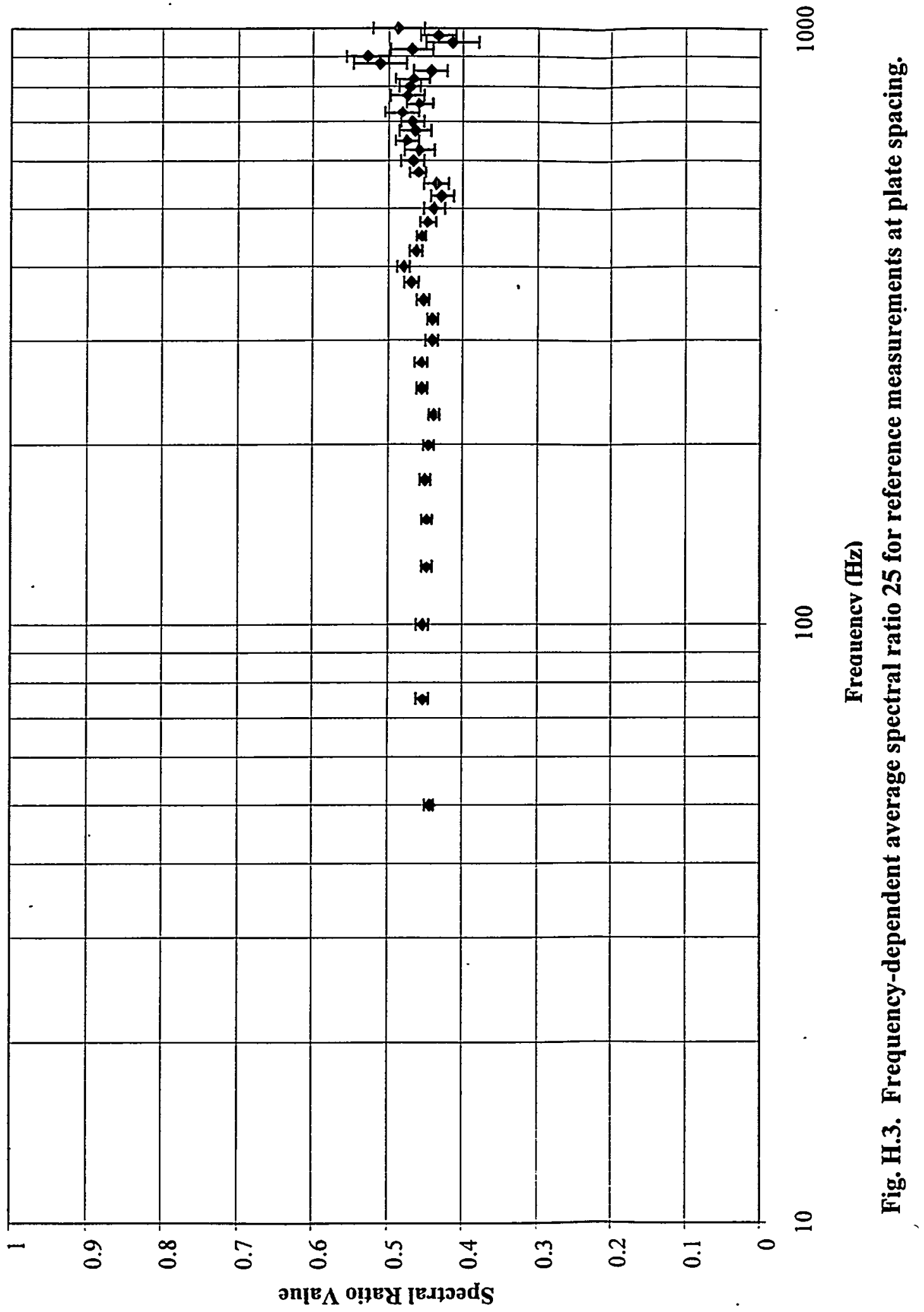




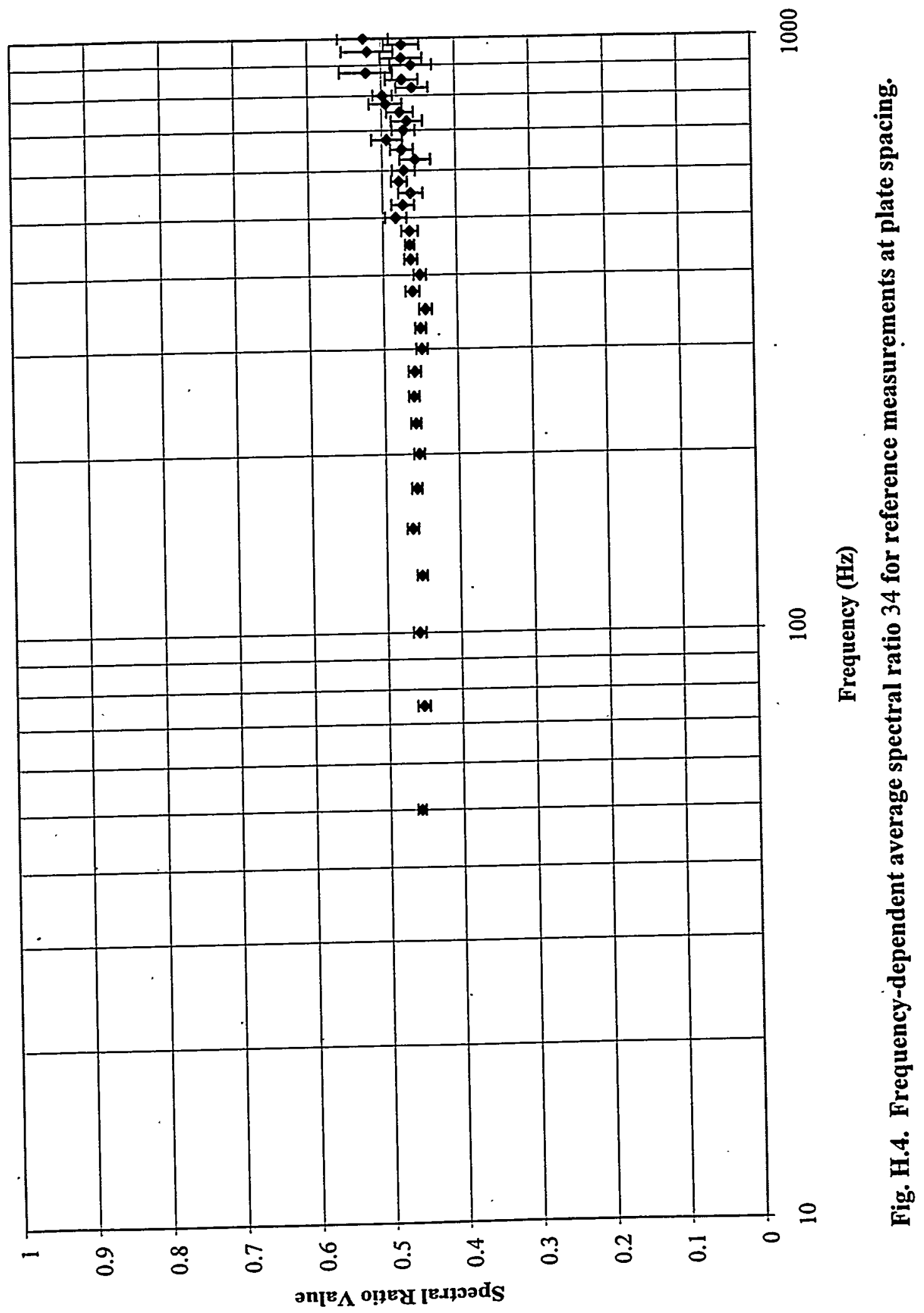




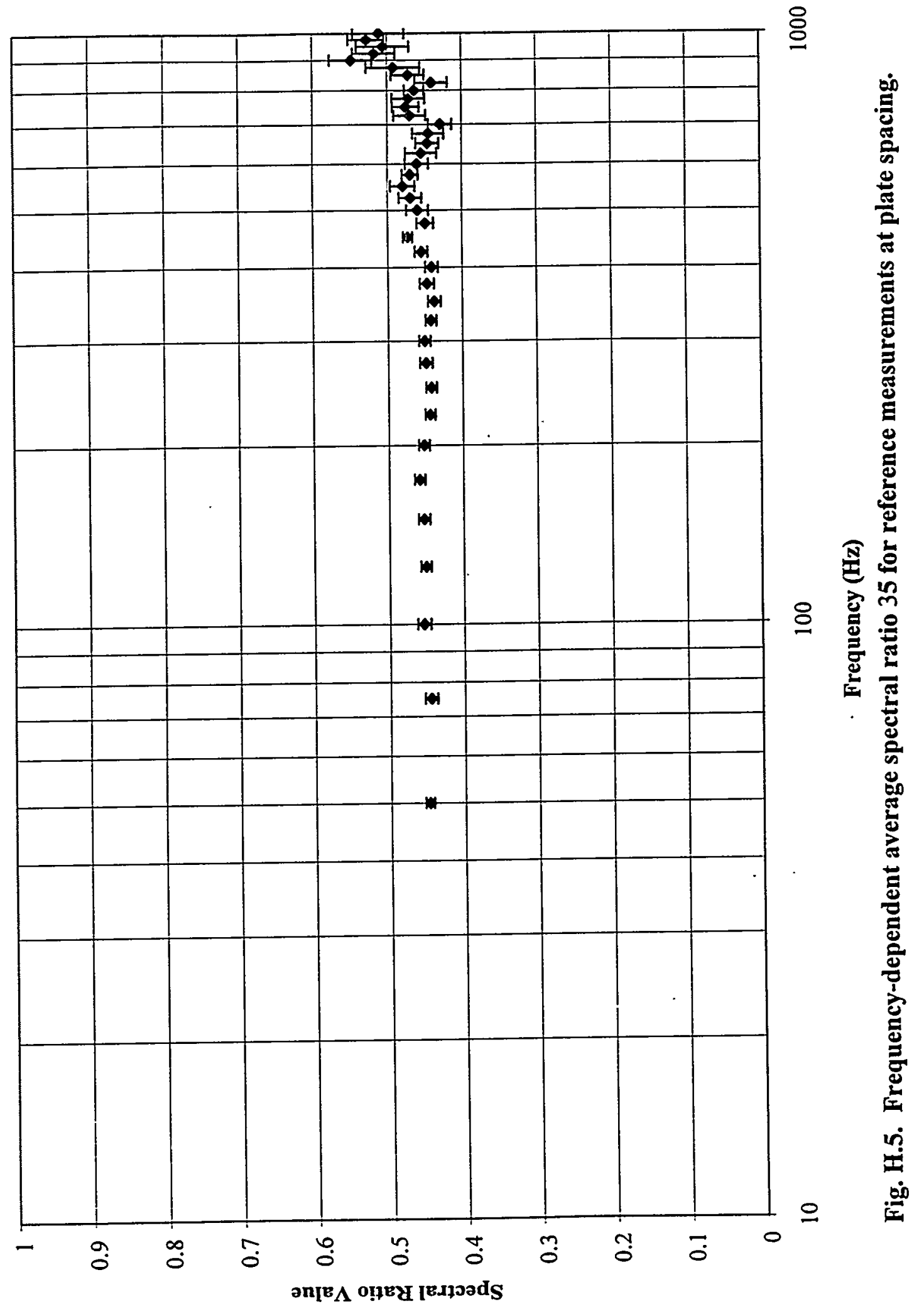




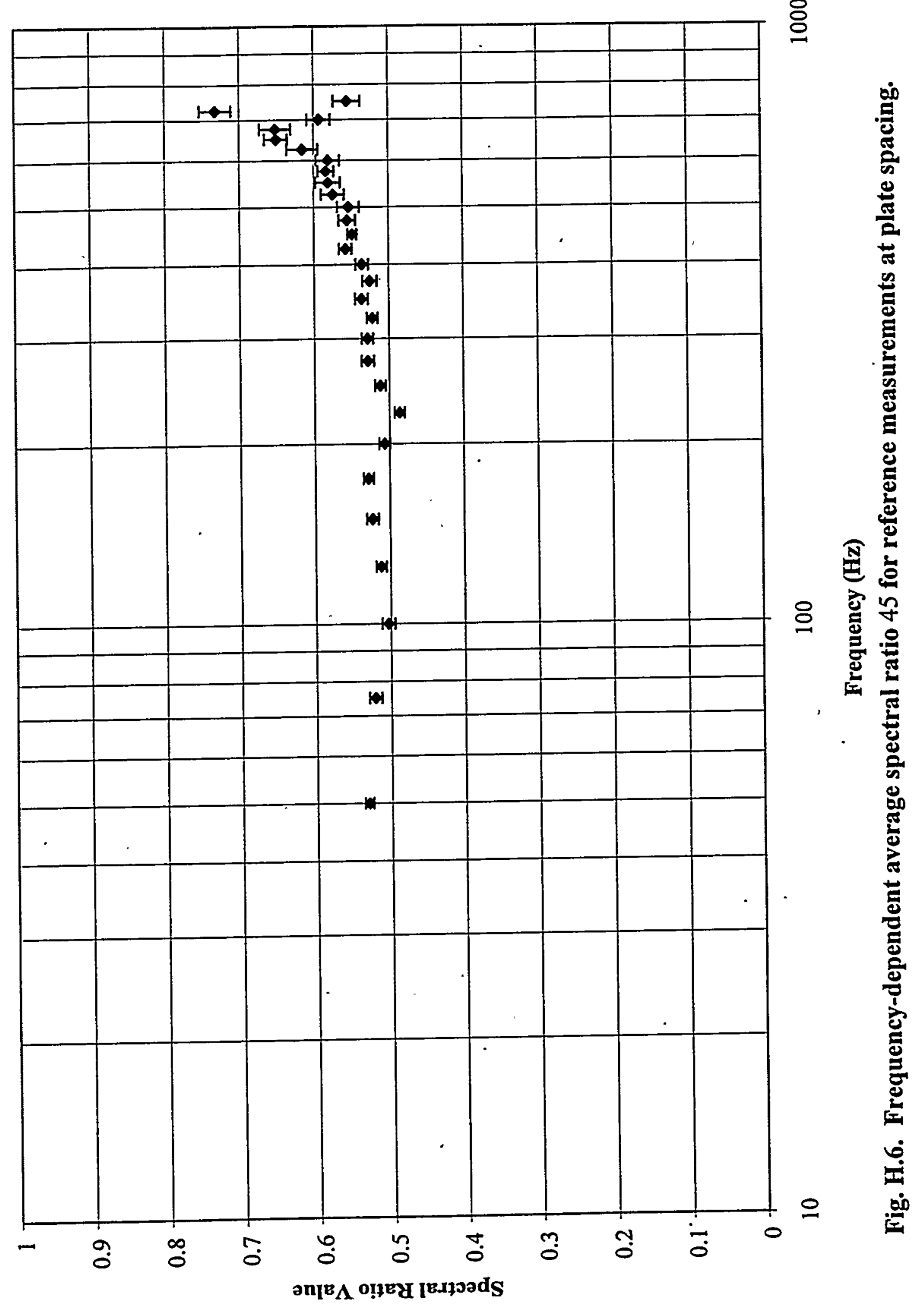




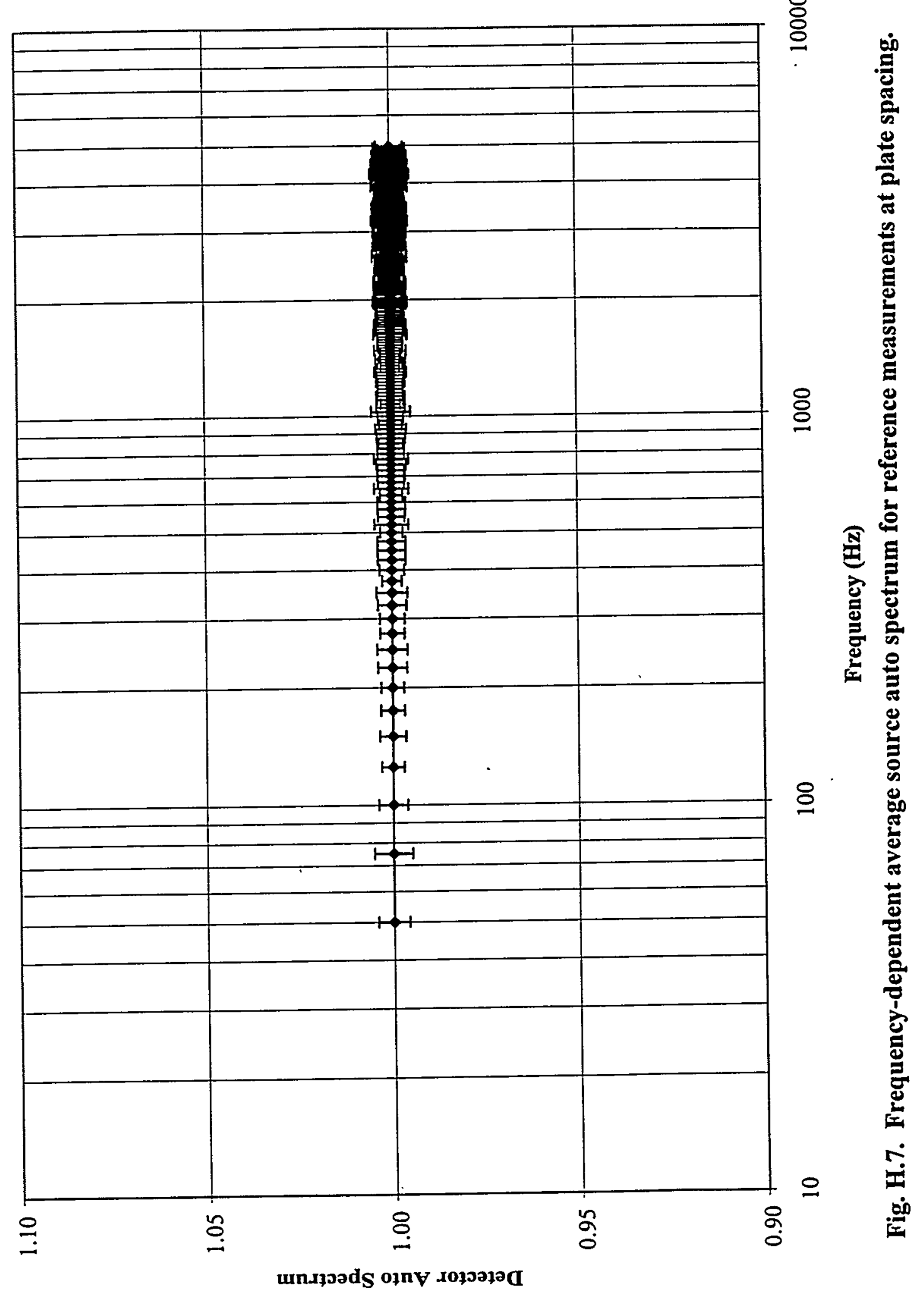




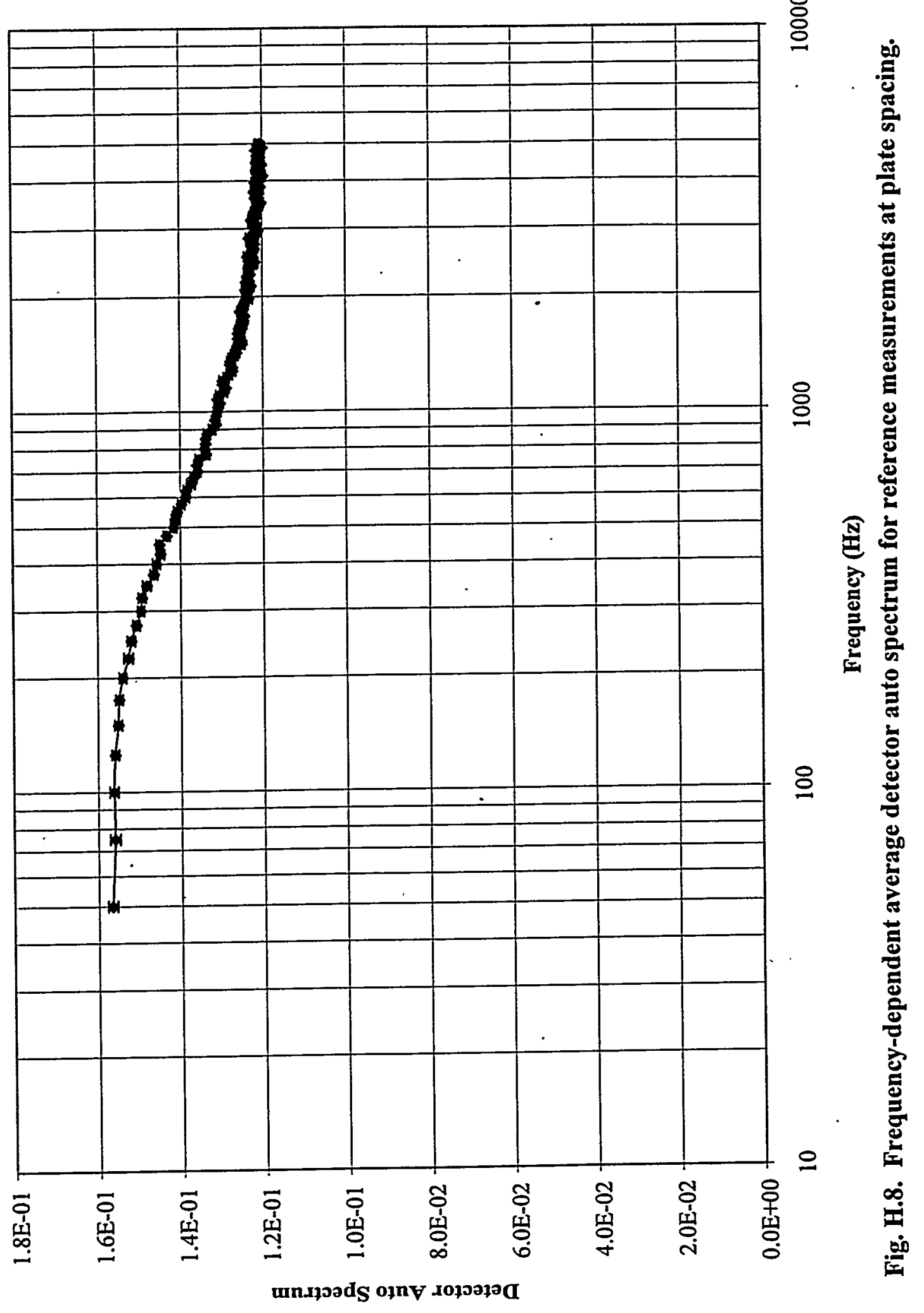




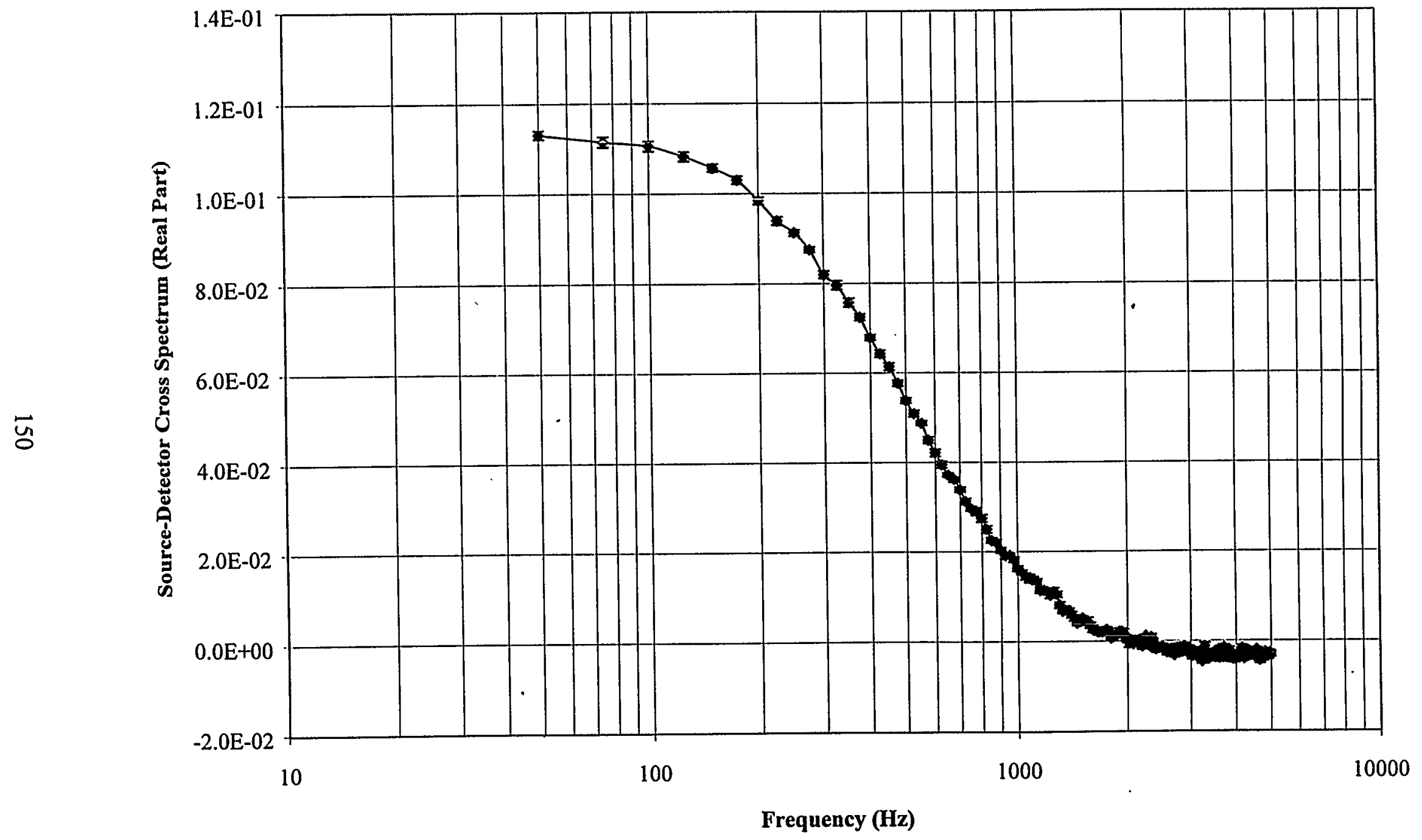

Fig. H.9. Frequency-dependent real source-detector cross spectrum for reference measurements at plate spacing. 


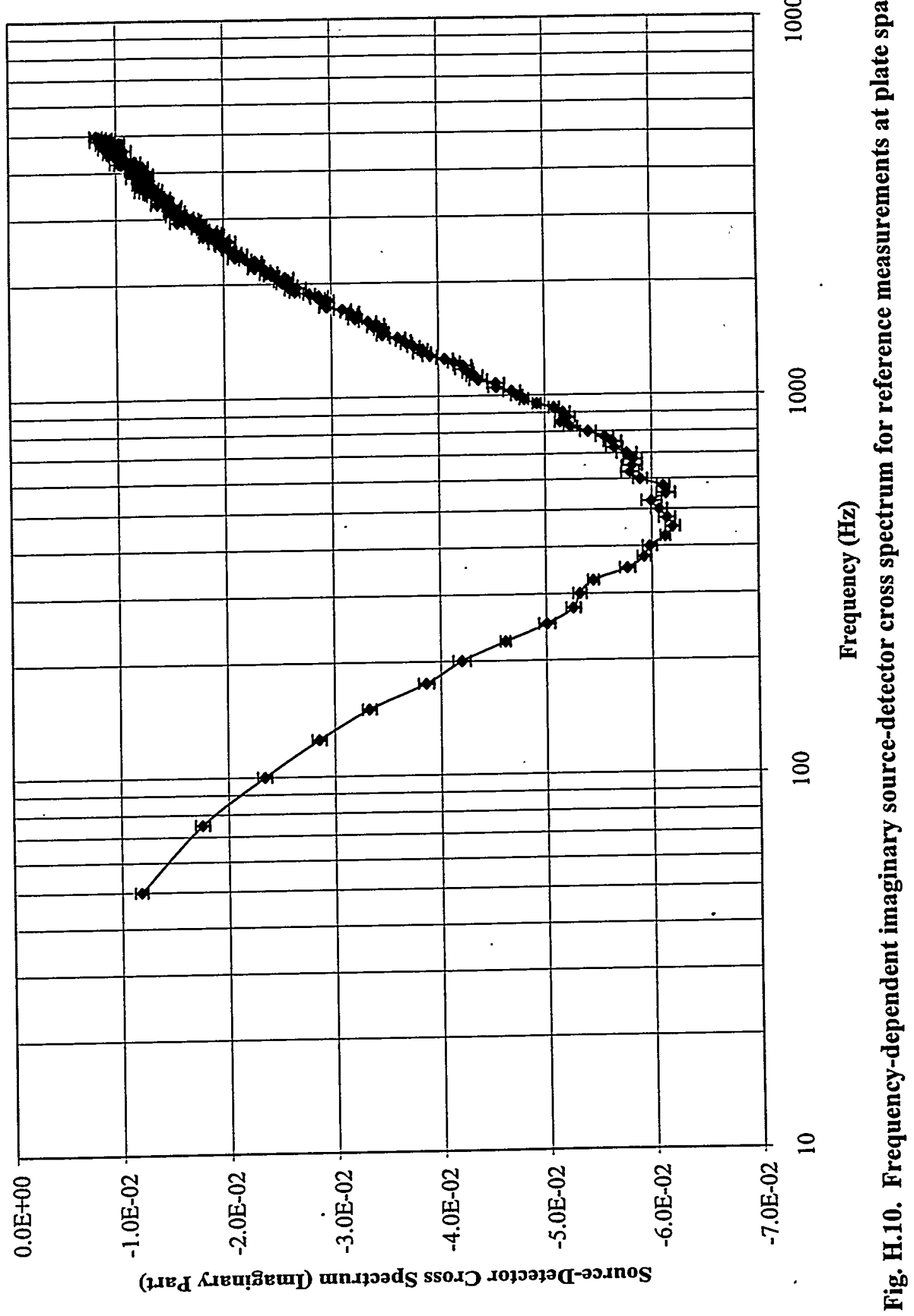




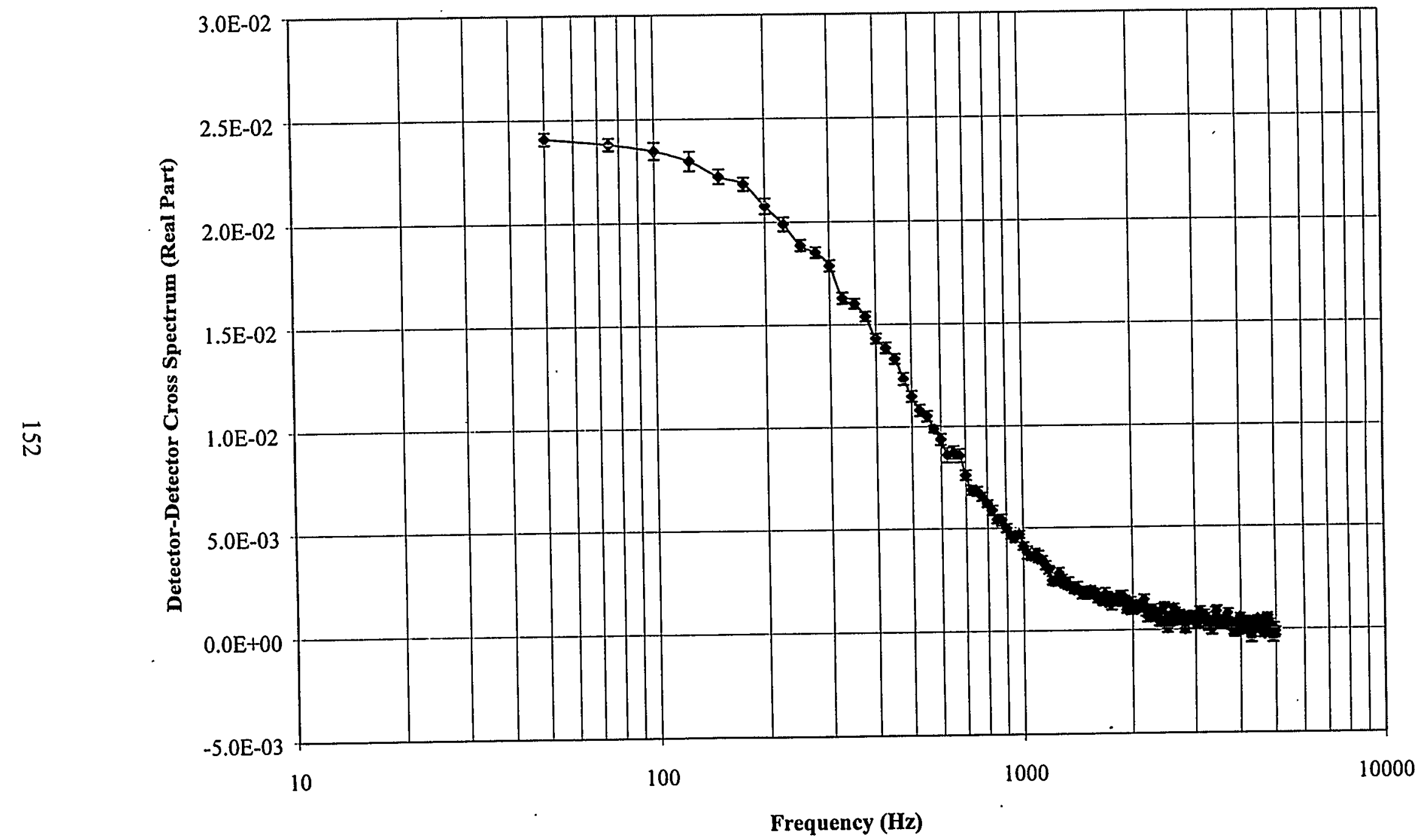

Fig. H.11. Frequency-dependent real detector-detector cross spectrum for reference measurements at plate spacing. 


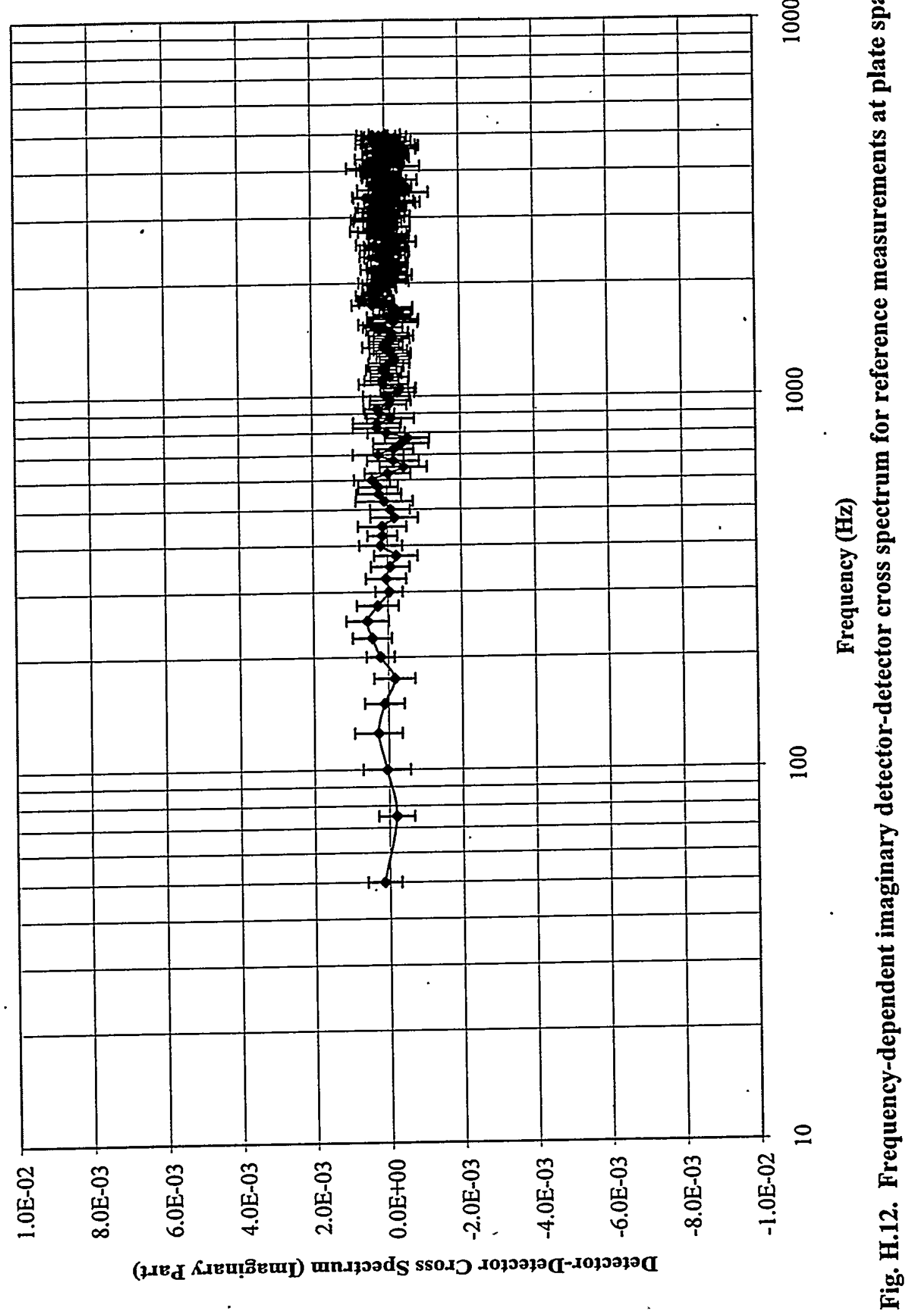


This page intentionally left blank. 


\section{DISTRIBUTION}

1. S. J. Ball

2. D. N. Fry

3. R. G. Gilliland

4. C. M. Hopper

5. W. C. Jordan

6. L. C. Leal

7. J. A. March-Leuba

8. J. K. Mattingly

9. D. W. McDonald

10. J. T. Mihalczo

11. C. V. Parks

12. R. B. Perez
13. R. C. Robinson

14. R. W. Roussin

15. R. G. Taylor

16. A. W. Trivelpiece

17. T. Uckan

18-28. T. E. Valentine

29. R. M. Westfall

30. J. D. White

31. M. C. Wright

32-34. ORNL Laboratory Records

\section{EXTERNAL DISTRIBUTION}

35. R. E. Anderson,

36. S. D. Burke,

37. J. N. Dewes,

38. C. B. Edwards,

39. R. L. Garrett,

40. C. A. Goulding,

41. K.Kutikkad,

42. J. C. McKibben,

43. Ichiro Nojiri,

44. F. Rahnema,

45. R. G. Sanchez,

46. C. Wang,
Los Alamos National Laboratory, P.O. Box 1663, NIS-6, MS J562, TA-18, Los Alamos, NM 87545

Savannah River Technology Center, P.O. Box A, Aiken, SC 29801

Savannah River Technology Center, P.O. Box A, Aiken, SC 29801

Missouri University Research Reactor, Research Park, University of Missouri, Columbia, Missouri 65211

Westinghouse Safety Management Solutions, Inc., 1993 South Centennial Drive, Aiken, SC 29803

Los Alamos National Laboratory, P.O. Box 1663, NIS-6, MS J562, TA-18, Los Alamos, NM 87545

Missouri University Research Reactor, Research Park, University of Missouri, Columbia, Missouri 65211

Missouri University Research Reactor, Research Park, University of Missouri, Columbia, Missouri 65211 Health and Safety Division, PNC Tokai Works, 4-33, Muramatsu, Tokai-mura, Ibaraki-ken, Japan, 319-11 Georgia Institute of Technology, Nuclear Engineering \& Health Physics Program, G. W. Woodruff School of Mechanical Engineering, Atlanta, GA 30332-0405

Los Alamos National Laboratory, P.O. Box 1663, NIS-6, MS J562, TA-18, Los Alamos, NM 87545

Georgia Institute of Technology, Nuclear Engineering \& Health Physics Program, G. W. Woodruff School of Mechanical Engineering, Atlanta, GA 30332-0405 


\section{EXTERNAL DISTRIBUTION (continued)}

47. T. G. Williamson, Westinghouse Safety Management Solutions, Inc., 1993 South Centennial Drive, Aiken, SC 29803

48. W. G. Winn, Savannah River Technology Center, P.O. Box A, Aiken, SC 29801

49. T. Yamamoto, Criticality Safety Laboratory, Department of Fuel Cycle Safety Research, Japan Atomic Energy Research Institute, Tokai-mura, Naka-gun, Ibaraki-ken, 319-11 Japan

50. J. F. Zino, Westinghouse Safety Management Solutions, Inc., 1993 South Centennial Drive, Aiken, SC 29803 